\title{
AN ANALYSIS OF UNDERGRADUATE HEAVY-VIDEO-GAMING STUDENTS: DEVELOPING TECHNOLOGY-ENHANCED LEARNING-SUPPORT AREAS BASED ON GAMING AND STUDY PRACTICES
}

A Dissertation
presented to
the Faculty of the Graduate School
at the University of Missouri-Columbia
In Partial Fulfillment
of the Requirements for the Degree
Doctor of Philosophy
Dr. Isa Jahnke, Dissertation Advisor
May 2021
Michelle Todd


(C) Copyright by Michelle Todd, 2021

All Rights Reserved 
The undersigned, appointed by the dean of the Graduate School, have examined the dissertation entitled

AN ANALYSIS OF UNDERGRADUATE HEAVY-VIDEO-GAMING-STUDENTS:

DEVELOPING TECHNOLOGY-ENHANCED LEARNING-SUPPORT AREAS BASED ON GAMING AND STUDY PRACTICES

presented by Michelle Todd,

a candidate for the degree of doctor of philosophy Information Sciences and Learning Technologies, and hereby certify that, in their opinion, it is worthy of acceptance.

Professor Isa Jahnke

Professor Joi Moore

Professor Johannes Strobel

Professor Candace Kuby 


\section{Acknowledgement}

I would like to express thanks to my patient and supportive advisor, Dr. Isa Jahnke, for staying the course with me throughout this research project. Her guidance through this process has been invaluable. Gratitude is also directed to the School of Information Sciences and Learning Technologies (SISLT) at the University of MissouriColumbia. Through the SISLT graduate research fund, I was provided a grant to cover the cost of the Indeemo ethnography software used in this research project.

I would also like to thank each of the undergraduate video-gaming students who participated in the study's surveys and interviews, which provided rich and helpful data. Additionally, I thank my many work colleagues of Hannibal-LaGrange University for their encouragement and support. Finally, I would like to thank my family for faithfully encouraging me along the formidable journey which led to the compilation of this dissertation. 


\section{Table of Contents}

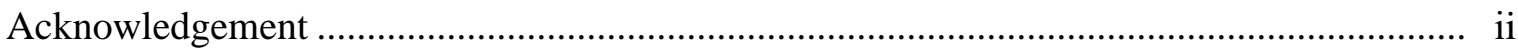

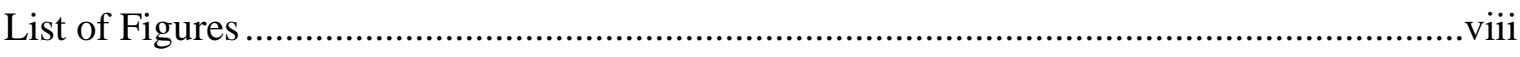

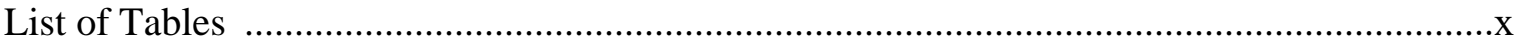

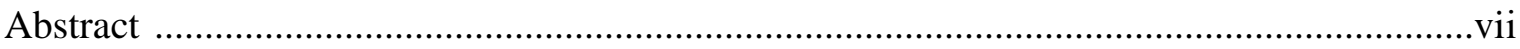

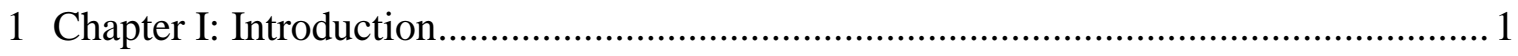

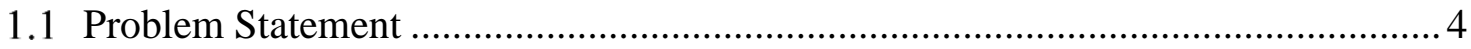

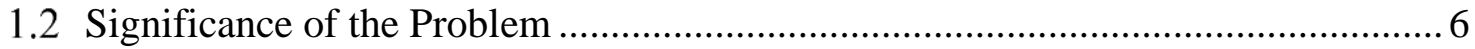

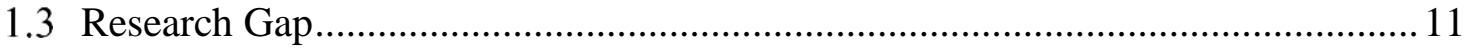

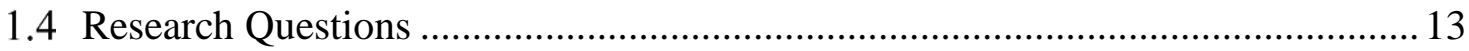

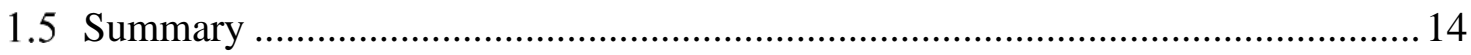

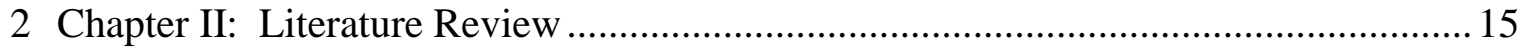

2.1 Three Themes: eSports, Relation of Gaming and Studying, Learning Supports ... 15

2.1.1 eSports: as Collegiate Athletics, as Industry, as Extracurricular .................... 17

2.1.2 Education: Learning, Academic Performance, Habits, Relation to Gaming.... 21

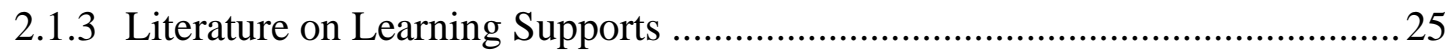

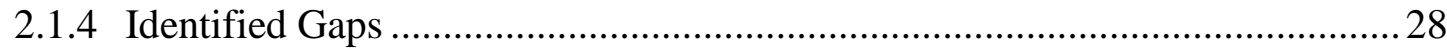

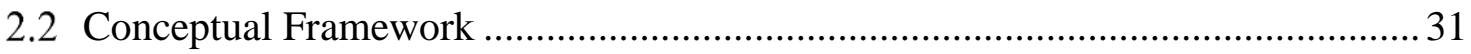

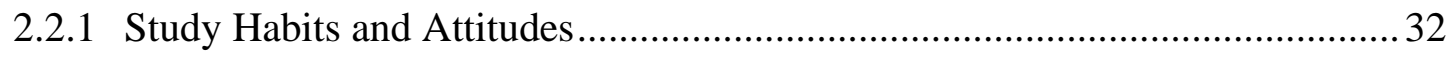

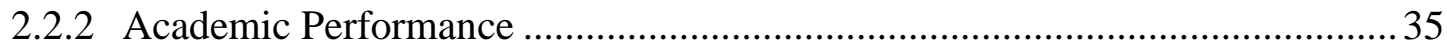

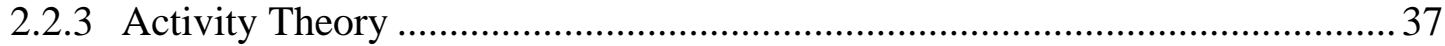


2.2.4 Utilization of the Conceptual Framework in the Study

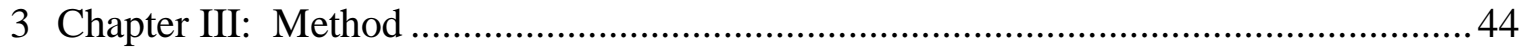

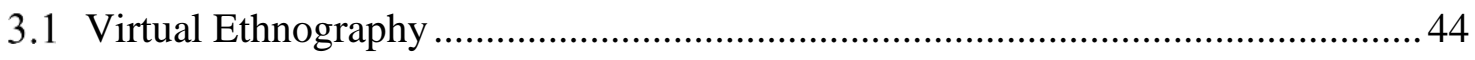

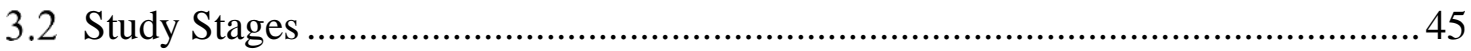

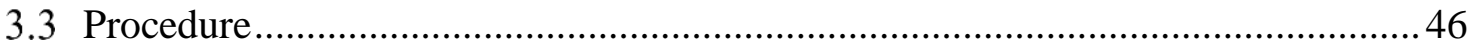

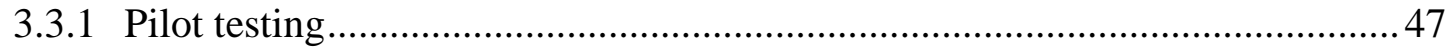

3.3.2 Recruitment of Study Participants ........................................................ 48

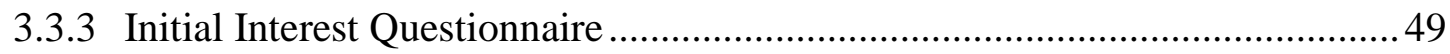

3.3.4 Instruments to Measure Study Habits and Attitudes, SSHA survey ................49

3.3.5 Indeemo Virtual Ethnography Weekly Tasks and Prompts ............................52

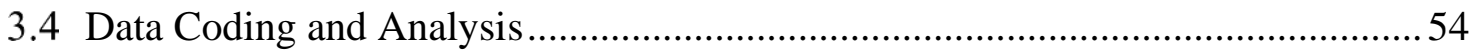

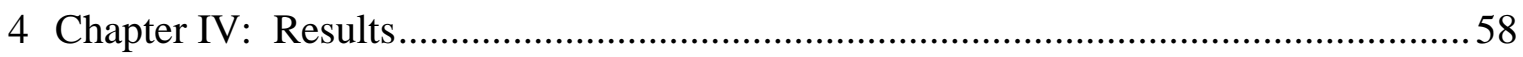

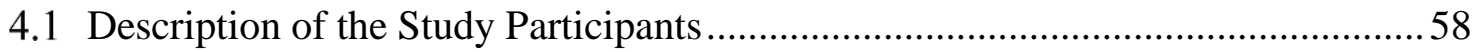

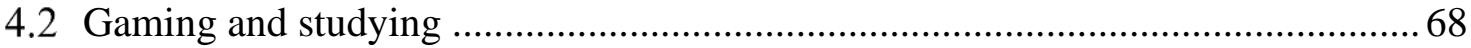

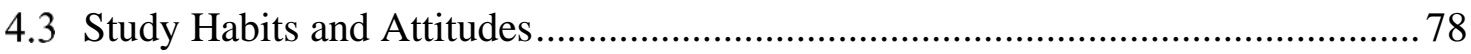

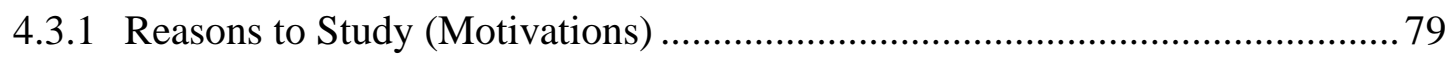

4.3.2 Study Practices of Video-Gaming Participants ............................................ 81

4.3.3 Gaming Attitudes and Academic Study Attitudes of Video-Gaming

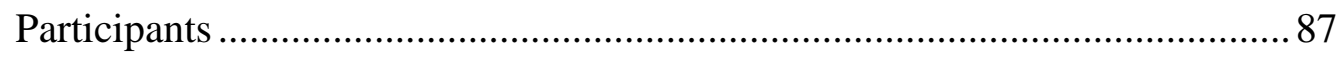

4.3.4 Academic Skills Learned Through Gaming of Video-Gaming Participants.... 89 
4.4 Learning Supports Used and Desired by Gamers .90

4.5 Gamers' Study Practice Approaches 103

4.5.1 Nonexistent/Poor Study Organization 104

4.5.2 Inconsistent/Mediocre/Chaotic Study Organization 105

4.5.3 Short Bursts of Concentrated Effort Organization 106

4.5.4 Responsive Attack of Study Organization 107

4.5.5 Planned Consistent Study Organization 107

4.6 Types of Heavy-Video-Gaming Students 108

4.6.1 Supportive Colleague Type

4.6.2 Pertinacious Problem Solver Type 111

4.6.3 Efficient Linear Thinker Type

4.6.4 Self-Reliant Associate Type.

4.6.5 Individualist with the Need for Community Type 116

4.7 Results from the SSHA 118

5 Chapter V: Discussion 121

5.1 Surprises and Highlights - New Knowledge Created 121

5.2 Heavy-Video-Gaming Students and Their Gaming Practices 126

5.3 Heavy-Video-Gaming Students' Study Attitudes and Practices 129

5.4 New Research Knowledge: How Heavy-Video-Gaming Students Organize Their Studies and Implications for Learning Supports 135 
5.4.1 Learning Supports Associated with Nonexistent/Poor Study Organization. . 137

5.4.2 Learning Supports Associated with Inconsistent/Mediocre/Chaotic Study Organization. 138

5.4.3 Learning Supports Associated with Short Bursts of Concentrated Effort Study Organization. 140

5.4.4 Learning Supports Associated with Responsive Attack. 141

5.4.5 Learning Supports Associated with a Planned Consistent Study Organization. 143

5.5 New Research Knowledge of the Five Types of Heavy-Video-Gaming Students and Implications for Technology-Enhanced Learning Supports

5.5.1 Learning Supports Associated with the Supportive Colleague Type 146

5.5.2 Learning Supports Associated with the Pertinacious Problem Solver Type.. 147

5.5.3 Learning Supports Associated with the Efficient Linear Thinker Type 148

5.5.4 Learning Supports Associated with the Self-Reliant Associate Type.

5.5.5 Learning Supports Associated with the Individualist with the Need for

Community 150

5.6 Concept of a Gamified Learning Support System 151

5.6.1 Data and Inputs Supporting the Gamification System 151

5.6.2 User Interface of the Gamified Learning Support System 162

5.7 The Video-Gaming Student Matrix for Identifying Learning Supports 166

5.8 Limitations 169 
References

Appendix A - Initial Interest Questionnaire 222

Appendix B - Consent Form. 223

Appendix C - Introductory Qualitative Questionnaire with Demographics . 225

Appendix D - Questionnaire of Study Habits and Attitudes (SSHA) 231

Appendix E - Indeemo Virtual Ethnography Tasks and Weekly Timeline. 239

Appendix F - Study Habits Metaphors 248

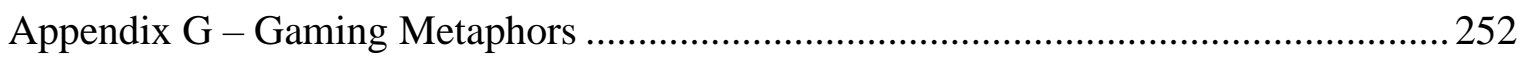

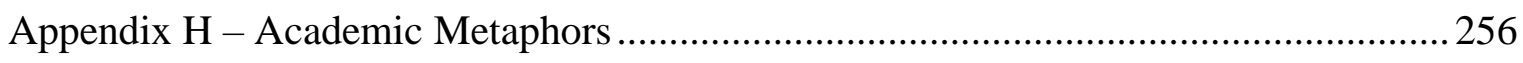

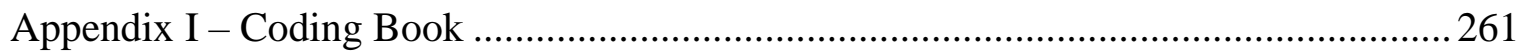

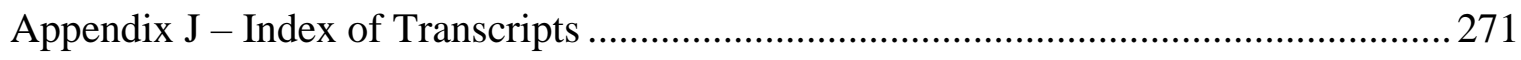

Appendix K - Video-Gaming Student Matrix To Develop Learning Support ............... 275

Vita 278 


\section{List of Figures}

Figure $\quad$ Page

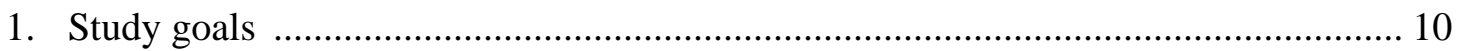

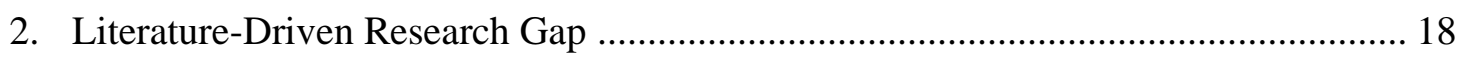

3. The Original Activity Theory Model from Kaptelinin and Nardi (2006) .................. 45

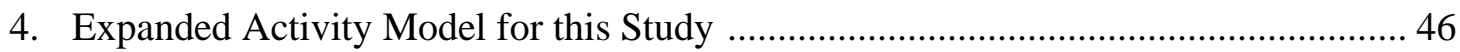

5. The Main Research Methods Used in the Three Study Stages ................................ 52

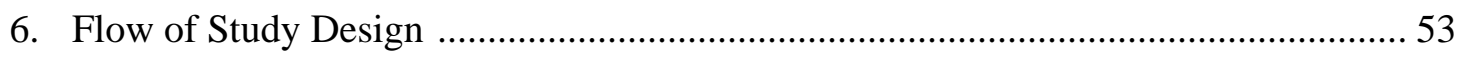

7. Examples of Study Habit Behaviors and Attitudes Identified from Literature .......... 56

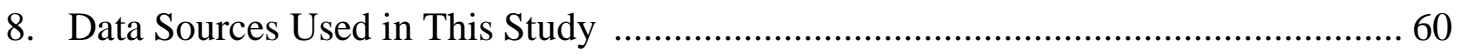

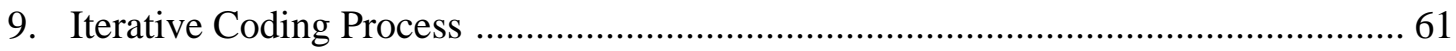

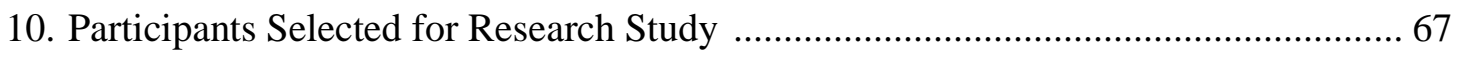

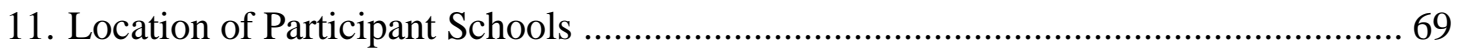

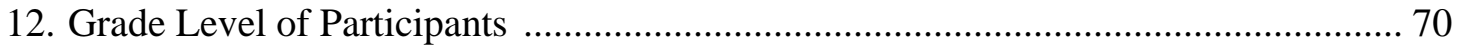

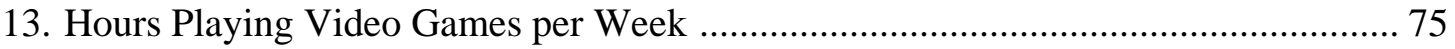

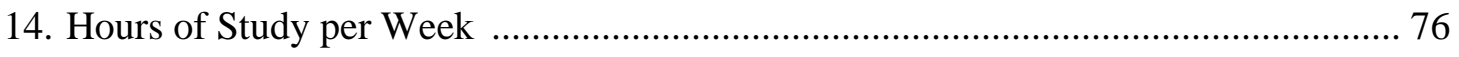

15. Academic Performance Rating Reported by the Participants ................................. 84

16. Campus Learning Supports Identified by Heavy-Video-Gaming Students ............... 97

17. Campus Learning Supports Desired by Heavy-Video-Gaming Students ................. 98

18. Activity Theory Model Adapted for the Proposed Learning Supports of this Study 131

19. Concept for Technology-Enhanced Learning Support System Integrated with

Participant Suggested Learning Support Inputs ............................................... 167

20. Technology-Enhanced Learning System Available on Various Computing Platforms 
21. Example of the SIMS Game User Interface to be Used as a Model in the TechnologyEnhanced Learning Support System 169

22. Sample SIMS Game Interface Showing Tasks and Reward System to be Used as a Model in the Technology-Enhanced Learning Support System

23. Sample Pokémon Game Interface for Capturing Characters when at Physical Meetings to be Used as a Model in the Technology-Enhanced Learning Support System ..... 171

24. Sample Dashboard to be Used as a Model in the Technology-Enhanced Learning

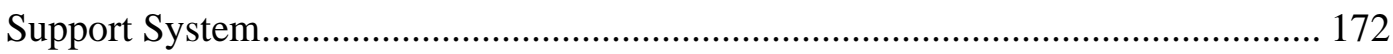




\section{List of Tables}

Table

Page

1. Video Gaming Presented as a Slightly Unique Extracurricular Experience 16

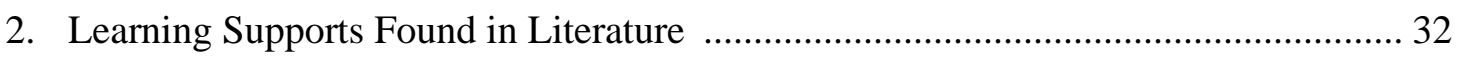

3. Study Habits Adopted from Literature …............................................................ 39

4. Student Self-Report, Criteria Filter Questions ..................................................... 65

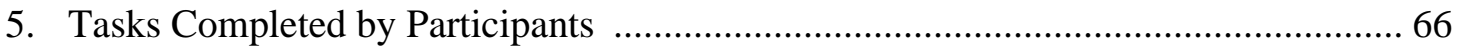

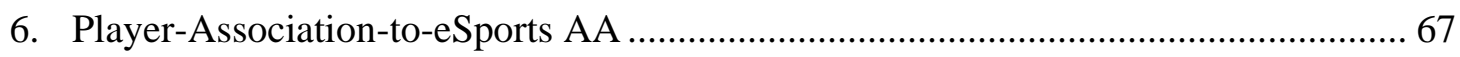

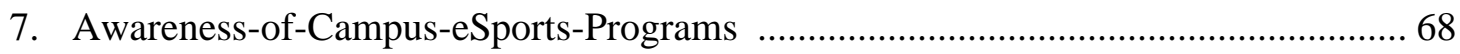

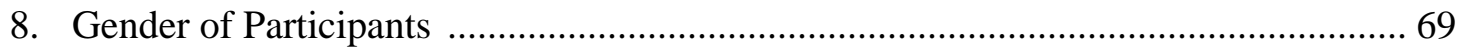

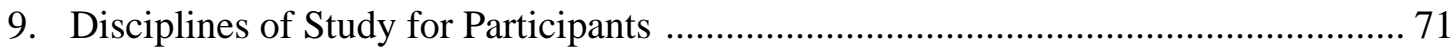

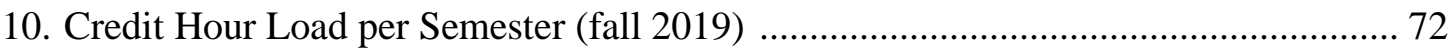

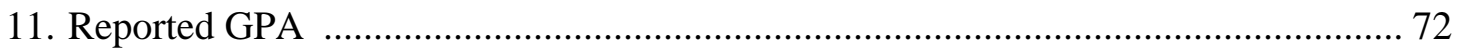

12. Reasons for Playing Video Games at College ....................................................... 78

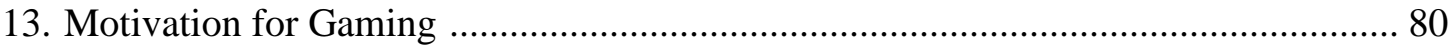

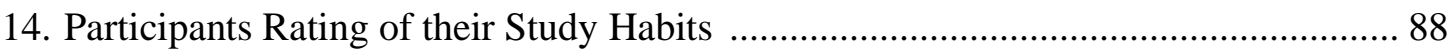

15. Gaming is Like... Metaphor Category List ....................................................... 93

16. Academic Study is Like... Metaphor Category List ........................................... 95

17. Academic Skills Learned Through Gaming …..................................................... 96

18. Learning Supports Video-Gaming Students Identified or Used in their Colleges ... 106

19. List of Learning Supports Desired by Heavy-Video Gamers, Not Yet Offered ...... 107

20. How Participants Organize Their Academic Studies ........................................... 110

21. Types of Heavy-Video-Gaming Learners ...................................................... 115

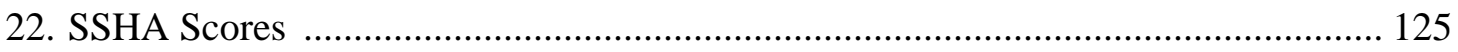

23. Surprises and Highlights: New Knowledge Created ........................................... 128 
24. Five Study Organization Approaches and the Potential Learning Supports 142

25. Types of Heavy-Video-Gaming Students with Study Practices and Learning Supports 150

26. Summary Learning Support Areas Requested by Participants 159

27. Classroom/Schedule Supports Requested by Participants 160

28. Assignment/Homework Supports Requested by Participants 161

29. Professor/Staff Supports Requested by Participants 162

30. Personal Study Supports Requested by Participants 163

31. Extracurricular Supports Requested by Participants 164

32. Social Needs Supports Requested by Participants 165

33. Physical Needs Supports Requested by Participants 166

34. The Video-Gaming Student Matrix 174

35. Qualitative Survey with Demographic Questions and Other Items 231

36. My Study Habits are Like .... Metaphors 254

37. Gaming is Like.... Metaphors 258

38. Academic Study is Like .... Metaphors 262

39. Demographics Survey Coding Book 269

40. Gaming Habits Coding Book 270

41. Study Skills Coding Book 271

42. Attitudes Coding Book 274

43. Characteristics of Gamers Study Approaches and Types 275 


\begin{abstract}
Video-gaming has become a popular extracurricular option for students in higher education. More than 70 percent of undergraduate students reported they played videogames at some level, with heavy-video-gaming students reporting they invest over 14 hours a week on games. When extracurricular activities take 14 or more hours of commitment, students' academic performance is at risk of falling. However, not much is known about the heavy-video-gaming students, their gaming and study practices, and whether new technology-enhanced academic learning supports may meet their needs. A conceptual framework using study habits and attitudes, academic performance, and activity theory provided a lens to view the research. This exploratory study applied a qualitative virtual ethnography methodology and interviews to investigate the gaming and study practices of 93 heavy-video-gaming students. Results indicate five study organizational approaches the video-gaming participants use in their study practices. In addition, five types of heavy-video-gaming students have been explored. More specifically, the findings unveil the contrast between undergraduate video-gaming students' study and gaming practices. For example, the results indicate that playing games offer the video gaming students a mental break they feel they need to take from their university studies, and students play games as a reward for their study efforts. Additionally, video-gaming students desire that their studies provide them with some ongoing reward system, similar to rewarding systems in games. Finally, learning supports for gaming students have been developed. This new knowledge about the study practices of video-gaming students can be used by educational professionals as a basis for
\end{abstract}


developing and implementing technology-enhanced academic learning supports to align with video-gamer student needs. 


\section{Chapter I: Introduction}

Over the last decade, a new type of extracurricular activity has entered higher education: video games, particularly competitive multiplayer video games, often referred to as eSports. The Pew Research Center (2019) reported that more than 70 percent of undergraduate students played video games at some level, and Kort-Butler (2020) claims the number is as high as 80 percent. For comparison, only 13 percent of the student body across the North Central Athletic Association (NCAA) Division I, II, and III schools participated in athletic extracurricular activities during the same time span (National Association of Collegiate Esports, 2020; National Collegiate Athletic Association, 2020; Reitman et al., 2020; Wimmer-Schwarb, 2018). The prevalence of video-gaming within universities is additionally evidenced by the doling of over $\$ 15,000,000$ in scholarships to collegiate-sanctioned eSport team players in 2019 (Bauer-Wolf, 2019; Reitman et al., 2020). Video-gaming has become one of the most popular collegiate extracurricular activities on campuses (Kort-Butler, 2020). According to Statistica (2019), player numbers are on the rise as there were 2.21 billion gamers worldwide in 2017 , and that number is expected to reach 2.73 billion by 2021 ("Newzoo Insights - Covering the Games, Esports, and Mobile Markets,” 2018). The video-gaming extracurricular activity has grown to involve millions of students globally, increasing the number of students who will bring video gaming skills to college and growing the number of video-gaming students who may need academic support in American higher education (Jacobsen \& Forste, 2011; Partin, 2017; Sun, 2017).

Researchers predict that 40 percent of all students will drop out or quit school before obtaining a degree. This fact alone gives researchers and educators reason to 
closely examine the study practices of all students, but especially heavy-video-gaming students, who are bringing their time-intensive hobby into the environment (Duggan, 2015; Gnambs et al., 2020; King \& Delfabbro, 2020; Thuma, 2012). Video-gaming is already often viewed as a detriment to learning, especially when played at the 14 hours or more level, as it interference with students' successful academic performance (Halbrook et al., 2019; Hurst, 2016; Jones et al., 2014; Seow \& Pan, 2014). Students take to school their previous practices of gaming, with many video-gamers reporting they easily play video games more than 14 hours a week, classifying them as heavy-video-gaming students (Morrison, 2018; Partin, 2017). Research indicates when extracurricular activities monopolize between 14 and 17 hours a week or more of a student's time and attention, academic performance enters a higher risk zone for being negatively impacted (Arockiyasamy et al., 2016; Bowman, 2018; Yilmaz et al., 2018). As a result of the unsuccessful academic performance of some video gamers, educational leaders can acquire the perspective that gaming is a "waste of time," hence claiming gaming and studying are at odds with one another as they vie for students' time and attention (Kassam et al., 2013; Nordby et al., 2019; Spring, 2015; Uuskoski, 2011). Yet, students claim that the video gaming serves to provide ample challenges, social interaction, and needed relaxation from school studies (transcripts, pp. 103-225).

Despite many adult's negative viewpoints about video-gaming, the number of college students who play video games at a heavy level is growing. More and more students are coming to schools with a firm intent on playing video games as eSports team members or just playing intensely for sheer recreation, and in doing so are often not honing the needed academic skills, leaving them unprepared for academic work (Diluna, 
2017; Duggan, 2015; Nuyens et al., 2019a; Rosenberg, 2017; Tham et al., 2020). Those video-gaming students coming to university with poor academic skill sets make the support of their successful academic performance an issue with which educational leaders are now contending on a regular basis (Arockiyasamy et al., 2016; Ballado-Tan, 2014; Gnambs et al., 2020).

As the number of college students who play video games grows, existing literature (Duggan, 2015; Gnambs et al., 2020; Manero et al., 2017; Nuyens et al., 2019a) shows that there is a need to better understand these learners and how their gaming and study practices intertwine. It may be beneficial to more deeply examine the video-gaming students' gaming and study practices and how they relate. The results may be useful in creating options for developing new academic learning supports, especially utilizing technology-enhanced options (Ballado-Tan, 2014; Halbrook et al., 2019; Jiwal et al., 2019). Universities have long offered a variety of learning supports for students of all types, so attempting to identify new technology-enhanced learning supports for the increasing number of video-gaming undergraduate students based on their gaming and study practices is a reasonable goal, which is the purpose of this research study (Arockiyasamy et al., 2016; Cerna \& Pavliushchenko, 2015; G. Freeman \& Wohn, 2017; Jacobsen \& Forste, 2011; Popescu \& Ghita, 2013).

Figure 1 shows the two goals of this study. The first goal of the study is to explore the gaming and study practices of video-gaming undergraduate participants, collecting data to inform the second. The second study goal is to use the data from the gaming and study practices to identify and design appropriate learning support areas, which focus on 
technology-enhanced learning supports that can benefit heavy-video-gaming students in their efforts to achieve successful academic performance.

The conceptual framework guiding this study is built on theories addressing study habits and attitudes (Aquino, 2011; Ballado-Tan, 2014; Nasution, 2015), study habits as the third pillar of academic performance (Credé \& Kuncel, 2008), and the learning technology activity theory (Devane \& Squire, 2012; Kaptelinin \& Nardi, 2006; Roth \& Lee, 2007). Each framework concept component is more thoroughly discussed in the Chapter 2 Literature Review.

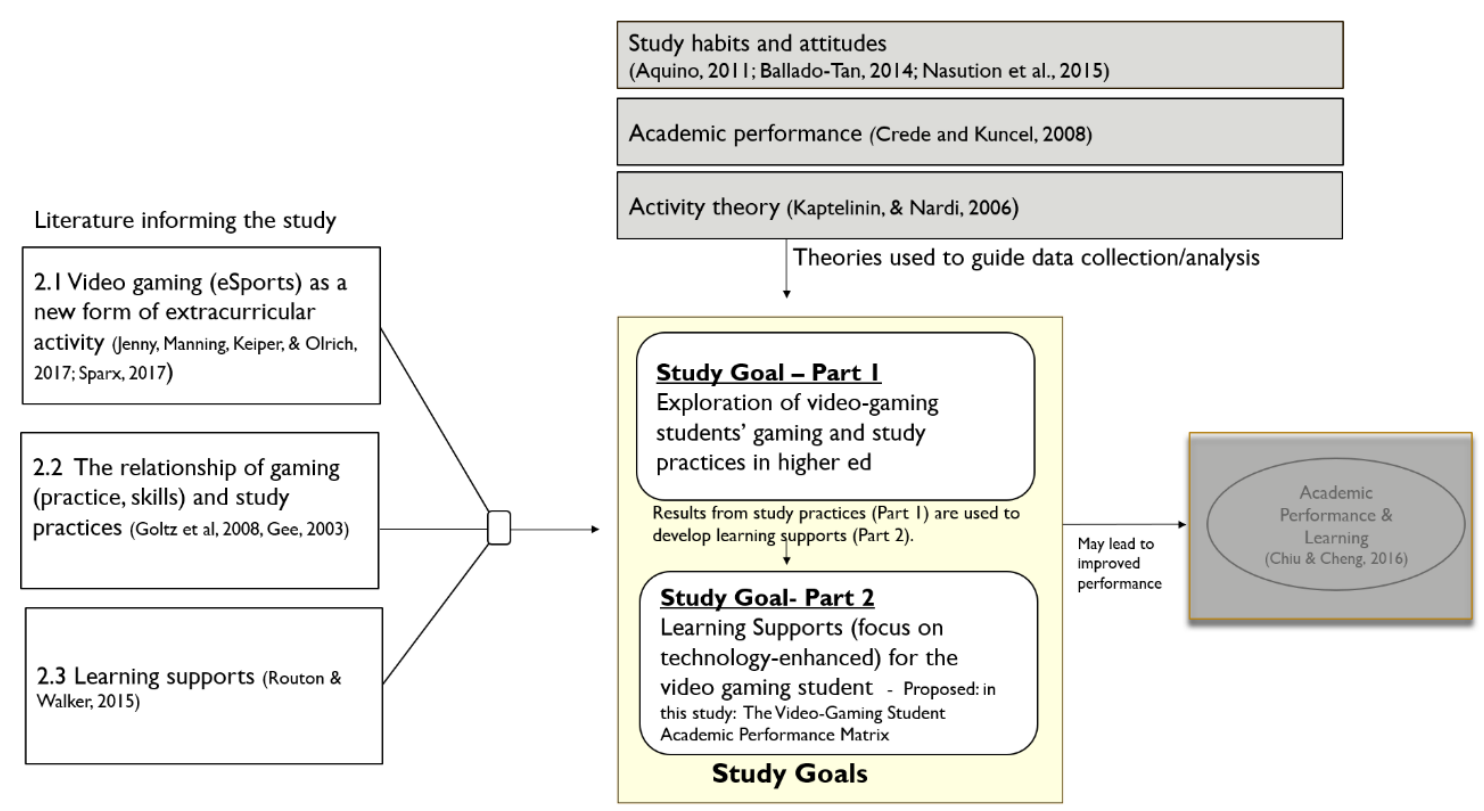

\section{Figure 1}

Study goals

\subsection{Problem Statement}

There is a need within the academic literature field to provide a deeper explanation of heavy-video-gaming students' gaming and study practices in order to clarify how to support their learning so they have appropriate opportunities to achieve 
successful academic performance. Researchers have focused on many aspects of videogaming in college but thus far have failed to provide a clear portrayal of the undergraduate heavy-video-gaming student as a learner. Research can be found instead on topics like video-gaming in relation to eSports as a "campus sport" (Jenny et al., 2017), eSport athletes (Bauer-Wolf, 2019; Schaeperkoetter et al., 2017), and videogaming as a study discipline (Jenny et al., 2018). Other studies emphasize elements of the gaming students' skill sets, such as player response time (University of Rochester, 2010) and motor and cognitive skills (Bejjanki et al., 2014; Nuyens et al., 2019a). The literature includes studies on social and behavioral aspects of video-gaming: teambuilding (G. Freeman \& Wohn, 2018), toxic behaviors (Paul, 2018), stereotyping of players (Paaßen et al., 2017), and social inclusion (Jacobsen \& Forste, 2011; Lenhart, 2015).

These research topics are all connected because of their mention of video-gaming, but despite the interest in examining the psychosocial and social aspects of gaming, the heavy-video-gaming students' study practices remain under-researched. Additionally, missing among the scholarly articles is the "how" or "in what ways" the heavy-videogaming student's gaming and study practices are related to each other; meaning how their gaming skills may affect their study habits and organization or vice versa. Literature does not clearly convey if or how video-gaming students align their gaming and study practices. The results of this study may be useful in the development of learning supports, especially those focused on technology-enhanced methods, to assist video-gaming students. Therefore, this research contributes to the field of knowledge about the heavyvideo-gaming students' gaming and studying practices, and the relation between the two of them. Implications include how educators can design appropriate learning supports. 


\subsection{Significance of the Problem}

The significant reasons to explore heavy-video-gaming students' study practices, as described previously, are seen in the following four areas:

- First, the undergraduate video-gaming student population increases with a fast rate and it is already a huge group. Understanding this specific group and how they study is crucial for academic success, as it is becoming one of the largest populations on campuses.

- Second, this new 'extracurricular' subculture activity (playing video games) can have a campus-wide impact on academic performance.

- Third, the video-gaming extracurricular activity has some distinct characteristics from other activities provided within the university, making its student participants a new, unique group to research.

- Fourth, video-gaming students have come to college with unhealthy study practices, and to uncover the details of how they study may help to develop learning supports specific outlined for them, and thus, to help them to succeed in college.

The first area of concern is that the undergraduate video-gaming student population is increasing at such a fast rate they are becoming a predominant populace on university campuses (Bauer-Wolf, 2019). Understanding one of the major populations of students at the university is important. If the gaming and study practices that the videogamers bring to college are unique in some manner, their thinking and study practices may drive the development of new learning support tools and potentially impact the entire higher educational system (Kauweloa \& Winter, 2019; Partin, 2017). 
A second area of significance to the research problem is because so many students are playing games, the video-gaming extracurricular activity can have a campus-wide impact upon student academic performance (Bowman, 2018). The subculture created by campus gaming can influence academic expectations and performance for all campus constituents (Pope, 2017; Yilmaz et al., 2018). The 24-7 gaming availability distraction can inadvertently interfere with classroom policies, such as attendance and homework, and at the same time impact larger areas of campus activity involvement and overall levels of productivity (Ballado-Tan, 2014; Credé et al., 2010). For example, when a new release for a popular video game comes available, the peer pressure to play the new game can be so strong, the subculture excuses the players from work they may need to do in order to play the game. The college or university has very little control over how recreational video-gaming play impacts the academic culture of the campus, particularly in regard to the recreational players who are in control of their personal extracurricular time.

A third concern is the impact that video-gaming extracurricular activities have on student academic performance. Extracurricular activities generally can have significant impact, both positive or negative, on student academic performance (Annetta et al., 2009; Broh, 2002; Guilmette et al., 2019; Hurst, 2016; Seow \& Pan, 2014). Video-games are classified as an extracurricular activity on campuses; thus, it is important to consider. Research shows extracurricular activities have a positive effect on students' overall college experiences and connections to campus life (Seow \& Pan, 2014). Kronholz (2011) articulates that extracurricular involvement and academic performance are in conflict over purpose, with one rendering sacrifice to the other. This conflict of purpose is 
again readily seen through the example of sports extracurricular activities on campuses. The time involvement required of sport athletes, with mandatory and voluntary practices, travel, and games, has been found to have a negative impact on students' academic performance, study behaviors, and overall success (Dyer et al., 2017). Many heavyvideo-gaming students are volunteering just as many hours in recreational gaming as some athletes are required to invest in scholarship sport play, with similar negative impacts appearing for both groups.

Heavy-video-gamers are given to spending more than 14 hours a week in game playing, which competes against dedicated study times (Gnambs et al., 2020; Kassam et al., 2013; Uuskoski, 2011). These recreational video-gamers may come to the university, like the athletes, having study behavioral weaknesses because of their former gaming and study practices. Frequently, these video-gaming students are left on their own to find academic learning supports, as they may have no ties to a formal campus extracurricular group of teammates or coach to assist them with their personal accountability (Manero et al., 2017; Popescu \& Ghita, 2013; Quinton, 2016; Reddy et al., 2015). The recreational video-gaming students do not have activities like mandatory team study halls, regular grade checks, or eligibility rules to keep them focused and in check (Aquino, 2011; Cheslock et al., 2016; Quinton, 2016; Seow \& Pan, 2014).

A fourth significant issue raised is that many video-gaming students come to college with unhealthy practices that have been beneficial in gaming, but not readily applied to current academic tradition settings, thus impacting the success of their academic outcomes at the university (Gnambs et al., 2020; Kassam et al., 2013; Oates \& Brookey, 2014). Colleges are establishing competitive eSport video-gaming teams and 
offering scholarship dollars in hopes of appealing to this digitally-engulfed student population (Partin, 2017; Twenge, 2017). The dollars, usually based on game performance rather than academics, serve as a way to interest and recruit heavy-videogaming students to their campus programs for numbers and profit (Wong, 2017). Students coming to campus with interests bent away from academics are regularly experiencing a need for some academic support (Kulp et al., 2019). According to Cerna and Pavliushchenko (2015), this phenomenon of promoting video-gaming teams in colleges entices some students to come to college who have spent a great deal of time playing games but have not yet established healthy academic study behavioral patterns. This potentially affects the academic performance negatively, since often they are not well versed in devoting time and attention to the longer, slower-paced study needs, such as large amounts of reading and writing, found in higher education (Bondoc, 2020; Cerna \& Pavliushchenko, 2015).

Additionally, according to literature, heavy-video-gaming students have devoted a great deal of time and money to games they play, making it an area of high importance for themselves. (Arockiyasamy et al., 2016; Jiwal et al., 2019). This devotion may lead to academic struggles because of time issues: the time they play may interfere with the time they need for studying. Furthermore, expectations that gaming students have for their academic experience are influenced by gaming such as a fast-paced world with instant feedback, appropriate level of challenge, rewards, and social support (Azziz, 2014, 2014; Ryan et al., 2019) . Traditional academic environments have often offered these videogaming students a much different experience, with slower-paced activities, slower feedback, less engagements, fewer intense challenges, fewer rewards, and more 
independent work (Paul, 2018; Pope, 2017). This raises questions about whether they may need some specialized or additional learning supports.

Research suggests video-gaming should be treated similarly to all other extracurricular activities or sports. But video-gaming has some distinct extracurricular characteristics making its student participants a new unique group to research (BauerWolf, 2019; Casinger, 2011; Paul, 2018; Yilmaz et al., 2018). In higher education history, there have always been students who have played games, but there has never been such a ubiquitous extracurricular activity, as has developed with competitive, continuous, online video-gaming eSports (G. Freeman \& Wohn, 2017; Partin, 2017; Walters et al., 2019; Wong, 2017). This is a new era of activity, and with it comes a new breed of university student. A comparison between video-gaming and traditional campus extracurricular activities are shown in Table 1.

\section{Table 1}

Video-gaming Presented as a Slightly Unique Extracurricular Experience

\begin{tabular}{ll}
\hline Extracurricular generally & Video-gaming specifically \\
\hline $\begin{array}{l}\text { Membership usually required (Bauer- } \\
\text { Wolf, 2019; Duggan, 2015; Farivar, }\end{array}$ & $\begin{array}{l}\text { Open to entire campus without } \\
\text { membership (Bauer-Wolf, 2019; }\end{array}$ \\
$\begin{array}{ll}\text { Duggan, 2015; Farivar, 2011). } \\
\text { Official groups are college sponsored, } \\
\text { with established participation }\end{array}$ & Video-gaming provides both official \\
boundaries (Santucci, 2012). & college-sponsored groups and \\
& unofficial options for participation. \\
& $\begin{array}{l}\text { Recreational play has no participation } \\
\text { boundaries (Brockman, 2011; G. }\end{array}$ \\
& Freeman \& Wohn, 2018; Hamari \& \\
& Sjöblom, 2017; Jacobsen \& Forste, \\
& 2011; Paul, 2018). \\
\hline $\begin{array}{l}\text { Collegiate level skills needed to } \\
\text { participate, built over lifetime } \\
\text { Kassam et al., 2013; Wagner et al., }\end{array}$ & No levels of skill are needed to \\
2008) & Warticipate (Kassam et al., 2013;
\end{tabular}


Table 1 (continued)

Average time investment -5 to 10

hours per week (Kulp et al., 2019;

Seow \& Pan, 2014).

Heavy-video-gaming students average time is $14+$ hours per week. This study shows average gaming time is 27.22 hours per week (Hamari \& Sjöblom, 2017; Jacobs, 2015; Paul, 2018; Stanton, 2015; Torres-Díaz et al., 2016).

Activities initiated for purpose of supporting academic disciplines and campus missions (Guilmette et al., 2019; McGrath, 2019).
Gaming activities have little purpose in supporting school missions, though it is growing into a distinct discipline (Bauer-Wolf, 2019; Nguyen, 2017)
Potential to affect a small to medium population of campus (Osborn, 2020; Routon \& Walker, 2015)
Potential to affect a large population of campus (Kort-Butler, 2020; Thuma, 2012).

Thus, the goal of this research is to understand heavy-video-gaming students' gaming and study practices with the aim of developing technology-enhanced learning supports for them (Torres-Díaz et al., 2016). By better understanding the way this large populous of video-gaming students think and study, researchers and educators may find new and better tools that are meaningful for the learners who come with study practices and learning methods that have been formulated within an engulfing digital world (Bennett \& Maton, 2010).

\section{$1.3 \quad$ Research Gap}

Research can be found on many topics about video games such as the rise of eSports in colleges (Hattenstone, 2017; Southern, 2017; Tillier, 2018), how games exercise player cognitive skills and reaction times (Blank-Rochester, 2010; Nuyens et al., 2019a), and how extracurricular activities like gaming encourage social behaviors (Kulp et al., 2019; Seow \& Pan, 2014), but few studies focus on the heavy-video-gaming 
students and their study practices and the development learning supports for these students.

Figure 2 illustrates the gap found in literature. Literature on many gaming topics exists, but none emphasizes the academic needs these video-gamers have as learners. In

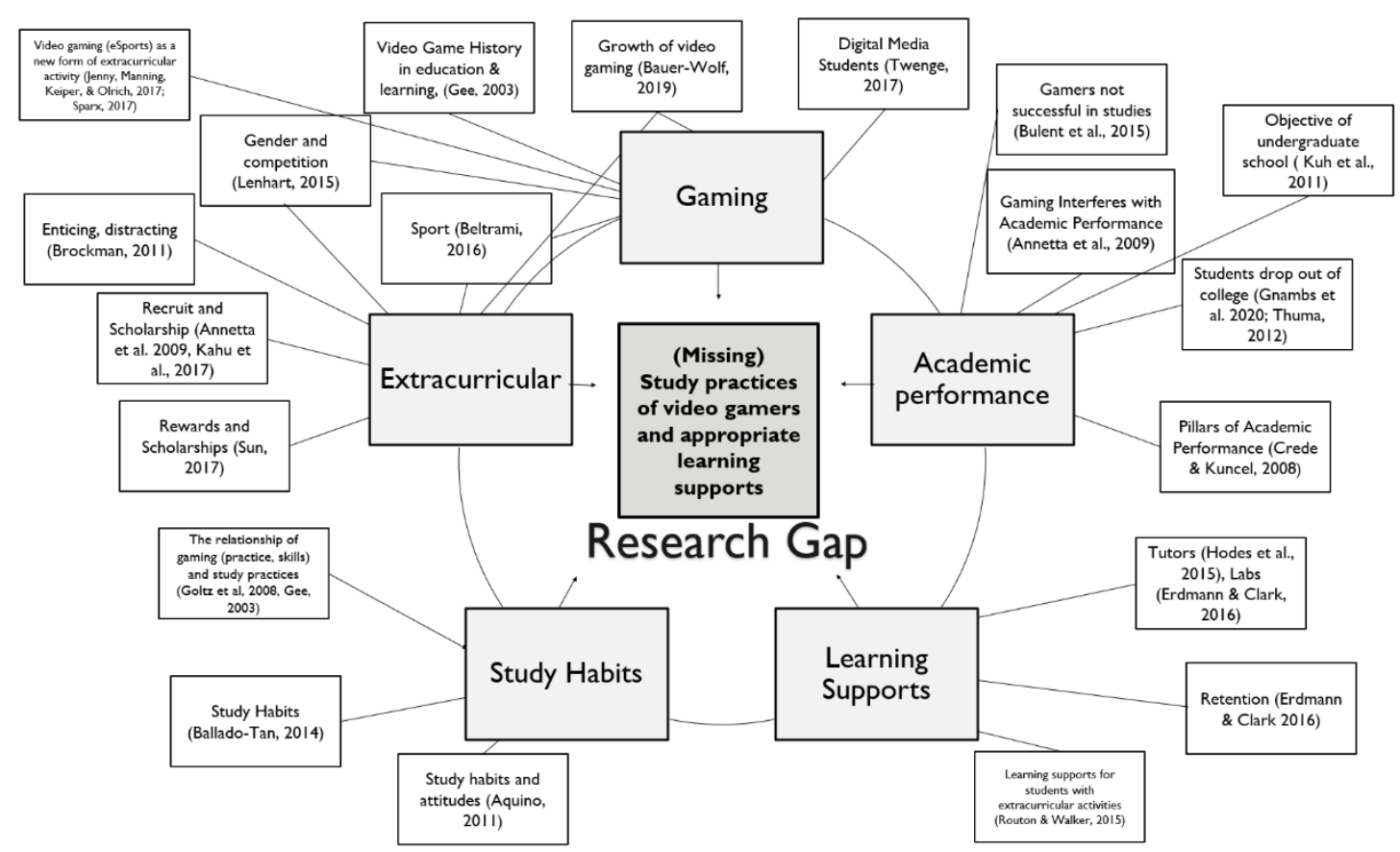

order to support the gaming students in their academic performance, it is first critically important to understand their gaming and study practices, which are not evident within the academic literature.

\section{Figure 2}

\section{Literature-driven Research Gap}

Having data on study practices of heavy-video-gaming students can lead educators and researchers to the development of appropriate learning supports. It is unknown which new technology-enhanced learning supports would better serve the undergraduate heavy-video-gaming student, and may also help other less-gaming or non- 
gaming students. (Erdmann \& Clark, 2016; Popescu \& Ghita, 2013; Routon \& Walker, 2015). Thus, this study explores the gaming and study practices of undergraduate heavyvideo-gaming students first, providing data for both the development and implementation of learning supports (Ballado-Tan, 2014; Wong, 2017).

\subsection{Research Questions}

Research questions for this study are focused on undergraduate heavy-video-gaming students in an effort to foster an understanding of these players and that can potentially also be used for other video-gaming students. The definition of heavy-video-gaming students in this study is those collegiate players who are either on a formal collegiate eSports team or play video games informally 14 or more hours a week (Brightman, 2015; Jacobs, 2015; Oates \& Brookey, 2014). Two research questions are addressed in this qualitative study:

1. What patterns of gaming and study practices can be identified among undergraduate heavy-video-gaming students?

2. What learning support areas, including those with a focus on technologyenhanced learning supports, can be developed for undergraduate heavy-videogaming students to support them during their academic studies?

Results from this empirical study provide an in-depth description of such heavyvideo-gaming students, offer a basis on which they can be better understood, and provide researchers and educators new information that can assist them in their efforts to support the heavy-video-gaming students in university-level academic endeavors. 


\subsection{Summary}

It is an appropriate choice for researchers and educators to adjust the learning supports they provide in an attempt to boost the academic success of their students. The purpose of this study is to clarify study practices of heavy-video-gaming students in order to develop technology-enhanced learning supports for them since game-playing has now become a major form of extracurricular activity at college.

Chapter 2 provides a 195-article systematic literature review on undergraduate video-gaming students which was conducted for informing this study. Five themes of video-gaming are addressed in the literature review. Also included in Chapter 2 is the conceptual framework used for the study, including 1) a look at current student study practices in higher education (Aquino, 2011; Ballado-Tan, 2014; Nasution, 2015); 2) study practices as a pillar of support to predicting and maintaining student academic performance (Credé \& Kuncel, 2008); and 3) activity theory and the role technologyenhanced learning supports play (Kaptelinin \& Nardi, 2006).

Chapter 3 outlines the specific methodology utilized for data collection and models used for data analysis of the study. Chapter 4 reports the findings as related to the research questions. Chapter 5 relates the results to current literature, shows the implications for the field, and gives recommendations for future research. 


\section{Chapter II: Literature Review}

Beginning in 2016, video-gaming was offered on a small number of university campuses as an official, sanctioned college sport (Consolazio, 2018), and millions of university students have played thousands of hours of games on all types of digital devices as college representatives and for their own recreation. This high-interest, fastpaced phenomenon of video gaming has generated various research interests across disciplines (cf. Section 2.1). To make sense of such a broad literature field, I conducted a systematic literature review focusing on the undergraduate video-gaming student (Todd, In preparation). This systematic literature review was useful in identifying works about video-gaming students across the study disciplines. The exercise made apparent that there is an abundance of gaming research, but most is about gamer's behavioral problems or health problems. The literature review makes obvious the large need for research about non-problematic undergraduate video-gamers as learners and the types of educational learning supports they may need.

\subsection{Three Themes: eSports, Relation of Gaming and Studying, Learning Supports}

Conducting the literature review required searching and filtering through more than 4,000 articles. The following search and selection criteria were applied: contains the word university OR higher education OR undergraduate AND video-game OR videogamer. Articles in which the group was younger or older than undergraduate students were eliminated. The final review resulted in 195 articles published between the years 2016 -2020 across 136 journal titles. The five-year time span and the large number and variety of journal publications indicated the topic of undergraduate video-gaming students is one of high interest. However, it has yet to find a home in a specific field of 
knowledge and is a topic with many unanswered questions, leaving open the research opportunities.

The 195 article topics from the literature review were divided into five overarching themes with subthemes:

1. Problem Gaming: Addiction - Internet Gaming Disorder (IGD), Gambling, Violence (67 articles - 34.4\%)

2. Behavior Science: Social, Gender-Sex, Personality, Behavior, Motivation (40 articles $-20.5 \%$ )

3. Health: Overall Health and Cognition/Brain studies (33 articles $-16.9 \%$ )

4. Education: Learning, Gamification, Academic Performance, Habits, Game Development (29 articles $-14.9 \%)$

5. eSports: as Collegiate Athletics, as Industry, as Extracurricular (26 articles $13.4 \%)$

A note of interest is that most articles in the literature review were related to the first identification category: problematic gaming. The emphasis of literature on the problematic heavy-video-gaming participants serves as an indicator there is a need to examine and try to understand the undergraduate heavy-video-gaming students, identifying ways they may need to be supported within the academic settings. In seeking to address this gap, I found that the literature most relevant for addressing the research question (cf. Chapter 1) was within topics four and five: 4) Education: Learning, Gamification, Academic Performance, Habits, Game Development; and 5) eSports: as Collegiate Athletics, as Industry, and as Extracurricular. Presented below are the sections of the most relevant literature, not in the order of rank, but rather as they relate to the 
study object diagram introduced in Figure 1 in Chapter 1. Discussed first is video gaming as a new form of extracurricular activity (2.1), followed by the relationship of gaming and study practices (2.2), followed by learning supports (2.3).

\subsection{1 eSports: as Collegiate Athletics, as Industry, as Extracurricular}

Video-gaming as an officially supported extracurricular activity at the university level, known as eSports, has a debate looming around it. In literature prior to 2016, researchers and educators argued that video-gaming and study practices have very little in common. Video-gaming was industry driven and had little concern for academic outcomes (Flew \& Humphreys, 2005; Nasution, 2015). Video gaming has been referred to as a waste of time (Ferguson \& Markey, 2017; Kassam et al., 2013; Uuskoski, 2011). More recently, however, researchers have taken a converse position claiming that bringing the formalized competitive video-gaming teams to campus is influencing students, especially males, in leadership and improved academic performance (Jung et al., 2020; Walters et al., 2019). To understand how the video-gaming debate moved to extreme ends of the spectrum, from one of distaste to tolerance to acceptance, a review of how video games found their place in the universities' history is in order (Consolazio, 2018; Scholz, 2019a; Schwartz, 2017).

With the rise of personal computer availability in the 1990s, college campus organizations started encouraging video game play by sponsoring digital game-play events called local-area-network (LAN) parties as social activities and fund raisers (Briscoe \& Mulligan, 2014; Taylor \& Witkowski, 2010). Industry game publishers recognized that college-aged players represented a lucrative amateur market for which gaming companies devised easy-to-enter college tournaments in the early 2000s. These 
tournaments encouraged regular involvement through competition and enticing reward packages (Sun, 2017). Since then, college students have regularly banded together as unofficial collegiate teams to compete in the popular video game college-level tournaments sponsored by industry game publishers, such as League of Legends (Schwartz, 2017; Sun, 2017). eSports video-gaming is now identified as the fastestgrowing sport in the world in both the professional and amateur worlds (Beltrami, 2016; Hollist, 2015; Southern, 2017; Tillier, 2018). In 2016, Robert Morris University established the first official collegiate eSports team in response to the world interest phenomenon (Consolazio, 2018). Across the world, university leaders recognized how students, especially young men, have been drawn to these competitive video games (Baltezarević \& Baltezarević, 2018; Hallmann \& Giel, 2018; Lenhart, 2015; Scholz, 2019b). Thus, there has been a push by both industry and higher education to use gaming as a lucrative recruitment tool into each respective environment (Jung et al., 2020; Kauweloa \& Winter, 2019).

Therefore, a recurring topic in the undergraduate video-gaming literature is related to the formation of collegiate eSports teams (García \& Murillo, 2020; Hallmann \& Giel, 2018). When campus leaders decide to initiate eSports teams, one of the complicating issues revolves around finding a place of belonging for the newlyformulated groups (DiFrancisco-Donoghue \& Balentine, 2018). The most popular perspective is that eSports should take on the form of other collegiate athletics sport teams and clubs, supported and controlled by college regulatory policies, allowing healthy competition between school players as athletes, offering scholarships, providing 
practice facilities, and becoming a part of the college recruitment experience (Beals, 2019; Holden, Kaburakis, et al., 2017; McCarthy, 2019).

A second view about video-gaming within universities is to embrace the notion as a new degree program and study discipline (Jenny et al., 2018; McCarthy, 2019). School leaders recognize the public's interest in gaming as a potential opportunity to prepare students for jobs the eSport-gaming industry provides, including business, law, marketing, game development, and broadcasting (Holden, Kaburakis, et al., 2017; Jenny et al., 2018; Johnson \& Woodcock, 2019). Thus a type of technical training is being developed for this industry (Hollist, 2015; Nguyen, 2017).

However, many students are coming to college or university campuses who will not play on an official collegiate eSports team or earn an eSports degree (Pope, 2017). Instead, they make up a larger subculture population of recreational players (Paul, 2018; Pope, 2017). These students invest a great deal of their private extracurricular time in eSports and video-games for their personal enjoyment. Yet, approximately $81 \%$ of individuals aged $18-29$, the typical age of college students, and $70 \%$ of university students report they play video games (Burgess et al., 2012), regularly investing over two hours a day in gameplay (Altintas et al., 2019; Bondoc, 2020; Hattenstone, 2017; Yao, 2019). Universities are filled with video-gaming students who play near or at the rate of 14 hours a week. This classifies them as heavy-video-gamers.

These recreational student heavy-video-gamers perceive their gaming time as a welcomed, relaxed, positive extracurricular activity of choice, a means by which they connected with friends, and do not feel it interfered with their overall school responsibilities (Hatmaker, 2017; Jenny et al., 2017, 2018; Sparx, 2017). The students in 
one study even acknowledged that while their game playing was a waste of time, they felt they kept up with their academics and believed the social aspect was beneficial in enhancing their face-to-face interactions in school (Latif et al., 2017). The concept of social engagement for video-gaming students was a consistent theme within the literature. Video-gaming students found these connections led to good friendships and stronger school experiences (Eklund \& Roman, 2019; Myers, 2019).

Other, more critical research declared video-gaming as a distracting extracurricular activity, driven by a third-party gaming industry, that kept students from the main business of academics (Guilmette et al., 2019; Paul, 2018). Paul (2018) makes the argument that the culture the gaming industry promotes is one of meritocracy, a system that forecloses critical thought and reflection. Meritocracy makes victors feel that they have earned their rewards and relegates others to their supposed deserved lesser status (Paul, 2018). This gaming culture then stands in opposition to the many universities who claim critical thinking and deep reflection are a vital part of their missional purposes. Other unwelcomed behaviors were exposed that surround heavyvideo-gaming culture, such as addiction (Hattenstone, 2017; King \& Delfabbro, 2020), toxic language (Holden, Rodenberg, et al., 2017; Khandaker, 2019), and sexual discrimination (King \& Delfabbro, 2020; Paaßen et al., 2017, 2017; Yao et al., 2010). These behaviors have been associated with a phycological and behavioral term internet gaming disorder (IGD) (Jung et al., 2020; Zajac et al., 2017). The literature review shows that these IGD behaviors are one of the largest areas currently being researched (Todd, In preparation). Universities spend millions of dollars to decrease such unwanted issues and behaviors on their campuses, and yet many schools are inviting the very video-gaming 
activity to campus that support them (Başol \& Kaya, 2018; Cantalupo \& Kidder, 2018; Durbach \& Grey, 2018; Hill, 2018; Yao et al., 2010).

This dichotomy of views invites the need for more research. Universities need to conduct further research to show the specific strengths and weaknesses of these gamers as learners. Understanding the undergraduate heavy-video-gaming students and their study practices is a relevant accomplishment as it adds factual data to the video gaming discussion. This new information can lead to the elimination of stereotyping gamers, ridding some of the ideas that all gamers have outlier tendencies, such as being an addict, engaging in ill-tempered violence, or lacking motivation. Instead, a deeper understanding can lead to the development of relevant technology, and other meaningful learning supports for this sector of college students.

\subsubsection{Education: Learning, Academic Performance, Habits, Relation to Gaming}

The literature on the topic of video-gaming students in education most frequently discusses the manner in which students responded to gamification of course content. Davis et al. (2018) reveals the positive effect of using a gamified informatics undergraduate course. In their study, 139 students were surveyed at three points during the course, with positive trends with respect to student perceptions of gamification. Bursztyn et al. (2017) found high student engagement levels when allowing students to use augmented reality (AR) game apps, much like Pokémon, on a simulated geoscience field trip. The study involved 849 students from five institutions and was used to evaluate engagement with AR field trips and predict interest in the study of geosciences, determined by the number of game modules completed. This study highlights key factors that video-gaming literature indicates are high interest areas of video-gaming students: 
the tangible interaction (Davis et al., 2018; Franz et al., 2012), immediate feedback (Roman et al., 2020; Ryan et al., 2019), and system of rewards (Oates \& Brookey, 2014; Wingfield, 2014).

The development of educational games was a small subsection of the literature review. Mozelius (2018) studied the way games were being constructed and how the games actually met the learning outcomes of given courses. Upon examination of 33 essays from the students, the results indicated that often students are reluctant to play educational games. However, when the games keep their interest, the game most often provides the learner with some new cognitive knowledge, such as vocabulary. A few games help increase motivation for learning a skill, and finally a few games actually address social behaviors (Mozelius, 2018). While games were found to help cognitive knowledge, motivational engagement, and behavior alterations in isolated education settings, it was difficult to find undergraduate articles that tied recreational video-gaming or eSports gaming to educational outcomes.

However, these video-gaming studies do not effectively provide the broader view of undergraduate heavy-video-gaming students' academic performance, but rather isolated classroom experiences. It remains unclear how video-gaming students at large, especially successful ones, are influenced by esports and recreational games when approaching their academic experiences. Researchers and educators need to understand the players' study practices, skillsets, and attitudes that can be utilized in supporting them toward successful academic performances (Beattie et al., 2019; Manero et al., 2017).

A few articles in the literature review emphasized study habits as relevant to the education discussion. The habit most often evaluated within research was the time video- 
gamers spent playing games as opposed to studying (Nuyens et al., 2019b; Triberti et al., 2018; Yilmaz et al., 2018). Nuyens et al. (2019) researched the variables of time loss and impaired time control in gamers, but determined the overextended time of play had more to do with the flow of interaction between the game and gamer. Yilmaz et al. (2018) took a qualitative approach, interviewing heavy-video-gamers to find out why they spend so much time gaming and how it impacts them in school. Results indicated that gaming is a safer place to socialize and it is easier to talk virtually with others than in person, impacting the social aspects of the school experience (Yilmaz et al., 2018). The work of Triberti et al. (2018) supported the claim that the time spent playing is more about who the student is playing with, the relationship, rather than the specific time of day or amount of time invested. Beattie et al. (2019) went deeper into understanding the students as thrivers and divers by comparing their study habits, attitudes, and mental health. Of the 6000 Toronto university students surveyed, the study revealed that thrivers studied nearly seven hours more than the divers. Divers were less likely to write down things, such as assignment instructions and due dates, and were less likely to ask for assistance from an instructor or support personnel (Beattie et al., 2019).

Research that indicated participation in video-gaming could provide multiple improved skillsets and habits for students. Some of the studies highlighted improved academic performance, showing increased GPAs and test scores after using some games in the classroom (Farb \& Matjasko, 2012; Manero et al., 2017), increased social and personal skills (Devilly et al., 2017), leadership (Walters et al., 2019), confidence (Reitman et al., 2020), improved time management with use of online scheduling tools (Nuyens et al., 2019b), responsibility (Eanes, 2013; Walters et al., 2019), better behavior 
(Kort-Butler, 2020), more engagement (Davis et al., 2018; Eanes, 2013), higher selfesteem, a chance to explore their own interests and talents and discover passions (Guilmette et al., 2019), better health in relation to stress relief and obesity (de las Heras et al., 2019), a desire to continue to learn and seek further education (Feldman \& Matjasko, 2005), extrinsic motivation (Schmidt \& Shreffler, 2015), challenge inhibitions (Kronholz, 2011), and an introduction to diversity (Seo \& Jung, 2016).

Other research disputes the benefits of video-gaming for students. For example, research showed that heavy involvement in any extracurricular activity regularly resulted in less study time, which led to poor academic performance (Morris, 2019). A study from Connecticut College emphasized the balance of all activities and found that of the 10,000 U.S. students who participated, those who had extracurricular activities that accounted for between one and 13 hours per week of their time actually showed some positive academic effects (Martin, 2016). However, no further academic improvement was seen when students were involved in gaming for more than 14 hours per week. Those who participated in ten extracurricular activities each week scored $4 \%$ lower on their grade average than others and performed at a lower level than peers who did not participate in extracurricular activities (Norman, 2017). Many studies made the connection that dedication of time to video games negatively impacts a student's academic performance (Kassam et al., 2013; Nuyens et al., 2019b; Wagner et al., 2008).

Other research disputing the benefit of video-gaming skillsets and habits highlighted the non-restorative sleep for students (Altintas et al., 2019). The sleep factor was a major concern of studies within the health topic of the literature review (Todd, In preparation). Other negative behaviors highlighted in studies included unpreparedness for 
classes (Bondoc, 2020), the prohibitive nature of costs that limit involvement for all and the spending of unavailable dollars on games to be part of the group (Quinton, 2016), the activity itself has limited resources (Quinton, 2016), time management issues and schedule conflicts (Morris, 2019), too many offerings for students (Yao, 2019), lack of personal commitment and effort (Norman, 2017), added stress (Hurst, 2016), mandatory participation can take fun out of the activity (Hurst, 2016), events take away free and down time and time away from family (Throuvala et al., 2019), academic performance at risk due to tiredness (Morris, 2019; Norman, 2017), as well as health problems and injuries (Norman, 2017). Within these research results, it becomes evident the group of non-problematic undergraduate heavy-video-gaming students (i.e., not focusing on health issues or addictive behavior) is still under-researched.

\subsubsection{Literature on Learning Supports}

Another area of relevant literature research is collegiate learning support areas, sometimes called learning supports, which focuses on current methodologies schools are using to support students. According to researchers, these support programs aid students in achieving the academic success level that is needed to be successful and stay in school, and they come in many forms such as writing labs, tutoring, and more shown in Table 2 (Erdmann \& Clark, 2016; Hodes et al., 2015; Kronholz, 2011; Lotkowski et al., 2004; Schaeperkoetter et al., 2017). While the articles focus on learning supports, they did not take into account the video gaming perspective or influences, which help to provide support that there is a need for this study. 


\section{Table 2}

Learning Supports found in Literature

\begin{tabular}{|c|c|}
\hline Learning Supports on Campus & Research/Studies \\
\hline \multicolumn{2}{|l|}{ Mentoring/Student Support } \\
\hline Academic advisors & Millicamp et.al, 2019 \\
\hline Professors' accessibility & Mottet et al.,2005 \\
\hline Peer Mentoring & Rusk et al., 2020 \\
\hline Professors keep office hours & $\begin{array}{l}\text { Lotkowski et al., 2004; Sharples et al., } \\
2016\end{array}$ \\
\hline Success coach assigned to students & Lawhorne, 2020 \\
\hline Teaching assistants (TA) for classes & $\begin{array}{l}\text { Sharples et al., 2016; Wheeler et al., } \\
2017\end{array}$ \\
\hline Tutors in specific subjects & Hodes et al., 2015 \\
\hline \multicolumn{2}{|l|}{ Homework/Practice Support } \\
\hline Academic success course & Blankenship, 2017 \\
\hline $\begin{array}{l}\text { Make use of explicit due dates in assigned } \\
\text { work }\end{array}$ & Bulent, 2015 \\
\hline Extended due dates on assignments & Archer, 2018 \\
\hline Homework as a way of knowledge practice & $\begin{array}{l}\text { Goehle \& Wagaman, 2016; Junger, } \\
\text { 1990; Vatterott, } 2018\end{array}$ \\
\hline Meaningful homework & Vatterot, 2018 \\
\hline Mandatory study hall & Kronholz, 2011 \\
\hline Remedial classes offered & Freeman \& All, 2017 \\
\hline Team mandated study groups & Kronholz, 2011 \\
\hline Writing Lab access & Erdmann \& Clark, 2016 \\
\hline \multicolumn{2}{|l|}{ Learning Space Support } \\
\hline Attending Class & Aquino, 2011 \\
\hline Dorm living options & Riker \& DeCoster, 2008 \\
\hline Space accessibility to students & $\begin{array}{l}\text { Beckers et al., 2016; Blackmore et al., } \\
2010\end{array}$ \\
\hline Library access/ late hours & Cha \& Kim, 2015; \\
\hline Multiple study spots & Beckers et al., 2016, Parker, 200 \\
\hline Nearby living quarters & Nurul Ulyani et al., 2010 \\
\hline Study spaces grouped by degree majors & Gillet et al., 2013 \\
\hline Small class sizes & Boyer et al., 2007 \\
\hline \multicolumn{2}{|l|}{ Assessment Support } \\
\hline Take-home tests & Duncan, 2007; Ennis-Cole, 2019 \\
\hline $\begin{array}{l}\text { Regular grade verification throughout the } \\
\text { semester for students }\end{array}$ & Lotkowski et, al., 2004 \\
\hline Required GPA for participation in activities & $\begin{array}{l}\text { Santucci, 2012; Schaeperkoetter et al., } \\
2017\end{array}$ \\
\hline
\end{tabular}


Table 2 (continued)

\begin{tabular}{|c|c|}
\hline \multicolumn{2}{|l|}{ Class Pedagogies/Materials Support } \\
\hline Choices of resources used for learning & Lee, 2009; Mandernach, 2015 \\
\hline Teacher notes available to students & Neri, 2007 \\
\hline Field trips & Davis et al., 2018*; Zhao et al., 2020 \\
\hline Study days implemented in the schedule & $\begin{array}{l}\text { Franz et al., 2012; Nonis \& Hudson, } \\
2010\end{array}$ \\
\hline $\begin{array}{l}\text { Honors programs available to students who } \\
\text { need academic challenge }\end{array}$ & Boligitz, 2020 \\
\hline Supportive personnel in all offices/classes & Li et al, 2018 \\
\hline \multicolumn{2}{|l|}{ Campus Resources Support } \\
\hline Innovative scheduling & Simmons, 2020 \\
\hline Intramural sports & McCarthy, 2019 \\
\hline Mental counseling & O'Connor et al., 2018 \\
\hline Online resources for easy access & Soni et al.,2018 \\
\hline Professional degrees offered & Sutton, 2019 \\
\hline Office of disabilities & Griful-Freixenet et al., 2017 \\
\hline Office of spiritual development & Sterk Barrett, 2015 \\
\hline $\begin{array}{l}\text { Technology equipment appropriate in classes } \\
\text { and available for student use }\end{array}$ & Greenwald et al., 2017 \\
\hline \multicolumn{2}{|l|}{ Other Support Areas } \\
\hline Family support & Li et al., 2018 \\
\hline Life pause, a chance to catch up & $\begin{array}{l}\text { Tabbers, Martens, \& Merriënboer, } \\
2004\end{array}$ \\
\hline Rest, a chance to recoup & $\begin{array}{l}\text { Ohayon, 2008*, Tabbers, Martens, \& } \\
\text { Merriënboer, 2004 }\end{array}$ \\
\hline Short degree programs offered & Sutton, 2019 \\
\hline Specific degrees offered & Quadlin, 2017 \\
\hline Time provided to complete work & Nonis \& Hudson, 2010 \\
\hline
\end{tabular}

Note: These articles are focused on learning supports in general but do not take specifically take video-gaming behaviors into account.

Many of these learning support efforts are aimed at students who lack academic skills or may need to show improvement to keep academic status (Routon \& Walker, 2015). Erdmann and Clark (2016) show that many librarians have created specialized learning support programs designed to explicitly aid athletic students reclaim the hours required to practice, travel, and fulfill other commitments related to a sports activity. Burgess et al. (2012) showed that learning supports addressing remediation may be necessary, facing the reality that students come to school, and may even be recruited, 
without the appropriate academic abilities, study practices, and attitudes for maintaining sufficient grades to persist and remain involved. Programs are needed to help the students succeed.

College leaders have long-established learning support programs for the athletic teams. As shown in Table 2, team members can be required to attend mandatory team study sessions, provide regular grade reports to coaches, or be assigned a personal tutor in an effort to help them maintain qualifying grades to retain eligibility and participate on the team. Schools are spending resources on writing, math, language, and other special support labs to help students through even basic college-level courses (Hallmann \& Giel, 2018; Shulruf, 2010; J. Wang \& Shiveley, 2009). This effort to retain students promotes the successful academic performance of these students and permits them to participate in their sport of choice (Erdmann \& Clark, 2016; Hodes et al., 2015; Routon \& Walker, 2015). While these learning support areas may work for some college teams and groups, individuals who do not have this type of extracurricular accountability in their daily routines may struggle and fall un-noticed in their academic performance.

When the college has oversight of the extracurricular activity, these programs may be enforced. However, the literature is very quiet about the learning supports that may be specifically needed by the many individual heavy-video-gaming students found within the college population.

\subsubsection{Identified Gaps}

When examining the gaming literature, there is little research about study practices, and even less is presented as to whether these gamers will utilize the traditional academic learning supports, or whether they require new emergent types of learning 
supports as they bring their gaming and problem-solving skills to campus. These gaps make room for future research in the area of undergraduate heavy-video-gaming students. An issue with the reviewed literature is that undergraduate video-gaming student research is not done on a continual, consistent basis in order to stay current (Dale et al., 2020; Partin, 2017). Literature from even five years ago is dated and gives indications of irrelevance, such as playing on stationary consoles in 2010 versus mobile online gaming in 2016, and local area network gaming parties of the 2000's verses the current online multiplayer games which can be in constant play mode (Consolazio, 2018; Goette et al., 2019). Graphics in games have become more realistic (Bown et al., 2017), and an entire industry called eSports has now developed around video-gaming (Bányai et al., 2019). The gaming genre is changing from individual players to a community of players (e.g., eSports)

The first gap in research revolves around the need to understand the behaviors of the non-problematic heavy-video-gamer. It is noticeable that much of the undergraduate video-gaming student research between 2016 and 2020 is related to problematic gaming (Di Blasi et al., 2020; Mérelle et al., 2017; Sanders \& Williams, 2019). The literature presented is highlighting problematic gamer behaviors, such as toxicity or addictions (Khandaker, 2019; King \& Potenza, 2020; Sanders \& Williams, 2019), and looking for treatments to solve the problems (Griffiths et al., 2016; Zajac et al., 2017). However, not all heavy-video-gamers are problematic. Because 70 percent of the undergraduate student population report they play games, more research needs to be conducted on the nonproblematic gamers (Kort-Butler, 2020; Partin, 2017; Reitman et al., 2020). Both, “thrivers and divers," discussed by Beattie et al. (2018) are found within this group of 
students. Intentional and practical study-practices training may be appropriate for divers to help these students move toward university success (Beattie et al., 2019; Erdmann \& Clark, 2016), Understanding the effective skillsets of students who are succeeding in life and school could be beneficial for creating models and learning supports used when working with video-gaming students of all types (Torres-Díaz et al., 2016).

A second noticeable gap is found in the within the research in the educational field. Many articles focused on teens and younger children rather than undergraduate students. Of the articles about undergraduates, educational research was related to gamification of class content (Bursztyn et al., 2017; Davis et al., 2018), measurement of academic performance though factors such as grade point averages (Ellis \& Kao, 2019; Maksy \& Yoon, 2019), gender (Manero et al., 2017; Yilmaz-Soylu \& Bruning, 2016), and game development (Indra et al., 2019; Mozelius, 2018). Research was not focused on the impact that the extracurricular video-game-playing activity has on the skill sets of participants as learners. Even when articles highlighted skills like memory (La Corte et al., 2019; Mallik et al., 2020) and cognition (Kwak et al., 2020; Samsuri et al., 2019), these were more often found in the health or behavior literature, and not related to education. There is room to better understand the heavy-video-gamer as a learner, focusing on the study practices and skillsets that these learners are honing because of gaming (Gnambs et al., 2020). Heavy-video-gamers may bring skills that could transform educational systems, influencing the way they problem solve, support others, and even approach study practices, which are further discussed in Chapter 5.

Finally, articles that were about video-gamers at the university were most often about the students who played on the campus eSports teams (Jenny et al., 2017). The 
articles were making cases for athlete status for collegiate eSports players or for new policies around the new campus activity (Bauer-Wolf, 2019; Jenny et al., 2017; Schaeperkoetter et al., 2017). However, research has not addressed the millions of recreational undergraduate students who are involved in video-gaming as their extracurricular activity on campus (Guilmette et al., 2019). There is a need for more research on this subculture of recreational video-gamers (Hallmann \& Giel, 2018; Paul, 2018; Pope, 2017). The aforementioned gaps lead to the refined and focused research questions building on the issues raised in Chapter 1 for this study.

R1: What patterns of gaming and study practices can be identified among undergraduate heavy-video-gaming students?

R2: What learning support areas, including those with a focus on technologyenhanced learning supports, can be developed for undergraduate heavy-videogaming students to support them during their academic studies?

Gathering empirical evidence surrounding these research questions can provide researchers and educators with in-depth information that can assist them in their efforts to support the heavy-video-gaming students in university-level academic endeavors. In order to study the heavy-video-gaming students, the conceptual framework of study habits and activity theory are applied and discussed further in section 2.2.

\subsection{Conceptual Framework}

In order to study the video-gaming students' gaming and study practices, a conceptual framework is applied which is composed of three main theories that are combined. These include: 1) study habits (Aquino, 2011; Ballado-Tan, 2014; Credé \& 
Kuncel, 2008), 2) academic performance (Credé \& Kuncel, 2008), and, finally, 3) activity theory (Kaptelinin \& Nardi, 2006).

\subsubsection{Study Habits and Attitudes}

Research supports the existence of a strong correlation between academic performance and a student's study habit behaviors and attitudes (Aquino, 2011; BalladoTan, 2014; Credé \& Kuncel, 2008; Nasution, 2015). A habit is defined as the ability to retain an act, movement, or behavioral pattern through practice and training that then becomes an easy manner of behaving without hesitancy or concentration (Beattie et al., 2019; Bray et al., 1980; Thompson, 1976). A habit is a "settled practice" which is hard to change (Desiderato \& Koskinen, 1969; Mendezabal, 2013). Habits in their totality make up the characteristics of the individual as they appear to others (Bray et al., 1980; Desiderato \& Koskinen, 1969; Özsoy et al., 2017).

A study habit is generally understood as a regular, systematic, and effective way of fulfilling related responsibilities and obligations (Elliott et al., 1990; Özsoy et al., 2017). For this research, the definition of study habits aligns with research from Aquino (2011) and Crede and Kuncel (2008) as the generic term which refers to the attitude, study materials, study techniques, study environment and actual study time. Thus, study habits operationally pertain to behaviors to which students make themselves accustomed and are methods of approach whereby students interact with units of learning.

Literature identifies several different behaviors as study habits, occasionally referred to as study skills (Bulent et al., 2015), ranging from being on time to sleeping well (Aquino, 2011; Credé \& Kuncel, 2008; Elliott et al., 1990). With many types of behaviors being classified as study habits, the actions are generally clustered within 
categorical titles, such as regular study, creating a study space, efficient reading, listening to lectures, noting, efficient written expression, participating in the lesson actively, doing homework, preparation for the exams, and attending exams (Dodge, 1994; Küçükahmet, 2000; Kuh et al., 2011; Walters et al., 2019). Combinations of these behaviors, as listed in Table 3, make up an individual's set of study habits and are posited as strong influencers of academic performance.

\section{Table 3}

Study Habits adopted from Literature

\begin{tabular}{ll}
\hline Name/Category of Human Behavior & Research/Studies \\
\hline Do not multitask - focus & $\begin{array}{l}\text { Denson, Austin, Hailey, \& } \\
\text { Householder, 2015; Richtel, 2013 } \\
\text { Ohayon, 2008 }\end{array}$ \\
Sleep well & Tabbers, Martens, \& Merriënboer, \\
\hline Inserting spaces between learning sessions & 2004 \\
Being on time & Aquino, 2011 \\
Setting and accomplishment of goals & Shim \& Ryan, 2012 \\
& \\
\hline Use of library & Demirbilek, 2014; Purdie \& \\
& Hattie, 1999 \\
\hline Reading material before class & Bulent et al., 2015; Thompson, \\
& $1976 a$ \\
Reading, listening, writing & Barrowski, 2009 \\
\hline Testing oneself & Wachelka \& Katz, 1999 \\
\hline Taking notes & Neri, 2007 \\
Use memory aids & Ortony, Vondruska, Foss, \& Jones, \\
& 1985 \\
\hline Paying attention in class & Chickering \& Gamson, 1987 \\
& Feldman \& Matjasko, 2005 \\
\end{tabular}


Table 3 (continued)

Completing homework in a timely manner

Aquino, 2011

Doing homework, doing revision, preparing

for presentations and projects

Delaying or avoiding work

Wagner et al., 2008

Brown \& Holtzman, 1967

\begin{tabular}{ll}
\hline Preparing for e0xams & Purdue \& Hattie, 1999 \\
Being on time & Aquino, 2011
\end{tabular}

Being on time

Aquino, 2011

Attending class

Mahoney, 2003

Although not every study habit is guaranteed to produce useful results in terms of academic performance, it would be anticipated that students who possess "good" study habits are, in general, better academic performers than those students with poor study habits (Aquino, 2011; Dyer et al., 2017). Influencing the heavy-video-gaming student to evaluate, identify, and select appropriate study habits or learning supports increases their chance to perform successfully in their academic environment (Arockiyasamy et al., 2016; Burgess et al., 2012; Nasution, 2015).

While study habits are useful to indicate academic performance, there is another relevant component; the attitude of the student is closely related to study habit behaviors (Bulent et al., 2015). Attitude, a psychological construct, is defined as a complex mental and emotional entity that can characterize a person (Perloff, 2016). Attitudes can range from severe negative to extreme positive and are usually acquired through an individual's experiences (Lord \& Lepper, 1999). This predisposed mindset of a person is associated with a perceived value and precipitated through a responsive expression toward a person, place or thing (Lord \& Lepper, 1999; Perloff, 2016). One of the main reasons for students' academic failure is their adverse attitudes associated with their studies (Bulent et al., 2015). Students can carry a disposition about studying that is not constructive, 
cooperative, or optimistic, which then distracts from the purpose of academic performance. Aquino (2011) and Ballado-Tan (2014) both provide data to support the importance of attitude on both the formation and the use of study habits and performance. The definitions and findings from this section help to provide a base list of study habits and attitudes used to identify the practices of heavy-video-gaming participants.

\subsubsection{Academic Performance}

Academic performance (Chiu \& Cheng, 2017; J. Wang \& Shiveley, 2009) is a term interchanged with a variety of similar verbiage, such as successful academic performance (York et al., 2015), academic achievement, student learning (Chiu \& Cheng, 2017), student outcomes (Shulruf, 2010), and academic success (Dyer et al., 2017). Ultimately, all these terms mean that a student is accomplishing tasks, maintaining an acceptable GPA, achieving learning outcomes, indicating levels of satisfaction with the overall experience, and pursuing a suitable career path (J. Wang \& Shiveley, 2009; York et al., 2015). Successful academic performance is an implied and expected part of higher education and is repeatedly stated as a main objective for undergraduate schools (Kuh et al., 2011). For the purpose of this study, the term academic performance is used.

Researchers evaluate academic performance in a variety of ways, including methods of measuring GPA, critical thinking, self-efficacy, cognitive development, and non-cognitive development (Banta et al., 1996; Shochet et al., 2015; York et al., 2015). According to the definition of academic performance used by York et al. (2015), based on Kuh et al. (2006) which is extended from Astin's work (1991), the theoretical framework of academic success includes inputs, environments, and outputs (I-E-O). In York's research, there are six operationalized areas expressed: 1) academic achievement, 
2) satisfaction, 3) acquisition of skills and competencies, 4) persistence, 5) attainment of learning outcomes, and 6) career success. For the purpose of this study, only the first four operational areas were utilized. The final two operational areas were outside the scope of research questions for this study.

In the work of Crede' and Kuncel (2008), the academic performance of a student is supported by three main pillars of activities which include 1) prior experience and previous performance; 2) standardized testing; and 3) study habits and attitudes. These can be used as indicators for predicting student success in future academic venues (Credé \& Kuncel, 2008; Flipped Learning Network Hub, 2014; Von Stumm et al., 2011). So based on a student's prior experiences in performing assessments and exhibiting study habits, the assertion is that the student will likely continue to perform in the same behavioral direction during the next learning undertaking (Credé \& Kuncel, 2008; Von Stumm et al., 2011). The first pillar addresses "prior experience," which is knowledge gained before taking on a new experience, and "previous performance," which has been defined as the scores on prior assessments. Studies have used grade point average (GPA) scores, class rankings, and involvement in extracurricular activities to quantify and reflect the first pillar of prior experience (Astin \& Antonio, 2012; Santucci, 2012). This study considers the gamers' prior experiences by evaluating how gaming and learning or study practices influence each other. The second pillar of standardized exams also serves as an indicator of academic performance, but this pillar is not a focus of this study because standardized exam scores of the participants were not available to the researcher (Astin \& Antonio, 2012; Bennett \& Maton, 2010; Lotkowski et al., 2004). Instead, the data focused on students' reported GPAs. The third pillar, study habits and attitudes, reveals 
more complete and thorough student profile. This pillar is a major structure for the framework of this study (read 2.2.1).

It is worth noting that not all researchers agree on what should make up the pillars of support for academic performance. Researchers argued for different fourth pillars. For example, Von Stumm et al. (2011) contend that curiosity plays an important role in student learning and argue that it alone is an entire support pillar. But Crede and Kuncel (2008) indicate that curiosity is a behavior or attitude, and therefore is accommodated within the study and habits support pillar. An individual's personality ought to be considered as part of the equation for academic performance prediction, and a few researchers believe it may also serve as a fourth pillar to indicate academic success (Alzahrani et al., 2013). One counter-argument is that personality type influences behaviors and attitudes rather than standing alone (Jyvaeskylae, 2007; Shim \& Ryan, 2012). The discussions about adding a fourth pillar to the performance predictor are beyond the scope of the present study. In this study, focus is given to the Bulent et al. (2015) approach of using study habits and attitudes as the strong third pillar (read 2.2.1).

\subsubsection{Activity Theory}

According to Devane and Squire (2012), the activity theory of Leontiev and Kharkov (1977), and Engeström (1987) is useful for research studies such as this one, as the theory strives to integrate the tools individuals use to support learning into the overall understanding of how learning takes place. Activity theory, also referred to Cultural Historical Activity Theory (or CHAT), is described by Devane and Squire (2012) as follows: 
Activity theory has always sought to understand human thought not just as an abstract and symbolic phenomenon, but also as a thing that takes place - that is practiced - in the real everyday world. Its study of cognition in the world - in classrooms, in workplaces, in hospitals - leads it to understand both the importance of tools to learning activities and the importance of activity systems in shaping how tools and technologies help people learn (pp. 298-300).

Activity theory, in short, embraces understanding the compound and chaotic reality of learning with tools and technologies, rather than an idealized and formulaic construct that occurs in a laboratory (Devane \& Squire, 2012). Hasan and Kalausah (2013) explain the crux of the theory as "who is doing what, how and why," aligning well with the research in this study, which is striving to find out how and why the video-gaming students are studying and what supports they need to meet with success. "Activity theory, with its emphasis on the importance of motive and consciousness - which belongs only to humans - sees people and things as fundamentally different" (Kaptelinin \& Nardi, 2006). This later work of Nardi and Kaptelinin (2006a) showed Activity Theory to be a powerful and clarifying descriptive tool rather than a strongly predictive theory. Figure 3 shows the Kaptelimin and Nardi model of Activity theory, highlighting the learning elements descriptions and the types of questions that are used when investigating a topic. 


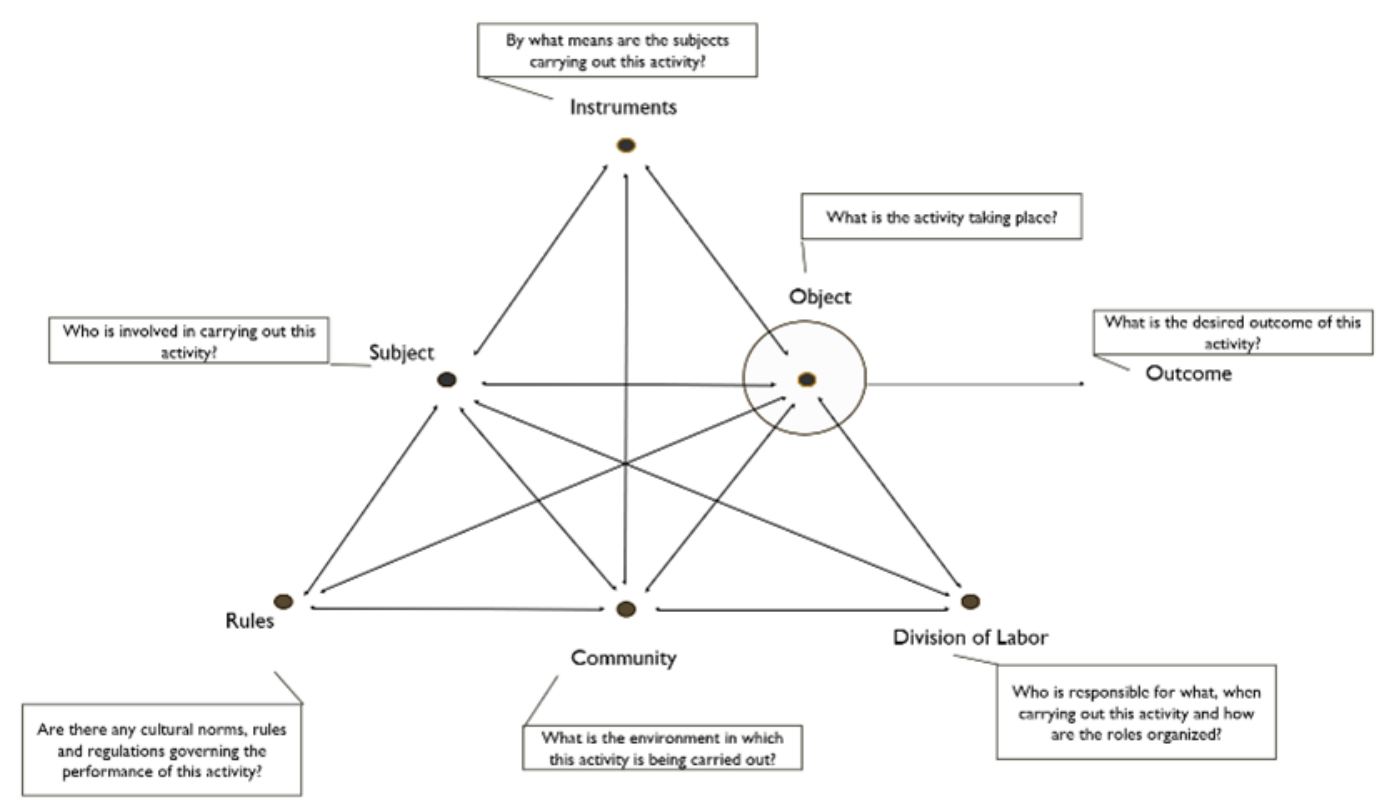

Figure 3

The Original Activity Theory Model from Kaptelinin and Nardi (2006)

Activity systems are in continual flux as participants negotiate tensions among different elements (Devane \& Squire, 2012). Learning can be viewed as the resolution of contradictions among elements allowing the subject to take advantage of an expanded range of actions, including access to a wider repertoire of mediational means, taking on new roles, and forging robust ways of working within existing constraints (Kaptelinin \& Nardi, 2006). Consequently, as an earlier researcher of activity theory Engeström (1987) emphasizes, new objects or goals come into view and the system of activity as a whole is capable of evolving. Many an educator or instructional designer have concluded that the success of learning technologies depends on how they are actually used in a learning context.

Many technology fields, such as information systems (Hwa, 2016; Vessey \& Galletta, 1991), human computer interface (Kaptelinin \& Nardi, 2006; Manero et al., 
2016), and now gaming, have found the activity theory (Gee, 2003; Prensky, 2006)) beneficial for research guidance. For this study, the most significant benefit of activity theory is that it offers the researcher a systematic way to study the use of technologies as they function in the complexity and untidiness of the real world. For this study, activity theory provides an appropriate theoretical lens by which to interpret and understand the heavy-video-gaming participants as subjects, and to observe their gaming and study practices as the object (Figure 4). Activity-theory is used in this study to guide datacollection methods are used to learn about the video-gaming players as subjects, as well as their gaming and study practices defined as object, and inquire about the types of learning supports they use and desire.

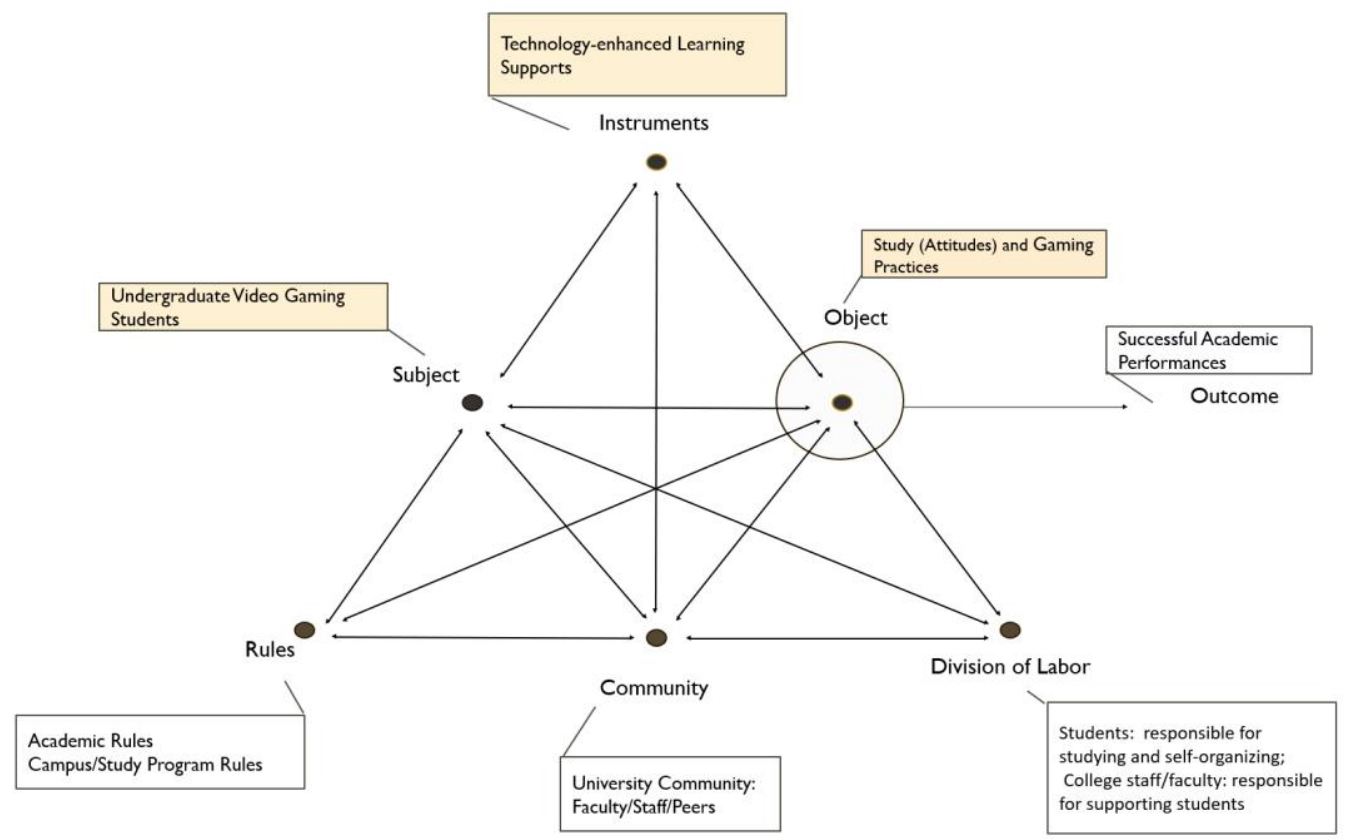

\section{Figure 4}

\section{Expanded Activity Model for this Study}

Activity theory is also used to provide the framework and reasoning for proposing new technology-enhanced learning support tools designed for video-gaming students, 
which might lead to stronger study practices and overall outcomes. All parts of the Activity Theory model integrate for the purpose of supporting the subjects, the heavyvideo-gaming students, in leading to successful academic outcomes. Figure 4 takes the elements used for this research project and overlays them onto the Activity Theory model.

A description of Figure 4, using the Hasan and Kalausah (2014) explanation of Activity theory as "who is doing what, how and why," shows the heavy-video-gaming participant subjects as the "who," and their gaming and study practices are the focus object of the task they are "doing." These video-gaming students are influenced by the "how" of the learning environment that includes rules, community, division of labor, and instruments. The "why" is the desired goal of successful academic performance. This study strives to understand both the "who" and the "doing what" in an effort to propose "how" technology-enhanced learning support systems that might be used to obtain a stronger "why" result in the students.

\subsubsection{Utilization of the Conceptual Framework in the Study}

The three areas previously described, study habits and attitudes, academic performance, and activity theory, were used to guide and shape this study. The literature found in about study habits and attitudes contributed to the formation of a baseline list of study habits which were then used in specific questions developed for the demographic survey, the virtual ethnography, and the interviews. For example, heavy video-gamers were asked to discuss their study habits and then choose the top three, and these were analyzed against a list of literature supported study habits derived from this framework. Additionally, the literature about the pillars of academic performance contributed to 
specific questions about the practices utilized by the video-gamers to support their own academic performances. As explained in Section 2.2.2, the three pillars that support academic performance served to direct how the questions for the surveys were formulated. The first pillar of support was about student previous experiences, so questions were developed to learn how long the students had played games, how academics were impacted by gaming and vice versa, as well as ways the students' study habits had developed at college. The second pillar of support emphasized standardized exams, of which participant scores were not available. However, the students did report grade point averages (GPA), an element discussed in the concept framework. Finally, a large number of questions for the study were developed around the third pillar, which was the examination of study habits and attitudes. These specific questions are found in Appendices D and E. This pillar was also used to support the idea of using questions that could be answered with metaphors, to gain a more complete image of the students' practices. These metaphors can be found in Appendices F, G, and H.

Activity theory specifically provided the framework by which to interweave, analyze, and make sense of the multiple data collected in this study. Since the study had two goals, to evaluate the gaming and study practices of the video gamers and the learning supports that may be needed, there was a great deal of data to analyze. The activity theory provided a way to "think about" and guide this data. For example, when video-gamers discussed different supports, sometimes it related to things they could do as the "subjects" of the theory. Other comments, however, related to tools they needed academically perform, yet other comments fell into the category of "community". Because there was so much data to analyze, the constructs provided within the activity 
theory served to provide helpful hooks on which to organize the research data, bringing together the many tentacles of participant ideas together. The framework not only helped to organize the data, but provided a way to better identify where new discoveries might developed.

Upon evaluation of this literature, a research project for this study was designed to investigate the gap identified. The need to understand the heavy-video-gaming students as learners, observe their study practices, and identify learning supports that are applicable, became the areas of focus within the research project. The design and methodologies used in this project are presented in the next section, Chapter 3. 


\section{Chapter III: Method}

This qualitative research study was conducted to explore gaming and study practices of full-time undergraduate collegiate students, focusing on heavy-video-gaming students (Berg \& Lune, 2004; Denzin \& Lincoln, 1994; "Sample Size for Qualitative Interviews,” 2015). The study applied a virtual ethnography methodology in which methods for data collection included one-minute video recordings, photos, short essays, short surveys, online questionnaires, and interviews. The project design was created to support the purpose of understanding the heavy-video-gaming students by learning more about their gaming and study practices and the learning supports that will help the individuals successfully perform in the academic setting.

\section{$3.1 \quad$ Virtual Ethnography}

The virtual ethnography method is a fitting platform for this study due to the media-savvy gaming participants, and it provides the researcher a practical, affordable way to conduct research (Berg \& Lune, 2004; Boellstorff et al., 2012). A virtual ethnography is a methodology which uses online access for gathering data from participants to observe their actions and behaviors. Virtual ethnography is grounded in traditional ethnography methods with its roots in social anthropology to record and analyze a culture or society (Stocking, 1983; Wax, 1972; Young, 2017). Due to the development of modern technologies, particularly the connected smartphone, limitations of traditional ethnographic research can now be overcome by utilizing mobile or virtual ethnography. Using these technologies, the researcher has a way to connect, interact, and capture in-the-moment photos, comments, and videos of the participants, as well as use video chat for conducting interviews. These digital tools allow opportunity to capture 
data in a way that is practical and affordable, as well as provides a broader scope of participants (Boellstorff et al., 2012). Research locations not accessible physically or financially achievable are accessible through online methods of virtual ethnography (Berg \& Lune, 2004). As demonstrated in studies of virtual ethnography by Hine (2000), Reeves et al. (2013) and Young (2017), the researchers are the spectators from a distance, and observe how respondents react in-context and in-the-moment.

In this study, the mobile application of Indeemo was selected as the virtual ethnography platform after it had been piloted in 2018, with good reviews, by University of Missouri colleagues in some class-assigned research. Indeemo permits the researcher to assign tasks to each participant, allowing them to respond using any mobile device, creating photos, short recorded video responses, or short essays. By utilizing the scheduling features of Indeemo, tasks were preassigned for each week, and the study participants responded within a three-day span, as the tasks came due throughout the sixteen-week semester study project timeline.

\subsection{Study Stages}

The study consisted of three basic methods as shown in Figure 5 that were applied one after the other (stages). Firstly, there was a questionnaire component that included an initial interest-filtering questionnaire, followed by a qualitative questionnaire with demographic questions for those participants qualifying through the interest questionnaire. Secondly, those qualifying contributors were invited to participate in the virtual ethnography which was to be conducted during the fall 2019 16-week college semester. Thirdly, interviews became an important part of the data collection to limit a declining participation rate in the virtual ethnography. 


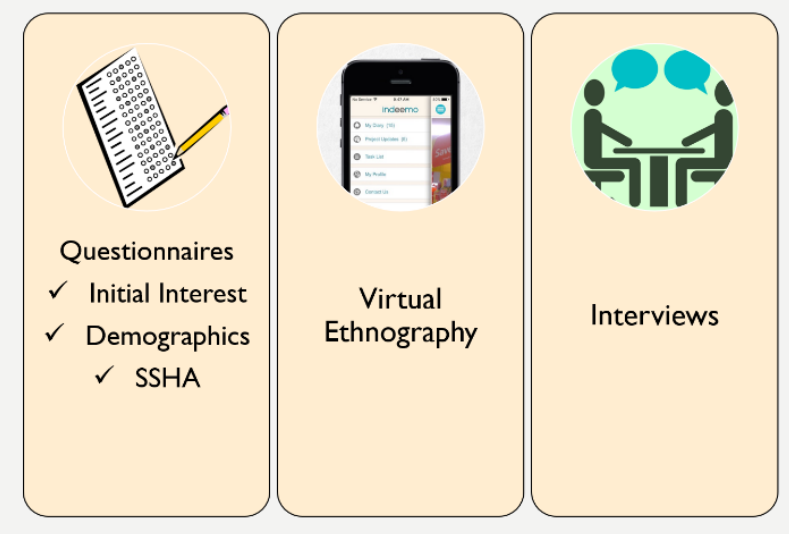

\section{Figure 5}

The Main Research Methods Used in the Three Study Stages

\subsection{Procedure}

The initial interest questionnaire was designed to be available to an unlimited number of people, through the use of email and social media platforms, asking them to participate in the project. Each person responding to the recruitment contact method was asked to take the initial interest survey, and those making it through the filter questions were asked to participate in the qualitative questionnaire with demographic questions (Appendices A and B). After completing the qualitative questionnaire with demographic questions, the participants were asked proceed as follows: 1) take the Survey of Study Habits and Attitudes (SSHA) questionnaire (Brown \& Holtzman, 1967) (Appendix D), 2) participate in the virtual ethnography component, which also included the SSHA or 3) exit completely from the study. To encourage students to stay involved for the duration of the study, an incentive of a drawing for a $\$ 20$ gift card was offered for completing the survey, and a guaranteed gift card of \$35 was offered for each student completing 100 percent of the virtual ethnography, which took sixteen weeks (Fall 2019 semester starting 
September 2, 2019, and ending December 20, 2019). Figure 6 shows the flow structure of the data collection process.

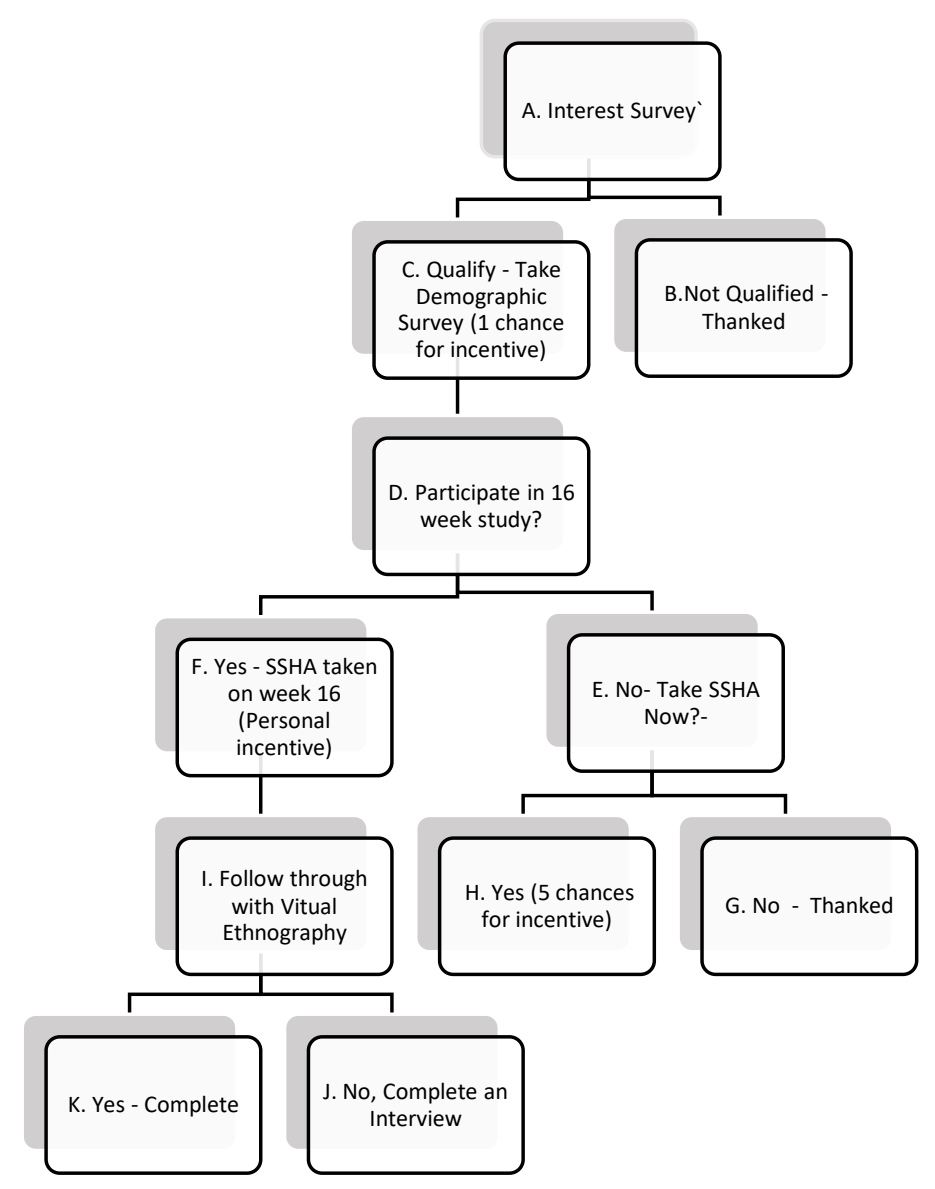

\section{Figure 6}

\section{Flow of Study Design}

\subsubsection{Pilot testing}

All questionnaires, with the exception of the SSHA instrument, were reviewed by a higher education colleague, a reading-teacher expert, and were issued in a small pilot study with five undergraduate students from a computer science program in a small private university located in Missouri during the summer of 2019. All Indeemo tasks were also reviewed by the expert and then piloted with the group of five students. 


\subsubsection{Recruitment of Study Participants}

Participant recruitment was conducted by the researcher through sharing the initial interest survey link through gaming sites such as www.Tesla.com; social media including Twitter, Facebook, and Reddit; direct emails to college reps; eSport coaches, professors and students; and college announcement boards. Seventy-five direct contacts were made by the researcher, with an unknown number of shares, that resulted in 395 initial interest responses to the study.

Participants (P) initially gave consent to be in the project by volunteering to take the initial interest 5-question questionnaire (Appendix A). If participants described themselves as full-time undergraduate students who identified as heavy-video-gaming students, meaning they played or watched 14 or more hours of video games per week (Duggan, 2015; Hamari \& Sjöblom, 2017; Jacobs, 2015), they were invited to the next stage of the study, the qualitative survey (Appendix C). No first-semester freshmen were included in the study in order to avoid the personal and learning adjustments freshmen encounter when coming to college.

Consent to participate in this stage of the study was requested before participants entered into the qualitative questionnaire. Information about the study along with the consent form is in Appendix B. During the qualitative questionnaire portion of the process, students were offered an opportunity to be entered into a $\$ 20$ gift card drawing for completing the survey, from one of the following sites, STEAM, X-Box, or Amazon. These gift cards were funded with personal funds of the researcher and a research grant provided by the University of Missouri Graduate Research office. The participants had 
the right to remain anonymous, using pseudo screen names and private settings, as well as to review and adjust their responses.

Sixty-two participants were invited from the pool of those who had completed the qualitative survey in an attempt to have 30 people stay involved with the sixteen-week study for the entire semester. The study was heavily populated by United States participants due to the recruitment resources available to the researcher.

For the purpose of the study, the identification of all participants was protected with a codename of $\mathrm{P}$ and a participant number, such as P3. All data collected was stored on a local hard disk drive within a password protected laptop, within a locked work area, for security purposes.

\subsubsection{Initial Interest Questionnaire}

An initial interest questionnaire was conducted via Qualtrics software to determine if the interested students would qualify to participate (i.e., heavy-video-gaming student playing 14 hours of games a week, undergraduate in $2^{\text {nd }}$ semester or above). The initial questionnaire (Appendix A) included filtering questions addressing the individual's age, status in an undergraduate school, hours of video-game play, and involvement in eSports. If any of the questions eliminated the participants from qualifying for this study, they were thanked for their interest and encouraged to get involved in future research studies.

\subsubsection{Instruments to Measure Study Habits and Attitudes, SSHA survey}

The Survey of Study Habits and Attitudes, SSHA, is well-known in educational literature and has been validated as one of the foremost questionnaires available on the topics of study habits and attitudes (Mendezabal, 2013; Thompson, 1976) and has been 
utilized within research numerous times despite the age of the instrument (Aquino, 2011; Credé \& Kuncel, 2008). Categories measured in the questionnaire are well accepted within the research community and are aligned with identified lists of study habits and attitudes as shown in Figure 7 (Altinkurt \& Yilmaz, 2012; Bulent et al., 2015).

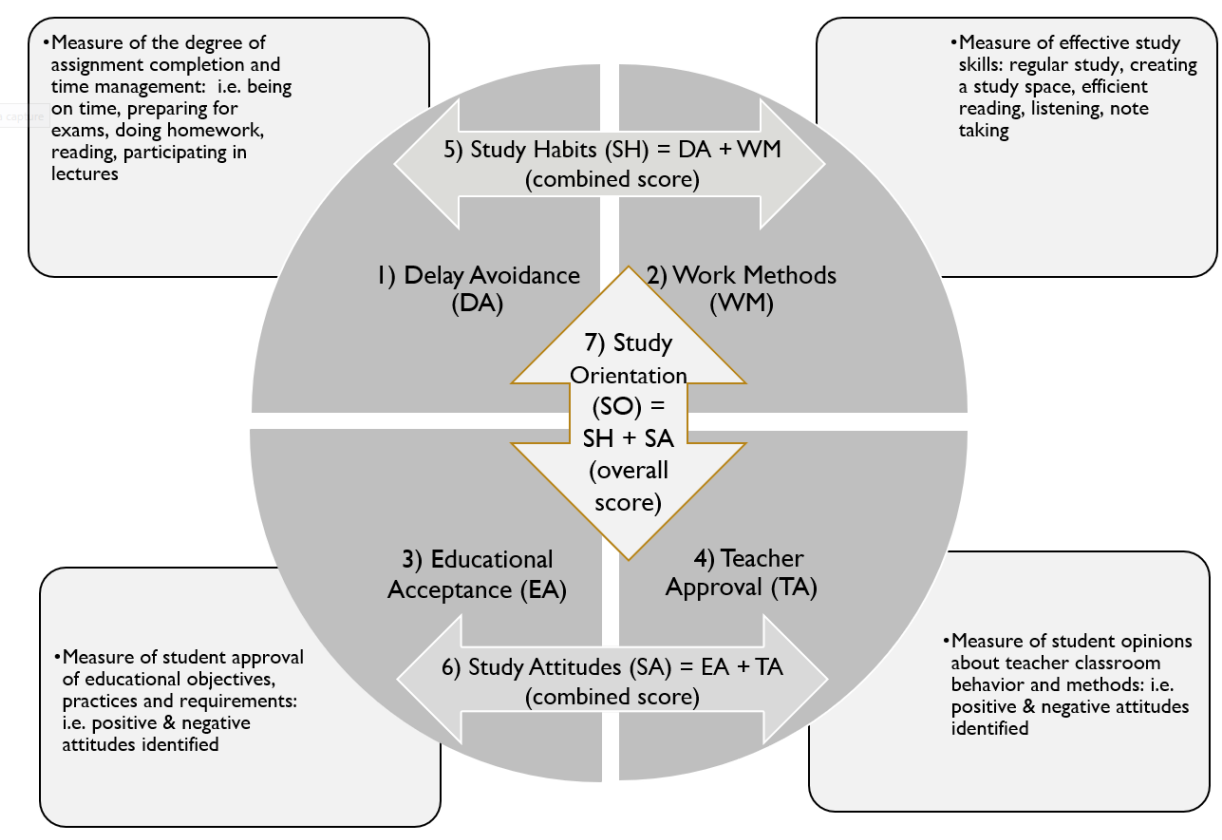

\section{Figure 7}

\section{Examples of Study Habit Behaviors and Attitudes Identified from Literature}

The updated 1967 version of the SSHA survey was adjusted to include 100 questions measuring educational values with 25 questions for each particular category. These educational values aligned well with the purpose of the video-gaming student study since it was important to understand the educational perspectives of the heavyvideo-gaming students. As defined in the study of Hurlburt, Koeker and Gade (1991), the seven educational values in the SSHA instrument are defined as follows: 1) Delay Avoidance (DA), a measure of the degree to which a student is prompt in completing 
assignments and is efficient in time management; 2) Work Methods (WM), a measure of effective study skills; 3) Teacher Approval (TA), a measure of student opinions about teacher classroom behavior and methods; 4) Educational Acceptance (EA), a measure of student approval of educational objectives, practices, and requirements; 5) Study Habits (SH), a combined score of the DA and WM scales; 6) Study Attitudes (SA), a combination of the scores of the TA and EA scales; and 7) Study Orientation (SO), an overall measure of a student's study habits and attitudes. Figure 7 gives an overview of the 7 sub-scales.

The study habits are measured on a 5-point scale form describing the habit within a range of :

- Rarely ( 0 to $15 \%$ of the time after $1^{\text {st }}$ Freshman semester of college until now);

- Sometimes (16 to $35 \%$ of the time after $1^{\text {st }}$ Freshman semester of college until now);

- Frequently (36 to $65 \%$ of the time after $1^{\text {st }}$ Freshman semester of college until now);

- Generally (66 to $85 \%$ of the time after $1^{\text {st }}$ Freshman semester of college until now);

- Almost always (86 to $100 \%$ of the time after $1^{\text {st }}$ Freshman semester of college until now).

Means, frequency count, and normative percentile ranks on each of the seven scales are used to compare the study habits and attitudes of the respondents (Brown \& 
Holtzman, 1967; Hurlburt et al., 1991; Mendezabal, 2013). The 100 items used in this study are listed in Appendix D.

The SSHA questionnaire was transferred into the Qualtrics software to generate an online link whereby the participants could take the survey. The SSHA included 100 questions clustered in five groups of 20 to help the students concentrate on the survey in shorter blocks. For some participants, the 100 questions of the SSHA were given after they completed the introductory and qualitative questionnaire with demographic questions. However, those participating in the virtual ethnography were given a selection of the SSHA questions each week, not all 100 items at once, to keep it manageable. The SSHA is being used as an instrument to understand study habits and attitudes of an array of student types, but literature could not be identified whereby heavy-video-gaming students had been analyzed with the tool. However, using the SSHA questionnaire alone was not the most adequate measure to use in order to reveal how gamers live in their daily academic life, as could only capture one point in time. For this reason, I made the decision to avoid relying solely on the SSHA as a stand-alone questionnaire; instead, I selected the qualitative ethnographic methodology, described above, to "follow" student gamers in a semester of their collegiate life, and to collect data about their study habits and attitudes from a more informative "subjective" view.

\subsubsection{Indeemo Virtual Ethnography Weekly Tasks and Prompts}

Participants were asked to participate for 16 weeks and were asked to respond to the three to five tasks per week by using any digital device, making participation in the virtual ethnography more convenient. The Indeemo assigned tasks included installing the Indeemo app (free for participants), creating one document of their anticipated weekly 
schedule of commitments, using the software to capture data, completing short lists of questions/tasks, short essays, photos, and one-minute videos, and completing the SSHA survey. Participants were also asked to leave an email and text number, so the researcher could stay in touch by offering encouragement and troubleshooting skills if necessary.

After participants registered on Indeemo, the study started on September 2. After this day, no new students were able to enroll in the virtual ethnography stage that ended on December 20, 2019. Once registered on the Indeemo platform, the participants were asked to install the software in their phones, share their semester schedule, respond to a list of questions each week, and complete the SSHA survey. Appendix E shows the timeline and the weekly tasks.

As a baseline artifact for analysis, the participating ethnography students submitted a copy of their semester schedule including items such as classes, practices, free time, and anticipated game time, and these were analyzed and tagged following the qualitative coding schema (Berg \& Lune, 2004; DeCuir-Gunby et al., 2011). As the study progressed and students responded to the Indeemo tasks, the schedule served as a baseline guide to determine if students were generally on task according to their schedule. Other items used for qualitative analysis came from the weekly Indeemo that required short one-minute video responses, photos, and short essay text responses. All video and photo data were transcribed for better integration with the text-based responses for analysis purposes (Boellstorff et al., 2012; Yin, 1989).

During the months of the Fall 2019 semester, it became evident that participant involvement had declined in the virtual ethnography. In November, the researcher chose to begin conducting individual interviews. By the end of the study in December 2019, 31 
individual interviews were recorded with heavy-video-gaming students, with an average of 40 minutes per interview. Interviewees were recruited from participants who did not complete the ethnography at a 100 percent level, or were new participants found through suggestion contacts made by other participants, eSport coaches, or school personnel at various colleges. Each of these 31 interviewees were asked the same questions that were used in the Indeemo platform and were prompted to complete the qualitative questionnaire with demographic questions and Survey of Study Habits and Attitudes (SSHA) surveys if they had not done so previously (Appendices D and E). The data collection methods are shown in Figure 8.
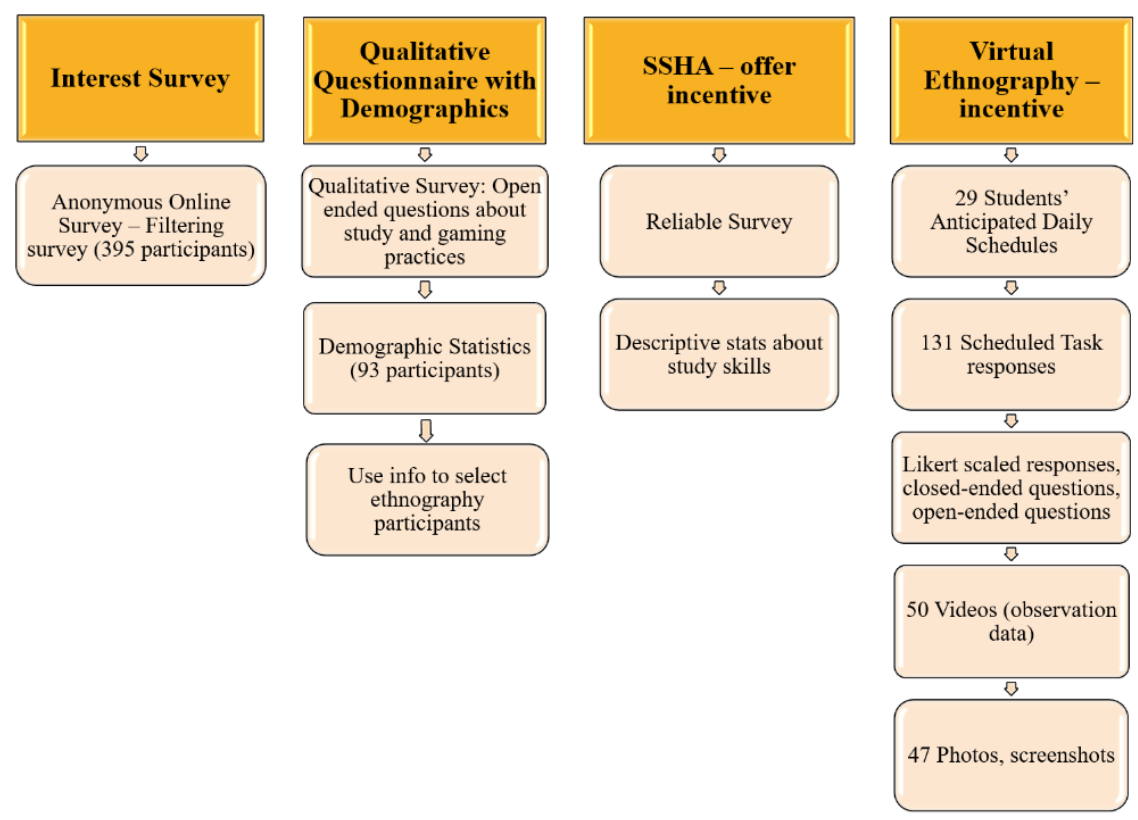

\section{Figure 8}

\section{Data Sources Used in This Study}

\subsection{Data Coding and Analysis}

Both raw quantitative and qualitative data were coded during the analysis portion of this research study. The quantitative data from the demographic survey, such as age 
and hours of gaming and studying, were analyzed with closed-ended coding methods, while the qualitative data used both closed and open-ended methods (Berg \& Lune, 2004; Boellstorff et al., 2012; Creswell et al., 2003; Merriam \& Tisdell, 2016). Data collected from the open-ended questions on the qualitative questionnaire and the 31 interviews were used for coding (Appendix I). An additional component of the coding was the evaluation of visual elements, such as the semester schedule of the student, as well as the transcribed photos and videos captured during the assigned Indeemo tasks.

A three-part coding book was created, which included codes for gaming habits, study skills, and attitudes (Figure 9). The coding book was developed through a fourcycle iterative exploratory process of data analysis looking for evidence of key concepts and themes to develop.
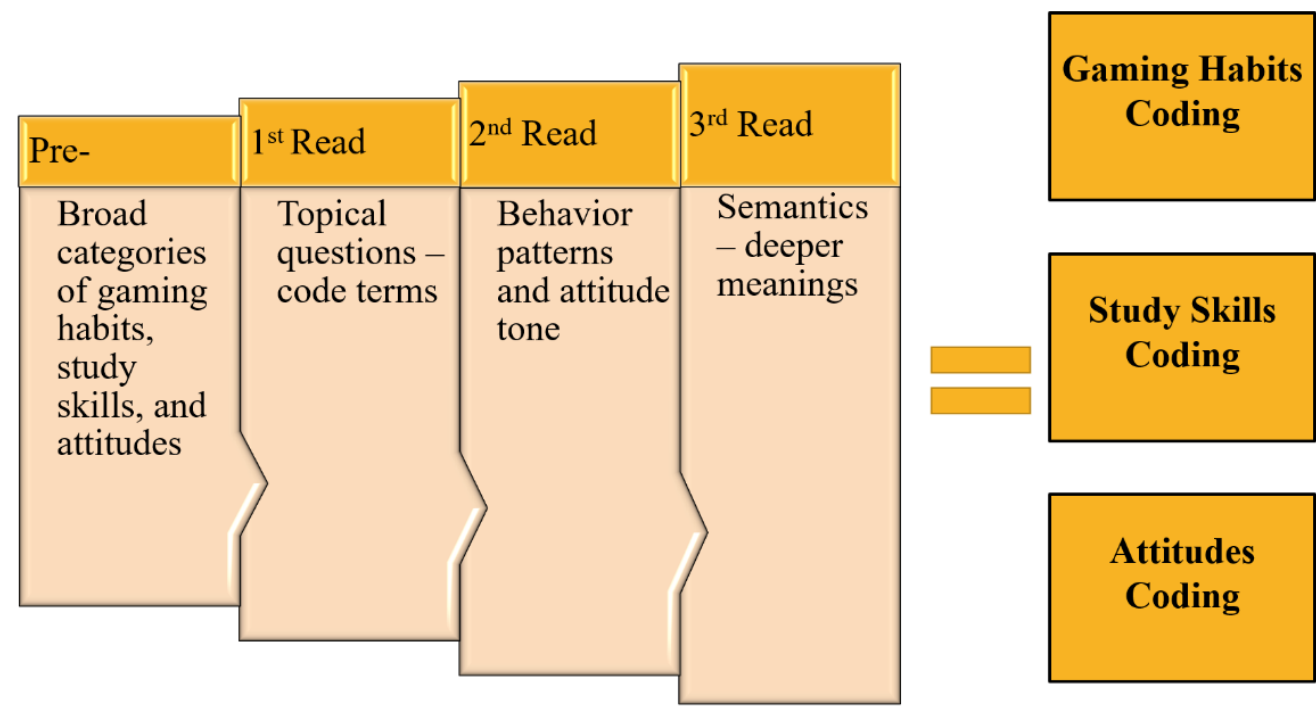

\section{Figure 9}

Iterative Coding Process

The first cycle, or the initial pre-data-collection thematic coding book, began with the researcher identifying some broad categories of gaming habits, study skills, and 
attitudes from anticipated answers participants would provide when taking the initial interest and qualitative questionnaires, as well as the tasks and questions designed for the virtual ethnography. This coding scheme was discussed with a research colleague.

During the second iteration of the coding cycle, all participant answers from each of the qualitative data collection methods used in the initial interest survey, the qualitative survey, and the Indeemo tasks were clustered by topical questions (Appendix I). For example, each participant's answer to the question "What is the easiest way for you to learn something new?" were clustered, so themes would be easier to identify. Appendix J lists the index of clustering topics.

The third iteration for coding analysis occurred as the researcher read through the topical clustering and applied a one to two-word code word, attempting to capture the behavior and tone of main ideas found within participants' responses. For example, if the participant was describing class attendance as an important study habit, the code written was attendance - positive. During this cycle, two experts were asked to conduct an interrater agreement on two randomly selected clusters. The experts added their one to two-code word responses to the statements, and then the researcher and experts compared notes to ensure interrater reliability existed within the coding procedure (Berg \& Lune, 2004; Boellstorff et al., 2012; Yin, 1989).

During the fourth iteration, the researcher read through transcripts and codes again, analyzing them for the semantic deeper meanings. It was within this reading that the "study practices," "types of heavy-video-gaming students," and "possible learning supports" were identified, and these categories are discussed in more detail in the results 
section of the paper (Chapter IV). Again, two experts were used for interrater reliability (Berg \& Lune, 2004; Boellstorff et al., 2012; Yin, 1989).

The total data analyzed through the Indeemo platform include 51 written comments ranging from two to three sentences apiece, 53 one-minute transcribed videos, 57 transcribed photos related to the gamers' schedules, activities, and study environments, and 63 qualitative responses from the open-ended items of the qualitative questionnaire. In addition, there are 140 pages of interview transcripts. Altogether there are 297 pages of transcripts that were coded and used for data analysis.

Quantitative analysis methods were used when reviewing data from the qualitative questionnaires and the SSHA survey. Mainly descriptive statistics were applied via measures of central tendency (e.g., mean, median and mode), which were applied to categories such as location, grade level of study, grade point average (GPA), gender, perceived levels of accomplishment in school and gaming, and time devoted to gaming or study (Creswell et al., 2003).

Chapter IV will present the results from the analysis of this rich dataset, presenting a number of figures, tables, and quotes. The data provides insight to the heavy-video-gaming students, their gaming and study practices, and their desired learning supports. 


\section{Chapter IV: Results}

This chapter presents the contextual data and findings that were derived using the qualitative research methods described in Chapter 3. Results include 1) description of the study participants; 2) gaming and studying; 3) study habits and attitudes; and 4) learning supports desired by heavy-video-gaming students; 5) gamers' study practice approaches; 6) types of heavy-video-gaming students; and 7) results from the Survey of Study Habits and Attitudes (SSHA). Each of the result sets provides a perspective for understanding the heavy-gaming participants, their gaming and study practices, as well as learning supports that may be proposed and developed to meet the gamers' needs.

\subsection{Description of the Study Participants}

There were 395 individuals who completed the initial interest questionnaire online. Interested participants were initially accepted or eliminated from the study by use of filter criteria questions found in Table 4. The study accepted students who were over 18 years old, enrolled in at least the second semester of an undergraduate higher education program, and played 14 or more hours of video games a week, which meets the criterion of a heavy-video-gamer defined in literature (Duggan, 2015; Hamari \& Sjöblom, 2017; Jacobs, 2015). 


\section{Table 4}

Student Self-Report, Criteria Filter Questions

$n=395$ interested people completed the criteria filter questions

\begin{tabular}{lll}
\hline Criteria Questions & Answer Choices & Answer Selected \\
\hline What is your age? & $\begin{array}{l}\text { 1. I am } 18 \text { or over. } \\
\text { 2. I am } 17 \text { or younger. }\end{array}$ & \\
& & \\
& &
\end{tabular}

\begin{tabular}{lll}
\hline Are you enrolled in an & 1. Yes & Yes \\
undergraduate college program & 2. No & \\
as a full-time student? & &
\end{tabular}

Is the semester you are entering your first ever in college?

In an average week how, many hours of video games do you watch or play?
1. No, this will be my second, or higher, semester in college. 2. Yes, I am a firstsemester freshman.

1. Fourteen hours or more a week

2. Thirteen hours or less a week
No, this will be my second, or higher, semester in college.

Fourteen hours or more a week

After completing the survey filtering process, 62 individuals were left who were willing to take part in the second stage of research, the qualitative questionnaire. The survey phase of the study was utilized for collecting data, as well as identifying and inviting participants to take part in the third stage of the study, the virtual ethnography. The researcher invited all 62 participants completing the qualitative questionnaire to participate in the virtual ethnography as a way to accommodate for students who would drop out of the virtual ethnography study in an attempt to maintain the research target of 30 participants.

At the beginning of the project on September 2, 2019, 40 people enrolled on the Indeemo virtual ethnography software, but only 34 participants contributed data. At the 
end of the study on December 19, 2019, only two participants completed 100 percent of the requested tasks, 20 participants completed between 10 and 99 percent of the tasks at various levels and times throughout the semester, while 12 people had a completion rate of lower than 10 percent, and six of the participants failed to contribute any data to the sixteen-week assignments (Table 5).

\section{Table 5}

Tasks Completed by Participants

\begin{tabular}{ll}
\hline $\begin{array}{l}\text { Participants in the virtual } \\
\text { ethnography }\end{array}$ & $\begin{array}{l}\text { Percentage of Tasks completed in the sixteen-week } \\
\text { study; usable data was captured (total tasks = 65) }\end{array}$ \\
\hline 2 & $100 \%$ (completed every task) \\
3 & $81-99 \%$ \\
2 & $61-80 \%$ \\
2 & $41-60 \%$ \\
3 & $21-40 \%$ \\
12 & $11-20 \%$ \\
10 & $1-10 \%$ \\
6 & $0 \%$ (took initiative to sign up, but did not contribute) \\
\hline
\end{tabular}

40 Total Participants

=34 active participants

To accommodate for the drop in participants during the ethnography, 31

individual interviews were conducted. Individuals granting an interview were also asked to take the qualitative survey. Participant data used in this study were selected from entrants who contributed to two of the data collection methods: the 34 Indeemo participants, 62 qualitative survey participants, and 31 interview participants. From this group of 127 contributors, 93 provided usable data as shown in Figure 10. 


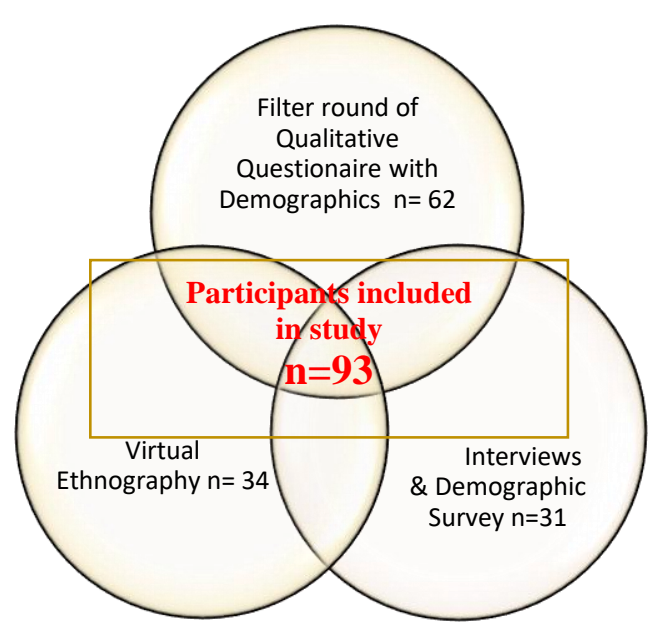

\section{Figure 10}

Participants Selected for the Research Study: From 127 only 93 participants provided usable data

The 93 participants included 72 (76.56\%) independent and recreational heavy-videogame players, who are not associated with an official collegiate eSports team, and 21 (23.44\%) who were collegiate eSports official team members (Table 6).

\section{Table 6}

Player-Association-to-eSports

\begin{tabular}{lll}
\hline Association to eSports & \# of Participants & Percentage \\
\hline $\begin{array}{l}\text { Play } \\
\text { Independently/Recreationally }\end{array}$ & 72 & $76.56 \%$ \\
$\begin{array}{l}\text { Play for an official collegiate } \\
\text { eSports team }\end{array}$ & 21 & $23.44 \%$ \\
\hline Total Participants & 93 & $100 \%$ \\
\hline
\end{tabular}

Table 7 makes known that of the 93 study participants, 57 (62.29\%) individuals were aware that the school had an official eSports team. Twenty-one (22.58\%) 
participants recognized the school did not have an official eSports team, and fifteen $(16.13 \%)$ individuals were unaware of what the school was doing in the area of eSports. This trend reveals the gamers are predominantly aware of the available eSport opportunities on their campuses.

\section{Table 7}

Awareness-of-Campus-eSports-Programs

\begin{tabular}{lll}
\hline Awareness level & \# of Participants & Percentage \\
\hline $\begin{array}{l}\text { Aware of an eSports program on } \\
\text { campus }\end{array}$ & 57 & $62.29 \%$ \\
$\begin{array}{l}\text { Aware there was not an eSports } \\
\text { program on campus }\end{array}$ & 21 & $22.58 \%$ \\
$\begin{array}{l}\text { No awareness of what was } \\
\text { occurring in regards to eSports } \\
\text { on campus }\end{array}$ & 15 & $16.13 \%$ \\
\hline Total Participants & 93 & $100 \%$ \\
\hline
\end{tabular}

Table 8 highlights that the majority of participants were male $(87.10 \%)$. This gender majority supports existing studies that indicate video-gaming is a male-dominated field (Kim, 2017; Manero et al., 2017; Paaßen et al., 2017). This data indicates the need for educators to be aware that many of the decisions made in supporting the videogaming learners could have an impact on the number of male students recruited and retained (Bear, 2019; Paaßen et al., 2017; Yao et al., 2010). Just as relevant is the low female involvement, which might require special attention or programmatic changes (Assunção, n.d.; Bear, 2019). 


\section{Table 8}

Gender of Participants

\begin{tabular}{lcl}
\hline Gender & \# of Participants & Percentage \\
\hline Male & 81 & $87.10 \%$ \\
Female & 9 & $9.68 \%$ \\
Prefer not to reveal & 3 & $3.33 \%$ \\
\hline Total Participants & 93 & $100 \%$ \\
\hline
\end{tabular}

Participants were from 32 colleges across 13 states in the United States of America, with 45 participants from Missouri, 21 from Virginia, 14 from California, two from Florida, two from North Carolina, and one apiece from Arkansas, Illinois, Indiana, Minnesota, New Jersey, Ohio, Pennsylvania, and two marked as other. Figure 11 provides state distribution information.

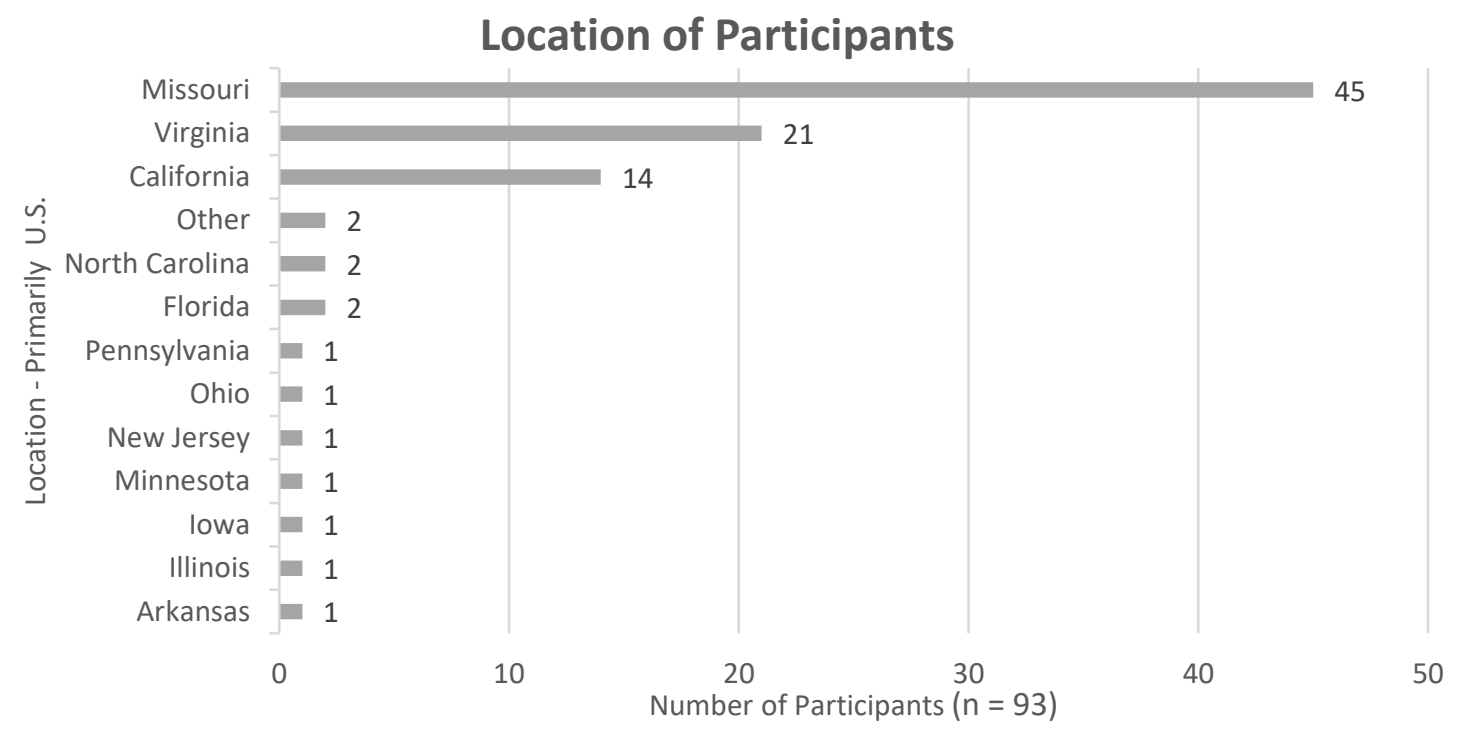

Figure 11

Location of Participant Schools

All 93 participants were enrolled as a second semester or higher, full-time student in an undergraduate program. Figure 12 shows details; four participants are freshmen 
(second semester), 34 sophomores (semesters three or four), 34 juniors (semesters five or six), and 21 seniors (semester seven and above).

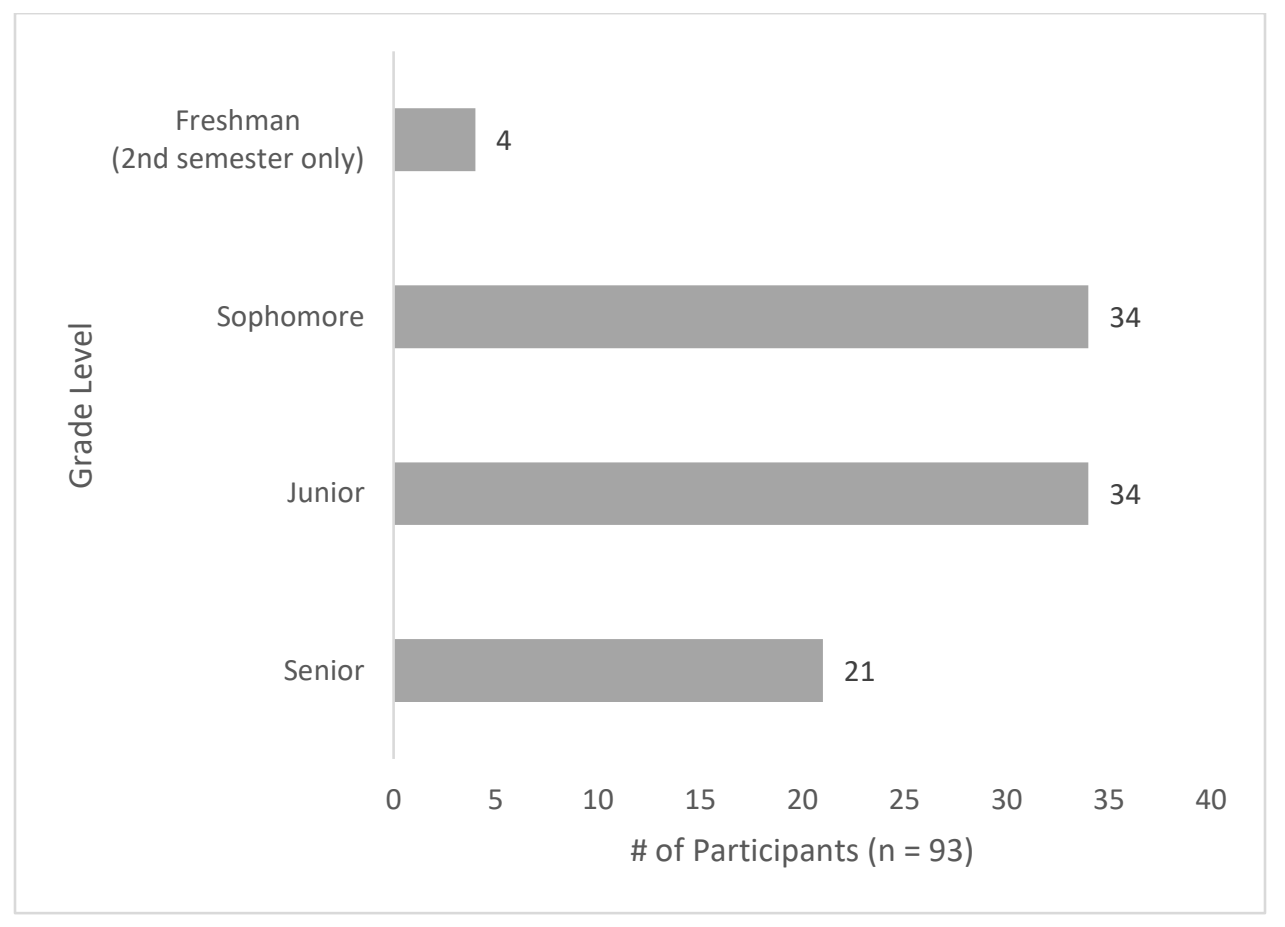

\section{Figure 12}

\section{Grade Level of Participants}

Forty-five participants (48.39\%) reported a major from the field of computing, engineering, or math. Thirteen (13.98\%) participants studied business and commerce; Table 9 presents details. 


\section{Table 9}

Disciplines of Study for Participants

\begin{tabular}{lll}
\hline Major area of Disciplines & Percent & Count \\
\hline Computing, Engineering, and Math & $48.39 \%$ & 45 \\
Business and Commerce & $13.98 \%$ & 13 \\
Health-and-Wellness, and Medical & $8.60 \%$ & 8 \\
Creative, Design, and Performing Arts & $7.52 \%$ & 7 \\
Other (e.g., Biblical Studies) & $6.46 \%$ & 6 \\
Natural, Environmental, and Life Sciences & $5.38 \%$ & 5 \\
Communication, Journalism Writing, and Media & $5.38 \%$ & 5 \\
Education and Helping Professions & $2.15 \%$ & 2 \\
Culture and Society & $1.07 \%$ & 1 \\
Social and Behavioral & $1.07 \%$ & 1 \\
\hline Total & $100 \%$ & $\mathrm{n}=93$ \\
\hline
\end{tabular}

All participants were classified as full-time students. Participants reported between 12 credit hours and 17 credit (and more) hours as shown in Table 10. Twelve credit hours are considered as full-time status for students in colleges and universities (Lotkowski et al., 2004; Strage \& Sorkhabi, 2017). Twenty-four participants (25.81\%) reported they take fifteen credit hours in a semester, which is equivalent to five threecredit courses. With this standard, approximately 35 percent were enrolled in more than five courses for the semester. 


\section{Table 10}

Credit Hour Load per Semester (Fall 2019)

\begin{tabular}{lll}
\hline Credit Hour Load & Percent & Count \\
\hline More than 17 cr. hrs. & $11.83 \%$ & 11 \\
17 cr. hrs. & $15.05 \%$ & 14 \\
16 cr. hrs. & $11.83 \%$ & 11 \\
15 cr. hrs. & $25.81 \%$ & 24 \\
14 cr. hrs. & $5.38 \%$ & 5 \\
13 cr. hrs. & $5.38 \%$ & 5 \\
12 cr. hrs. - considered full time & $24.73 \%$ & 23 \\
\hline Total & $100 \%$ & 93 \\
\hline
\end{tabular}

Note. cr. hrs. $=$ credit hours

The grade point average (GPA) mean was reported at 3.04, with no student reporting lower than a 2.0. Table 11 shows the self-reported GPA scores distributed across the range. As P43 said, "I am a fairly consistent college student, but I procrastinate as much as any other." (transcript, p. 2).

\section{Table 11}

Reported GPA

\begin{tabular}{lll}
\hline GPA & Count of students $(\mathbf{n = 9 3})$ & Percent \\
\hline 4.0 & 5 & $5.38 \%$ \\
3.5 to 3.9 & 25 & $26.88 \%$ \\
3.0 to 3.4 & 29 & $31.18 \%$ \\
2.5 to 2.9 & 29 & $31.18 \%$ \\
2.0 to 2.4 & 5 & $5.38 \%$ \\
\hline
\end{tabular}

Participants indicated they were willing to take the risk of a lower grade versus the reward of making the choice of when and how to perform in the class. A participant stated, "I know my GPA went down, but it was a really hard four-credit class, and I had 
to withdraw, so I made the wise choice and dropped, to save my GPA" (P28, transcript, p. 33). P34 stated, "I can be smart when I want to" (P45, transcript, p. 38). Three students described themselves as "intelligent" (transcript, p. 40), and one said, "if I listen I do not have to work too hard on studying" (P15, transcript, p. 48). Students blamed their lower first semester GPAs on their lack of study practices. One participant stated, "I made some very bad decisions in my freshman year, and I let my grades slip" (P85, transcript, p. 31).

A common statement from gamers indicated that when they were freshmen, they had lower GPAs, but they had learned a lot about studying after the first semester because they better understood what to expect from classes and were actively working to maintain or improve their GPA (transcript, p. 30-34). P29 stated, "I had to learn how to study because in high school, I was the naturally smart kid, but I didn't try as much as I have learned "til now" (P29, transcript, p. 32)

Three students indicated that their GPA would likely go down during the Fall 2019 semester, and none blamed heavy-video-gaming as the reason for the decline; instead, they argued, "life events" (P47, transcript, p. 34) or "taking harder classes" had interfered (P87, transcript, p. 35). The majority of 90 participants indicated their GPA was staying the same or getting stronger.

Money was a strong motivation for enrolling in an undergraduate study program. When the heavy-video-gaming student participants were asked about their motivation to go to college, they most often said "to get a job" with 43 responses and "to make money" with 30 responders. These students were coming to college to gain skills for work applications and to get jobs. Only a few students $(n=5)$ implied they were interested in becoming better academic or liberal arts thinkers or creative producers. Rather most of 
the participants took the position of a consumer, a sense of "challenge me with me the tools I need to survive in the job world, so I can use them," such as programming skills $(n=30)$.

A small group of other motivating factors for attending college that were mention were "to please my parents $(n=6)$, " "a desire to learn" $(n=10)$, "gain the college experience and get the opportunities a degree provides $(n=12)$," "grow as a person $(n=9)$, , and "network with others $(n=3) . "$ One participant said, "simply societal pressure" (P16, transcript, p 241).

\subsection{Gaming and studying}

All participants reported they played or watched a minimum of fourteen hours of video games each week, in order qualify for the study. When the participants were asked the same question again during the sixteen-week study, the results reflected that they actually played much more than 14 hours a week. Some participants played fewer games during the week; however, the majority of 83 (89.2\%) participants still show a heavy weekly involvement with video games with a 27.22 hour mean, as seen in Figure 13. Data reflects that 82.20 percent of all participants are recreationally playing video games while at college. With such a large percentage of players on campuses, and for so much time, a new and interesting social video-gaming subculture is influencing university campuses. 


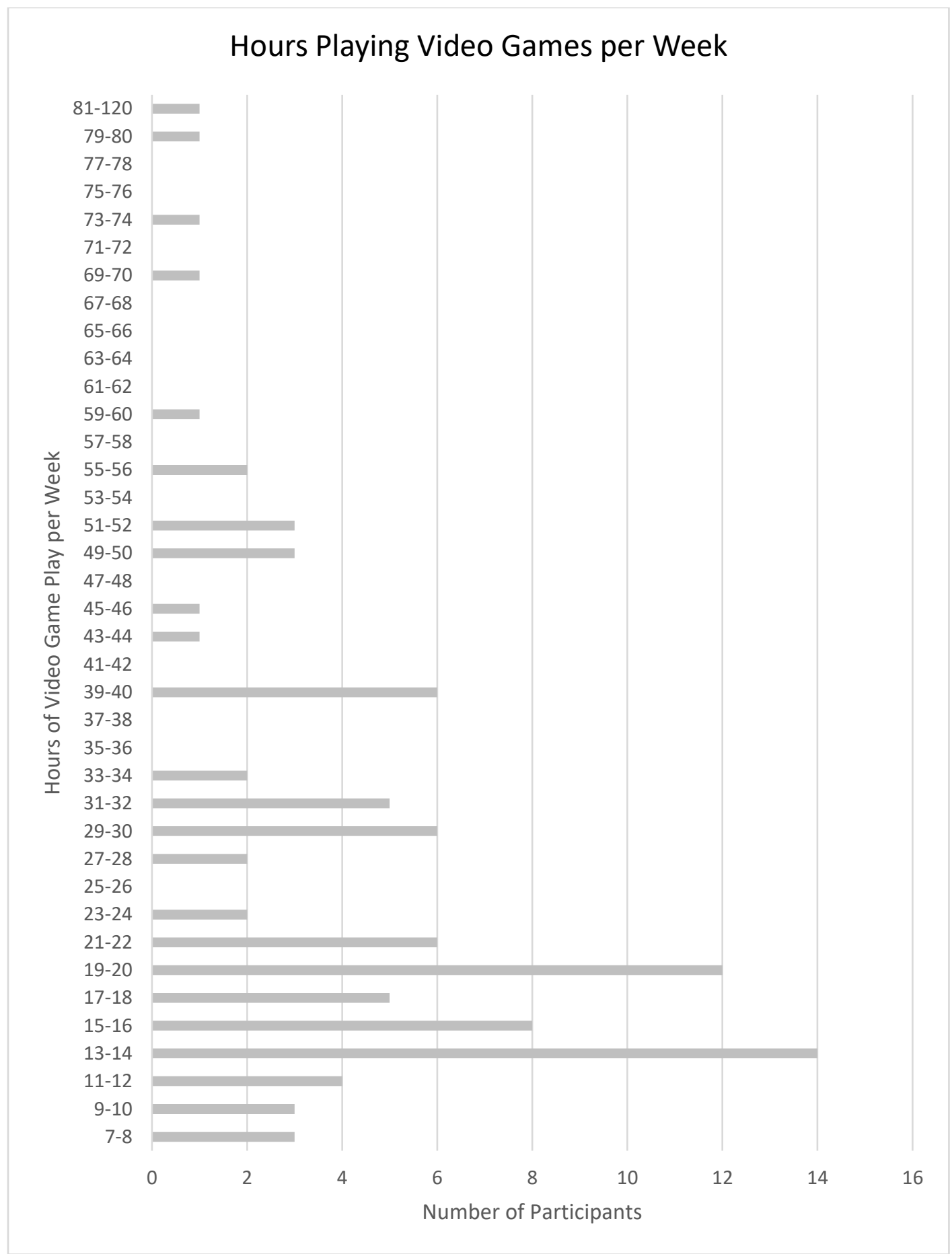

\begin{tabular}{llll} 
Minimum & Maximum & Mean & Std Deviation \\
\hline 7 hours & 118 & 27.22 & 14.61
\end{tabular}

\section{Figure 13}

Hours Playing Video Games per Week 
In addition, students were asked to share how many hours they spent studying per week. This weekly account includes activities, such as assignments for course work, studying at home, and attending lectures. The average was 13.2 hours per week as displayed in Figure 14.

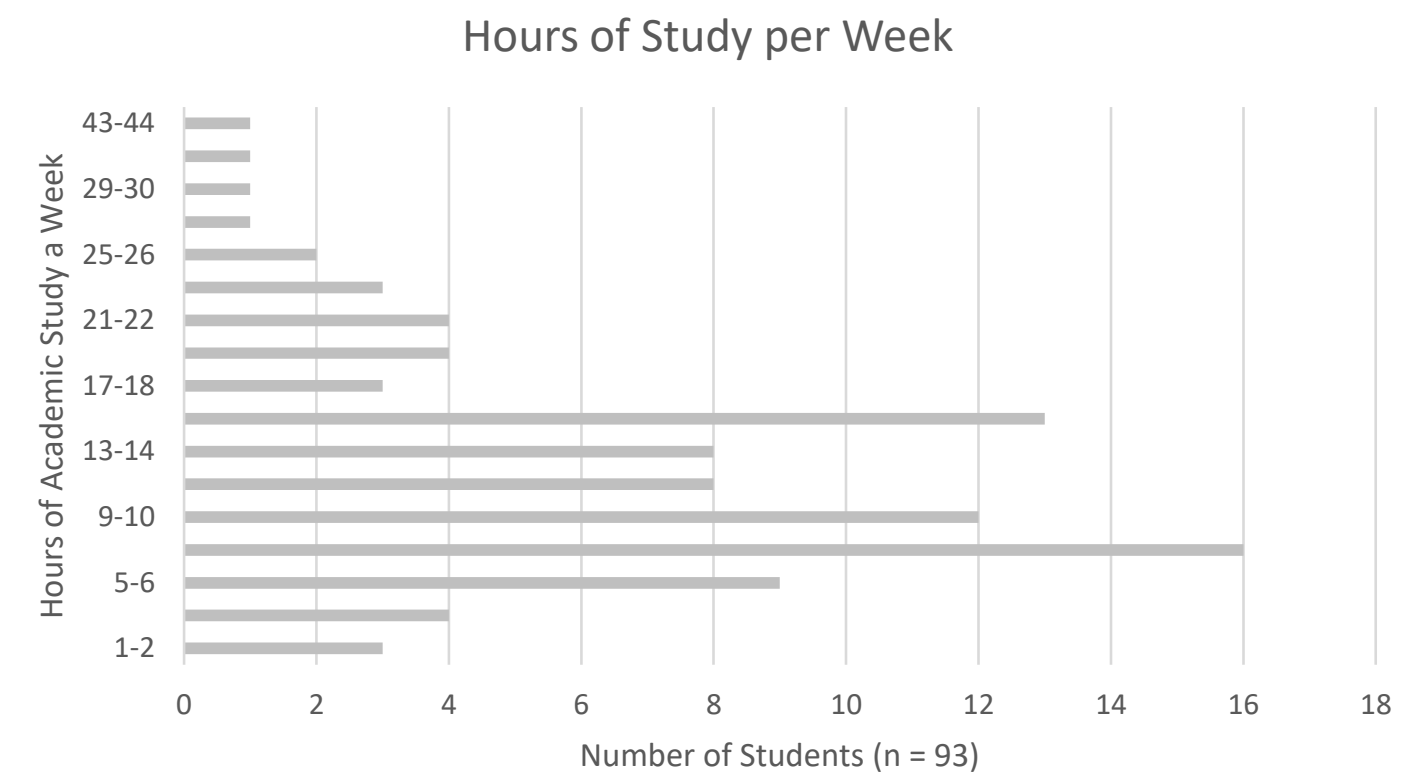

\begin{tabular}{llll} 
Minimum & Maximum & Mean & Std Deviation \\
\hline 1 & 44 & 13.2 & 3.59
\end{tabular}

\section{Figure 14}

Hours of Study per Week

As Figures 13 and 14 show, the students gave video games more than twice the time commitment they give to studying. In summary, heavy-video-gaming participants responded they spend an average of 27.22 hours a week playing games and an average of 13.2 hours per week studying. Gaming was a major priority in their schedules.

Nearly two-thirds of participants $(63 \%)$ reported that they had a time management method they used for handling the balance between gaming and study, which was to do the assignments that needed to be done and to postpone major game play until weekend: 
One student reported, "I just do my best not to pick up any games until after I'm done accomplishing the set of goals I have for that day. Otherwise, I end up procrastinating for a really long time. I save that for the weekend" (P42, transcript, p. 176).

If these students played games during the week, it was, according to them, in short fifteen-minute to one-hour bursts because gaming felt more like taking a break than an extracurricular activity: "I try to get my study assignments done first, but if I am struggling, I'll take a break and do something like a short game or something" (P22, transcript, p. 177).

When the weekend arrived and the students felt the other tasks had been completed adequately, then gaming would begin and continue for multiple hours:

I don't work on Fridays and now that is my relax day.

It is a huge gaming day, and you know it's the weekend.

I got the whole weekend to play (P36, transcript, p. 168).

Sometimes players chose to compromise sleep hours in order to play games during the week though it may cost them because they choose to sacrifice other things such as class attendance:

"I do the tasks I need to do in the day, then if it's late at night I tend to play a couple hours of games, more than I should. If that happens, I just stay up later to finish the work, or make ends meet somewhere else, so I don't fall behind on my work. Sometimes, I have slept through an early morning class" (P27, transcript, p. $175)$.

The participants' reasons to play video games so frequently are shown in Table 12. 


\section{Table 12}

Reasons for Playing Video Games at College

\begin{tabular}{lll}
\hline $\begin{array}{l}\text { \# of } \\
\text { Participants }\end{array}$ & Percent & Category of Play \\
\hline 28 & $30.11 \%$ & I play at a competitive level with a team of friends. \\
28 & $30.11 \%$ & I play for leisure. \\
16 & $17.20 \%$ & I play on an official eSport team. \\
15 & $16.13 \%$ & I play at a competitive level by myself. \\
6 & $6.45 \%$ & $\begin{array}{c}\text { Answers of participants that met two of stated categories, } \\
\text { such as "I play competitively AND for leisure". }\end{array}$ \\
\hline
\end{tabular}

Heavy-video-gaming student participants reported that gaming is a social or leisure activity ( $\mathrm{n}=56$ of $93,60.22 \%$ ). They also play because of the competition, reported by fifteen study participants (16\%). Gamers coming to college view games as an important part of their overall college experience, especially as related to social aspects as the qualitative data indicate that heavy-video-gaming student participants speak about the social impacts of the benefits of teams, getting together with others, and the community that gaming provides as indicated in the following comments.

"Video-gaming is helpful to the academic experience, because, rather than the traditional mold of going out and hanging out with friends, I'm hanging with my friends online" (P43, transcript, p. 13).

"Definitely, 100\%. Gaming has led to me being able to make the friend group that I have in college. Without that ...I would definitely be a lot less social” (P77, transcript, p. 98). 
"I just love being able to contribute to a team, but think not only about the individual performances, but how the team works as a whole" (P28, transcript, p. 75).

"I like that game, and sometimes I play a game by myself, it's a little boring. But if you share time with friends, and you play together, you've not only played the game, but shared time with friends" (P89, transcript, p. 143).

Without the social component of gaming, participants admit they can become bored and may quit the game. As P89 stated, "When my friends are busy, sometimes games get boring, and I quit, I try to find more interesting things to do" (transcript, p. 45).

In a question listed later in the questionnaires, the participants were asked to describe their game performance level in an effort to learn more about their motivations for playing. For slightly more than 50 percent of the players, playing for fun was more important than participating in the competitive ranking level of the games, with 49 (52.69\%) students identifying that their gaming was just for fun, 24 (25.81\%) playing for the college teams, $17(18.28 \%)$ considering gaming as a semi-professional level having won money, and $3(3.23 \%)$ identifying as professional gamers.

Another reason for playing games at college was that heavy-video-gaming participants generally have a lot of time and money wrapped up in gaming. Players have regularly devoted not just hours, but years, into their gaming passion. Slightly more than half of the $93(51 \%)$ participants stated they have been gaming seriously since they were age twelve or younger, revealing a minimum investment of five years into their gaming skillsets, purchasing a collection of games, and establishing friend groups. One participant stated, "I've played games basically my whole life" (P90, transcript, p. 2). 
Over half of gamers (59\%) have played enough time to earn a globally-ranked level in their chosen game. In order to keep this ranking, players must continually invest time in play, or others will surpass them. The heavy-video-gaming students have played games for more years than they may even intend to be at university, making the activity something that is not easily given up, especially as they plan to continue playing in their future.

Participants were asked to choose from the following areas to tell why they are motivated to play games, as shown in Table 13. The leading response was the love of competition ( $\mathrm{n}=44$ of $93,47.31 \%)$.

\section{Table 13}

\section{Motivation for Gaming}

\begin{tabular}{lll}
\hline Motivation for gaming & Percent & \# of Participants \\
\hline $\begin{array}{l}\text { I love the competition playing games } \\
\text { provides. }\end{array}$ & $47.31 \%$ & 44 \\
Motivated by the game itself & $17.20 \%$ & 16 \\
$\begin{array}{l}\text { Playing games is a way to pass the time - } \\
\text { it is something to do. }\end{array}$ & $17.20 \%$ & 16 \\
$\begin{array}{l}\text { Because my friends play } \\
\text { Because I make money by playing }\end{array}$ & $0 \%$ & 0 \\
(rewards, scholarships) & & \\
Other & & 0 \\
\hline
\end{tabular}

As in the previous Table 12, Table 13 also shows that the competitive level is a strong motivation for gaming. The motivation or the drive to compete is the strong response in this set, with 47 percent highly motivated by the competition and challenge 
games as opposed to the 10.75 percent of students who choose to play due to the fact that their friends play.

The result indicates heavy-video-gaming students are motivated to keep coming back to the game to achieve something and would likely continue to play even if friends were not a part of the game. This motivation to be pertinacious toward achievement is a strong skill set, and the players do not appear to be afraid of this type of challenge; there is a sense of achievement or reward that accompanies it. Participants said,

"Gaming just builds more character and you know like being able to complete accomplishments" (P41, transcript, p. 144);

"I can learn something from games" (P23, transcript, p. 145);

"For me, it like opened up a whole new world, figuring out new things" (P67, transcript, p.146).

Three-fourths of the participants ( $\mathrm{n}=68$ ) said they preferred to play with a group of close friends and are motivated by them. P86 said it like this: "Gaming helps in socializing because I can't always find someone to socialize with because everyone's busy in college. So, video games are a pretty good way to step in the gap" (P86, transcript, p. 147). Another participant added, "It's my way of hanging out with friends. It's just fun" (P44, transcript, p.122).

For the participants, gaming revolves around the need to socially interact, which also leads then to the fun of competition. Without the engagement of other players, it is difficult to be motivated to play in the competition.

While gaming is an important form of social interaction for the participants, 58 gamers considered themselves an introvert. The heavy-video-gaming student participants 
indicated they prefer to study alone $(n=45)$, enjoy their alone time $(n=27)$, do not like being the center of attention ( $(=10)$, are quiet in class $(n=33)$, are not eager initiators of social events $(n=17)$, and are not energized from being in groups of people $(n=16)$.

No participants responded that they were motivated by scholarships or making money from playing the game. Eight participants mentioned their desire to work in the eSports industry, and two responders spoke of making money in tournaments. However, this unraised issue of finances is interesting since universities have started offering scholarship dollars to play on eSport teams.

In summary, data reveals heavy-video-gaming participants are intrinsically motivated to play games for the social connections they provide, and they have the internal desire to be challenged or compete.

Heavy-video-gaming students agree that gaming has been and could be a distraction to getting started on study and academic projects, but rarely $(\mathrm{n}=5)$ did they admit that gaming was the reason academic performance or grades were not as good as they could be. Participants recognize that they spend more time on gaming than studying. For instance, P92 confessed that one of his longest school projects took him six hours to complete, which was an outline of a textbook. Then, he compared that to a big gaming tournament for which he had prepared. He admitted spending twelve to fifteen hours in preparation for the tournament - twice the time of his studying. Yet he did not feel that the school project was impacted by the time he spent playing games (transcript, p. 34).

When gaming did impact students' grades, participants did not seem to be overly concerned about the consequences. An individual admitted with little remorse "I received a B- in a class for missing two quizzes. I was playing Overwatch" (P8, transcript, p. 56). 
However, gaming was viewed as only moderately hindering grades, with $50(53.75 \%)$ students responding that gaming interfered only one to two times out of every five times they intended to focus on studying for an exam, attend class, or do homework. Rather than viewing gaming as hindrance, students felt that gaming was instead the tool that provided them needed mental breaks from academic study. As one student explained, "gaming is accessible and an easy way to take breaks" (P12, transcript, p. 263). Heavyvideo-gaming students perceived that taking breaks made them alert and ready to tackle the next study session.

The students indicated that university-sponsored extracurricular activities put more strain on their studies than gaming. P86 stated, "When I play, sometimes I get lost in the game and lose track of time, but it's my time and I make it up. Extracurriculars are worse, because games can be played for a short time and you can pause them, but other extracurriculars can't be paused, instead you have to plan to attend them and you don't have control of the time" (P86, transcript, p. 201). Other named factors that impacted student academic performance included just life - "the dishes, laundry etc. Sometimes it is just life that is a distraction" (P33, transcript, p. 78); personal mood of the student - "I just have to be in the mood to study (P14, transcript, p. 79); basic time management - "it takes me a long time to start my work I find other things I want to do" (P77, transcript, p. 79); boring, uncaring teachers - "If we had teachers that cared it would be easier to study" (P1, transcript, p. 78); and class schedules - "Our schedules pull us so many different directions. In a perfect world the school would do a better job coordinating between classes, like I don't need two major papers and 3 tests all in the same week, but I know that can't happen" (P47, transcript, p. 179). 


\subsection{Study Habits and Attitudes}

Students were asked to rate their academic performance on a net promoter range scale (Hamilton et al., 2014) of 0 to 10 with 10 being the highest. The net promoter range scale shows low range, midrange, and high range of how the participants rate their academic performance. Figure 15 shows the detractor is someone who fails to make much effort in regards to his or her own academic performance (low range); 19 participants rated themselves as detractors. Second, passive is a student who takes academic performance as it comes, not putting in extra work, but not failing (midrange); 49 participants were passive. Third, the promoter student completes the tasks needed to complete class work and academically perform (high range); 25 participants were promoters.

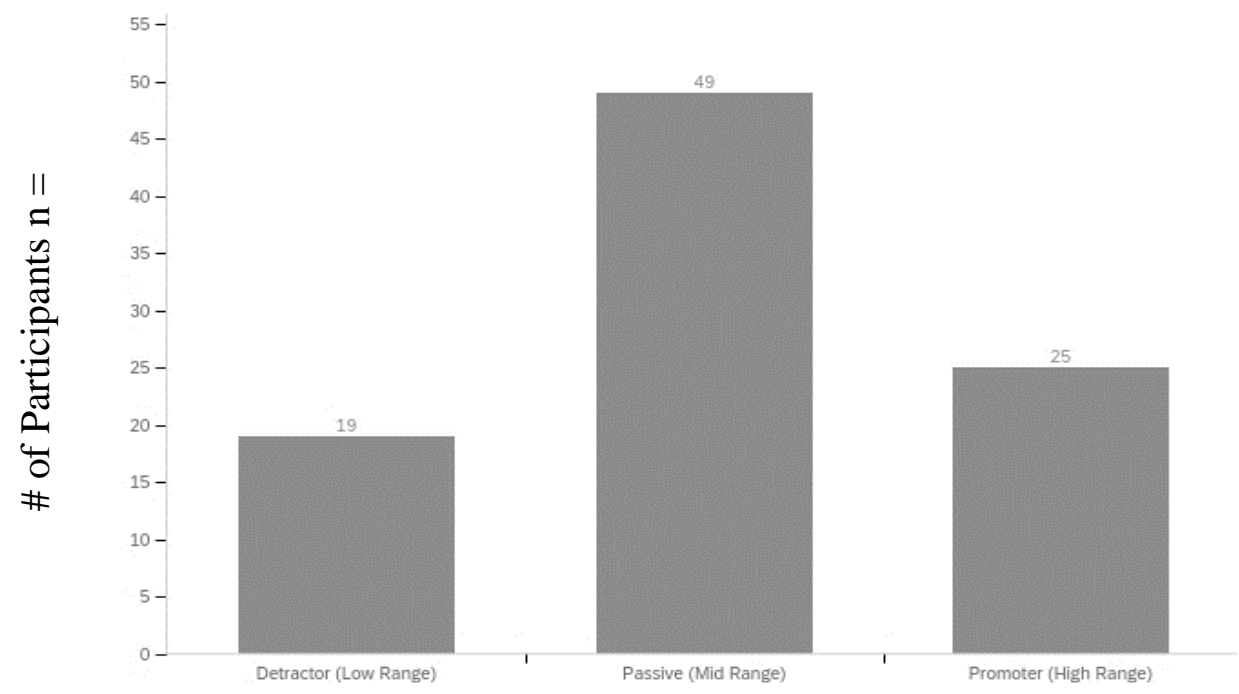

Net promoter range scale

\section{Figure 15}

Academic Performance Rating Reported by the Participants 
In addition, $89(84.95 \%)$ of the participants indicated they considered themselves to be procrastinators. The results show that a passive, procrastinator combination tend to indicate that students work in a reactive mode rather than a proactive mode. There may be a number of possibilities that these results suggest. First, the gamers may not be putting forth their full effort in academics but instead are doing enough work to get by, amplified by their procrastinating habits. Second, the disciplines the majority of gamers choose to study, such as computing, engineering, and math, are challenging fields in which it is easy to procrastinate and difficult to earn high scores, so the students are happy to perform at a rate that only ensures passing. A third possibility may be that students maintain a passive performance mode because they are willing to sacrifice some school work to ensure they have plenty of gaming and social time. The following statements indicate the students try, but still carry a passive tone. According to P77, "I don't really plan, I just try to get things done as they are needed, but when I decide to work, I am efficient" (transcript, p. 37). And P21 said, "I try to accomplish the goals I have for the day, otherwise I will procrastinate for a very long time" (transcript, p. 182).

\subsubsection{Reasons to Study (Motivations)}

Heavy-video-gaming student participants indicated that grades are a major factor in their motivation to study. The term good grades was given as a response more than any other $(n=21)$. However, the term good was never clearly defined by the participants. As participant P14 said, "good grades equal a good job, and more money” (P14, transcript, p. 257). The data indicates that while grades motivate, GPA scores do not. Not a single response mentioned grades in the terms of GPA, such as the need to obtain a 4.0 average, but rather indicated they only needed to perform at a level to get a grade that 
was "good enough" (P23, transcript, p. 259). This type of thinking mimics game players' actions, where they do enough to complete a quest so they can move on toward the bigger prize.

The next two reasons mentioned as motivators to study were the needs of passing the class and completing the program $(\mathrm{n}=11)$. Again, the letter grade earned was not as important to the student as moving on to the "next big thing" (P12, transcript, p. 37). The students wanted to be making visible forward progress toward a "meaningful goal" (P1, transcript, p. 241).

As negative motivators, fear and family were terms that came up regularly $(n=34)$. Students were motivated to study to "avoid the embarrassment" (P65, transcript, p. 251) or "inconvenience" (P45, transcript, p. 251) that failing a course would cause.

Additionally, participants were motivated to please their family with an expected grade as that would avoid moments of conflict, inconveniences, or consequences.

The term deadlines $(\mathrm{n}=7)$ appeared equally as often as fear. Deadlines gave students something to work towards or attack to muster up some motivation. For these participants, there is a need to have some type of adversary to attack, and in this case, deadlines represent that. Deadlines are viewed in both positive tones and negative. Deadlines were beneficial for participants to focus on tasks due, feeling accomplished when work was completed and turned in promptly, and yet the due dates were many times unclear and caused the sensation of stress in school. Participants said,

"We tried to meet the deadline by the end of the week, but if we didn't make it the teacher would move it or give partial credit" (P68, transcript, p. 105), and 
"I like getting things checked off my list, it helps me focus" (P38, transcript, p. 242).

"I have no free time, there is always something due, and I never get a break." (P34, transcript, p.166).

"School is stressful. I need a break from all the homework" (P23, transcript, p. 144).

Other reasons to study that participants shared included that the topic of study was interesting $(\mathrm{n}=6)$ and a vision of how this schooling might better prepare them for a specific career $(n=12)$. Only four students mentioned the need to do well to keep a scholarship or stay on an eSports team, and an even fewer number mentioned the learning experience itself motivated them $(n=2)$. A most noble comment came from P28, who seemed to really understood the big picture of his choices, when he indicated the motivation for study was "to go on and make an impact on this world by helping others with prosthetics" (transcript, p. 257), though at another time in the interview indicated that he was highly distractable in the day-to-day work, needing lots of reminders to stay on task (P28, transcript, p. 155). While the heavy-video gamers may have noble aspirations, getting to the goal requires a need for some learning supports to be in place.

\subsubsection{Study Practices of Video-Gaming Participants}

The heavy-video-gaming student participants were asked to identify their three strongest study habits from a list of twenty well-known study habits (Table 14) compiled from the literature review (Aquino, 2011; Credé et al., 2010; Credé \& Kuncel, 2008; Elliott \& Healy, 2001; Nonis \& Hudson, 2010; Yu, 2011). The category of class attendance was ranked as the first choice by a large margin with $44(47.3 \%)$ votes. 
Notetaking came in second with 15 (16.1\%) votes, followed by knowing class

expectations as the third choice with $14(15 \%)$ votes. After summing the three rounds of ranking scores, it was interesting to observe is how the placement of study habits shifted. Class attendance remained in first place with 63 (67.7\%) votes. However, knowing class expectations moved into second place with 30 (32.2\%) votes, and noted is the move of the study habit of active listening into third place with 29 (31.1) votes, moving ahead of notetaking. Active listening received a consistent vote in all three ranking sessions, indicating it steadily remained one of the strong top choices. Another interesting observation is the first five ranked study habits listed are all most often utilized while in class: class attendance, notetaking, know the class expectations, active listening, and have a good attitude. After the top five habits, personal rest and sleep finds a place in the ranking, which was an important response in participant interviews $(n=8)$ as well.

\section{Table 14}

Participants Rating of their Study Habits

Gray highlights show the highest ranked scores per voting section, ordered in rank by the top three. When the three rounds of voting were summed, notice how Notetaking moves to the fourth position. The summed rankings are highlighted in blue.

\begin{tabular}{lllll|ll}
\hline $\begin{array}{l}\text { Well-Known } \\
\text { Study Habits }\end{array}$ & $\begin{array}{l}\# \mathbf{1} \\
\text { Vote }\end{array}$ & $\begin{array}{l}\mathbf{\# 2} \\
\text { Vote }\end{array}$ & $\begin{array}{l}\mathbf{\# 3} \\
\text { Vote }\end{array}$ & $\begin{array}{l}\text { Top 3 } \\
\text { Votes \% }\end{array}$ & Total & Total \% \\
\hline Attending class & 44 & 13 & 6 & $\begin{array}{l}\mathbf{4 7 . 3 \%} \\
\left(1^{\text {st }}\right)\end{array}$ & 63 & $67.7 \%\left(1^{\text {st }}\right)$ \\
\hline $\begin{array}{l}\text { Note taking in } \\
\text { class }\end{array}$ & 8 & 15 & 4 & $\begin{array}{l}\mathbf{1 6 . 1 \%} \\
\left(2^{\text {nd }}\right)\end{array}$ & 27 & $29.0 \%\left(4^{\text {th }}\right)$ \\
\hline $\begin{array}{l}\text { Knowing class } \\
\text { expectations }\end{array}$ & 6 & 10 & 14 & $\begin{array}{l}\mathbf{1 5 . 0 \%} \\
\left(3^{\text {rd }}\right)\end{array}$ & 30 & $32.2 \%\left(2^{\text {nd }}\right)$ \\
\hline $\begin{array}{l}\text { Active listening } \\
\text { Positive }\end{array}$ & 10 & 10 & 9 & -- & 29 & $31.1 \%\left(3^{\text {rd }}\right)$ \\
\hline \begin{tabular}{l} 
Attitude \\
\hline
\end{tabular} & 7 & 5 & 8 & -- & 20 & $21.5 \%$ \\
\hline
\end{tabular}


Table 14 (continued)

\begin{tabular}{|c|c|c|c|c|c|c|}
\hline Proper rest & 1 & 6 & 11 & -- & 18 & $19.3 \%$ \\
\hline $\begin{array}{l}\text { Making time to } \\
\text { study }\end{array}$ & 4 & 6 & 7 & -- & 17 & $18.2 \%$ \\
\hline $\begin{array}{l}\text { Effectively } \\
\text { reading } \\
\text { assigned } \\
\text { material }\end{array}$ & 3 & 5 & 7 & & 15 & $16.1 \%$ \\
\hline $\begin{array}{l}\text { Organization for } \\
\text { study }\end{array}$ & 5 & 6 & 2 & & 13 & $13.9 \%$ \\
\hline $\begin{array}{l}\text { Think about your } \\
\text { thinking }\end{array}$ & 6 & 3 & 3 & & 12 & $12.9 \%$ \\
\hline $\begin{array}{l}\text { Good review } \\
\text { strategies }\end{array}$ & 5 & 2 & 4 & & 11 & $11.8 \%$ \\
\hline $\begin{array}{l}\text { Planning for } \\
\text { writing essays }\end{array}$ & 2 & 4 & 4 & & 10 & $10.7 \%$ \\
\hline $\begin{array}{l}\text { Developing a } \\
\text { study plan }\end{array}$ & 4 & 1 & 4 & & 9 & $9.6 \%$ \\
\hline Proper nutrition & 0 & 4 & 3 & & 7 & $7.5 \%$ \\
\hline $\begin{array}{l}\text { Choosing } \\
\text { correct writing } \\
\text { styles }\end{array}$ & 2 & 3 & 1 & & 6 & $6.4 \%$ \\
\hline $\begin{array}{l}\text { Designating a } \\
\text { study area }\end{array}$ & 1 & 2 & 1 & & 4 & $4.3 \%$ \\
\hline $\begin{array}{l}\text { Avoiding } \\
\text { distractions } \\
\text { such as social } \\
\text { media }\end{array}$ & 0 & 4 & 0 & & 4 & $4.3 \%$ \\
\hline Other & 0 & 1 & 3 & & 4 & $4.3 \%$ \\
\hline
\end{tabular}




\subsubsection{Rated Study Practice - Class Attendance}

Class attendance was ranked as the most effective study practice of heavy-videogaming students, with 47 percent of participants naming it as their strongest study practice. This first-place ranking of class attendance is also supported through the qualitative data. Eighty-three percent of interviewees indicated they rarely missed class and that class attendance was important. Participants noted "It's the most efficient way to get material" (P77, transcript, p. 24), "I don't like missing class, I value it like gold in a game" (P28, transcript, p. 26), and "In class, the teacher can pay attention to you" (P87, transcript, p. 27).

Participants attend class when they perceive what they consider something of relevance. Factors pointed out by participants included theses: "When teachers go more in depth than is in the book" (P93 transcript, p. 28); "finding more information flowing through in class, than relying on my own intuition" (P43 transcript, p. 27); "material discussed to help with an assignment" (P77 transcript, p. 28); "a professor who shares experiences and stories directly related to the topic" (P33, transcript, p. 29), "engaging class discussions" (P7, transcript, p. 27); and "grades tied to attendance" (P31 transcript, p. 25).

\subsubsection{Rated Study Practice - Knowing class expectations}

The second-highest ranked study habit was knowing the class expectations (15\%). A gamer mentioned, "Just tell me what to do, and I will get it done" (P29, transcript 40). This study practice is also connected to their gaming practice; if the gamers know the overarching objective or understand the purpose, achieving is not generally a problem. As P45 stated, "I am an achiever" (transcript, p. 36). 


\subsubsection{Rated Study Practice - Note Taking}

The third-highest rated study skill by the video-gaming participants was note taking, though the students revealed repeatedly that they did not write their own notes $(\mathrm{n}=$ 10). Interviewees pointed out that some of the instructors made their notes available, and the students affirmed their desire for this resource (93, transcript, p. 117). Thus, it is difficult to know what "note taking" looks like for students. P43 explained he usually took up to three pages of detailed notes on his iPad in every class (transcript, p. 27). Others mentioned that when they studied, they only reviewed the teacher's notes and filled in the blanks with their own notes (P47, transcript, p. 118). Another interviewee expressed a desire for teacher-created study guides that could be given before tests (P91, transcript, p. 119). Regardless of the notes' originator, students wanted something to refer to during times of study. Students indicated that when preparing for exams, they would study no more than 30 minutes, and most often it was in bursts of 5 to 10 minutes of the 30 minutes dedicated to the effort (transcript, pp. 110-114). Heavy-video-gaming participants wanted straightforward information and did not want to do a lot of extra work in order to have the information available. This need for available information is connected to the participants' gaming practice as information in games is gathered in a similar manner, and players can readily find any information then need to be successful in the game online. Participants desire the same ease of availability for their academic studies.

\subsubsection{Rated Study Practice - Active Listening}

Active listening was signposted as the fourth-strongest study practice in the list and may be directly related to notetaking. As far as comparing percentages, the two skills 
were very close in score, with active listening at an overall 31.1 percent and notetaking at a 29.0 percent. Observing the active learning scores, they had a very consistent count in each of the three turns of ranking votes. The skills correlate because in order to take effective notes, one needs to listen.

The participants indicate that active listening is a more efficient way to gain information. A participant said that in games he was always looking for the most efficient way to get from point A to point B, and that skill has carried over in his academics as he looked for the most efficient way to gather information and prepare for assignments (P77, transcript, p. 113). Going to class and actively listening to the instructor was viewed as a much easier way to find information than digging for it in a book or compiling it from various web pages.

Thus, the note taking study practice may be part of the active listening that is occurring, as students write down a few things to prompt their memory later. While class attendance, notetaking, knowing the class expectations, and active listening were top study skills, on multiple occasions the qualitative responses revealed the gamer students believed they also had good recall skills, and when taking an exam, they just needed to mentally replay or reflect on the class conversation they heard. From this data, it is possible to understand that even if video-gaming students do not appear engaged during class, they may be actively listening (transcript, p. 237). P43 indicated that all he had to do was go to class and listen as he had "yet to meet a teacher who tested on much other than what was talked about in class" (P43, transcript, p. 110). In summary, the participants reflect on their notes and depend on their active listening and recall abilities to score a passing grade in a host of their classes. 


\subsubsection{Gaming Attitudes and Academic Study Attitudes of Video-Gaming Participants}

Participants were asked to reveal their deeper attitudes about gaming and academic study by describing thoughts with metaphoric language (Lakoff \& Johnson, 1980; McGlone, 2007). The participants were asked to complete the incomplete metaphors, "Gaming is like ...." and "Academic studying is like ....". In an effort to better detect attitudes, the responses were grouped and rated as to whether they were positive, positive/negative, or negative in tone.

Results of the "Gaming is like ... ." metaphor list reveal that 33 of the $41(80.4 \%)$ responses were positive-toned indicators. Shown below in Table 15 are the major groups for the "Gaming is like ...." statements and then the number of comments in each. The full "Gaming is like" metaphor list is offered in Appendix G, which lists the 41 unique responses.

\section{Table 15}

Gaming is Like ... . Metaphor Category List

\begin{tabular}{ll}
\hline $\begin{array}{l}\text { Gaming is like... } \\
\text { Broad categories }\end{array}$ & $\begin{array}{l}\text { \# of Comments in metaphor } \\
\text { list }\end{array}$ \\
\hline Relaxing, Escapism, Pleasant Emotions & 14 \\
Work, Achievement, Challenge & 11 \\
Comfort & 7 \\
Thrill & 6 \\
Negative Comments & 5 \\
Food & 4 \\
Supportive & 1 \\
\hline
\end{tabular}

The participants made comments indicating gaming provided them the "needed place to relax" (P54, transcript, p. 261) and "escape" (P19, transcript, p. 261) from their current stresses of life. P12 defined gaming as a vacation by saying, "It's departure from the stress of reality and helps to put me in a good state of mind" (transcript, p. 261). 
Some felt playing afforded them a "means of achievement" (P12, transcript, p. 261) as they were rewarded for their work within the game ventures. Participants suggested that gaming is like solving a complicated math problem (P22, transcript, $\mathrm{p}$. 261) and learning any other skill (P30, transcript, p. 261). The learning was explained in this way:

I play clarinet at a very high level and something that surprised me most is that the learning process is almost identical between the two.

You identify your weaknesses and slowly chip away at problems until you refine your play style to the highest degree possible (P30, transcript, p. 261).

Other feelings about gaming were compared to items that were thrilling (P81, transcript, p. 261), a venue that "provided comfort" (P17, transcript, p. 261), enjoyment like "food" (P92, transcript, p. 261), and a skill that improves (P38, transcript, p. 261).

Only a few negative comments were made about gaming. As an example, gaming could be an "obsession" (P6, transcript, p. 261) or "a loss of control" (P79, transcript, p. 261).

In contrast, the same students were asked to describe their academic study experience with a metaphor. The students' perspectives in this list deliver a very bleak tone about learning. The results in Table 16 show that 47 of the $59(79.6 \%)$ responses in the "Academic Study is like ...." metaphor list were negative in tone. Appendix H lists the 59 unique data responses. 


\section{Table 16}

Academic Study is Like . . . Metaphor Category List

\section{Academic Study is like... Broad categories}

Struggle

An unpleasant necessity to achieve reward

Adventure

Practical

\section{\# of Comments in metaphor list}

30

20

11

5

A more moderate view indicated the compared study to "paying taxes" (P34, transcript, p. 262) and "working out" (P41 transcript, p. 262), something they did not enjoy in the moment but could see there was some benefit for those who would "stick it out" (P54, transcript, p. 262).

The few students who seemed to enjoy studying used metaphors such as “academic study is like a vast expanse of unknown horizon" (P75, transcript, p. 262) and “oiling a gear" (P13, transcript, p. 262), explaining there were limitless possibilities in academics, and these were helpful in the creation of a smooth working machine.

A comparison of the metaphor lists implies the distinct way in which heavyvideo-gaming students approach the areas of gaming and study and it clearly illuminates that they are vastly different in attitudinal tonality. Gamers enjoy and look forward to gaming, while they tolerate and feel burdened by study. Social behavioral research studies serve as a reminder that an individual's attitude can make an impactful difference in all of their human activity (Aquino, 2011; Bray et al., 1980; Özsoy et al., 2017).

\subsubsection{Academic Skills Learned Through Gaming of Video-Gaming Participants}

Students named a number of skills they learned from their gaming experience as helping them become better academic students. Three students were quick to admit their 
typing speed had doubled and their typing accuracy had improved (transcript, pp. 159167). Heavy-video-gaming students commented ten times they had learned to persist and "grind" as they worked through long endeavors to another gaming level (transcript, p. 159-167), which translated to "grinding" through the homework they were assigned. Another five referred to the ways gaming had improved their ability to pay attention and recall details (transcript, pp. 159-167).

By far the response that was mentioned the majority of times $(n=47)$ was that the heavy-video-gaming students had gained the ability to work with others and communicate better (transcript, pp. 159-167). They described learning to become more patient, understanding and articulate as they explained or "taught" others about the game or the maneuvers needed within the game (transcript, pp. 159-167), which were all useful skills in academia and learning. Topics are listed in Table 17.

\section{Table 17}

Academic Skills Learned Through Gaming

\begin{tabular}{ll}
\hline Skills listed (Top 3) & \# of responses \\
\hline Communicating with & 47 \\
others & 10 \\
Persistence & 3 \\
Typing speed increased & \\
\hline
\end{tabular}

\subsection{Learning Supports Used and Desired by Gamers}

In this section, the learning supports that exist, are identified by the video-gaming students. The students described the learning supports that they use, and those they desire: some that could be enhanced or created as they do not exist yet.

The heavy-video-gaming students identified learning supports, services and processes that their institutions currently have in place to aid them with their studies 
(Erdmann \& Clark, 2016; Hodes et al., 2015). Figure 16 is a word cloud that shows the terms listed by the participants, displaying them by the weight of how often they appeared in the transcripts. Colleges may provide more learning supports than shown, but these were the services the participants identified.

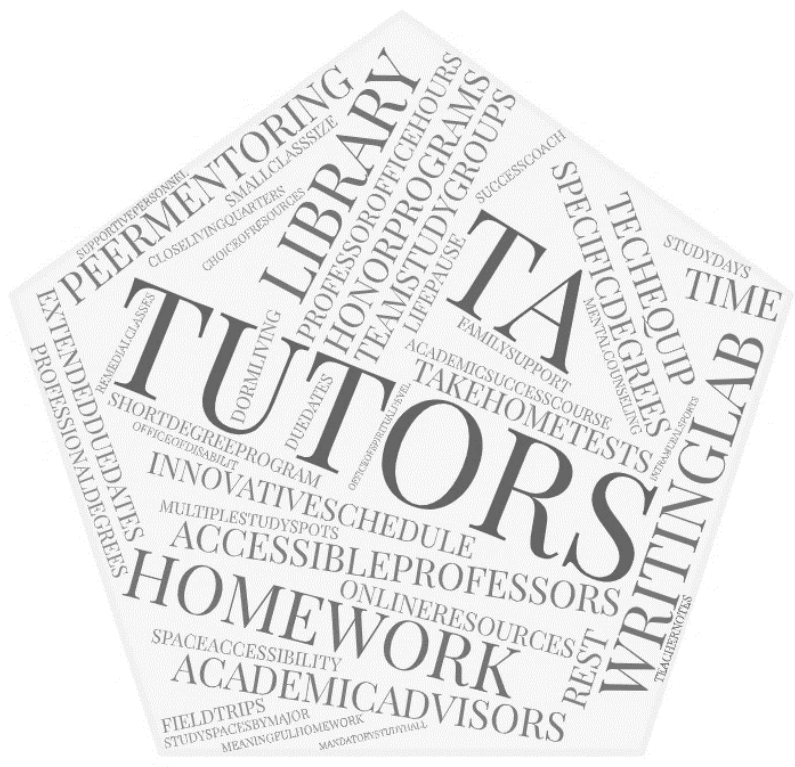

\section{Figure 16}

\section{Campus Learning Supports Identified by Heavy-Video-Gaming Students}

The most referenced learning support service was campus tutoring. A little less than one-third (30\%) of the students admitted to using tutoring or any of the learning support services. Even when they were aware of a support service, they were somewhat vague about the specifics of the support as they did not personally use them. P5 said, "I am ok just knowing they are available if I should ever find myself needing help, though I never have" (transcript, p. 68) while another reminds, "I like to figure things out by myself”'(P24, transcript, p. 68). 
When students used some of the services, they did so as a response to a requirement made by the teacher. One student said, "I have used the writing center but only because they made us go for an assignment" (P92, transcript, p. 68).

Other comments included:

"I know we have tutoring, English, Writing, Math, I think.... I'm not sure what else" (P65, transcript, p. 69).

"No, I don't use the tutors" (P84, transcript, p. 69).

"No, I would like to use them, but their schedule doesn't match up with mine" (P47, transcript, p. 45).

"I used them once, and didn't really like it. They just didn't teach in my style" (P29, transcript, p. 87).

With the supports in place on campuses, the students still had some desires for things that they believed would make the college academic learning experience better, and those responses are displayed in the Figure 17.

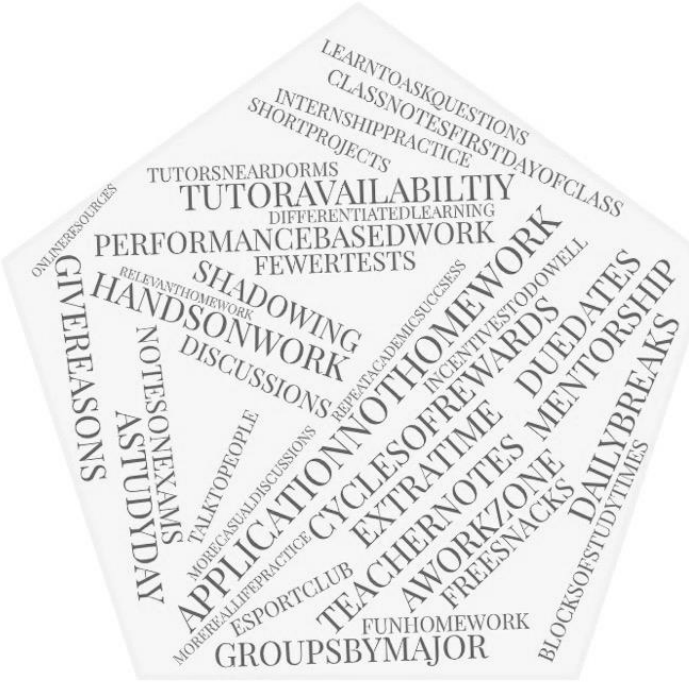

\section{Figure 17}

Campus Learning Supports Desired by Heavy-Video-Gaming Students 
In Figure 17, there is no single desired learning support that stands out among the rest, but as the terms are examined, there are several related terms that could be weighted together. When examining the generated word cloud, the students' perspectives of learning supports differ a great deal from traditional university definitions (Kuh et al., 2011; Shim \& Ryan, 2012; Torres-Díaz et al., 2016). The student statements include suggestions that address curricular decision, not necessarily only campus supports or processes that can be implemented by a campus support office. Instead, the students present a more holistic learning support wish list.

Participants wanted more performance and application-based work. The heavyvideo-gaming students want more mentorship and practical experiences and less traditional homework. The results indicate they want extra time for assignments, prefer to utilize pre-developed study notes, and recognize they could use practice in communication, particularly asking questions.

Participants longed for a balance in scheduling, which related to the desire for extra time. Some had five classes in a row on Mondays, Wednesdays, and Fridays, while having no classes on Tuesday and Thursday (transcript, p. 67). Others mentioned “choppy class schedules" (P86, transcript, p. 68). Participants felt the length of class time should be better balanced based on disciplines, and desired more time working together with peers in the area with the resources in order to complete homework (P68, transcript, p. 69). P66 spoke of a positive schedule that worked for him, saying

Each class was only four weeks in length, but the class was four hours of lecture followed by four hours of lab, meeting for three days a week. This gave the student the opportunity to take two courses during the month, and only have to 
really concentrate to those two classes, but do so for longer periods of time, and immediately get the homework completed in the lab section, where the resources were (transcript, p. 69).

In regards to time management and scheduling, students desired a system that assisted the instructors in a manner that would balance major assignments across the courses. P86 recognized the request would be nearly impossible to implement from his perspective, but he still had a desire that instructors should be aware of other major exams, projects, or events occurring across campus, which ones impact their students, and help to even out the work load for students in the class (P86, transcript, p. 85). With a campus-wide academic scheduler, instructors could more strategically schedule the big items in a way that students could avoid having 3 or 4 major assignments due in the same week.

Another suggestion related to scheduling was timing of classes. Students did not relish 8:00 a.m. courses, nor did they state the need to eliminate them as the earlymorning class schedule "taught real life work habits" (P44, transcript, p. 93). However, P9 made known his desire that difficult courses, such as engineering math avoid the 8 a.m. hour and felt that the class had two strikes against it, in that it was difficult material and he was being asked to think about it during his least favorite and lowest functional part of the day (transcript, p. 94).

Over half of the heavy-video-gaming students indicated learning new things was easier when presented through visual means. The students wanted instructors to present material in more visual ways to support them when teaching the content, whether through "flow charts" (P84, transcript, p. 58), "examples" (P65, transcript, p. 59), “diagrams" 
(P89, transcript, p. 59), "images" (P91, transcript, p. 60), "demonstrations" (P33, transcript, p. 60), or "video" (P47, transcript, p. 58). Interestingly, students did not consider presentations full of text as "real" visual aids, but rather notes (P89, transcript, p. 63). The heavy-video-gaming students wanted plentiful "examples and premade notes" (P93, transcript, p. 56). The students voiced a strong desire to be "shown how to do things" (P87, transcript, p. 60).

One strategy for learning new things that kept arising was the "use of more projects" (P37 transcript, p. 62) that used the "knowledge presented in class" (P41, transcript, p. 63), "promptly in meaningful real-life ways" (P46, transcript, p. 63). One student was questioning the reason for learning such specific dates and names in history, just so they could be reproduced for a test. The participant expressed, "I know history is important so we don't repeat it, but why can't it be more like a story. That would help me remember it and be meaningful," (transcript, p. 74). P66 described how his English Comp class had each student write a "formal email response to a professional" in their respective fields (P66, p. 98). P33, who studied criminal justice, spoke about a "mock forensic crime scene that was set up for students on a local farm using some animals, allowing the students to use some sophisticated blood analysis tools" (P33, transcript, p. 34). P73 described a spring break trip to a code-a-thon to help create software solutions (P73, transcript, p. 260). Students wanted more of these types of meaningful experiences. Small homework exercises were helpful, but the desire to "see how things fit together" in a relevant context was requested more frequently (P65, transcript, p. 69).

Students expressed the need to be challenged in ways that allowed them to work together in groups, but also independently. They liked projects where they could find 
ways to accomplish tasks working solo within the group, as they felt confident in their own abilities.

“They told me engineering was the toughest major. That's why I chose it. I wanted to challenge myself' (P24, transcript, p. 4).

"I'm confident, I can perform, if asked I can do anything, and do it well" (P88, transcript, p. 37).

"So far every situation I have found myself in, I have gotten out of, and I haven't had a true 'challenge' yet in which I failed miserably. That would be an eyeopener." (P43, transcript, p. 85).

Furthermore, while working on a project, they enjoyed having access to resources while being near peers and teaching mentors who could help the students solve the problems as quickly as possible (P14, transcript, pp. 120-123). However, after figuring out the project challenge, students desired a small audience with which to share or teach the concept. P68 said, "What helps me the most is to learn it like I am going to teach it to someone else" (transcript, p. 132). Giving students opportunities to hear material and use it to solve problems in meaningful ways, keeping near resources, and then providing opportunities for teaching the new skills to others is the overall theme the data presented (transcript, p. 65-96).

Heavy-video-gaming students liked their independence on projects but wanted the support of a team to make sure they did not feel stuck or "fail alone" (P28, transcript, p. 147). Hence, gamers indicated they themselves regularly play support roles in their games and enjoy helping others through problems, like "I enjoy helping others through things I have struggled with myself” (P43, transcript, p. 142). 
These heavy-video-gaming students preferred to be assessed by demonstrating their knowledge through application, not only taking an exam. When tests are given, students feel notes and expectations should be readily available online for their consumption, so their "study time can be efficient" (P23, transcript, p. 116) without a lot of extra effort made having to "teach myself" (P12, transcript, p. 67). They are used to having information at their fingertips on any topic and do not appreciate academia expecting them to spend great amounts of time on assignments, especially when relevance is not correlated (transcript, pp. 116-119).

Heavy-video-gaming students wanted the support of their professors. They preferred instructors who would mentor and take the time to "show them what needed to be done" (P87, transcript, p. 123), but who would also allow the students to try for themselves (transcript, p. 65-69). They enjoy having access to a caring professor, one who will share knowledge, tell stories of his or her experiences, and be available when they have questions. P23 said it like this: "Colleges could stop having garbage professors and TAs who don't care about their students or their ability to succeed - maybe then I'd listen to them more" (transcript, p. 122).

The participants want someone to believe in them as indicated in this statement: "We want professors that take seriously the dreams we have and they will help us do what is necessary to achieve those dreams." (P68, transcript, p. 67). Heavy-video-gaming students did not have a love for instructors who expected them to learn in specific ways. It was described as "Sometimes I think the teacher gets their feelings hurt, when students do not learn the way the teachers think it should be done" (P48, transcript, p. 117). 
Participants want regular and frequent feedback from mentors and professors for the work they do (transcript, p. 70-96). This recompence system is similar to gaining multiple "rewards" or successes in their work (transcript, p. 159-167). Guiding students through a series of short successes with opportunities to learn from the actions has a similar achievement feel as a game that provides points for every positive act, serving as motivation to continue. As they improve through these shorter projects and assignments, they do not mind repetition if they are awarded partial credit or opportunities to resubmit, much like the respawning of a character in a game. P36 described the idea of every time he accomplished a short study-goal, he rewarded himself in some manner by playing games (transcript, p. 156).

Participants acknowledged at a rate of 60 percent that they had introvert personalities and admitted the need to be better at working with others (transcript, p. 812). The comments made reflected that gaming had afforded the introverted gamers the desired social opportunity (transcript, p. 147-152). For instance, P34 touted his experience in the computer lab, where each computer major learned a lot about working with others. All students involved in the major discipline were given their own "office" space in the larger lab. Students were given a key to access the room as needed. This area became a study space for the majors. In the shared lab-office, the student indicated that all students learned to respect personal boundaries of other people, cooperate by sharing space and tools, work with other like-minded people, ask questions of one another as resources, experience and appreciate diversities such as cultural practices, taste in music, organizational skills, and social skills. P34 shared it like this: 
I love the lab, it helps you to get to know people, and talk to them. There is always someone there who I can ask a question. Sometimes it's quiet and sometimes it's not, but you cannot go in that room without learning something. You might be learning by reading a book, doing some homework, or hearing a new joke, or seeing a new web site - but you will learn. It's easier because we are all the same major and already have that in common. I get more done when I go to this designated space for work. I am in the work zone when surrounded by these computer things, and then when I am home - I'm home. The lab is great for a lot of reasons (transcript, p. 45).

The students wanted all information to be online and readily available, and yet preferred to have choice in how to consume that information. For example, P28 felt he could be better supported if school restaurants would put their food items online, so he could check for food allergies. He indicated that obtaining that information should be no big deal in today's environment, and yet he was frustrated that he could not get it (transcript, p. 87).

Students wanted to have online books and still wanted the choice to purchase if printed books fit their needs better (transcript, p. 65-67). Heavy-video-gaming participants wanted all school information readily available online so they could reach it when they want it, in order that they might self-service anything they need or want. Students felt that schools are still catching up to this online idea.

One final learning support that was mentioned was the need for readily available snacks and caffeine. Some students wanted free or at least affordable snacks made 
available to them on campus $(n=4)$. Caffeine consumption was mentioned specifically by five participants in the study (transcript, p. 65-67).

On the next pages, Table 18 and Table 19 give summaries of the learning supports of which the students were aware, and then those desired, that were described in the paragraphs above.

\section{Table 18}

Learning Supports Video-Gaming Students Identified and/or Used in their College

\begin{tabular}{ll}
\hline $\begin{array}{l}\text { Learning Supports Gamers Knew About and Identified for their } \\
\text { College }\end{array}$ & \# of Resp. \\
\hline Tutors and tutor availability & 30 \\
\hline Teaching assistants (TA) & 30 \\
\hline Writing lab access & 20 \\
\hline Accessible professors & 15 \\
\hline Library access & 12 \\
\hline Professor office hours & 10 \\
\hline Peer mentoring & 5 \\
\hline Homework serves as a support to learning & 5 \\
\hline Academic advisors available for degree program planning & 3 \\
\hline Honors programs to support students who need an academic challenge & 3 \\
\hline Team mandated study groups/study halls to aid in homework completion & 3 \\
\hline
\end{tabular}

Note: An additional 31 identified learning supports are not included in this table because they received only one response and, therefore, are not seen as important to the group. Further research may be needed.

Shown in the left column of Table 18 is a summary of the learning supports heavy-video-gaming participants were aware of on their campus. The main identified areas of learning support include services and functions, such as tutors and their availability, teaching assistants, writing labs, talking with professors, and library availability. The right column indicates the number of responses for that learning support that were received during the data collection. 


\section{Table 19}

List of Learning Supports Desired by Heavy-Video Gamers But Not Yet Offered

\begin{tabular}{ll}
\hline Learning Supports Desired by Gamers & \# of Resp. \\
\hline Application of knowledge / no homework given in class & 10 \\
\hline Hands on activities/exercises for class & 6 \\
\hline Performance-based activities/exercises for class & 5 \\
\hline Incentives / rewards to do well (gamification) & 5 \\
\hline $\begin{array}{l}\text { Better and quicker feedback from instructors about homework; all } \\
\text { school information presented in a 24 hour/7days a week }\end{array}$ & 3 \\
availability mode & 2 \\
\hline Scheduled protected game time & 2 \\
\hline Instructor class notes available on first day of class & 2 \\
\hline A work zone dedicated to their area of study (lab, study space) & 2 \\
\hline $\begin{array}{l}\text { Instructors give clear and reasonable explanations reasons for } \\
\text { assigned homework }\end{array}$ & 2 \\
\hline
\end{tabular}

Note: An additional 14 desired learning supports are not included in this table because they received only one response, and, therefore, are not seen as important to the group. Further research may be needed.

Table 19 shows the participants' top responses when asked about the learning supports they desired that should be made available. The learning supports the videogaming students expressed in their desired interests are categorically different from the learning supports that they were aware of and in place on the campuses. Some university staff might argue that what the students seem to want in terms of desired learning supports are not actually learning supports but rather are the pedagogies of specific professors. These pedagogy requests would require professional development training be implemented for professors to ensure that department curricular and individual courses are designed for the needs and strengths of the $21^{\text {st }}$ century student (P45, transcript, $\mathrm{p}$. 235). The participants do not view learning supports along an organization's division of work lines, as do the university employees. Rather, the areas named by the participants as new learning supports were personal in nature. 
The learning supports shown in Table 19 were functions not current offered on these student campuses, highlighting these items as of high interest and unique to gamers. For example, the video gamers desire support in their learning that provides them with applied learning and problem solving exercises rather than a read and response homework assignment. Participants did not report that this desired type of learning support was a current learning support offering. And while literature could be found that discusses the benefits of applied learning (Bills, 2008; Toyoda \& Kanegae, 2019), the research articles did not mention how this support may be a necessary area of support for some video-gaming learners. Gamers who have spent much time applying their skills and strategies in a game for the purpose of accomplishing tasks, are bringing those patterns of study to their education and indicated they want a framework around their educational experience that provides the application of knowledge to help give purpose to the skills they learn.

Another highlighted example of desired learning support for video-gamers was the reward system. Research discussing motivation and reward systems did not take into consideration learning needs of video-gaming learners whose time and interests and practices have been greatly influenced by digital world. For example, Radhakrishna et, al (2009) referenced the idea that incentives were used to motivate student learning; however, there was no mention of game-like incentives and reward systems, such as point accumulations, leaderboards for tracking rankings, competition badges, collection of loot, the acquisition of power and privilege, and in some cases tangible rewards, such as money (Cruz et al., 2017; Sun, 2017). There was no connection within the incentive research between the video-gamers' practices and how learning supports could mimic 
their world. For example, in games players are rewarded by multiple attempts to complete tasks, which increases their motivation to continue (Partin, 2017; Schmidt \& Shreffler, 2015; Sun, 2017). This form of reward presents a different model than many educational environments. The students expressed a desire for creative ways to schedule and coordinate school work so they did not feel overwhelmed, and could use their free time as they saw fit. These expressed desired academic support ideas, represent tools and exercises found in gameplay, and are the types of supports the students seem to be requesting.

It is apparent to see the gap in learning supports offered by colleges and the ones that are desired by video-gaming students. For example, in the data, though tutors were identified as a resource for learning support more than 30 times, not one of the interviewees admitted to making use of the tutor services. Knowing about the learning supports is not equivalent to using the supports. More research like this study is needed to understand how to better align university learning supports to one of the largest campus demographics, the video-gaming students. From the responses made by the participants, it appears there is room for much more research in the area of learning supports to determine the most effective options for them specifically, since most research is not related to practices that video-gaming students may use in their approach of study. However, in this study, the named desired supports in column three were used to identify the suggested video-gaming learning supports discussed later in Chapter IV.

\subsection{Gamers' Study Practice Approaches}

Participants were asked to describe their study practices in a metaphorical manner by completing the phrase, "My study habits are like..." as shown in Table 20. 
Table 20

How Participants Organize Their Academic Studies

\begin{tabular}{llll}
\hline $\begin{array}{l}\text { How participants } \\
\text { approach study } \\
\text { organization }\end{array}$ & Description & $\begin{array}{l}\text { Responses } \\
(\mathbf{n = 7 8})\end{array}$ & Percent \\
\hline Non-Existent/Poor & $\begin{array}{l}\text { Students had nonexistent or very poor } \\
\text { study habits. }\end{array}$ & 10 & $12.8 \%$ \\
$\begin{array}{l}\text { Inconsistent/ } \\
\text { Mediocre/Chaotic }\end{array}$ & $\begin{array}{l}\text { Students do not plan or organize their } \\
\text { studies in any fashion, but instead they } \\
\text { just work on assignments as they want, } \\
\text { when they want. }\end{array}$ & $48.8 \%$ \\
$\begin{array}{l}\text { Short Bursts of } \\
\text { Concentrated Effort }\end{array}$ & $\begin{array}{l}\text { Students study in short bursts of } \\
\text { energy, and can easily be persuaded to } \\
\text { move from the assigned job to one of } \\
\text { lesser priority. }\end{array}$ & 7 & $8.9 \%$ \\
Responsive & $\begin{array}{l}\text { Students are dependable, but must be } \\
\text { called into action. They give all the } \\
\text { effort they have for a short period of } \\
\text { time. }\end{array}$ & 14 & $17.9 \%$ \\
Planned Consistent & $\begin{array}{l}\text { Students carefully strategize and } \\
\text { calculate methods for studying. }\end{array}$ & \\
\hline
\end{tabular}

A total of 78 responses listed in Appendix F were coded and categorized. Using this list along with the collective thematic coding process, five distinct study practices were developed: Non-Existent/Poor study organization; Inconsistent/Mediocre/Chaotic study organization; Short Bursts of Concentrated Effort study organization; Responsive Attack study organization; and A Planned Consistent study organization.

\subsubsection{Nonexistent/Poor Study Organization}

A portion of the participants (12.8\%) reported they had nonexistent or very poor study practices. The heavy-video-gaming students indicated they simply do no organizing or planning for their studies, explained as "nonexistent" (P8, transcript, p. 263) or 
"pushing a mountain, they get me nowhere" (P18, transcript, p. 263). If these gamers were approaching video games in the same manner, they would be the participants most quickly eliminated from the contest. This same consequence can be observed in academics (Schargel \& Smink, 2014; Stark \& Noel, 2015). For those who will not put in the effort to prepare, they may not last long in the learning environment.

\subsubsection{Inconsistent/Mediocre/Chaotic Study Organization}

The majority of participants (48.8\%) said that they do not plan or organize their studies in any fashion, but instead they just worked on the assignments as they wanted, when they wanted, describing their study practices as inconsistent, mediocre, and at times, chaotic, hence the category name. While these study practices worked in the gamers' favor on occasion, the approach just as often failed them.

A participant stated it this way: “They're good enough for what you want them for, but there's definitely better out there" (P33, transcript, p. 39). These students carry somewhat of a win-some/lose-some attitude about their work, and there is little rhyme or reason to their method of play or study.

Gamers described study skills like this:

"My habits are like a rabbit with ADHD. I am easily distracted from study" (P17, transcript, p. 263);

"A river, one small thing can change the flow of it" (P23, transcript, p. 263);

or a "Dice, sometimes they are good and sometimes they aren't" (P12, transcript, p. 263).

The heavy-video-gaming students treat study much like a game which allows for multiple lives or offers numerous chances to the players. If things do not work out well, 
there will always be a second chance or another opportunity, and players know there will be minimal consequences for the need to try again. This second chance attitude is usually in opposition to formal academic settings. Limited by its schedule, academia only can allow time to take a one-and-done approach for assignments and exams. For example, instructors may give one or two big tests for a course, and do not regularly provide chances to repeat them for improved standing. Heavy-video-gaming students desire the convenient opportunity to repeat assignments in effort to improve their scores with no consequences attached. The gap these two conflicting approaches create what could be a major area of concern in regards to academic performance, and it may serve as a platform of opportunity where new learning support strategies could be developed.

\subsubsection{Short Bursts of Concentrated Effort Organization}

A few of the participants (8.9\%) describe study planning as short bursts of energy. The students may study for 10 to 15 minutes and then feel they have to do something else stating, "I am like a dying light bulb. Sometimes I can study but most of the times I get distracted really easy or just cannot sit in place so get up every five minutes and do something" (P10, transcript, p. 263). These practices mimic a gamer who enjoys games with short-term, achievable levels, or one who is running in and out of conflict. As learners, the gaming students can get to the academic target, but it may take longer, and if they lack any discipline or energy, described as "a cat mostly lazy, with bursts of energy" ( $\mathrm{P} 7$, transcript, p. 262), they can easily be persuaded to move from the assigned job to one of lesser priority. The amount and quality of work that is accomplished is based on the student's mood or energy levels at a given moment. One student noted, "I'm kind of lazy, and need to be in the mood" (P34, transcript, p. 40). 


\subsubsection{Responsive Attack of Study Organization}

Almost 20 percent of participants (17.9\%) had a reactive or responsive attack of approaching, organizing, or planning their studies. These students describe their study practices like gaming practices, where they remain in a defensive mode needing to protect the treasure in a game. The students are dependable, but they must be called into action. When an assignment is announced, the students are then "called into battle" (P25, transcript, p. 262). They may work hard and "sharpen the sword" (P79, transcript, p. 263) before an exam, but then the skills lie dormant until the next exam calls them back into action.

The heavy-video-gaming participants regularly give all the effort they have for a short period of time, hoping this barrage of firepower will eliminate the enemy. The sudden weight of the assignment causes pressure enough that they begin to focus on the task at hand (P20, transcript, p. 262).

In regards to study practices, these participants do not really have a plan of action, but instead when a deadline comes, they respond by finding the time to attack the assignment and complete whatever tasks are needed to "win the prize" (P5, transcript, p. 262). These students respond to the "call of the class," with little preparation, then give it their best efforts in hopes they can accomplish enough to earn a winning grade, "an action of potential, all at once before it's due" (P3, transcript, p. 263).

\subsubsection{Planned Consistent Study Organization}

Some participants (11.6\%) approach their studies in a planned, consistent, attack approach, describing it as a carefully strategized and calculated method for studying, as if playing on a familiar map in a game with a direct plan for reaching the goal (P34, 
transcript, p. 263). These heavy-video-gaming students took an offensive approach to studying, setting aside regular times for homework and studies "like clockwork" (P54, transcript, p. 263). The students carry more than just a reactive attempt of winning; instead, they choose to be proactive and prepared so they can conquer in every battle, in every game, and in every assignment (P72, transcript, p. 263).

\subsection{Types of Heavy-Video-Gaming Students}

In the transcripts on the fourth interrelation of the coding analysis, specifically reading for semantic meaning (Berg \& Lune, 2004; "Sample Size for Qualitative Interviews," 2015) (Chapter III Method in detail), types of heavy-video-gaming students categories began to emerge. The characteristics described are based on the undergraduate participants who have successfully worked through their first semester of college and have learned about studying and study organization. The students have had one semester to have learned something about balancing their gaming and study practices, and they were able to successfully move on in college.

Table 21 lists the five types of heavy-video-gaming students that emerged from the findings and are discussed in greater depths below: supportive colleague, pertinacious problem solver, efficient linear thinker, self-reliant associate, and individualistic with the need for community. 


\section{Table 21}

Types of Heavy-Video-Gaming Students

\begin{tabular}{ll}
$\begin{array}{l}\text { Type of Heavy- } \\
\text { video-gaming } \\
\text { Students }\end{array}$ & Summary Description \\
\hline $\begin{array}{l}\text { Supportive } \\
\text { Colleague }\end{array}$ & $\begin{array}{l}\text { Individual who prefers playing support roles; supporting people } \\
\text { in general, in classes, and in life situations. }\end{array}$ \\
$\begin{array}{l}\text { Pertinacious } \\
\text { Problem Solver }\end{array}$ & $\begin{array}{l}\text { Individual who will persist and repeat skills to show } \\
\text { improvement. This pertinacious behavior keeps occurring until } \\
\text { the person meets with some type of success and fewer } \\
\text { consequences. }\end{array}$ \\
$\begin{array}{l}\text { Efficient Linear } \\
\text { Thinker }\end{array}$ & $\begin{array}{l}\text { Individual spends a lot of time thinking about efficiencies and } \\
\text { logical steps, which translate into finding linear paths to } \\
\text { determine the quickest way to get things done. }\end{array}$ \\
$\begin{array}{l}\text { Self-reliant } \\
\text { Associate }\end{array}$ & $\begin{array}{l}\text { Individual has a general confidence or self-reliance; there is also } \\
\text { a need to associate or work with others. }\end{array}$ \\
$\begin{array}{l}\text { Individualist with } \\
\text { the Need for } \\
\text { Community }\end{array}$ & $\begin{array}{l}\text { Individual spends a great deal of time alone. However, the } \\
\text { student is happy to be invited into small group activities, } \\
\text { making it easier to contribute and converse with others. There is } \\
\text { a desire to be included }\end{array}$ \\
\hline
\end{tabular}

\subsubsection{Supportive Colleague Type}

The supportive colleague type includes the heavy-video-gaming students who prefer playing support roles. Throughout the study, 47 of 93 of the gamers spoke about taking on the support roles within their games and keeping "watch over their fellow players" (P43, transcript, p. 67). Interestingly, these individuals also talked a lot about supporting people in general, in classes, and in life situations. As P86 stated, "I'll put other people's needs beyond what I want to do for fun. But if it doesn't usually call for a 
need and it's a pleasure one way or the other, then I would rather play games" (transcript, p. 133).

This supportive colleague type becomes especially visible when assigned to work with a team. When working alone, these students are quite confident in their own skills. However, when a team is involved, they do not want to let the team down, as seen in this statement: "I don't really need help, but I like to help others" (P43, transcript, p. 40). These students want to be generally helpful to meet the greater purpose, sometimes giving up something personal in order to do so. P68 explains,

When we had assignments in the lab, I usually finished early, but I found out I really liked staying to help others solve their problems.

I got a real sense of reward from helping others (transcript, p. 112).

This type of gamer does not, however, want to necessarily be the initiator or leader of a particular activity or group of people. If someone else initiates the activity, this type of student is willing to support, participate, and join the team (transcript, pp. 41-56).

Once on a team, these students work hard to keep their team from failing, sometimes by default taking on leadership roles, so the team will not fail. Avoidance of failure qualities were evident in participants' responses as shown below:

"We had a group project, and we tried to divide the workload, but it was not going so well. I knew I could write papers, so basically, I did it the hard part and let them handle the rest. I could count on myself, and didn't want our team to fail" (P17, transcript, p. 114).

"I have learned to adapt to new ideas, people and understand what people are doing in a game to get the upper hand for our team" (P1, transcript, p. 159). 
These participants do short-term, rather than long-term planning, and are generally willing to use their strengths and time to support the greater good.

\subsubsection{Pertinacious Problem Solver Type}

When things do not work out, gaming students just expect to persistently try again, or be pertinacious. This repetition action found in games can teach persistence and can lead players to a form of mastery. Players spoke of the number of times they would keep coming back to a challenge in a game in order to "try to get it, and try a different way" (P84, transcript, p. 160).

Students admit that games sometimes "feel like work," but they know if they will persist and repeat, their skills will show improvement $(n=3)$. For this type of individual, this pertinacious behavior keeps occurring until the player meets with some type of success and fewer consequences. When pertinacious heavy-video-gaming students perceive there is a real problem to be solved, they will try repeatedly until a solution is developed $(n=32)$. The downfall for gamers is that they tend to exhibit this characteristic only when the topic is of high interest to them. Repetition is not always applied to every situation, especially one that is not perceived as a viable problem to be solved, such as mundane homework assignments (transcript, p. 178-186). For example, P34 reveals, "I really do not like the boring assignments; the ones where I essentially am just reading the book and regurgitating answers out of it” (transcript, p. 73). P5 states,

If the class is something I really enjoy, I will study harder for that because it's fun to learn more about that kinds of stuff. If it is not interesting, or has a lot of boring homework, I don't work too hard, well I work to get a passing grade (transcript, p. $5)$. 
"I learn best, with hands-on application and demonstrations", says P22 (transcript 77).

These pertinacious problem solving video-gaming student types are do not give up easily and are willing to try until they reach some type of solution. They prefer positive rather than negative consequences.

\subsubsection{Efficient Linear Thinker Type}

Participants spent a lot of time thinking about efficiencies and logical steps, which translate into finding linear paths of the quickest way to get things done. They continually try to improve their reaction time, "quickly out think opponents" and "find the quickest path from A to B” in their games (P33, transcript, p. 48). P77 writes,

I find the shortest path to get to a location or buying the best item to kill the boss.

I have applied those same skills to my academics, so I look for the most efficient way I can prepare for a test. The most efficient way I can remember something. I might not worry about things that might not appear on the test (transcript, p. 164).

P5 stated his need for efficiencies like this:

I hate it when an assignment that should take 30 minutes takes much longer. Sometimes there is just extra stuff that is included that is not needed (transcript, p. 123).

The students are viewing homework as an opponent that needs to be efficiently beaten, rather than lingering and learning from it. In one way these characteristics make these heavy-video-gaming students' great strategists. As P43 put it, "Gaming has provided me a systematic approach to solving problems, finding resources and asking peers for help" 
(transcript, p. 169). The gaming student knows how to break big problems into smaller parts in an efficient manner: "I learned how to accomplish things. I set minor goals. I learned to set more realistic short goals and achieve those rather than trying to set a huge goal" (P88, transcript, p. 170). Part of the efficiency skillset translates to the fact that gamers have learned to absorb a great deal of information quickly. They learn how to pay attention to small details that can be reused in the games. They learn to do things like listen to the surrounding sounds in the games while also communicating to others on the team on their next move (transcript, pp. 159-167).

The players process a lot of data and make many decisions by sorting through a barrage of information quickly. This decision-making method is also how they claim they are handling academic information as well. They are trying to decipher and absorb only the things that will serve the greater purpose, such as being on the next test (transcript, pp. 159-167).

When there is too much noise, details are not clear, facts cannot be absorbed quickly, or there is little immediate reward in the effort, the students may be confused or tend to lose interest, feeling the material is not efficient nor worth their time (transcript, pp. 178-186). A common statement made in the research data was that "if I am not interested in the subject, I do not work too hard. It has to interest me" (P12, transcript, p. 59). However, after absorbing interesting knowledge and working to understand it, three video-gaming participants commented that they rarely forgot it and believed they had ability to easily recall the knowledge learned (P67, P72, P84, transcript, p. 50). These comments support the idea that many video-gamers use active listening as a study habit, as discussed previously in Chapter IV. 
While efficiencies can be effective in some settings, in others the quickest approaches to the end are not the most effective methods. This discrepancy between efficiency and effectiveness is seen regularly in students and their work ethic. They will get the work done as fast as possible at the risk of quality (transcript, pp. 112-117). Earlier it was stated that individual's study in this "efficient" way when they responsively attack their work, or study in short bursts (transcript, pp. 58-64). This quantity-versus-quality tension is sometimes a factor in the academic world, and it will be something students will face for the rest of their life. The challenge, then, is how schools can capture and use the strengths the efficient thinkers bring to the university, while still encouraging and supporting these same students to produce the most effective work they can.

These efficient linear thinking type of video-gaming students are often looking for the most efficient way to accomplish the task. This means they are actively thinking and want work expectations to be clear, concise, and accomplishable.

\subsubsection{Self-Reliant Associate Type}

Participants display a general confidence or self-reliance about themselves. P45 stated "I can do it" (transcript, p. 41). Firstly, they have been performing in front of a stage of peers in multiplayer games gaining sense of confidence about their skills in front of others, and secondly, the gamers are used to trying independently to improve personal skills in the games. While heavy-video-gaming students are practicing self-reliance, they have also learned there is a need to associate or work with others, especially as teams on the games. The connection with others tends to reflect a relationship that could be found between work associates: separate, and yet part of the larger business team. 
Gamers regularly stated they liked their independent time, and that the best way for a majority of them to learn something new was to "let me do it" (P23, transcript, p. 63) or "recreate it" (P55, transcript, p. 62) for themselves. These students like to make use of visuals, videos, and demonstrations (transcript, pp. 65-96) as references so they could be introduced to a skill and then go back and reteach themselves or "do it" themselves (P23, transcript, p. 63).

But while they want to do it themselves, they also like it when someone can "show them" how to do things (P44, transcript, p. 64), which reflects an associate mentality of learning. This "show-me" mentality might explain the popularity of video training, for all people, but especially this group of gaming students. The one-to-one mentorship received, the repetitive nature, the visual aspect, and the fact that video methods can be manipulated to help students absorb content quickly and efficiently comprise exactly the form of learning most of these gamer students say they prefer (transcript, pp.65-96).

The relationship that is developed by associating around common experiences, such as games, is one the self-reliant individual can learn to enjoy, as they receive many win-win benefits from the association. Though these self-reliant gamer types are independent, comments highlighted how gaming had really helped them learn to "come out of their shell” (P35, transcript, p. 147), communicate with others, and work on a team (transcript, pp. 142-146).

The heavy-video-gaming students were surprised that working with a team could get so much more accomplished, and, in fact, some tasks could not be done without the association of the team (transcript, pp. 178-186). Because gaming is a global 
phenomenon, it is possible to be playing and associating with a diverse group of people ,mixing ages, culture, language, and ability (transcript, pp. 159-167). The participants mentioned how much they learned "on teams," "working with diverse people," and "how this had helped them to be more patient as they waited for others to improve, or had to hear their ideas for a game attack" (P45, transcript, pp. 159-167).

The self-reliant associate type of video-gaming student desires to accomplish tasks independently that can contribute to a larger team effort. They gain self-confidence by conquering tasks on their own, but really enjoy sharing that work with others.

\subsubsection{Individualist with the Need for Community Type}

The heavy-video-gaming student participants, though mostly individually introverts (transcript, pp. 8-12), still enjoyed belonging to a community (transcript, pp. 116-119) and having an easy platform whereby they could make friends and social comrades (transcript, pp.142-146). Transcripts indicate that gaming makes conversing easy as everyone there is having a common experience allowing players to have a common conversation.

P34 said,

I like gaming and getting together with my guy friends. It gives us something to do. We never have to fight or plan something, games are just there, we all jump on and have something to do and talk about. We don't have to think about it (transcript, p. 143).

Gamers admitted that communicating with others in general conversation was not always easy, and they can have a difficult time initiating conversations or activities. They do not regularly enjoy being the center of attention, and thus, it becomes difficult to put 
themselves into social settings and feel they have things to say, and thus spend a lot of time alone. P72 explained it like this:

I have problems with thinking that I have something valuable to contribute to the group conversations. I know I am an important part of the team, and what I want to say is important, but I struggle with weather others will want to hear what I have to say (transcript, p. 208).

The gamers will try to get involved in a few extracurriculars on campus.

However, the video-gamers protect their free time and try not let these others experiences overrun their commitments to the gaming communities (transcript, pp. 204-207). Gaming students expressed that while they sometimes enjoyed other extracurricular activities, the events were taxing because they dictated time involvement, demanded more effort to communicate, and were not sporadic like game playing (transcript, pp. 204-207). A person could not just squeeze an extracurricular activity into any space in the schedule; instead, it demanded planning and additional effort to pursue, and thus games were more relaxing (P67, transcript, p. 206).

Gamers felt that while extracurricular activities, such as the debate club, criminal justice club, intramurals, and others were beneficial to them, nearly all participants indicated they would prefer to be spending the time playing games with friends online, as game play provided them with rest and comfortable community (transcript, pp. 204-207). So, while gamers want to be independent, they are drawn to the social interaction games provide. 
The individualist with a need for community video-gaming type of students like to work alone, but want a community to which they can be attached. They do not want the community to demand much, but the students need to know they belong.

\subsection{Results from the SSHA}

As the study progressed, the SSHA questionnaire did not become as important a tool as originally perceived, though it was still was a helpful support. The survey data was collected in part from 56 of the 93 heavy-video-gaming students, with only 30 completing it in its entirety. As was discussed earlier in Chapter II's Literature section, the 100-question questionnaire was based on a five-point Likert scale measuring study habits categories of delay avoidance ( $\mathrm{DA}=125$ points), and work methods $(\mathrm{WM}=125$ points), which produces total study habits score ( $\mathrm{DA}+\mathrm{WM}=250$ points); followed by attitude categories of teacher approval ( $\mathrm{TA}=125$ points $)$, and educational acceptance $(\mathrm{EA}=125$ points $)$; which produces a total score for study (learning) attitudes $(\mathrm{TA}+\mathrm{EA}$ $=250$ points), and finally a combined study orientation category (500 points) which is the total score of the questionnaire (Brown \& Holtzman, 1967). Table 22 shows the mean scores for each group of SSHA question types, with a total score, percent, standard deviation, and percentile. 


\section{Table 22}

SSHA Scores

\begin{tabular}{|c|c|c|c|c|c|c|}
\hline & $\begin{array}{l}\text { Score in } \\
\text { Points }\end{array}$ & $\begin{array}{l}n= \\
\text { Number }\end{array}$ & $\begin{array}{l}\text { Mean } \\
\text { Score }\end{array}$ & $\begin{array}{l}\text { Standard } \\
\text { Deviation }\end{array}$ & $\begin{array}{l}\text { Percent } \\
\text { of total }\end{array}$ & Percentile \\
\hline $\begin{array}{l}\text { Total Study } \\
\text { Habits }(\mathrm{SH}) \\
(\mathrm{DA}+\mathrm{WM})\end{array}$ & 250 & 30 & 137.20 & 17.69 & $54.8 \%$ & $50^{\text {th }}$ \\
\hline $\begin{array}{l}\text { Delay } \\
\text { Avoidance } \\
\text { (DA) }\end{array}$ & 125 & 30 & 73.06 & 7.54 & $58.4 \%$ & $50^{\text {th }}$ \\
\hline $\begin{array}{l}\text { Work } \\
\text { Methods } \\
(\text { WM) }\end{array}$ & 125 & 30 & 64.13 & 13.14 & $51.3 \%$ & $50^{\text {th }}$ \\
\hline $\begin{array}{l}\text { Study } \\
\text { Attitudes } \\
\text { (SA) } \\
(\mathrm{TA}+\mathrm{EA})\end{array}$ & 250 & 30 & 116.75 & 21.85 & $46.7 \%$ & $60^{\text {th }}$ \\
\hline $\begin{array}{l}\text { Teacher } \\
\text { Approval } \\
\text { (TA) }\end{array}$ & 125 & 30 & 54.62 & 12.77 & $43.6 \%$ & $60^{\text {th }}$ \\
\hline $\begin{array}{l}\text { Educational } \\
\text { Acceptance } \\
\text { (EA) }\end{array}$ & 125 & 30 & 62.13 & 10.03 & $49.7 \%$ & $60^{\text {th }}$ \\
\hline $\begin{array}{l}\text { Study } \\
\text { Orientation } \\
(\mathrm{SO}) \\
(\mathrm{DA}+\mathrm{WM}) \\
+(\mathrm{TA}+\mathrm{EA})\end{array}$ & 500 & 30 & 253.95 & 35.67 & $50.7 \%$ & $60^{\text {th }}$ \\
\hline
\end{tabular}

According to the SSHA data, the heavy-video-gaming students would be considered midrange students in nearly every category. The total SH score, which is the combined categories of DA and WM, was 137.20 average out of 250 total points. This percentage of 54.8 percent places the students within the $50^{\text {th }}$ percentile. The DA score may support 
the idea that heavy-video-gaming students avoid delaying their work about 58.4 percent of the time but can succumb to distractions. The WM score indicates students have a middle-of-the-road work methods skill set that may help them about 51.3\%, but that leaves a lot of room for work that does not get completed.

The second major grouping was the SA, which had a mean score of 116.75 out 250. The 46.7 percent it posits, however, is a higher $60^{\text {th }}$ percentile. The overall TA score of 43.6 percent and the EA of 49.7 percent were a bit lower overall. The students have less confidence in the instructors and learning systems than they do in their own abilities. 


\section{Chapter V: Discussion}

Video-gaming students are filling universities at a fast-growing rate and are making up one of the largest college populations on campuses. Literature, as discussed in Chapter 2, reveals mixed messages about how video-gaming impacts undergraduate students. Literature topics ranged from eSports teams to toxic behavior, but failed to provide research about the undergraduate video-gaming student as a learner, their study practices, and ways to deliver appropriate learning supports to this large campus population. This discussion chapter adds to the literature field of knowledge by providing research that adds analyzed data pertaining to the video-gaming students as learners by understanding the gaming and study practices they are using for academic learning, in order to better understand the students and establish whether there is a need to develop new learning supports for this population. New knowledge from this research is summarized in the following sections.

\subsection{Surprises and Highlights - New Knowledge Created}

In this section, I selected some surprising findings that indicate a-ha moments. Table 23 gives an overview of the highlights; then, I will describe them below the table. 


\section{Table 23}

Findings: Surprises and Highlights

\section{Findings from this Study (cf. Sections 4.1 to 4.4):}

Surprises

- Huge contrast between game time and studying time

- Gaming as a mental break from studying

- Huge commitment to the gaming community

- Educational experiences should mimic gamified environments

- Gaming students desire a reward system for their studying efforts that mimics their gaming experience

\section{Highlighted: New Categorical Types Derived this Study (cf. Sections 4.5 \& 4.6)}

- Five study practice approaches of heavy-video gaming students

- Five Types of Heavy-Video-Gaming Students

\section{Highlighted: Development of Learning Supports (cf. Section 4.4)}

- Development of two new learning support concepts

- Activity theory lens shows a focus on the person level and neglects the system level

The first surprise indicates huge contrasts in the time the video-gaming students spent playing games versus the time they spent studying. Participants in this study were playing games nearly twice the amount of time they spent on their academic studies (cf. Section 4.2).

The second surprise in the chart was that video-gaming students are playing video games for the mental break it provides them from their studies. Terms such as "winding down", "relaxing", and "escape from homework" (transcripts, pp. 245-247) were used by participants to describe their reason for playing games. Along with the idea of a mental break, gaming provided the students consistent social interactions, whether just a quick hello to a friend or a place to ask questions (cf. Section 4.2). These social interactions led to specific gaming communities being formed.

The third a-ha moment was the huge commitment of the students to their gaming community of choice. This community is a place where they develop friendships, 
maintain a sense of belonging, hone skills, and find enjoyment (cf. Section 4.2). The data indicated that the video-gamers are very protective of the time they meet and play with the online community group, often spending two to three hours at a time with people there for multiple nights in a week. Gamers in the study mentioned more than 10 times they were willing to dedicate the entire weekend to online game play with their community. Participants shared that the gaming communities specifically provide them the competition desired and a place where they can apply their knowledge and skills in meaningful ways, receive continual feedback, have multiple attempts at success, and are rewarded in tangible ways, all within an environment where they can socially connect (cf. Section 4.2). These results align with other research related to gamers (Abrams, 2010; Dolar, 2018; Hewett, 2016; Jyvaeskylae, 2007; Kauweloa \& Winter, 2016; Zhao et al., 2020).

A fourth surprise noted in this study indicates that heavy-video-gaming students want their educational experience to have features that assimilate the games they play (transcripts, pp. 100 - 113). Since gaming provides a framework in which they enjoy performing and excelling, the heavy-video gamers have desires that their educational experience could provide a similar experience (transcripts p. 100-113). The supports the heavy-gamers named as desires for learning aid echo the elements that are found in games: socialization, mentoring, application of skills, competition, multiple attempts to reach success, resources, continual feedback, and rewards (Arockiyasamy et al., 2016; Cruz et al., 2017; Oates \& Brookey, 2014; Rusk et al., 2020; Seo \& Jung, 2016). The academic study organizational approaches of the video-gaming students regularly mimic the manner in which they play games. For example, some video-gaming players work to 
make complex strategy plans for striving to win the games, while others take a more "lackadaisical” approach (Colder Carras et al., 2018) that means lacking spirit, liveliness, or interest; languid. Both are reflected in study practices.

The final surprise identified was that video-gaming students desire a reward system for their studying efforts that mimics their gaming experience. Gaming provides a system by where the players earn points and collect valuable loot throughout the game experience (Cruz et al., 2017). Within the game there are ongoing opportunities to practice and re-practice skills in order to improve, or level-up, to a new challenge (Seo \& Jung, 2016). Each element in the game is carefully designed to engage and reward the player in some manner (Yilmaz-Soylu \& Bruning, 2016). This study data indicates videogamers have a desire to see some of these same types of features developed around their educational experience. The constant feedback, reward accumulation, and social leader board announcements are a far different world from academia. In educational experiences, students will likely experience slow feedback, grade reward accumulation once a semester, and regulations that prohibit student grade-ranking comparisons (Dolar, 2018; Ryan et al., 2019). The gamer's desire is for an educational reward system that provides instant feedback, provides a way to see one's self improving, and understand where one ranks with peers in the larger setting.

Other highlights in the study include new views of the video-gaming student and how they approach the organization of their study practices discussed in more detail in Section 5.4. Also emerging from the data are five types of gaming students. Gamers enjoy taking on particular roles in their games, and this is reflected in the way these students are relating to their academic communities. For example, video-gaming students 
show the need to have purposeful roles in their interaction with the community. Some gamers claim the role of supporter, while others show the need to be a conqueror. These roles are exhibited not only in their gaming, but as the data indicates, are characteristics that are visible in their studies as well. This is discussed further in Section 5.5. Finally, this study developed learning supports through the view of the activity theory model (Fig. 18).

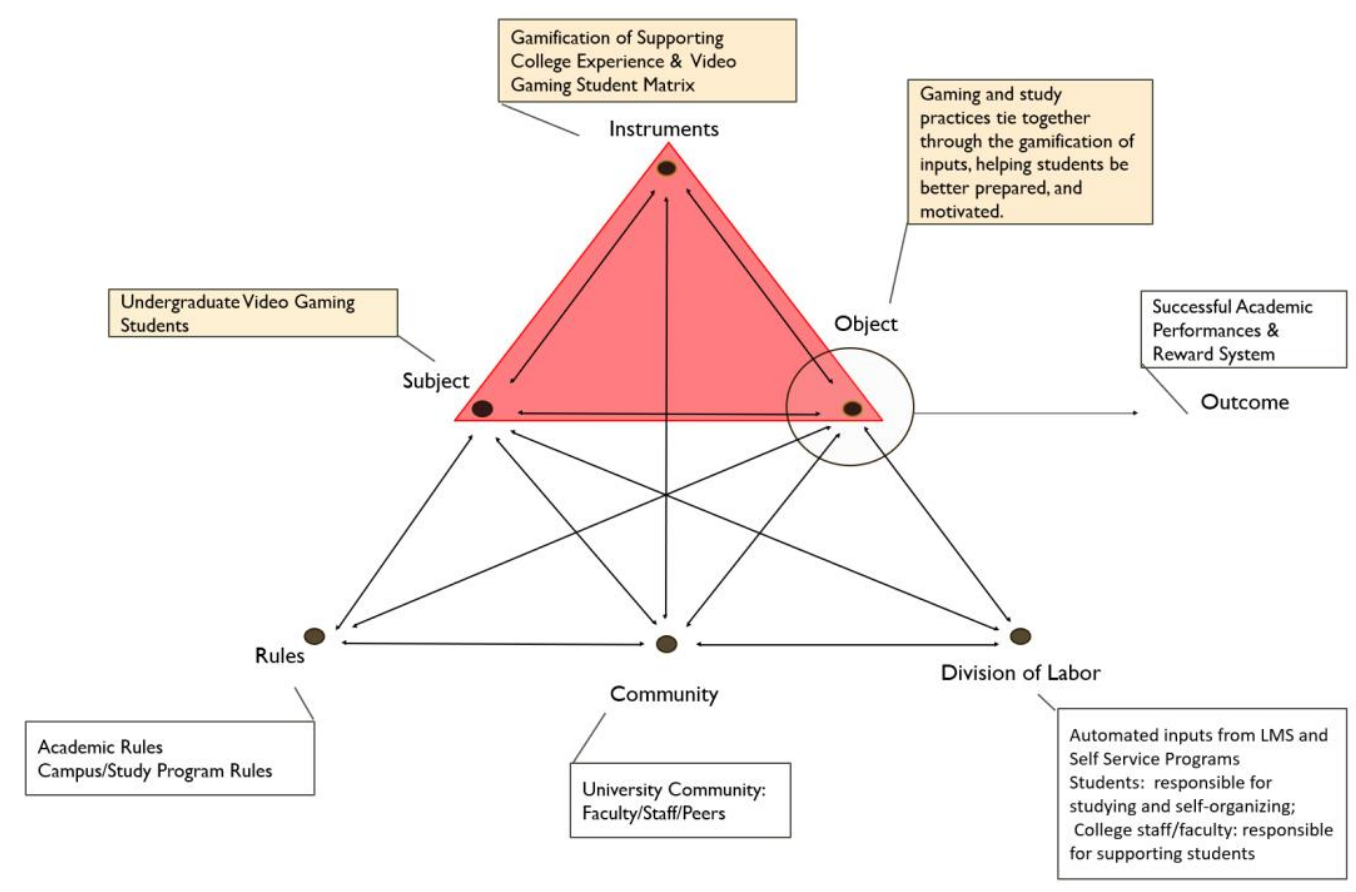

\section{Figure 18}

\section{Activity Theory Model Adapted for the Proposed Learning Supports in this Study}

The activity theory applied in this study and shown in Figure 18 indicates the way new instruments (the proposed learning supports) could be integrated into the system of study practices (object) for video-gaming students (subject). Using activity theory as a guide, this study indicates that gaming students get some support from the higher educational institutions; however, these supports focus on the "student level". Examining the learning supports using the activity theory model clearly indicates that the broad 
system level is left out such as "academic rule policies", the university "community", and the "existing technologies" The emphasis is indicated by the red colored triangle.

However, it is important to note that in order for any of the learning supports to work effectively, the bottom dots (rules, community, and division of labor) would need to be considered and integrated. The learning support systems have not taken into account the broader scope in which they can offer support to students. It indicates that current methods for viewing and establishing learning supports for the video gamers leaves out the broader system level components, such as academic rules and policies, which help the student with organization and time management; the university community, which addresses social needs these students express; and the integration of existing technologies, which can serve to automate processes and make resources easily accessible. Developing learning supports to address the entire model is a new approach. In summary, the results of my study indicate that the application of the activity theory to gaming students shows the gap in learning supports. Current learning supports that exist or were mentioned by the participants focus on the "person level" and neglect the "system level", which include the three lower elements of rules, community, and division of labor. This theory provides a framework on which all elements of this study can find a place of significance.

\subsection{Heavy-Video-Gaming Students and Their Gaming Practices}

The results show that the traditional gaming student is male. Games have been playing a major role in the lives of the overwhelming-male gaming participants - the majority started to play at age twelve or younger (cf. Section 4.2). Participants had already played for more years than they intended to be in college, and they have every 
intention of playing into their adult life (P90, transcript, p. 2). They have invested large amounts of money in games and equipment and spent time building social communities around the games (cf. Section 4.2). These investments are not things that study participants are willing to give up, especially to a seemingly meaningless school assignment (Kahu et al., 2017; Pope, 2017).

The results also indicate that their gaming practices include a number of skills like quick-response times, problem solving, decision making, and information consumption. These are skills gamers have been honing since the age of 12 , meaning these gaming and thinking patterns are deeply engrained, and likely not going away (cf. Section 4.2). However, as seen in the results Section 4.2, when the students come to university, the skills they that they need are different, and it is often difficult for the gaming practices to fit well with academia. For example, eight participants (gaming students) said it took nearly a full semester in college before they learned to adjust their schedules to maintain some sense of balance between game-playing and study (P43, transcript, p. 2). This result confirms other studies highlighting the importance of personal organization, which includes practices such time management, set up of study spaces, and dedicated study times (DuPaul et al., 2017; Samsuri et al., 2019; Shim \& Ryan, 2012).

Another set of results indicate that students gaming serves as a 'mental break'. For example, P12 explained that his game play during the weekdays helped him to "clear his mind and relax" (P12, transcript, p. 263). Participant 23 did not feel so "alone" in work (transcript, p. 264) when having a way to connect with others and ask questions. Three other participants indicated it was relaxing just to talk with friends (transcript, pp. 263264). These results go along with other writings, such as expressed by Beattie et al. 
(2019) that social components in general are relevant for thriving in school. The data also gives insight to the way the participants view the school schedule. The video-gamers will give up a few hours of their game time and "go to work", such as school, for the week (cf. Section 4.2), but are protective of their weekend game play. Game playing during the week did not often keep gamers from meeting their scheduled appointments (transcript, pp. 263-264), such as attending a class (Credé et al., 2010).

The participant gamers also expressed the need for finding a balance between gaming and studying. It helps the video-gaming students to find the balance when they have experiences outside of games (P29, transcript, p.32). Learning supports can, therefore, start with giving those students access to 'outside gaming experiences', which has been confirmed other works, such as Tham et.al (2020) and Twenge (2017). For example, as study participants were involved in activities that involved helping others, going places, learning by experience or making a monetary reward, the study participants were willing lay aside some game play time and work to balance their schedule to include both gaming and outside activities (transcript, p. 176).

Furthermore, results indicate that the participants found great satisfaction in solving gaming problems and especially enjoyed strategically conquering their foes with the help of a team (Bear, 2019; Goltz et al., 2008; Seo \& Jung, 2016). The gamers were willing to invest two to four hours to learn how to overcome an issue they faced in the game (P67, transcript , p. 146). They know how to research the issues as they watched videos, studied the issues, and repeatedly practiced until the issue was overcome (P84, transcript, p. 160). This result is important as it may help to develop exciting learning supports for the gaming student, such as options to repeat homework for improved 
outcomes, or leaderboards that show how they are accomplishing tasks as compared to their friends.

\subsection{Heavy-Video-Gaming Students' Study Attitudes and Practices}

The participants had been through one semester or more of college. They indicated that their personal study practices had greatly improved since when they entered university. One gaming student described he had to learn to improve his study habits "the hard way and take some hard knocks to my GPA" (P24, transcript p. 221). Other gaming student participants indicated that they did not realize how much study time would be required of them when first coming to college, and had to learn to balance time better (transcript, pp 221-224). Now, after one semester or more in the college, they expressed how they approached the study practice in a different way, which can be summarized as follows.

1. The video-gaming students view classroom attendance as the most efficient way to absorb information; however, homework is postponed (procrastinated) until the due date.

2. They prefer gamified content and study experiences to mimic real-world job or work environments.

3. They are socially engaged.

4. They prefer the creation of a relationship with the instructor or peers.

5. They are not afraid of hard work; they enjoy solving challenging problems that have a purpose.

6. They suggest integrating gamified learning rewards to accumulate for study efforts. 
7. They prefer online courses because those courses can be done at their own pace, but only if they are equipped with easy-to-follow instructions.

Overall, the study practices that the video-gaming students brought to college needed to be further developed in order to become college thrivers rather than divers as Beatie et al. (2019) described. Thrivers are successful students and meeting their own study expectations in a class, while divers are students who struggle (Beattie et al., 2019). The following sections give details about the items listed.

\section{The video-gaming student views classroom attendance as the most efficient} way to absorb information; however, homework is postponed (procrastinated) until the due date: The study results concerning the attendance of class aligns with current literature that class attendance aids academic performance (Credé et al., 2010). They believe attending class is important and that physically going to class is the most efficient way to absorb information (P77, transcript, p. 64). Participants carried a sense of confidence to their studies, expressing a belief that they are intelligent and do not have to work very hard to understand material (cf. Section 4.1), so going to class was the best approach to easily get the needed information (Casey, 2012; Whelan et al., 2016). While in class, they reported that they listen actively to learn class expectations (c.f. Section 4.3.2 (Barr, 2018; Nonis \& Hudson, 2010) and take a few notes (P43, transcript, p. 27). When the assignments were given as homework (Aquino, 2011; Reitman et al., 2020; Wagner et al., 2008), the participants say they tend to procrastinate until very close to the announced due date (P21, transcript, p. 182). Participants could still be found skipping classes for the following reasons: if they felt the lecture was boring (cf. Section 4.3.2; transcript, p. 27-29), if it was basic work they could do on their own (P23, transcript, p. 
63 (Franz et al., 2012; Goette et al., 2019), if they had other classwork to complete (Credé et al., 2010), or if they were ill (Blerkom, 1992; Credé et al., 2010; Gump, 2005).

The video-gaming student prefers gamified content and study experiences to mimic real-world job or work environments: Video-gaming participants said they more easily remembered classroom lessons when the content interested them (cf. Section 4.4), contained a demonstration or discussion, or used a form of "edutainment" or gamification (Davis et al., 2018; Goehle \& Wagaman, 2016). The participants reported that they appreciate applying the presented content in a meaningful way as quickly as possible after it is taught (P46, transcript, p. 63). They say that they understand that homework provides them with a form of such practice (P73, transcript, p. 260), but students often indicate standard forms of homework did not provide that meaningful experience (Akkara, 2019; Chow, 2015; Fish, 2015; Walker et al., 2016). When an assignment can be given that mimics the real work application or can be completed in an environment that imitates a real-world workplace (P1, transcript, p. 241; P47, transcript, p. 74), these would booster the video-gaming students motivation for studying (Beard, 2012, 2012; Blackmore et al., 2010).

The video-gaming student is socially engaged: The participants (transcript, $p$. 175) perceive their gaming time as a welcomed, relaxing, positive extracurricular activity of choice, a means by which they connect with friends, and do not feel it interfered with their overall school responsibilities (Hatmaker, 2017; Jenny et al., 2017, 2018; Sparx, 2017). The students even acknowledged that while their game playing was a waste of time, but felt they kept up with their academics and believed the social aspect of gaming was beneficial in enhancing their face-to-face interactions in school (Latif et al., 2017). 
Social engagement for video-gaming students is also a consistent theme in the literature (Eklund \& Roman, 2019; Myers, 2019). Video-gaming students found these connections led to good friendships and stronger school experiences (P77, transcript, p. 98).

\section{The video-gaming student prefers the creation of a relationship with the}

instructor or peers: Video-gaming participants expressed the importance to build a relationship with the professor and peers that is easily fostered (cf. Section 4.3.1). Even though as a group the gamer participants are introverts (transcript, pp. 116-119), they do not wish to truly be alone (Blackmore et al., 2010; Popescu \& Ghita, 2013). Unlike extroverts, introverts recharge in their alone time, but they still have a desire for social interaction (P34, transcript, p. 143), and while they are not usually the initiators of the social activity, such as a study group or fun gathering, they are regularly willing participants (Chiu \& Cheng, 2017; Seo \& Jung, 2016).

Video-gaming students said they prefer to do repetitive homework online (cf. Section 4.6.5), but when working on a major project they like working in a class setting, a lab, or with a team and resources nearby (Carter et al., 2016; Goltz et al., 2008; Nonis \& Hudson, 2010). Providing spaces and opportunities where fostering relationships is comfortable and natural for these students could be critical for their academic performance (Devilly et al., 2017; Short \& Weidner, 2019).

The video-gaming student is not afraid of hard work: Gamers enjoy solving challenging problems that have a purpose. Participants said that they are not afraid of challenges or hard work (cf. Section 4.2). Participants like taking a challenge to win a battle, especially if it is advancing to something bigger (Beltrami, 2016). Moving the students toward a bigger career goal by tying small meaningful homework assignments 
(P65, transcript, p. 69) together would be more likely to motivate them (Kuncel et al., 2004; Nguyen, 2017). For video-gaming study participants, a major connection between motivation and going to college is gaining vocational knowledge and practice in preparation for a "good" and "high-paying" job (P 14, transcript, p 257). Perhaps this practical viewpoint that college is equivalent to a good job is a reality for all college students, but it is particularly so for these video-gaming student participants. Implications are that colleges may want to demonstrate that their programs provide a way for students to get practical training, preferably through paid, meaningful internships (Hogan et al., 2013; Nguyen, 2017).

\section{The video-gaming student suggests integrating gamified learning rewards to}

accumulate for study efforts: This study shows that heavy-video-gaming students invest almost twice the time in gaming as they are studying (Ashton, 2017; Nonis \& Hudson, 2010; Triberti et al., 2018; Yao_, 2019). Their “love for playing" (cf. Section 4.2) is regularly driven by the rewarding extrinsic outcomes which they receive from investing in the game, whether social, financial, or personal (as in the personal relaxation they acquire) (Schmidt \& Shreffler, 2015). Participants reported they like watching their gaming rewards build (Morris, 2019; Shim \& Ryan, 2012; Wingfield, 2014). This characteristic of acquiring rewards in a game can transfer directly to student study practices (transcript, pp. 159-167). For example, students know the importance of study, but find they are not often motivated to do so, and thus need to reward themselves in order to accomplish the work (P36, transcript, p. 156). Adding gamified elements into the study program to gain rewards as they study may help the video-gaming student alter their own study behaviors (Başaran, 2015; Manero et al., 2017). Participants said they 
desire an academic system that is more engaging and rewards them for the time and effort they invest in the studying (transcript, p. 159-167). Finding meaningful rewards, such as receiving tangible rewards, such as points toward scholarship dollars (transcript, p. 156) for completing academic work, or following a point leaderboard creating a sensation of competition could be more engaging reward systems for these students (Cruz et al., 2017; Schaeperkoetter et al., 2017). The current grading system does not tend to motivate them in the same manner (cf. Section 4.3.1), leaving open the possibilities for developing a new technology enhanced learning support system (Schmidt \& Shreffler, 2015; Shim \& Ryan, 2012; Sun, 2017). Using technology to gamify a learning support system could produce a new product which utilizes many of the game features that the students are already familiar with and enjoy (Cruz et al., 2017), such as instant feedback, leader boards, and reward collections (transcript, p. 159-167). The concept of such a system is explained further in this thesis (cf. Section 5.5).

The video-gaming student prefers online courses, but only if they are equipped with easy-to-follow instructions, because those courses can be done at their own pace: Learning at their own pace is relevant for this group because it mimics their gaming practices; they play in their own pace. The results indicate the video-gaming participants were satisfied with online classes (transcripts p. 38-40). They felt they could easily read and follow the directions on their own, not really needing the instructors' guidance (P88, transcript, p. 37). This supports literature stating video-gaming participants like to explore their own passions (Guilmette et al., 2019). Participants felt that it made a lot of sense to choose these online options for their less-interesting courses, giving them a sense of freedom to do homework when it suited them, and thus feeding 
their procrastination practices (P42, transcript. P. 176). Scheduling online courses gives more control over their free time, which they tend to preserve for gaming.

\subsection{New Research Knowledge: How Heavy-Video-Gaming Students Organize Their Studies and Implications for Learning Supports}

In this section, the new research knowledge gained in this study about how videogaming participants organize their studies is described, along with implications for learning supports. The implications are supported by the data discussed previously in section 4.4, 4.5 and 4.6. The study groups video-gaming students as having one of five study organization approaches: from a non-existing or poor study organization to a consistently planned approach (Results in Chapter 4). This is a more nuanced and differentiated set of knowledge than Beattie's (2019) thrivers and drivers who distinguish students in only two types. Based on these five study organization approaches, learning supports can be developed.

In Table 24, the study practices are aligned with possible technology-enhanced learning supports that can be used to address specific needs of the students. While this is not an exhaustive list of practical methods, it does provide a broad insight into the type of supports that would be beneficial for these students. 
Table 24

Five Study Organization Approaches and the Potential Digital Learning Supports

\begin{tabular}{|c|c|c|c|}
\hline $\begin{array}{l}\text { Video- } \\
\text { gaming } \\
\text { Study } \\
\text { Approach } \\
\text { (Themes) } \\
\end{array}$ & Study Practice & $\begin{array}{l}\text { Associated } \\
\text { Learning Supports }\end{array}$ & Practical Suggestions \\
\hline $\begin{array}{l}\text { Nonexistent/ } \\
\text { Poor Study } \\
\text { Organization }\end{array}$ & $\begin{array}{l}\text { Does not exert effort to } \\
\text { study; either not } \\
\text { interested or too self- } \\
\text { confident (cf. Section } \\
4.5 .1 \text { ) }\end{array}$ & $\begin{array}{l}\text { Offer assignments } \\
\text { with real life } \\
\text { applications and } \\
\text { reason to study; } \\
\text { create a reward } \\
\text { system for study - } \\
\text { other than grades } \\
\text { (cf. Section 4.4) }\end{array}$ & $\begin{array}{l}\text { Use a tangible digital } \\
\text { reward system, such as } \\
\text { earning scholarship with } \\
\text { frequent online feedback; } \\
\text { give assignments that } \\
\text { resemble life situations }\end{array}$ \\
\hline $\begin{array}{l}\text { Inconsistent/ } \\
\text { Mediocre/ } \\
\text { Chaotic } \\
\text { Approach }\end{array}$ & $\begin{array}{l}\text { Disorganized; does very } \\
\text { little preparation; attend } \\
\text { class and study by } \\
\text { listening; do best with } \\
\text { demonstrations (cf. } \\
\text { Section 4.5.2) }\end{array}$ & $\begin{array}{l}\text { Alter course } \\
\text { schedules so all } \\
\text { classes have } \\
\text { collaborative lab } \\
\text { hours (cf. Section } \\
\text { 4.4) }\end{array}$ & $\begin{array}{l}\text { One-month classes with } \\
\text { four-hour lecture, } \\
\text { followed by four-hour } \\
\text { lab; Online collaborative } \\
\text { lab }\end{array}$ \\
\hline $\begin{array}{l}\text { Short Bursts } \\
\text { of } \\
\text { Concentrated } \\
\text { Effort } \\
\text { Approach }\end{array}$ & $\begin{array}{l}\text { Studies in short bursts of } \\
\text { time; focuses for only } \\
\text { about } 20 \text { minutes; } \\
\text { method finds both } \\
\text { success and distraction } \\
\text { (cf. Section 4.5.3) }\end{array}$ & $\begin{array}{l}\text { Break long } \\
\text { assignments into } \\
\text { online-gamified } \\
\text { parts (chunking); } \\
\text { break lectures into } \\
\text { online-gamified } \\
\text { parts (cf. Section } \\
4.4 \text { ) }\end{array}$ & $\begin{array}{l}\text { Provide lots of short } \\
\text { video trainings; Provide } \\
\text { short online examples } \\
\text { that lead to a larger result }\end{array}$ \\
\hline $\begin{array}{l}\text { Responsive } \\
\text { Attack } \\
\text { Approach }\end{array}$ & $\begin{array}{l}\text { Tries to mentally } \\
\text { remember class } \\
\text { assignments, but forgets; } \\
\text { needs reminders; } \\
\text { distractible; when in } \\
\text { attack mode, can absorb } \\
\text { a lot of information } \\
\text { quickly (cf. Section } \\
\text { 4.5.4) }\end{array}$ & $\begin{array}{l}\text { Give regular } \\
\text { reminders online } \\
\text { via email or social } \\
\text { media; provide } \\
\text { digital enhanced lab } \\
\text { spaces that provide } \\
\text { personal space } \\
\text { mimicking a work } \\
\text { environment (cf. } \\
\text { Section 4.4) }\end{array}$ & $\begin{array}{l}\text { Use specific due dates } \\
\text { (e.g., always Mondays } \\
\text { 4am); Require courses to } \\
\text { use LMS or digital } \\
\text { material listing } \\
\text { assignments and dates } \\
\text { online }\end{array}$ \\
\hline
\end{tabular}


Table 24 (continued)

\begin{tabular}{|c|c|c|c|}
\hline $\begin{array}{l}\text { Planned } \\
\text { Consistent } \\
\text { Attack } \\
\text { Approach }\end{array}$ & $\begin{array}{l}\text { Provides adequate time } \\
\text { to prepare; accomplishes } \\
\text { every assignment; does } \\
\text { more than is required; } \\
\text { pursues of their own } \\
\text { personal improvement } \\
\text { (cf. Section } 4.5 .5 \text { ) }\end{array}$ & $\begin{array}{l}\text { Provide well } \\
\text { organized digital } \\
\text { enhanced (or } \\
\text { completely online) } \\
\text { courses and } \\
\text { resources that } \\
\text { include digital } \\
\text { game-based } \\
\text { learning elements } \\
\text { (cf. Section 4.4) }\end{array}$ & $\begin{array}{l}\text { Gamify the use of } \\
\text { calendared due dates and } \\
\text { detailed syllabus; Provide } \\
\text { online or digital gamified } \\
\text { ways to expand } \\
\text { assignments and let the } \\
\text { students share their } \\
\text { achievements } \\
\text { ("rewards") }\end{array}$ \\
\hline
\end{tabular}

Note. The possible digital learning supports listings are not exhaustive. As learning supports are identified, it may be necessary to distinguish curricular and pedagogical design at the departmental and instructor level from the campus-level supports.

\subsubsection{Learning Supports Associated with Nonexistent/Poor Study Organization.}

There are study participants who admit they do not even try to study (cf. Section

4.5.1). Lack of effort may be related to two causes. First, the participants are in school for reasons other than their own internal motivation (McGrath, 2019; Schmidt \& Shreffler, 2015), such as attending school due to societal pressure, to please the family, or to gain social experiences (c.f. Section 4.3.1). These participants do not ultimately find the goal of the academic courses worthy of their time (Kahu et al., 2017). Their minimal effort may relate to their lack of interest in the content, and thus the participants refuse to make the effort (P12, transcript, p. 263), or they find that the reward and value they receive from the class activity are not as worthy as the alternate activity they can choose to participate in at that moment (Stuart et al., 2011). These participants rely on others to carry them through the event in both gaming and in study. They want to put in only the amount of effort that keeps them from complete failure, but sometimes that does not work, as one participant described the effort as "moving a mountain" (P8, transcript, p. 263). These individuals are the ones who are not usually successful at the end of the game, or perhaps the end of the academic semester. Secondly, there were the participants 
in the study who alleged they did not need to study as they had excellent memories (P62, transcript, p. 40). This self-confidence may also lead the participants down a path of unpreparedness and exhibits an arrogant attitude which refuses to submit to the idea that there is more to learn. These individuals who exhibit arrogant attitudes do not usually last long in the gaming or academic worlds. Literature supports the concept that lack of studying does not lead to academic success (Mendezabal, 2013). These video-gaming participants particularly need to understand the reason for the study they are to do, as well as find real life application (P44, transcript, p. 93) in the exercise (Akkara, 2019; Bradley \& Hernández, 2019; Fink, 2013). Participants respond well to mentoring, apprenticeships, and internships (P28, transcript, p. 147). Because of their need to be encouraged to study, they benefit from receiving a large number of small rewards for their efforts (P88, transcript, p. 170). Grades used as rewards in the current educational systems are not usually motivating to these participants in a meaningful way ( transcript, p. 159-167). Instead methods such as regular and frequent formative online feedback (Ennis-Cole, 2019; Roman et al., 2020; Ryan et al., 2019) and the tracking score movement in an online and ranking system (Cruz et al., 2017; Fink, 2013) may be viable learning supports for the participants with this weak study approach (transcript, p. 70-96). Further research on frequent feedback and online ranking systems as learning supports would be needed.

\subsubsection{Learning Supports Associated with Inconsistent/Mediocre/Chaotic Study Organization.}

In this study, a majority of the participants reflected that they had no approach for their study strategies. This lack of approach in strategy is often seen in gaming as well 
when individuals do not prepare in advance for the events that will occur in a game. Rather, the gameplay starts and players react as needed, applying the actions and strategies they believe are relevant in the moment. In the same manner, these gaming participants prepare for their studies using the same inconsistent, mediocre, and somewhat chaotic methods (Stuart et al., 2011). They do not have a planned approach for conquering much of anything, particularly schoolwork (P28, transcript, p. 3). Instead, they deal with assignments and responsibilities as the needs arise, using the study actions they deem adequate at the time (P25, transcript p. 262). There is little long-term planning or structured approach (P33, transcript, p. 39). These video-gaming participants (P17, transcript p. 263) get distracted, looking around trying to find the next new and exciting event (Gallardo-Echenique et al., 2015). The video-gaming participants try something, lose interest, and do not really become an expert at any one game or skillset, nor do they even complete all the tasks. They do not intend to study their gameplay; instead, they are just playing for "relaxation" (c.f. Section 4.2) The video-gamers enjoy the experience in the moment but do not have any long-term approach for games or academics, and it can show in their performance results (P12, transcript, p. 263). Literature supports the need for a focused study plan for gaming video-gaming participants as an indicator of success (Lunceford \& Rockwell, 2017; Nonis \& Hudson, 2010, 2010; Short \& Weidner, 2019).

A suggested learning support identified for this group might be for colleges to change course schedules to allow for a focused immediate lab time after class to help heavy-video-gaming participants get engaged in the project work, build consistency, and surround them with resources, peers, and mentors (Lasley, 2017). One participant in the study told of how the campus changed the entire scheduling block of classes (P66, 
transcript, p. 69). Each class lasted a month met every day with a four-hour lecture, followed by a four-hour lab as needed to complete the work (transcript, p. 16). This arrangement would provide many participants with the need for less planning to get study done, and give no reason to take such a laisser-faire attitude toward completing the assignment. Additionally, this type of schedule more accurately mimics the workplace, prepping the participants for employment (Jenny et al., 2018; Kropp et al., 2014; Lohmann et al., 2019). This type of learning support would require a college-level view. If these extended types of schedule arrangements were not feasible, it would be advantageous to for advising services to help students optimize their class schedules in manners that factor in study, that the students may not readily observe without support.

\subsubsection{Learning Supports Associated with Short Bursts of Concentrated Effort Study Organization.}

Participants commented that they devoted short bursts of time to both gaming and studying (P23, transcript, p. 263). Participants expressed they used gaming in short sessions as a way to relax (P7, transcript, p. 262). They would play a game for a short 20minute session, leave the game to take care of some other task, and then get back on the game for another short round. Academic studiers who practiced this short-burst approach found they had a hard time focusing on the material for more than about 20 minutes in a given session, and had to take frequent breaks (transcript, p. 262-263). While pedagogy of "chunking information" is a tested and known method helpful for aiding a participant's understanding, it can also lead to disjointed functionality (Blackmore et al., 2010; Mulcahy et al., 2015). Sometimes the short breaks are excellent for the mind; other times they lead to more distractions and interruptions (Antonio, 2006; Bodie et al., 2006; Chiu 
\& Cheng, 2017). Support for these video-gaming participants includes breaking the long assignments into parts to provide assignments in a more online and gamified (mobile) microlearning way (Jahnke et al., 2020) and providing short examples that lead to the larger results quickly (P22, transcript, p. 77). These video-gaming participants tend to use a lot of pre-recorded video training, which give the learners accessibility to control the amount and speed of the material they consume, allowing for the desired breaks (P 86, transcript, p. 201). Instructors should recognize this desire for visual learning content exists within many of their students. Rather than leaving the video-gaming students to search for their own visual content and run the risk of finding inaccurate material, instructors could provide accurate educational videos and visual content (Boot et al., 2011). This learning support allows the students to be in control of their learning in time, speed, and have the ability to break as needed (P86, transcript, p. 85) While this chunking type of learning support would be most likely implemented at the classroom/instructor level, some video-gaming learners find it crucial to their overall success, and it should be taken into consideration when implementing a support plan.

\subsubsection{Learning Supports Associated with Responsive Attack.}

Participants who play games as responsive attackers have a great deal of knowledge about their games but may not be fully paying attention until the call to action is given. Instead, they are bored and distracted until they need to attack or protect something. Twenge (2017) describes many video-gaming students within the current generation as distracted, with a shortened attention span. However, when called into attack mode, they will come into focus and give all energy and effort to the task in order to gain the desired result (P20, transcript p. 262). This gaming trait emulates some 
students' study behaviors. The video-gaming participants have an awareness of the expectations of their classes, but are not really paying attention to all the details. Instead, they are waiting to be "wakened" by the attack, which in the school setting is the assignment (P5, transcript p. 262). Rather than reading and growing throughout the semester, the video-gaming participants are reactive, attacking the things that need to be accomplished when they are prompted. Even though they have great reaction times to the requests, they do not give themselves enough time to be as prepared as they could (Blank-Rochester, 2010; Twenge, 2017). Sometimes the attack on the academic project goes well, and other times they miss their mark because they were not prepared (P3, transcript p. 263). These video-gaming participants indicate they want to do well but are not willing to devote their full attention to doing so, and thus reacting, they are usually achieving average results (P20, transcript, p. 262). Such video-gaming participants may benefit from "agile methods." Literature indicates a current practice in business is the agile/scrum method (Kropp et al., 2014; Miles, 2013). This is a flexible, collaborative management approach to planning, attacking, and solving projects for the company. The group starts with a fifteen-minute planning meeting each day to decide on things that should be accomplished. The responsive attack type of video-gaming participants would work well in a learning environment that is agile and flexible in nature (P25, transcript, 262), providing them a way to respond to daily events that need to be accomplished.

One learning support that could align with these video-gaming participants' desires might be a daily online check-in meeting with an advisor, mentor, or team/peer member (transcript, pp. 70-96). This collaborative - quick online - meeting could be done by video chat (Abrams, 2010; Bracken \& Skalski, 2010; Lohmann et al., 2019). The 
frequency of the check-in meetings could be automated, directly tied to metrics such as class attendance or grades, and triggered at particular levels, helping to balance workloads (P 67, transcript, p. 206). Many of the tools needed to accomplish a regular video connection are already being utilized through educational learning management systems (LMS), and the system could be set up to notify students of needed meetings or activity. Additionally, LMSs have capabilities to be used for other time management issues. Both instructors and students are able to post online due dates and projects which can become digital daily prompts for these video-gaming participants to use in time management and attack of the course work (Mendezabal, 2013).

\subsubsection{Learning Supports Associated with a Planned Consistent Study Organization.}

Participants who excel at their game usually intend to do so. They spend a great deal of time learning about the game, practicing and competing (P34, transcript, p. 263). There are some heavy-video-gaming participants who approach their study in this same fashion. Their study practices are calculated, are used as tools to plan, and then help them work the plan (P72, transcript, p. 263). These video-gaming participants give themselves adequate time to accomplish every assignment, turn it in on time, and on occasion do more than is required. If there are issues of incomplete work, the video-gaming students are quick to obtain resources to resolve any (transcript, p. 263). These video-gaming participants study in pursuit of personal improvement in the content area. The pillars of academic success literature affirms that students with these types of study practices meet a high level of academic success (Credé \& Kuncel, 2008; Credé \& Niehorster, 2012). Learning supports for these video-gaming participants include providing plenty of wellorganized online course materials such as digital syllabi (Antonio, 2006; Palocsay \& 
Stevens, 2008). The participants appreciate an overarching objective and clear plans for the tasks assigned, including methods and materials that help them to learn (transcript, $p$ 87). While these video-gaming participants do not want extra work just for the challenge, they do appreciate conquering difficult exercises to prove their achievement (P68, transcript. p. 132; P84, transcript, p. 160). Neri (2007) writes of this type of diligence in nursing students who strive to pass state board exams. The nurses know the specific goal, so they lay out consistent study plans and regularly meet with a successful result. The video-gaming participant utilizing a planned attack organization method also prefer knowing the specific goal, which aids in knowing how to plan the attack strategy (P72, transcript p. 263).

\subsection{New Research Knowledge of the Five Types of Heavy-Video-Gaming Students and Implications for Technology-Enhanced Learning Supports}

Understanding video-gaming participant learning types can be a way of guiding video-gaming students and offering appropriate learning supports (Table 24). While the learning supports shown in Table 25 are not an exhaustive list of practical methods, it does provide broad insight into the type of supports that would be beneficial for videogaming students. Some learning supports would need to be implemented on a campus level, some are classroom integrations, and others can be applied at a personal level.

\section{Table 25}

Types of Heavy-Video-Gaming Participants Showing Related Study Practices and

\section{Learning Supports}

\begin{tabular}{llll}
\hline $\begin{array}{l}\text { Five Types of } \\
\text { Heavy-Video- } \\
\text { gaming Students } \\
\text { (Themes) }\end{array}$ & $\begin{array}{l}\text { Gaming/Study } \\
\text { Practices }\end{array}$ & $\begin{array}{l}\text { Associated } \\
\text { Learning Support }\end{array}$ & $\begin{array}{l}\text { Practical } \\
\text { Suggestions }\end{array}$ \\
\hline
\end{tabular}


Table 25 (continued)

\begin{tabular}{|c|c|c|c|}
\hline $\begin{array}{l}\text { Supportive } \\
\text { Colleague }\end{array}$ & $\begin{array}{l}\text { Take on } \\
\text { supportive roles; } \\
\text { helpful to others } \\
\text { (cf. Section 4.6.1) }\end{array}$ & $\begin{array}{l}\text { Place in situations } \\
\text { where it is easy and } \\
\text { natural to be helpful } \\
\text { (cf. Section 4.4) }\end{array}$ & $\begin{array}{l}\text { Online classroom } \\
\text { presentations and } \\
\text { classroom } \\
\text { assistantships - for } \\
\text { credit (rewards) }\end{array}$ \\
\hline $\begin{array}{l}\text { Pertinacious } \\
\text { Problem Solver }\end{array}$ & $\begin{array}{l}\text { Return to } \\
\text { problem to try } \\
\text { various solutions; } \\
\text { think about issues } \\
\text { (cf. Section 4.6.2) }\end{array}$ & $\begin{array}{l}\text { Provide regular and } \\
\text { digital gamified } \\
\text { problem solving and } \\
\text { the time to engage } \\
\text { with the problem } \\
\text { (cf. Section 4.4) }\end{array}$ & $\begin{array}{l}\text { Provide online real- } \\
\text { world problems to } \\
\text { solve (challenge the } \\
\text { gaming students); } \\
\text { rearrange course } \\
\text { work schedules to } \\
\text { allow for allotted } \\
\text { online lab time after } \\
\text { class with online } \\
\text { resources and } \\
\text { mentors }\end{array}$ \\
\hline $\begin{array}{l}\text { Efficient Linear } \\
\text { Thinker }\end{array}$ & $\begin{array}{l}\text { Gets from point } \\
\text { A to point B in } \\
\text { the fastest way } \\
\text { possible; looks } \\
\text { for the most } \\
\text { efficient way to } \\
\text { get things done } \\
\text { (cf. Section 4.6.3) }\end{array}$ & $\begin{array}{l}\text { Provide online step- } \\
\text { by-step instructions } \\
\text { that are clear and } \\
\text { concise; make } \\
\text { finding digital } \\
\text { resources easy; they } \\
\text { will not invest much } \\
\text { extra time (cf. } \\
\text { Section 4.4) }\end{array}$ & $\begin{array}{l}\text { Use of lots of short } \\
\text { online videos, clear } \\
\text { online instruction } \\
\text { guides (gamified), } \\
\text { step by step tutorials } \\
\text { (gamified) }\end{array}$ \\
\hline $\begin{array}{l}\text { Self-reliant } \\
\text { Associate }\end{array}$ & $\begin{array}{l}\text { Likes to rely on } \\
\text { self for } \\
\text { accomplishments, } \\
\text { but will work } \\
\text { with others to } \\
\text { carry the load } \\
\text { when necessary } \\
\text { (cf. Section 4.6.4) }\end{array}$ & $\begin{array}{l}\text { Place in positions to } \\
\text { associate and work } \\
\text { on projects with } \\
\text { others; still } \\
\text { responsible for } \\
\text { independent work } \\
\text { (cf. Section 4.4) }\end{array}$ & $\begin{array}{l}\text { Online internships, } \\
\text { digitally enhanced } \\
\text { work environments, } \\
\text { gamified apprentices, } \\
\text { online community- } \\
\text { of-practice }\end{array}$ \\
\hline $\begin{array}{l}\text { Individualist with } \\
\text { the Need for } \\
\text { Community }\end{array}$ & $\begin{array}{l}\text { Loner type, but } \\
\text { has internal } \\
\text { desire to belong } \\
\text { to a group (cf. } \\
\text { Section 4.6.5) }\end{array}$ & $\begin{array}{l}\text { Need a group of } \\
\text { people to which } \\
\text { they can belong } \\
\text { (either physical or } \\
\text { online); with regular } \\
\text { alone time (cf. } \\
\text { Section 4.4) }\end{array}$ & $\begin{array}{l}\text { Provide online } \\
\text { organized activities } \\
\text { to group of like } \\
\text { minds and not leave } \\
\text { planning completely } \\
\text { up to the students; let } \\
\text { students participate } \\
\text { in online leadership } \\
\text { teams }\end{array}$ \\
\hline
\end{tabular}




\subsubsection{Learning Supports Associated with the Supportive Colleague Type}

Individuals aligning within this gaming category type enjoy supporting others and gain a great sense of accomplishment from helping people problem-solve to overcome struggles (Freeman \& Wohn, 2018, 2017; Kow \& Young, 2013; Syvänen et al., 2014). These participants regularly take on the support roles in their multi-player games, and this behavior naturally comes out in the way they study. These individuals are the students to whom others come to for help (Hewett, 2016; Tham et al., 2020). They are team players and want success not only for themselves but also for the entire team, so they keep a watchful eye on situations and quietly plan solutions (Spoelstra et al., 2013). However, because of these players' introverted personalities, offering their support is not something they enjoy; instead, they wait to be asked for help. Placing the supportive colleague type in situations where it is easy and natural to be helpful to others could be an effective learning support for them. This might be in shared lab spaces or situations in which they can teach and mentor. One learning support proposal is the creation of office-type digitally enhanced or online lab spaces that allow video-gaming students to have dedicated work space, but where they will naturally interact and collaborate with others also online (Hodes et al., 2015; Syvänen et al., 2014). Providing a more natural course work environment makes the flow of conversation and opportunities for support easy (Beard, 2012; Jyvaeskylae, 2007; Saz et al., 2016). When the video-gaming participants support fellow peers, they are teaching things they have learned, and thus gain a deeper understanding of the content, enhancing their own learning (Gardner \& Sheaffer, 2017; Greenwald et al., 2017; Hammond \& Pötzsch, 2019; Kropp et al., 2014; Lasley, 2017). 


\subsubsection{Learning Supports Associated with the Pertinacious Problem Solver Type}

The heavy-video-gaming participants in this category enjoy a good puzzle or problem to be solved. Their minds can get cognitively lost in figuring out a solution (Jiwal et al., 2019; Nuyens et al., 2019a). They keep returning to the task to try various solutions (Jiwal et al., 2019). Participants who hone pertinacious skills will play the same portion of a game multiple times just to overcome the obstacle blocking their success. They do not give up easily on problems as they insist there is a possible solution. These participants will pertinaciously return to their study assignments until they have reached a satisfactory level of accomplishment. However, the participants need an actual problem to solve to be motivated to study (Goltz et al., 2008). Reading text to memorize facts is a task that needs to be completed, not really a problem to solve in the mind of these videogaming participants. Homework needs to be a problem to solve, not just a simple regurgitation of facts. Instructors could hone in on these problem-solving skills by providing real-world problems for the video-gaming participants to challenge them in their course work, letting their creative minds exercise (Alonso-Díaz et al., 2019). This pertinacious problem-solving skill is one that global businesses desire (Alonso-Díaz et al., 2019; Goltz et al., 2008; Spring, 2015). One learning support proposal that makes sense for these participants would be to rearrange the school day so that classes have lectures but are immediately followed by a formal time to work on the problems with others, such as an online lab session (Beard, 2012; Ennis-Cole, 2019). This lecture/lab model of training could follow the schedule described in the data, where video-gaming students have only two classes at a time, for four weeks. The courses were four hours of lecture, followed by a mandatory four-hour lab, providing time for the students to 
problem solve and complete the assignment. Educators may engage these video-gamingstudent minds with challenging real-world problems to help get the video-gaming students excited about learning (Franz et al., 2012; Hwa, 2016; Kahu et al., 2017). Students could repetitively focus on solving the week-long problem. Schools could intentionally put these problem-solving skillsets to action within the curriculum, keeping video-gaming students engaged in their course work and maybe even solving real campus issues (Bradley \& Hernández, 2019; Sandi-Urena et al., 2012).

\subsubsection{Learning Supports Associated with the Efficient Linear Thinker Type}

This video-gaming participant type strives to get from point A to point B more efficiently as anyone. They want to solve the problem in as few steps as possible, and these video-gamers can find shortcuts and loopholes in any situation to accomplish the task faster. Application of efficiency is highly beneficial in games, and these participants try to apply it to their studies as well (Abrams, 2010; Baepler et al., 2014; Seow \& Pan, 2014). On many occasions, their methods for finding efficiencies in studies include putting in as little effort as possible into tasks (Drummond \& Sauer, 2020; Gawrysiak et al., 2020; Jessi, 2018). The assigned tasks will get accomplished, but participants do not like to put in extra work. Their efficiency methods can be a benefit when time is saved and better strategies are identified. However, if efficiencies are utilized just to create shortcuts to completing assignments, then effectiveness may be reduced, resulting in a lower quality of work. Efficiencies are not a guarantee of effectiveness (Samsuri et al., 2019). To support these video-gaming students, online step-by-step instructions that are clear and concise and provision of needed resources are beneficial because they do not require students to spend extra time to find additional digital material. This group 
appreciates how-to videos that show the steps of a task needing to be completed. Once these video-gaming participants have cognitively organized a concept, they rarely need to visit the subject again, and they attempt to apply the new material to their benefit in the most efficient way possible (Jones et al., 2014; Kwan \& Wong, 2015; Vessey \& Galletta, 1991).

\subsubsection{Learning Supports Associated with the Self-Reliant Associate Type.}

This self-reliant type does not ask many questions because participants in this category view themselves as self-sufficient and like to accomplish things for themselves. Almost none of these self-reliant participant types made use of supports, such as school tutors, because they enjoyed overcoming the assignment hurdle on their own. They spend time in self-reflection and are quite confident in their personal abilities to accomplish anything required (Kauweloa \& Winter, 2016). They do not like to fail (Oates \& Brookey, 2014). Dislike of failure is a positive thing in a game, as a player with these tendencies will not let the multi-player team fail even if he must rely on himself to get things accomplished. Thus, these players can be great assets to teams though they are frequently found carrying the load (Kirschner et al., 2009; Oates \& Brookey, 2014). Yet, it is in playing with a team that this player type is forced into a working relationship with others, learning to associate in order to get a job done (Spoelstra et al., 2013). The players may view the relationship with fellow players or students as a work-only association, not choosing to socialize or befriend. The participants tend to use the relationships they build with other people as a means to a greater end (Kropp et al., 2014). They might flourish when finding an online community of like-minded people who are working toward a common end, known as a community-of-practice (Kow \& Young, 2013; Wenger et al., 
2002). These participants might be put in positions that require them to work on online projects that demand skillsets from all people in a group, forcing a softening of their selfreliant tendencies to carry the load.

\subsubsection{Learning Supports Associated with the Individualist with the Need for}

\section{Community}

These video-gaming participants are the loner personality types, but they still have a need for belonging to a community. They do not mind spending time alone and may feel they must do so in order to recharge (Kuncel et al., 2004; Nicklen et al., 2015). In academic settings, loners need quiet areas, such as individual study places (Beard, 2012; Rath, 2014). However, they are drawn to the gaming platform where they can easily interact and belong with friends. These individuals are not the natural ice-breaker personalities in social settings and content with just one or two friends, but internally they still want to be included in campus activities (Eklund \& Roman, 2019). They will be glad to come to the pizza party when invited to do so though they would rarely plan one for others to join. They want to belong but are uncomfortable joining groups (Arockiyasamy et al., 2016; Bauer-Wolf, 2019; Whelan et al., 2016). One learning support recommendation is to ensure there are regular online activities planned among the majors with whom they study. These participants need a group of people to which they can belong but find it difficult to gravitate toward groups (Bradley \& Hernández, 2019). For example, some of these individuals might desire an (online) study group and social interactions but would rarely initiate one. Educators may offer support to these videogaming students by finding foster relationships in a safe social circle they already know from classes. When these video-gaming participants include others, their study 
experience starts coming into better balance - meaning they create a better sense of the real world - and this helps them with the rest of their course work or study responsibilities (Tham et al., 2020; Twenge, 2017). Practical applications of this idea might come in the following forms: offering them online tutoring sessions, having them eat together, or occasionally conducting a social activity, such as a game night. These small group activities can help video-gaming students to settle in and find the sense of belonging and community-of-practice they desire (Wenger et al., 2002).

\subsection{Concept of a Gamified Learning Support System}

The previous sections of chapter five used the analyzed data from this study to addressed research question one as stated in Chapter I:

RQ1: What patterns of gaming and study practices can be identified among undergraduate heavy-video-gaming students?

Then, the following sections of Chapter $\mathrm{V}$ more specifically address research question two, as stated in Chapter I:

RQ 2: What learning support areas, including those with a focus on technologyenhanced learning supports, can be developed for undergraduate heavy-videogaming students to support them during their academic studies?

The first idea is the conceptual gamified learning support system and many of the learning support components are shown in Tables 27 through 33. In section 5.6, a videogaming student matrix is discussed in greater detail.

\subsubsection{Data and Inputs Supporting the Gamification System}

Data from Chapter IV of this research study were used to identify study practices and learning supports specific to the heavy-video gamers. While a number of the items 
identified are practices and supports already in place and helpful to many, the videogaming participants did emphasize the need to have flexible time, multiple attempts at learning with less consequence, a challenging but achievable path to success, the need for consistent and regular feedback, and a way to make all learning resources available to them in one location. Video-gaming learners want all of this easily managed and accessible similarly to the way they deal with their games. Such requirements lend themselves well to fit with an engaging gamified learning support system, which is proposed later in this paper.

The data shown in Tables 26 through 33 include the learning-support ideas derived from participants in this study. This study was able to capture the video-gamers' desired learning supports and then make suggestions on how these could be gamified. There would need to be further research to evaluate the effectiveness of each support identified. These learning supports are grouped by characteristics related to the part of their learning experience that is impacted (Table 26). For example, areas of gamification within the technology-based learning support system might address needs related to the study practice of classroom needs or personal study time needs. The following Tables 27 through Table 33 provide detail into overarching areas the participants indicated were important learning areas supports. In the column "Participant Requests for Learning Supports" are the ideas interviewees provided about desired support areas without gamification in mind. The "Gamification Suggestions to Incorporate in to TechnologyEnhanced Learning Support System” column contains suggestions indicating how some of the use-cases could be gamified into the technology-enhanced learning system. 
Table 26

Summary Learning Support Areas Requested by Participants

\begin{tabular}{l|l}
\hline Detailed Table & Learning Support Area \\
\hline Table 27 & Classroom/Scheduling Supports Requested by Participants \\
\hline Table 28 & Assignment/Homework Supports Requested by Participants \\
\hline Table 29 & Professor/Staff Supports Requested by Participants \\
\hline Table 30 & Personal Study Supports Requested by Participants \\
\hline Table 31 & Extracurricular Supports Requested by Participants \\
\hline Table 32 & Social Needs Supports Requested by Participants \\
\hline Table 33 & Physical Needs Supports Requested by Participants \\
\hline
\end{tabular}

The remainder of this page has been intentionally left blank. 
Table 27

Classroom/Schedule Supports Requested by Participants

\begin{tabular}{|c|c|c|c|}
\hline $\begin{array}{l}\text { Section } \\
\text { of } \\
\text { Informa } \\
\text {-tion } \\
\text { from } \\
\text { Data } \\
\text { Result } \\
\text { Chapter }\end{array}$ & $\begin{array}{l}\text { Participant } \\
\text { Request for } \\
\text { Learning } \\
\text { Supports } \\
\text { (data from } \\
\text { this study) }\end{array}$ & $\begin{array}{l}\text { Established } \\
\text { in } \\
\text { Literature } \\
\text { or New } \\
\text { Learning } \\
\text { Support }\end{array}$ & $\begin{array}{l}\text { Gamification Suggestions to Incorporate } \\
\text { in to Technology-Enhanced Learning } \\
\text { Support System }\end{array}$ \\
\hline 4.4 & $\begin{array}{l}\text { Provide a way } \\
\text { to gain better } \\
\text { balance in } \\
\text { scheduling of } \\
\text { classes }\end{array}$ & $\begin{array}{l}\text { New } \\
\text { (Mendezaba } \\
1,2013 \text { ) }\end{array}$ & $\begin{array}{l}\text { An online system within game interface that } \\
\text { coordinates course offerings and student } \\
\text { input parameters, forecasting the most } \\
\text { effective use of the student's time. }\end{array}$ \\
\hline 4.4 & $\begin{array}{l}\text { Adjust the } \\
\text { length of class } \\
\text { and align per } \\
\text { discipline } \\
\text { needs }\end{array}$ & $\begin{array}{l}\text { Block } \\
\text { scheduling } \\
\text { (Küçükahm } \\
\text { et, 2000; } \\
\text { Schepens, } \\
\text { 2019) }\end{array}$ & $\begin{array}{l}\text { Students give input to the length of class } \\
\text { time through use of online votes. This } \\
\text { information feeds overall campus } \\
\text { scheduling and class, forecasting game } \\
\text { modules. }\end{array}$ \\
\hline 4.4 & $\begin{array}{l}\text { Develop a } \\
\text { system to } \\
\text { coordinate } \\
\text { tasks among } \\
\text { instructors }\end{array}$ & $\begin{array}{l}\text { New } \\
\text { support (G. } \\
\text { Freeman \& } \\
\text { Wohn, } \\
2018 ; \\
\text { Oloyede et } \\
\text { al., 2012) }\end{array}$ & $\begin{array}{l}\text { A game module that coordinates an online } \\
\text { calendar of a given assignment by } \\
\text { individual instructor or class groups. This } \\
\text { system could notify students how many } \\
\text { assignments are due on a single day or } \\
\text { week. The teacher gets a report from } \\
\text { students in each class so he or she can } \\
\text { choose to alter the assignment date if they } \\
\text { feel it would be beneficial to balance the } \\
\text { work load of the students. Students could } \\
\text { flag requests to alter the schedule. }\end{array}$ \\
\hline 4.4 & $\begin{array}{l}\text { Organize } \\
\text { class } \\
\text { schedules to } \\
\text { address the } \\
\text { placement and } \\
\text { timing of } \\
\text { classes to suit } \\
\text { student } \\
\text { learning needs }\end{array}$ & $\begin{array}{l}\text { Advising } \\
\text { (Feldman \& } \\
\text { Matjasko, } \\
\text { 2005; Lee, } \\
\text { 2005) }\end{array}$ & $\begin{array}{l}\text { A module that could schedule classes by } \\
\text { relevant parameters, such as ranking them } \\
\text { by difficulty. As an example, a struggling } \\
\text { math student may want to avoid an early- } \\
\text { morning math class because it is difficult to } \\
\text { focus at that time of the day. The system } \\
\text { could be integrated into the game asking } \\
\text { students to have input on ranking the course } \\
\text { difficulty or time placement and use a } \\
\text { forecasting system to plan a schedule. The } \\
\text { game could track trends of data for } \\
\text { administrative planning. }\end{array}$ \\
\hline
\end{tabular}


Table 28

Assignment/Homework Supports Requested by Participants

\begin{tabular}{|c|c|c|c|}
\hline $\begin{array}{l}\text { Section } \\
\text { in the } \\
\text { result } \\
\text { chapter }\end{array}$ & $\begin{array}{l}\text { Participant } \\
\text { Request for } \\
\text { Learning } \\
\text { Supports }\end{array}$ & $\begin{array}{l}\text { Established in } \\
\text { Literature } \\
\text { or New Learning } \\
\text { Support }\end{array}$ & $\begin{array}{l}\text { Gamification Suggestions to Incorporate in } \\
\text { to Technology-Enhanced Learning Support } \\
\text { System }\end{array}$ \\
\hline 4.4 & $\begin{array}{l}\text { Assign } \\
\text { performanc } \\
\text { e-based } \\
\text { work }\end{array}$ & $\begin{array}{l}\text { Performance } \\
\text { Based } \\
\text { learning(Fish, } \\
\text { 2015; Kuncel et } \\
\text { al., 2004) }\end{array}$ & $\begin{array}{l}\text { Using competency-based learning assignments, } \\
\text { dashboards could be created for work } \\
\text { accomplished, and rewards could be earned at } \\
\text { certain levels of completion. A final certificate } \\
\text { is awarded for completion of all projects. }\end{array}$ \\
\hline $\begin{array}{l}4.5 .2 / \\
4.6 .2\end{array}$ & $\begin{array}{l}\text { Provide } \\
\text { second } \\
\text { chances to } \\
\text { complete } \\
\text { tasks, } \\
\text { allowing } \\
\text { persistent } \\
\text { tries until } \\
\text { success }\end{array}$ & $\begin{array}{l}\text { Multiple } \\
\text { Homework } \\
\text { attempts (Archer, } \\
\text { 2018) } \\
\text { Competency based } \\
\text { learning(Alonso- } \\
\text { Díaz et al., 2019) }\end{array}$ & $\begin{array}{l}\text { Give students the ability to repeat an exercise } \\
\text { until they earn the grade desired. This is } \\
\text { competency-based learning and may work on } \\
\text { some tasks better than others. An algorithm } \\
\text { could be devised to give rewards based on } \\
\text { number of tries, correctness, and more, } \\
\text { rewarding each completed assignment, but } \\
\text { those correct the first time may get bonus } \\
\text { points. }\end{array}$ \\
\hline 4.3 .1 & $\begin{array}{l}\text { Give } \\
\text { relevant } \\
\text { assignments }\end{array}$ & $\begin{array}{l}\text { Applied Learning } \\
\text { (Barnett et al., } \\
\text { 1997; Bills, 2008) }\end{array}$ & $\begin{array}{l}\text { Integrate scenarios in games that represent } \\
\text { problems that must be solved. Game rewards } \\
\text { are earned. }\end{array}$ \\
\hline 4.5 .3 & $\begin{array}{l}\text { Allow for } \\
\text { short bursts } \\
\text { of work, } \\
\text { giving } \\
\text { frequent } \\
\text { breaks }\end{array}$ & $\begin{array}{l}\text { Chunking (Bodie } \\
\text { et al., 2006) }\end{array}$ & $\begin{array}{l}\text { Games tend to give many short tasks with } \\
\text { constant feedback. Breaking assignments into } \\
\text { short tasks to make up the whole, students } \\
\text { could be awarded points for "leveling up" on } \\
\text { the assignment to completion. }\end{array}$ \\
\hline 4.4 & $\begin{array}{l}\text { Allow extra } \\
\text { time for } \\
\text { assignments }\end{array}$ & $\begin{array}{l}\text { Multiple attempts, } \\
\text { flex deadlines } \\
\text { (Manero et. Al, } \\
\text { 2017; Yu, 2011) }\end{array}$ & $\begin{array}{l}\text { Allow students an option to purchase an } \\
\text { extension of time for an assignment, but it } \\
\text { costs some game points (or game loot). Each } \\
\text { assignment could carry appropriate point costs. } \\
\text { In reversal, if the assignment is completed on } \\
\text { time, points are rewarded, and if early, bonus } \\
\text { points are given. }\end{array}$ \\
\hline 4.2 & $\begin{array}{l}\text { Assign } \\
\text { immediate } \\
\text { homework } \\
\text { in lab space } \\
\text { after lecture }\end{array}$ & $\begin{array}{l}\text { Question of } \\
\text { homework } \\
\text { (Archer \& Olson, } \\
\text { 2018; Palocsay \& } \\
\text { Stevens, 2008) }\end{array}$ & $\begin{array}{l}\text { When tasks are completed in the lab, characters } \\
\text { or a special game code could be captured for } \\
\text { rewards. }\end{array}$ \\
\hline
\end{tabular}


Table 28 (continued)

\begin{tabular}{llll}
\hline $4.4 /$ & Make notes & Making resources \\
4.6.3 & $\begin{array}{l}\text { Provide assignment tasks in game, and then } \\
\text { and provide } \\
\text { clear logical } \\
\text { instructions } \\
\text { for any } \\
\text { assignments }\end{array}$ & & $\begin{array}{l}\text { al., 2018) (Soni et } \\
\text { notes or instructions can pop up as text } \\
\text { prompts. Provide avenues for students to } \\
\text { contribute and share notes. }\end{array}$ \\
& & \\
\hline
\end{tabular}

Table 29

Professor/Staff Supports Requested by Participants

\begin{tabular}{|c|c|c|c|}
\hline $\begin{array}{l}\text { Section } \\
\text { in the } \\
\text { result } \\
\text { chapter }\end{array}$ & $\begin{array}{l}\text { Participant } \\
\text { Request for } \\
\text { Learning } \\
\text { Supports }\end{array}$ & $\begin{array}{l}\text { Established in } \\
\text { Literature } \\
\text { or New } \\
\text { Learning } \\
\text { Support }\end{array}$ & $\begin{array}{l}\text { Gamification Suggestions to Incorporate } \\
\text { in to Technology-Enhanced Learning } \\
\text { Support System }\end{array}$ \\
\hline 4.4 & $\begin{array}{l}\text { Give } \\
\text { frequent } \\
\text { feedback }\end{array}$ & $\begin{array}{l}\text { Importance of } \\
\text { feedback } \\
\text { (Dolar, 2018) }\end{array}$ & $\begin{array}{l}\text { Games are effective at providing immediate } \\
\text { feedback. Watching rewards collect in the } \\
\text { game against competition is part of the } \\
\text { feedback. This could be tied to the LMS } \\
\text { programs where feedback on assignments is } \\
\text { easy to give. Points could be awarded for } \\
\text { interacting with the feedback. }\end{array}$ \\
\hline 4.4 & $\begin{array}{l}\text { Present } \\
\text { material in a } \\
\text { more visual } \\
\text { way }\end{array}$ & $\begin{array}{l}\text { Visual } \\
\text { Strategies } \\
\text { (Yenawine \& } \\
\text { Miller, 2014) }\end{array}$ & $\begin{array}{l}\text { The gamification system would naturally } \\
\text { allow for some visual prompts in the study } \\
\text { experience, but the system interface could } \\
\text { host photos, videos, and demonstrations. } \\
\text { Students would have ability to add to the } \\
\text { collection of visual aids. Points could be } \\
\text { awarded for presenting, watching, or adding } \\
\text { a video/demonstration with faculty approval. }\end{array}$ \\
\hline 4.4 & $\begin{array}{l}\text { Engage the } \\
\text { support of } \\
\text { professors - } \\
\text { students } \\
\text { need } \\
\text { someone to } \\
\text { believe in } \\
\text { them }\end{array}$ & $\begin{array}{l}\text { Faculty } \\
\text { mentoring/ } \\
\text { Mentor teacher } \\
\text { (Antonio, } \\
\text { 2006; Rusk et } \\
\text { al., 2020) }\end{array}$ & $\begin{array}{l}\text { Professors could post encouraging words to } \\
\text { the students in the game. These could be } \\
\text { manual or pre-recorded statements and } \\
\text { triggered by certain events. }\end{array}$ \\
\hline
\end{tabular}


Table 30

Personal Study Supports Requested by Participants

\begin{tabular}{|c|c|c|c|}
\hline $\begin{array}{l}\text { Section } \\
\text { in the } \\
\text { result } \\
\text { chapter }\end{array}$ & $\begin{array}{l}\text { Participant } \\
\text { Request for } \\
\text { Learning } \\
\text { Supports }\end{array}$ & $\begin{array}{l}\text { Established in } \\
\text { Literature } \\
\text { or New Learning } \\
\text { Support }\end{array}$ & $\begin{array}{l}\text { Gamification Suggestions to } \\
\text { Incorporate in to Technology- } \\
\text { Enhanced Learning Support } \\
\text { System }\end{array}$ \\
\hline 4.3 & $\begin{array}{l}\text { Provide strategies } \\
\text { for avoiding } \\
\text { procrastination }\end{array}$ & $\begin{array}{l}\text { Time Management } \\
\text { (Drummond \& } \\
\text { Sauer, 2020; Nonis } \\
\text { \& Hudson, 2010) }\end{array}$ & $\begin{array}{l}\text { Game rewards earned for events } \\
\text { and assignments completed on or } \\
\text { before a time limit. Game points } \\
\text { can be awarded. }\end{array}$ \\
\hline 4.2 & $\begin{array}{l}\text { Provide forms of } \\
\text { competition in } \\
\text { work }\end{array}$ & $\begin{array}{l}\text { Collaborative, } \\
\text { Individual and } \\
\text { Competitive } \\
\text { Learning (Oloyede } \\
\text { et al., 2012) }\end{array}$ & $\begin{array}{l}\text { Maintain a leaderboard of points } \\
\text { for game, allowing all to see their } \\
\text { rank. }\end{array}$ \\
\hline 4.4 & $\begin{array}{l}\text { Provide flexible } \\
\text { tutoring }\end{array}$ & $\begin{array}{l}\text { Tutoring (S. Li et } \\
\text { al., 2017) }\end{array}$ & $\begin{array}{l}\text { Integrate tutoring by recorded and } \\
\text { live video, and award in some } \\
\text { fashion for use of the tutorial } \\
\text { system. }\end{array}$ \\
\hline 4.3 & $\begin{array}{l}\text { Provide reasons } \\
\text { and paths to } \\
\text { persistence }\end{array}$ & $\begin{array}{l}\text { Comprehensive } \\
\text { supports } \\
\text { Persistence } \\
\text { Engagement } \\
\text { (Elliott \& Healy, } \\
\text { 2001; Kahu et al., } \\
2017 \text { ) }\end{array}$ & $\begin{array}{l}\text { Awarding rewards for those } \\
\text { persisting to a new semester could } \\
\text { be integrated into the game. They } \\
\text { become stronger students as they } \\
\text { persist, perhaps gaining "power" } \\
\text { points. }\end{array}$ \\
\hline
\end{tabular}


Table 31

Extracurricular Supports Requested by Participants

\begin{tabular}{|c|c|c|c|}
\hline $\begin{array}{l}\text { Section } \\
\text { in the } \\
\text { result } \\
\text { chapter }\end{array}$ & $\begin{array}{l}\text { Participant } \\
\text { Request for } \\
\text { Learning } \\
\text { Supports }\end{array}$ & $\begin{array}{l}\text { Established in } \\
\text { Literature } \\
\text { or New Learning } \\
\text { Support }\end{array}$ & $\begin{array}{l}\text { Gamification Suggestions to } \\
\text { Incorporate in to Technology- } \\
\text { Enhanced Learning Support } \\
\text { System }\end{array}$ \\
\hline 4.3 & $\begin{array}{l}\text { Provide social } \\
\text { interactions } \\
\text { with multi- } \\
\text { participant } \\
\text { activities }\end{array}$ & $\begin{array}{l}\text { Collaborative Group } \\
\text { work (Kropp et al., } \\
\text { 2014; Syvänen et al., } \\
\text { 2014) }\end{array}$ & $\begin{array}{l}\text { Students have avatars in the game, } \\
\text { and multiplayer contests could be } \\
\text { played. An example might be to } \\
\text { challenge a friend to a word puzzle } \\
\text { that comes up in the system. The } \\
\text { system could have class challenges } \\
\text { as well as non-class challenges. The } \\
\text { multiplayer challenges provide } \\
\text { competition and social interaction. }\end{array}$ \\
\hline 4.3 .1 & $\begin{array}{l}\text { Allow free } \\
\text { time to be free }\end{array}$ & $\begin{array}{l}\text { New Support } \\
\text { Time } \\
\text { Management(Carter } \\
\text { et al., 2016; Gardner } \\
\& \text { Sheaffer, 2017) }\end{array}$ & $\begin{array}{l}\text { Integrate the use of a digital calendar } \\
\text { in the game, allowing students to } \\
\text { enter their schedule. This can } \\
\text { support students with time } \\
\text { management. As they meet classes, } \\
\text { capture codes, and complete } \\
\text { assignments, the plotted schedule } \\
\text { assigns points for completion and } \\
\text { helps them find available free time. }\end{array}$ \\
\hline $\begin{array}{l}4.2 \& \\
4.5 .5\end{array}$ & $\begin{array}{l}\text { Provide } \\
\text { specific } \\
\text { extracurricular } \\
\text { events and } \\
\text { offer } \\
\text { community }\end{array}$ & $\begin{array}{l}\text { School inclusion, } \\
\text { belonging (Hanghøj } \\
\text { et al., 2018; Pietersen } \\
\text { et al., 2018) }\end{array}$ & $\begin{array}{l}\text { Students input into the game the } \\
\text { particulars of their extracurricular } \\
\text { interests. This generates an } \\
\text { opportunity to connect avatars in } \\
\text { group chats for communicating, } \\
\text { receiving reminders and perhaps } \\
\text { having some virtual reality } \\
\text { interactions. Activities, both real and } \\
\text { virtual, could receive rewards for } \\
\text { participation. }\end{array}$ \\
\hline 4.2 & $\begin{array}{l}\text { Avoid hosting } \\
\text { so many } \\
\text { activities on } \\
\text { the weekend }\end{array}$ & $\begin{array}{l}\text { New Learning } \\
\text { Support (Morris, } \\
\text { 2019; Stuart et al., } \\
\text { 2011) }\end{array}$ & $\begin{array}{l}\text { Students provide polling input on } \\
\text { the types of activities they want and } \\
\text { need, and when they should be } \\
\text { scheduled. Participating in polls } \\
\text { earns points. }\end{array}$ \\
\hline
\end{tabular}


Table 32

Social Needs Supports Requested by Participants

\begin{tabular}{|c|c|c|c|}
\hline $\begin{array}{l}\text { Section } \\
\text { in the } \\
\text { result } \\
\text { chapter }\end{array}$ & $\begin{array}{l}\text { Participant } \\
\text { Request for } \\
\text { Learning } \\
\text { Supports }\end{array}$ & $\begin{array}{l}\text { Established in } \\
\text { Literature } \\
\text { or New Learning } \\
\text { Support }\end{array}$ & $\begin{array}{l}\text { Gamification Suggestions to } \\
\text { Incorporate in to Technology- } \\
\text { Enhanced Learning Support } \\
\text { System }\end{array}$ \\
\hline $\begin{array}{l}4.4 / \\
4.6 .4\end{array}$ & $\begin{array}{l}\text { Prompt working } \\
\text { together in } \\
\text { groups, but also } \\
\text { make sure the } \\
\text { assignment } \\
\text { contains a way to } \\
\text { work } \\
\text { independently/ } \\
\text { associate but also } \\
\text { be self-reliant }\end{array}$ & $\begin{array}{l}\text { Group work } \\
\text { Peer mentoring } \\
\text { (Rusk et al., } \\
\text { 2020; Whelan et } \\
\text { al., 2016) }\end{array}$ & $\begin{array}{l}\text { The game could be set to make } \\
\text { subsets of student groups for } \\
\text { assignments, and after all students } \\
\text { show engagement with the group, } \\
\text { game points could be awarded. For } \\
\text { each project, there could be a } \\
\text { timeline of tasks assigned to the } \\
\text { individual members. As these tasks } \\
\text { are completed, game points } \\
\text { awarded. }\end{array}$ \\
\hline $\begin{array}{l}4.4 / \\
4.6 .1\end{array}$ & $\begin{array}{l}\text { Require learners } \\
\text { share or teach the } \\
\text { concept and } \\
\text { demonstrate their } \\
\text { knowledge }\end{array}$ & $\begin{array}{l}\text { Cooperative } \\
\text { learning (Hanghøj } \\
\text { et al., 2018; } \\
\text { Oloyede et al., } \\
\text { 2012) }\end{array}$ & $\begin{array}{l}\text { A showcase area could be inserted } \\
\text { into the game or produced in a live } \\
\text { venue where students demonstrate } \\
\text { skills. Points would be awarded for } \\
\text { participation, and if in a physical } \\
\text { space, students could capture a } \\
\text { "character" or a special code at the } \\
\text { event. }\end{array}$ \\
\hline 4.4 & $\begin{array}{l}\text { Provide practice } \\
\text { in communication }\end{array}$ & $\begin{array}{l}\text { Communication } \\
\text { in the classroom } \\
\text { (Bodie et al., } \\
\text { 2006; Perloff, } \\
\text { 2016) }\end{array}$ & $\begin{array}{l}\text { Allow users to create avatars in the } \\
\text { game so students/faculty can } \\
\text { communicate about their studies and } \\
\text { work together. It could be that } \\
\text { avatars need to go to a particular } \\
\text { place in the game to be able to talk } \\
\text { about study items. Game points } \\
\text { could be awarded for study groups. }\end{array}$ \\
\hline
\end{tabular}


Table 33

Physical Needs Supports Requested by Participants

\begin{tabular}{|c|c|c|c|}
\hline $\begin{array}{l}\text { Section } \\
\text { in the } \\
\text { result } \\
\text { chapter }\end{array}$ & $\begin{array}{l}\text { Participant } \\
\text { Request for } \\
\text { Learning } \\
\text { Supports }\end{array}$ & $\begin{array}{l}\text { Established in } \\
\text { Literature } \\
\text { or New } \\
\text { Learning } \\
\text { Support }\end{array}$ & $\begin{array}{l}\text { Gamification Suggestions to } \\
\text { Incorporate in to Technology- } \\
\text { Enhanced Learning Support } \\
\text { System }\end{array}$ \\
\hline 4.6 .5 & $\begin{array}{l}\text { Provide space for } \\
\text { individualists to } \\
\text { be in comfortable } \\
\text { social settings }\end{array}$ & $\begin{array}{l}\text { Social Space } \\
\text { (Mulcahy et al., } \\
\text { 2015; Rath, } \\
\text { 2014; Syvänen et } \\
\text { al., 2014) }\end{array}$ & $\begin{array}{l}\text { This space might be a specialized lab } \\
\text { or study space for members of like- } \\
\text { mindedness. For gamification, when } \\
\text { visiting in these spaces "virtual } \\
\text { characters" can be caught for points. }\end{array}$ \\
\hline 4.6 .5 & $\begin{array}{l}\text { Provide physical } \\
\text { space for } \\
\text { individualists to } \\
\text { be in comfortable } \\
\text { social settings }\end{array}$ & $\begin{array}{l}\text { Social, Living } \\
\text { Space (Beckers } \\
\text { et al., 2016) }\end{array}$ & $\begin{array}{l}\text { This space might be a specialized lab } \\
\text { or study space for members of like } \\
\text { mindedness. For gamification, when } \\
\text { visiting in these spaces "virtual } \\
\text { characters" can be caught for points. }\end{array}$ \\
\hline 4.4 & $\begin{array}{l}\text { Make snacks and } \\
\text { caffeine readily } \\
\text { available and } \\
\text { affordable }\end{array}$ & $\begin{array}{l}\text { Snacks (Lee, } \\
\text { 2005; Sogari et } \\
\text { al., 2018) }\end{array}$ & $\begin{array}{l}\text { Game points and rewards could be } \\
\text { transferred to student accounts by } \\
\text { which a "debit" type card could be } \\
\text { used for spending the points on real } \\
\text { food, college gear, and maybe even } \\
\text { scholarships. }\end{array}$ \\
\hline
\end{tabular}

The technology-enhanced learning support system concept shown in Figure 19 was created based on data found in this study. Gamifying student learning supports could address many of the learning support desires expressed by the heavy-video-gaming participants in this study. This could integrate many services into one environment, offering competition and reward within the system, both elements of interest to videogaming students. Conceptually, the gamification of the student learning support system would allow university academic and functional areas to add specific tasks and elements to the game to be accomplished by the video-gaming students. The gamification of the learning experience could generate personalized learning supports for each participant. Tasks supporting learning from each area would be entered into the gamified system, 
using both automated and manual inputs. Tying current school learning management systems and administrative systems to the game could automate the process of transposing daily information into the game as tasks to complete for rewards. Special events outside those systems could be manually entered by appropriate school personnel.

As students work through tasks in the game, they earn rewards, providing a form of learning support in itself by encouraging them to persist and succeed. Figure 19 indicates the concept for the larger learning support system, and how various components of the learning environment might provide data to the system.

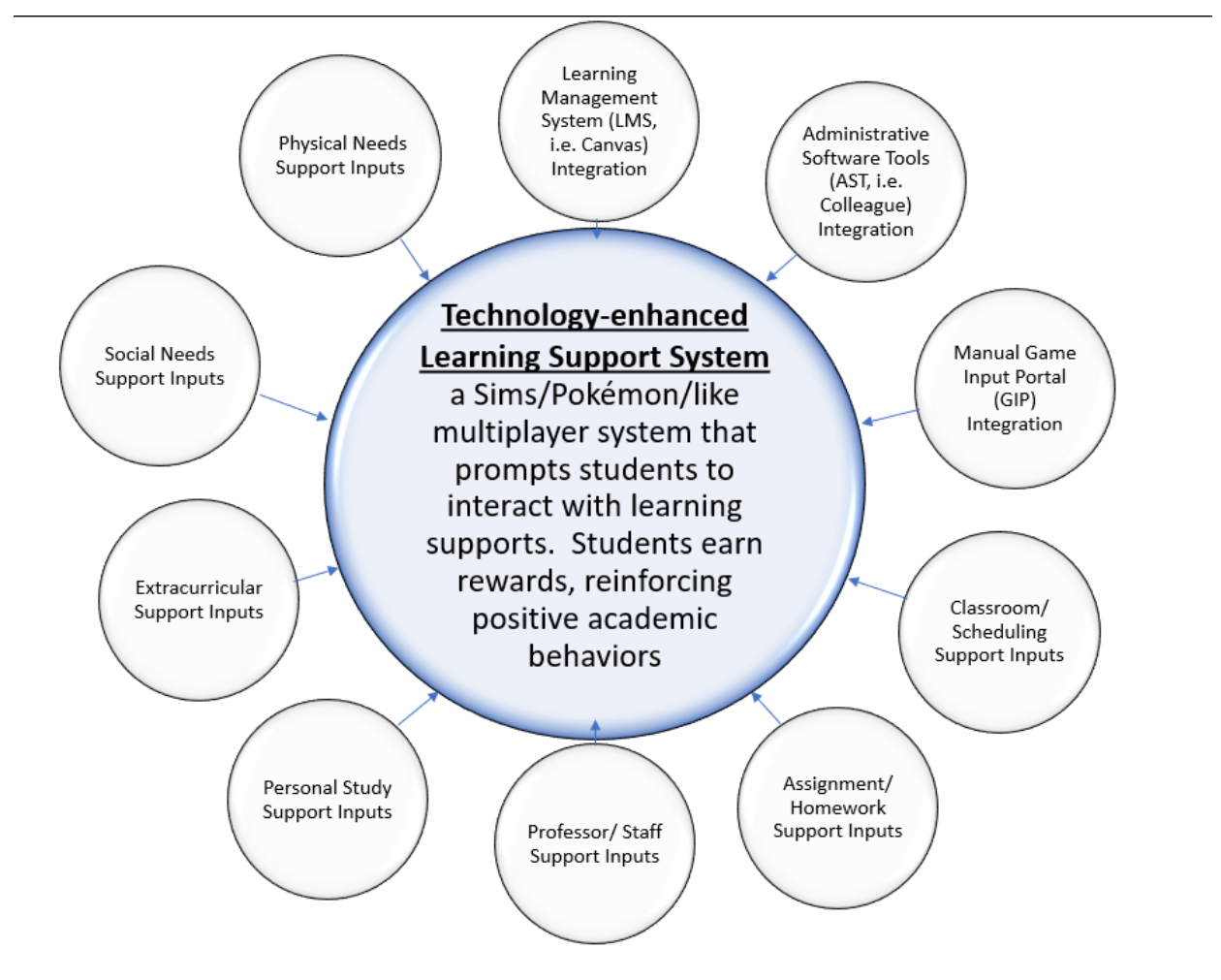

\section{Figure $\overline{19}$}

Concept for Technology-Enhanced Learning Support System Integrated with Participant Suggested Learning Support Inputs 


\subsubsection{User Interface of the Gamified Learning Support System}

This section shows how gamified learning support system user interface might look. The learning support system would be available on both computers and mobile devices, such as desktop computers, laptops, phones, and iPads as demonstrated in Figure 20.

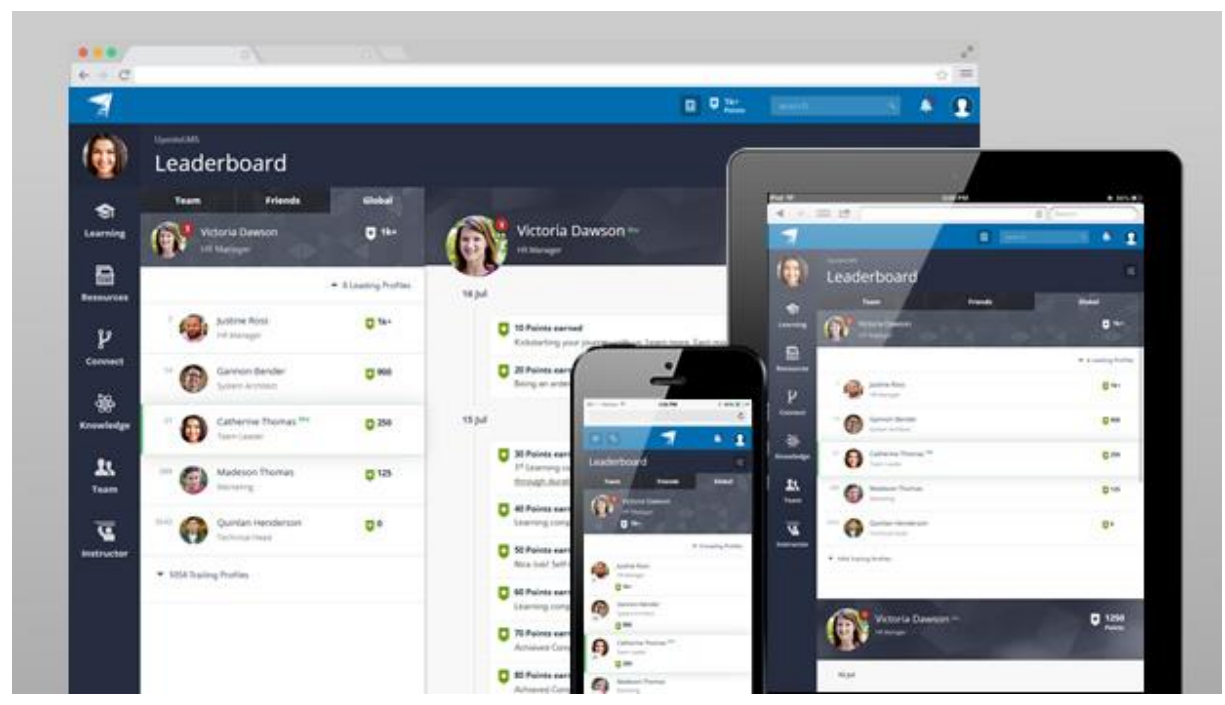

Figure 20

Technology-Enhanced Learning Support System to be Available on Various Computing Platforms

The gamified interface could be created using a model from the current SIMS game shown in Figure 21. 


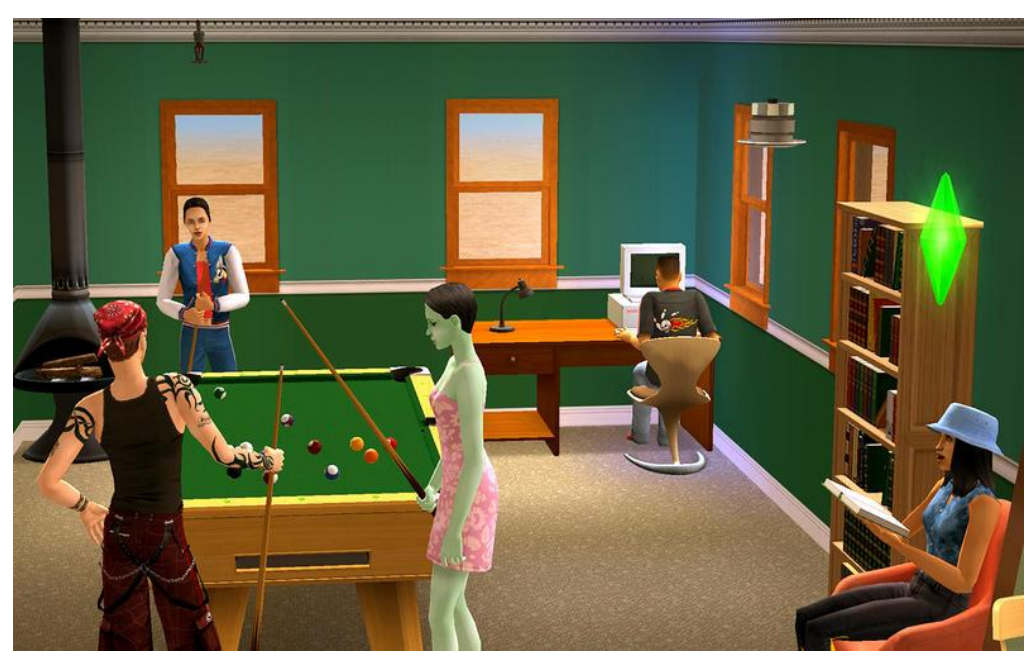

Figure 21

Example of the SIMS Game User Interface Used as a Model for Technology-Enhanced Learning Support System

The students create avatars that have the ability to interact with others. Students would respond to "study" tasks that need to be completed for their school assignments. The proposed technology-enhanced learning support system would be filled with prompts such as deadlines, homework activities, videos to watch, places to meet for study groups, and more. Eventually this list of prompts could grow to include other areas of the school environment. As the students complete the tasks, meet deadlines and interact with other avatars, their account's reward system would be affected. Points are earned, health power is increased, "loot" can be earned that can be transferred to real, tangible rewards, such as food, university gear, and perhaps scholarship dollars when moving in a positive direction. When missing a deadline or desiring a repeat on an assignment, it could "cost" the student something of their reward system (Figure 22). 


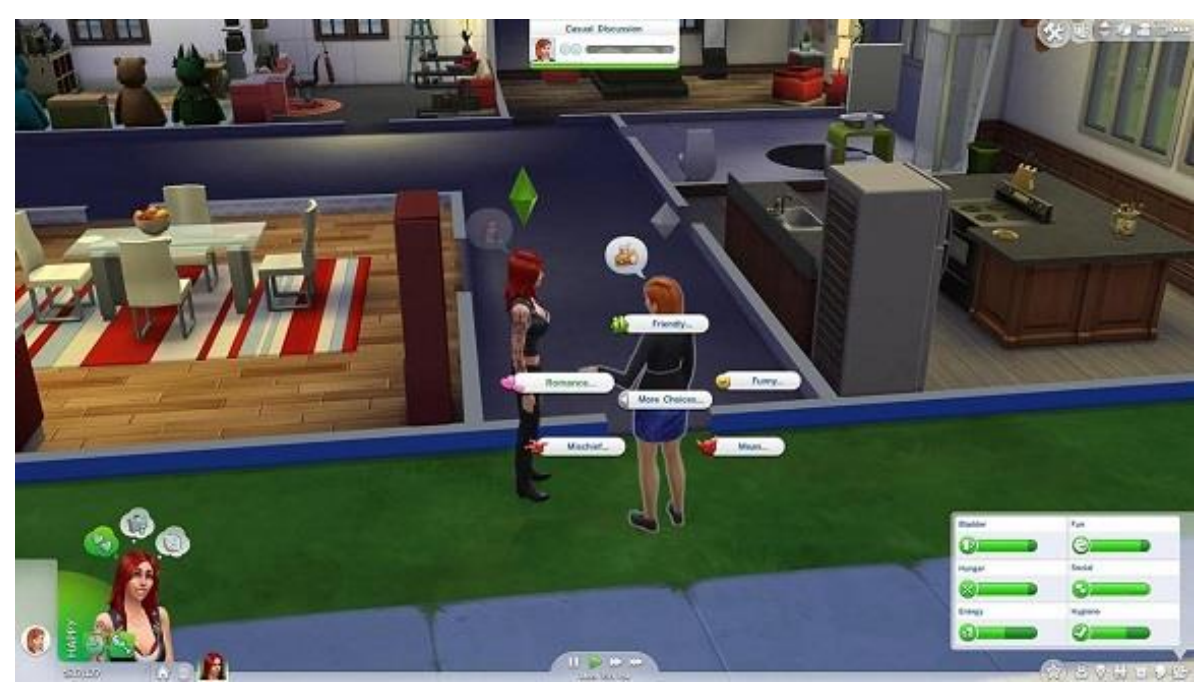

Figure 22

Sample SIMS Game Interface Showing Tasks and Reward System to be used as a Model for the Technology-Enhanced Learning Support System

When the students attend physical meetings on the campus, such as classes or inperson study groups, the gamified learning support system would be integrated into a virtual map that shows the location of those events. When attending the event, a special virtual character or code would be presented, as is done in the current Pokémon game (Figure 23), to be captured for points in the learning support system. The special characters would be available only during particular time frames for capture and would be used to add points to the overall learning support system. Capturing an item for rewards would encourage participation in activities such as class meetings and study groups. 


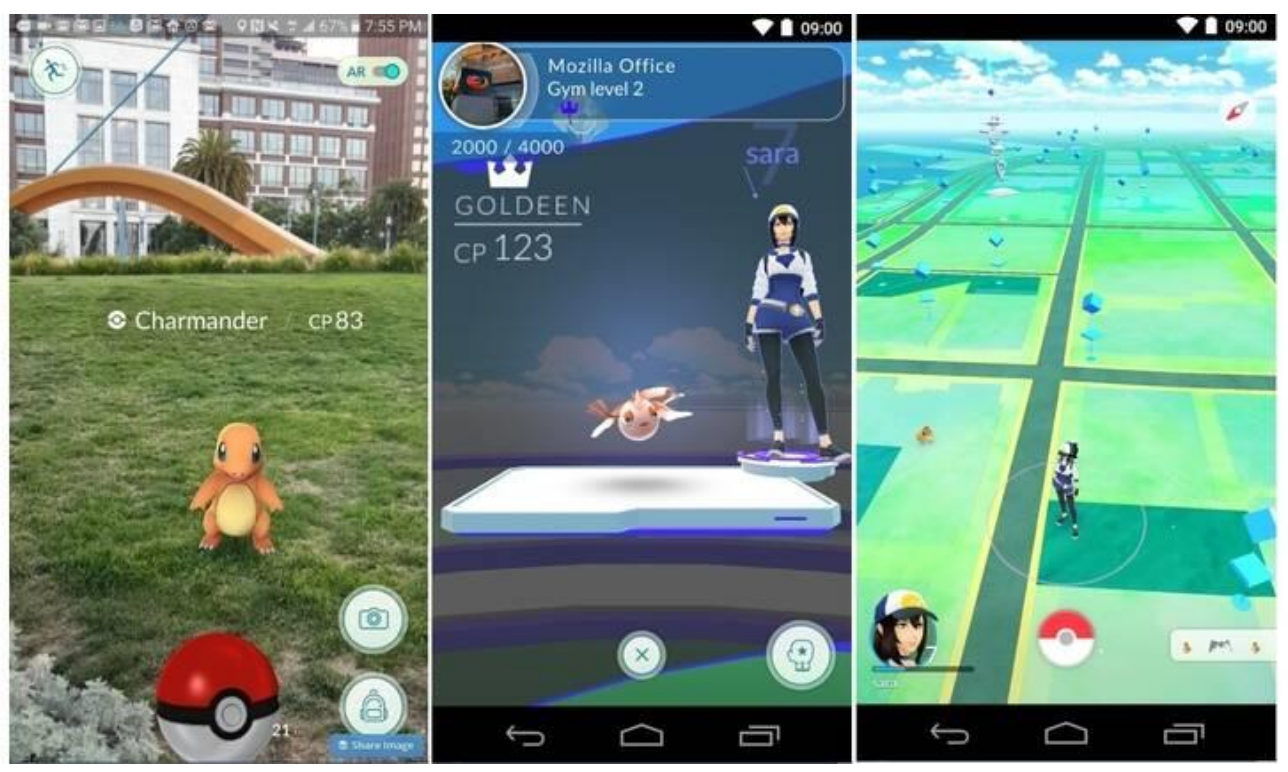

Figure 23

Sample Pokémon Game Interface for Capturing Characters when at Physical Meetings to be Used as a Model for the Technology-Enhanced Learning Support System

Within the technology-enhanced learning support system, the students would receive immediate feedback regarding their study activities such as grades, class attendance, completed course assignments, and participation points earned through the use of special dashboards and leaderboards (Figure 24). Here, the video-gaming students could monitor some of their personal study trends, track badges and rewards they have earned, and evaluate how their points rank against peers. 


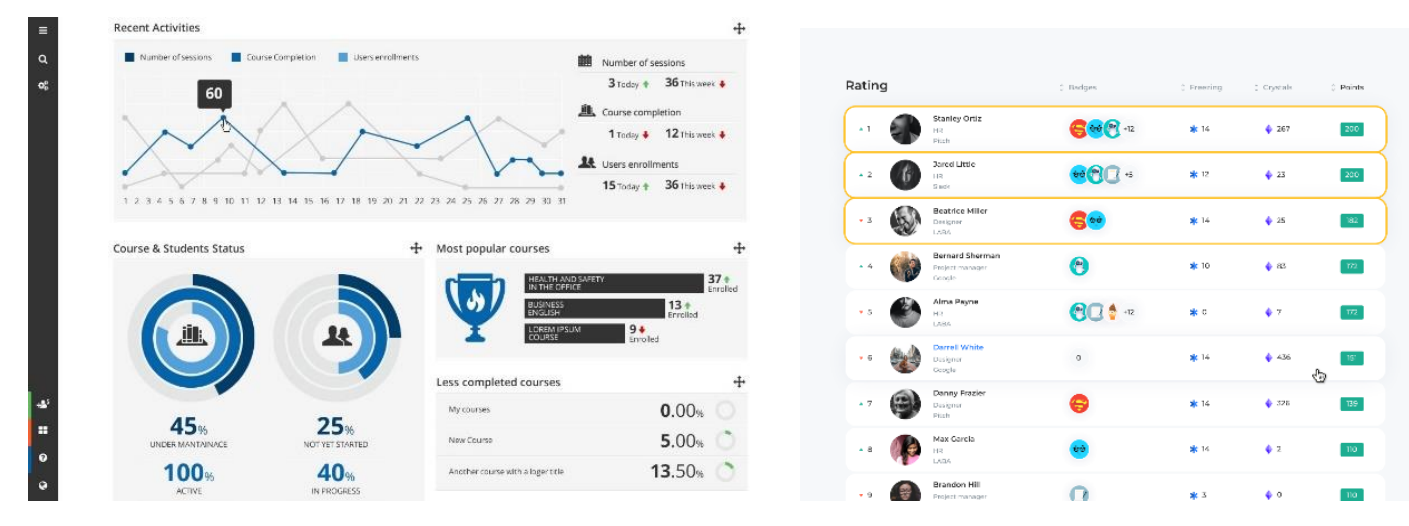

Figure 24

Sample Dashboard to be used as a Model for the Technology-Enhanced Learning Support System

Shown above are a sample dashboard and leaderboard that could be available in the technology-enhanced learning support system. The entire technology-enhanced learning support system would seek to serve as an interactive interface for the integrated campus systems, providing an engaging system to support learning for the video-gaming students.

\subsection{The Video-Gaming Student Matrix for Identifying Learning Supports}

The final section of the discussion is centered around a newly-developed matrix that could be used by video-gaming students and professionals early in the college career of the individual to help determine a learning support plan of action for both parties. The matrix combines the categories of the video-gaming study approaches and the types of heavy-video-gaming students, forming a matrix that allows a participant to mark the grid according to the described categories. The video-gaming student types do not have the same level of influence on an individual's academic performance success as do the study practices. For example, people aligning with any of the five video-gaming student types can all have a strong study approach and perform very well. But any of the video-gaming 
student types can also align with the weaker study practices and perform poorly. Thus, this grid amplifies the importance of study practices.

This matrix form itself is a learning support and can be utilized in academic advisement settings or even student self-planning sessions. It will help video-gaming students identify specific study practices, as well as optional learning supports that align with their personal traits. This form extends Crede and Kuncel's (2008) theory of study habits as being one of the three pillars of academic performance. The matrix provides video-gaming students and professionals a tangible way to identify study practices and personal behavior tendencies. Once video-gaming students identify a learning performance position, they can be advised of actions to take that will specifically aid their learning performance. The process can take place at the beginning of a semester or school experience when the use of study practices and learning supports can be explicitly encouraged, and a plan of action can be formulated.

Table 34 shows the suggested form grid, but Appendix K shows the entire form and reference that have been developed for the tool. 


\section{Table 34}

The Video-Gaming Student Matrix

\section{The Video-Gaming Student Matrix}

This is a three-step exercise to provide heavy-video-gaming students and educational professionals with a tool to assist building an academic performance plan which will address the video-gaming student's study practices, gaming student type, and possible learning supports that best align.

Step 1 - Instructions: The student should make one selection from the Type of VideoGamer column and one selection from the Study Approach row. Base the selections on the categories described below the grid.

Place a mark in the grid where the two selections meet. Then look at Learning Support numbers (LS\#) for both selections. Using these learning support suggestions found on page two, formulate an academic performance plan with your advisor.

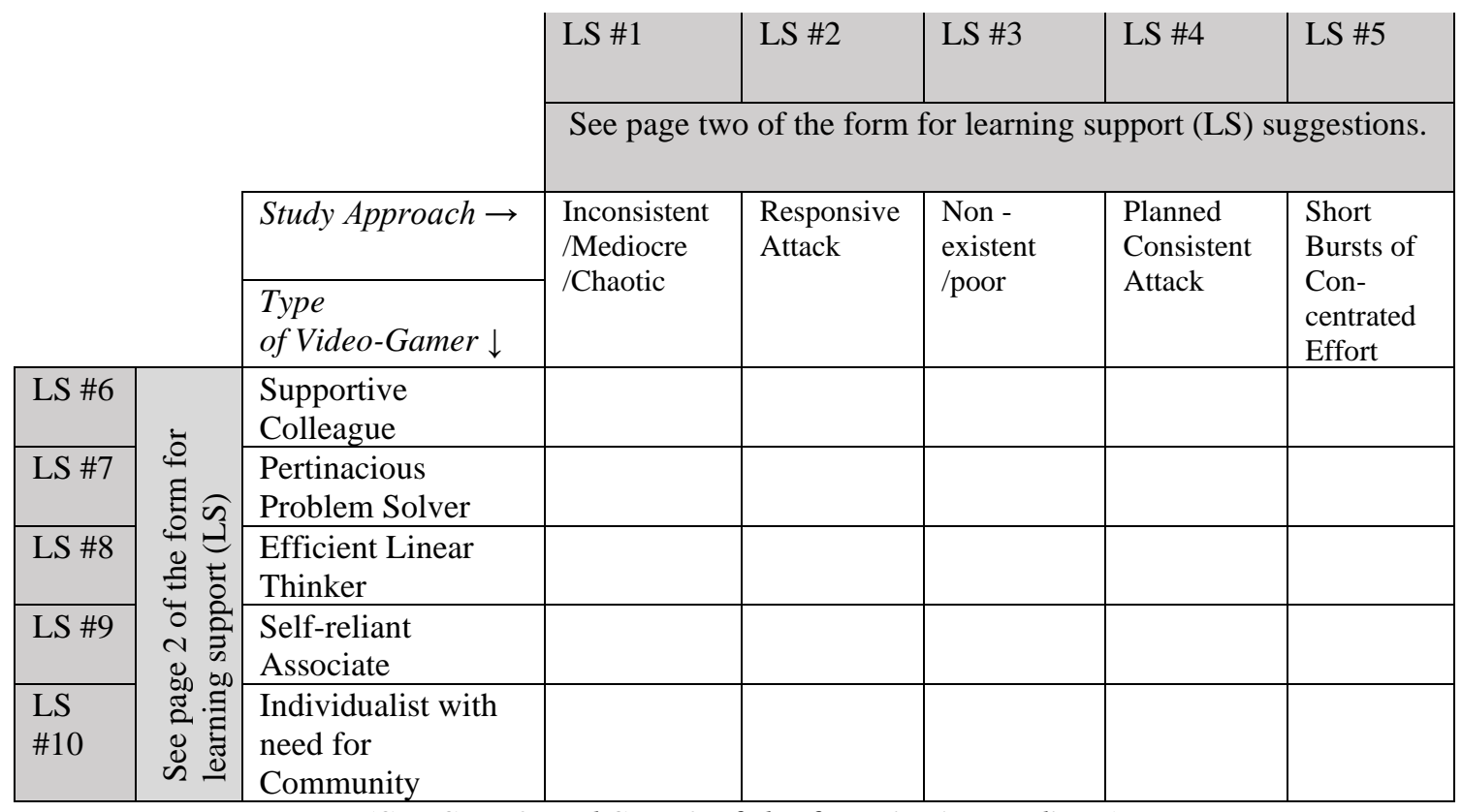

(See Step 2 and Step 3 of the form in Appendix K)

It is important to remember this research study is exploratory in nature. There is a need for The Video-Gaming Student Matrix to go through validation and pilot testing, but 
the grid provides the initial ideas for a new advising tool designed to help heavy-videogaming students and perhaps a number of other students.

Both the gamified learning support system and the video-gaming student matrix could be populated with both well-established learning supports and newly-developed tools. Giving the video-gaming students new ways to plan and evaluate their study and learning experiences, such as this matrix tool, may be very effective early in the college experience (DuPaul et al., 2017; Kulp et al., 2019; Short \& Weidner, 2019). This early intervention may be the missing link for setting up some of the students for improved academic performance.

\subsection{Limitations}

Limitations were identified in the study. During the study, the intent was to observe heavy-video-gaming participants' study practices for a traditional sixteen-week college semester. The data collected and analyzed was from short video response clips recorded by participants in their real environments, but due to the video observation method, the study was forced to rely on participant self-reported data, along with interviews. If the study were continued for an extended period of time, longer than 16weeks, it would be possible to observe how participant study practices progressed during their undergraduate experience, providing rich historical content to the project.

Virtual ethnography itself is a limiting factor in a manner because the research was done in a remote fashion. There are certain disadvantages that arise when the researcher is not "living" with the study participants. Examples of limitations include the way engagement of participants can be thwarted due to the out-of-sight out-of-mind effect, and the lack of true environmental awareness. Participants found it easier to 
dismiss themselves from the project because remote anonymity was involved. In this study, even though a great deal of data was collected, only two participants completed the ethnography tasks at the level of $100 \%$. The decline of participants' involvement caused the researcher more work by creating the need to conduct additional interviews. However, the use of interviews enhanced the ethnography data by providing appropriately aligned, thick, rich data.

Conversely, the virtual ethnography tool made this study possible in a different way by giving the researcher access to video-gaming students across the nation that would have otherwise been impossible to reach. The limitations related to physical space, time, and costs were lessened due to the remote tool, especially since this research was conducted by a single researcher. However, a specific advantage of using the internet as the means for research was that the participant selection was not limited to one college or region, enlarging the scope of the project.

Another limitation of the study is the absence of information on things other than being male or female. For instance, race, socioeconomic status, or disability and other identities might make a difference in terms of providing services and perceptions as well as one's status as a gamer.

Finally, a limitation relates to the fact that the exploratory nature of this study generated a large amount of data, compounding the time needed for analysis. However, the rich result-set from this research study provides a useful basis for a number of future studies as discussed in the next section. 


\subsection{Recommendations for Future Work and New Research Questions}

There are several recommendations for future research that can be developed from this study. First is to identify and interview more female participants until there are enough to accurately compare male and female video-gaming student study practices. However, it is important to recognize this may take a while as the gaming field is heavily dominated by men. Additional topics for expansion could include other ways gamer identity might be formulated around topics such as race/culture, socioeconomic status, disability status, and more. Second, a recommendation is to take the newly-identified "heavy-video-gaming students study organization approaches" and the "five types of heavy-video-gaming students" from this study and develop a self-reporting rating survey that could be given to all students, providing a comparison between the heavy-videogaming student and all non-gaming students. Third, there is a need to continue researching learning supports to identify the most effective methods that could be utilized and integrated into tools, such as a gamified learning support system. This research study has been used to examine the video-gamers and capture their desired supports, but these identified supports would need to be validated to determine the effectiveness of each.

Future research questions that emerge from this study are:

- How do undergraduate heavy-video-gaming students' gaming and study practices change over time from beginning of degree program until graduation?

- What is the difference between male and female undergraduate heavy-videogaming student gaming and study practices?

- In what ways is the gamified learning support system concept practicable, and do the heavy-video-gaming students like it? This is a future research question that 
includes the study of the learning effectiveness, efficiency, and appeal of the gamified learning support system for heavy-video-gaming students (Honebein \& Honebein, 2015).

\subsection{Conclusion}

This study contributes to a body of new research knowledge of the relationship of gaming and study practices of heavy-video-gaming students, and how these aspects may influence their academic performance. The new results of how heavy video-gaming learners organize their studies and the types of heavy-video gaming learners provides new ways for undergraduate university educational leaders to understand one of the largest populations on campus. This research also introduced a gamified learning support system concept as a technology-enhanced tool, along with a matrix evaluation tool that can support video-gaming learners.

Heavy video-gaming students specifically do well in competitive situations where they can apply their knowledge and skills in meaningful ways, receive continual feedback, have multiple attempts as success, and are rewarded in tangible ways, all within an environment where they can socially connect. A gamified learning support system may offer these video-gaming learners the tool they need use as they are guided to new academic performances.

The results of this thesis provide researchers and practitioners (e.g., instructors, program coordinators, decision-makers) with two new lenses that can be used when supporting heavy-video-gaming students. The first lens is the gamer study approach, which includes the following: Inconsistent/mediocre/chaotic Approach; Responsive Attack Approach; Nonexistent/poor Approach; Planned Consistent Attack Approach; and 
Short Bursts of Concentrated Effort Approach. The second lens shows five types of heavy-video-gaming students, which include Supportive Colleague Type; Pertinacious Problem Solver Type; Efficient Linear Thinker Type; Self-reliant Associate Type; and Individualist with the Need for Community Type. The two lenses were integrated in the practical advisement tool, The Video-Gaming Student Matrix, for aiding researchers, practitioners, and students in identifying and developing appropriate learning supports. The research conducted on this specific population of video-gaming learners may lead to the development of effective learning support tools meeting specific needs for them, which, in turn, may lead to the use of these tools by a number of other student populations, thus helping many.

Higher educational leaders can use the results for further developing learning supports specifically for heavy-video-gaming students. Additionally, researchers may continue to build on this study about heavy-video-gaming students. Heavy-video-gamers may gain insight to their own study habits and attitudes and better utilize appropriate learning supports as they aim to apply them toward their successful academic performance. 


\section{References}

Abrams, S. S. (2010). The Dynamics of Video Gaming: Influences Affecting Game Play and Learning. In P. Zemilansky \& D. Wilcox (Eds.), The Dynamics of Video Gaming: Influences Affecting Game Play and Learning (pp. 78-91). IGI Global. www.igi-global.com/chapter/dynamics-video-gaming/42447

Akkara, J. (2019). IT Apprenticeship Programs: Building the Last Mile in Tech Education. New England Journal of Higher Education, N.PAG.

Alonso-Díaz, L., Yuste-Tosina, R., \& Mendo-Lázaro, S. (2019). Adults video gaming: Key competences for a globalised society. Computers \& Education, 141. https://doi.org/10.1016/j.compedu.2019.103616

Altinkurt, Y., \& Yilmaz, K. (2012). Prospective science and mathematics teachers' computer anxiety and learning styles. Energy Education Science and Technology Part B: Social and Educational Studies, 4(2), 933-942.

Altintas, E., Karaca, Y., Hullaert, T., \& Tassi, P. (2019). Sleep quality and video game playing: Effect of intensity of video game playing and mental health. Psychiatry Research, 273, 487-492. https://doi.org/10.1016/j.psychres.2019.01.030

Alzahrani, A., Callaghan, V., Gardner, M., \& Alzahrani, A. (2013). Towards Personalised and Adaptive Learning Paths in Immersive Educational Environments. Proceedings of the 3rd European Immersive Education Summit. EiED. http://s3.amazonaws.com/academia.edu

Annetta, L. A., Minogue, J., Holmes, S. Y., \& Cheng, M.-T. (2009). Investigating the impact of video games on high school students' engagement and learning about genetics. Computers \& Education, 53(1), 74-85. 
Antonio, C. (2006). Teaching in the Knowledge Society: New Skills and Instruments for Teachers: New Skills and Instruments for Teachers. Idea Group Inc (IGI).

Aquino, L. (2011). Study Habits and Attitudes of Freshmen Students: Implications for Academic Intervention Programs. Journal of Language Teaching and Research, 2(5). https://doi.org/10.4304/jltr.2.5.1116-1121

Archer, K. K. (2018). Do Multiple Homework Attempts Increase Student Learning? A Quantitative Study. The American Economist, 63(2), 260-269. https://doi.org/10.1177/0569434518774790

Archer, K. K., \& Olson, M. (2018). Practice. Practice. Practice. Do Homework Management Systems Work?. International Journal for the Scholarship of Teaching and Learning, 12(2), 12.

Arockiyasamy, G., Surendheran, K., \& Bullard, S. K. (2016). The influence of playing video games on academic performance among graduates of Karunya University. Journal of Advances in Humanities and Social Sciences, 2(3), 119-132.

Ashton. (2017, December). What is the Optimum Training Time for Esports Players? The Esports Observer. https://esportsobserver.com/optimum-player-training-time/ Assunção, C. (n.d.). "No Girls on the Internet": The Experience of Female Gamers in the Masculine Space of Violent Gaming. Retrieved July 2, 2020, from https://core.ac.uk/reader/73961436

Astin, A. W. (1991). Assessment for excellence. Macmillan.

Astin, A. W., \& Antonio, A. (2012). Assessment for excellence: The philosophy and practice of assessment and evaluation in higher education. Rowman \& Littlefield Publishers. 
Azziz, D. R. (2014, February 26). A Looming Challenge in Higher Education: Our Changing Student. Huffington Post. https://www.huffingtonpost.com

Baepler, P., Walker, J. D., \& Driessen, M. (2014). It's not about seat time: Blending, flipping, and efficiency in active learning classrooms. Computers \& Education, 78, 227-236. https://doi.org/10.1016/j.compedu.2014.06.006

Ballado-Tan, J. (2014). Academic Performance, Aspirations, attitudes and study habits as determinants of the Performance in licensure examination of accountancy graduates. International Journal of Education and Research, 2(12), 10.

Baltezarević, R., \& Baltezarević, B. (2018). The Impact of Video Games on the eSports Formation. Facta Universitatis, Series: Physical Education and Sport, 16(1), 137-147. https://doi.org/10.22190/FUPES170614012B

Banta, T. W., Lund, J., Black, K., \& Oblander, F. (1996). Assessment in Practice: Putting Principles To Work on College Campuses. Jossey-Bass Higher and Adult Education Series. Jossey-Bass Inc.

Bányai, F., Griffiths, M. D., Király, O., \& Demetrovics, Z. (2019). The Psychology of Esports: A Systematic Literature Review. Journal of Gambling Studies, 35(2), 351-365. https://doi.org/10.1007/s10899-018-9763-1

Barnett, M. A., Vitaglione, G. D., Harper, K. K., Quackenbush, S. W., Steadman, L. A., \& Valdez, B. S. (1997). Late Adolescents' Experiences With and Attitudes Toward Videogames 1. Journal of Applied Social Psychology, 27(15), 13161334. 
Barr, M. (2018). Student attitudes to games-based skills development: Learning from video games in higher education. Computers in Human Behavior, 80, 283-294. https://doi.org/10.1016/j.chb.2017.11.030

Başaran, B. (2015). Students' aptitude to edutainment. Procedia-Social and Behavioral Sciences, 176, 772-778.

Başol, G., \& Kaya, A. B. (2018). Motives and Consequences of Online Game Addiction: A Scale Development Study. Archives of Neuropsychiatry, 55(3), 225-232. https://doi.org/10.5152/npa.2017.17017

Bauer-Wolf, J. (2019, February). A new frontier in college athletics-Video games. Inside Higher Ed. https://www.insidehighered.com/news/2019/02/12/new-frontiercollege-athletics-video-games

Beals, Z. (2019). Oversight in Collegiate eSports: Is the NCAA the Answer? Arizona State University Sports and Entertainment Law Journal, 9, 78. https://heinonline.org/HOL/Page?handle=hein.journals/selj9\&id=78\&div=\&colle ction $=$

Bear, L. (2019). How female video gamers experience being part of a male dominated community. Journal of Applied Psychology and Social Science, 5(1), 31-50. https://ojs.cumbria.ac.uk/index.php/apass/article/view/594

Beard, C. (2012). Spatial ecology: Learning and working environments that change people and organizations. In K. Alexander \& I. Price (Eds.), Managing organizational ecologies: Space, management and organization (pp. 69-80). Routledge. http://shura.shu.ac.uk/5542/ 
Beattie, G., Laliberté, J.-W. P., Michaud-Leclerc, C., \& Oreopoulos, P. (2019). What sets college thrivers and divers apart? A contrast in study habits, attitudes, and mental health. Economics Letters, 178, 50-53.

https://doi.org/10.1016/j.econlet.2018.12.026

Beckers, R., van der Voordt, T., \& Dewulf, G. (2016). Why do they study there? Diary research into students' learning space choices in higher education. Higher Education Research \& Development, 35(1), 142-157. https://doi.org/10.1080/07294360.2015.1123230

Bejjanki, V., Zhang, R., Li, R., Pouget, A., Green, S., Lu, Z.-L., \& Bavelier, D. (2014). Biological Sciences Action video game play facilitates the development of better perceptual templates. PNAS, 111(47), 16961-16966. https://doi.org/10.1073/pnas.1417056111

Beltrami, G. (2016, March). Esports Rising. Media Theory and Criticism 2016. https://medium.com/media-theory-and-criticism/esports-rising-beb9bca209b4

Bennett, S., \& Maton, K. (2010). Beyond the 'digital natives' debate: Towards a more nuanced understanding of students' technology experiences. Journal of Computer Assisted Learning, 26(5), 321-331. https://doi.org/10.1111/j.13652729.2010.00360.x

Berg, B. L., \& Lune, H. (2004). Qualitative research methods for the social sciences (Vol. 5). Pearson. http://www.msu.ac.zw/

Bills, D. B. (2008). Applying Workplace Models of Learning in Social Science Computer Labs. Journal of Applied Social Science, 2(2), 66-76. https://doi.org/10.1177/193672440800200207 
Blackmore, J., Bateman, D., Loughlin, J., O’Mara, J., \& Aranda, G. (2010). The connection between learning spaces and student learning outcomes: A literature review. Melbourne: Department for Education and Early Childhood Development.

Blankenship, M. D. (2017). Examination of a University Success Coaching Program [PhD Thesis]. Oklahoma State University.

Blank-Rochester, A. (2010, September). Video games speed up reaction time. Futurity. https://www.futurity.org/video-games-speed-up-reaction-time/

Blerkom, M. L. V. (1992). Class Attendance in Undergraduate Courses. The Journal of Psychology, 126(5), 487-494. https://doi.org/10.1080/00223980.1992.10543382

Bodie, G. D., Powers, W. G., \& Fitch-Hauser, M. (2006). Chunking, priming and active learning: Toward an innovative and blended approach to teaching communication-related skills. Interactive Learning Environments, 14(2), 119135. https://doi.org/10.1080/10494820600800182

Boellstorff, T., Nardi, B., Pearce, C., \& Taylor, T. L. (2012). Ethnography and Virtual Worlds: A Handbook of Method. Princeton University Press.

Boligitz, K. (2020). The Perceptions, Attitudes, and Behaviors of Students Toward Their Honors Program: A Study of the Temple University Honors Program. Honors Scholar Projects.

Bondoc, B. C. (2020). Relationship of online Gaming addiction and study skills and habits of College Students. International Journal of English Literature and Social Sciences (IJELS), 5(2), Article 2. http://journalrepository.com/index.php/ijels/article/view/1793 
Boot, W. R., Blakely, D. P., \& Simons, D. J. (2011). Do Action Video Games Improve Perception and Cognition? Frontiers in Psychology, 2. https://doi.org/10.3389/fpsyg.2011.00226

Borowski, V. J. (2009). Leisure reading materials and urban adolescents: Do school libraries collect for these readers?

Bowman, N. (2018). Video Games | A Medium That Demands Our Attention (1st ed.). Routledge. https://www.taylorfrancis.com/books/e/9781351235259

Bown, J., White, E., \& Boopalan, A. (2017). Looking for the Ultimate Display: A Brief History of Virtual Reality. Boundaries of Self and Reality Online: Implications of Digitally Constructed Realities, 239.

Boyer, K. E., Dwight, R. S., Miller, C. S., Raubenheimer, C. D., Stallmann, M. F., \& Vouk, M. A. (2007). A Case for Smaller Class Size with Integrated Lab for Introductory Computer Science. Proceedings of the 38th SIGCSE Technical Symposium on Computer Science Education, 341-345. https://doi.org/10.1145/1227310.1227430

Bracken, C. C., \& Skalski, P. (2010). Immersed in Media: Telepresence in Everyday Life. Routledge.

Bradley, K., \& Hernández, L. E. (2019). Big Picture Learning: Spreading Relationships, Relevance, and Rigor One Student at a Time. (Deeper Learning Networks Series). Learning Policy Institute.

Bray, J. H., Maxwell, S. E., \& Schmeck, R. R. (1980). A Psychometric Investigation of the Survey of Study Habits and Attitudes. Applied Psychological Measurement, 4(2), 195-201. https://doi.org/10.1177/014662168000400206 
Brightman, J. (2015, January 29). Twitch reaches 100 million viewers per month. Games Industry. https://www.gamesindustry.biz/articles/2015-01-29-twitch-reaches-100million-viewers-per-month

Briscoe, G., \& Mulligan, C. (2014). Digital innovation: The hackathon phenomenon. Queen Mary University of London. http://qmro.qmul.ac.uk/xmlui/handle/123456789/11418

Brockman, J. (2011). How is the Internet Changing the Way You Think?: The net's impact on our minds and future. Atlantic Books Ltd.

Broh, B. A. (2002). Linking Extracurricular Programming to Academic Achievement: Who Benefits and Why? Sociology of Education, 75(1), 69-95. https://doi.org/10.2307/3090254

Brown, W. F., \& Holtzman, W. H. (1967). Survey of study habits and attitudes. Psychological Corporation.

Bulent, A., Hakan, K., \& Aydin, B. (2015). An Analysis of Undergraduates' Study Skills. Procedia - Social and Behavioral Sciences, 197, 1355-1362. https://doi.org/10.1016/j.sbspro.2015.07.389

Burgess, S. R., Stermer, S. P., \& Burgess, M. C. R. (2012). Video game playing and academic performance in college students. College Student Journal, 46(2), 376388.

http://search.ebscohost.com.proxy.mul.missouri.edu/login.aspx?direct=true $\& d b=e$ $\mathrm{ft} \& \mathrm{AN}=77698068 \&$ site $=$ eds-live $\&$ scope $=$ site

Bursztyn, N., Shelton, B., Walker, A., \& Pederson, J. (2017). Increasing Undergraduate Interest to Learn Geoscience with GPS-based Augmented Reality Field Trips on 
Students' Own Smartphones. GSA Today, 4-10.

https://doi.org/10.1130/GSATG304A.1

Cantalupo, N. C., \& Kidder, W. C. (2018). A systematic look at a serial problem: Sexual harassment of students by university faculty. Utah L. Rev., 671 .

Carter, D. F., Ro, H. K., Alcott, B., \& Lattuca, L. R. (2016). Co-curricular connections: The role of undergraduate research experiences in promoting engineering students' communication, teamwork, and leadership skills. Research in Higher Education, 57(3), 363-393.

Casey, M. (2012, November). Could playing video games make you smarter? CBS News. https://www.cbsnews.com/news/playing-video-games-could-make-you-smarter/

Casinger, J. (2011). College extracurricular activities: The history of activities. Article Dashboard. http://www.articledashboard.com//Extracurricular-Activities--theHistory-of-Activities/

Cerna, M. A., \& Pavliushchenko, K. (2015). Influence of Study Habits on Academic Performance of International College Students in Shanghai. Higher Education Studies, 5(4). https://doi.org/10.5539/hes.v5n4p42

Cha, S. H., \& Kim, T. W. (2015). What Matters for Students' Use of Physical Library Space? The Journal of Academic Librarianship, 41(3), 274-279. https://doi.org/10.1016/j.acalib.2015.03.014

Cheslock, J. J., Ortagus, J. C., Umbricht, M. R., \& Wymore, J. (2016). The Cost of Producing Higher Education: An Exploration of Theory, Evidence, and Institutional Policy. In M. B. Paulsen (Ed.), Higher Education: Handbook of 
Theory and Research (pp. 349-392). Springer International Publishing. https://doi.org/10.1007/978-3-319-26829-3_7

Chickering, A. W., \& Gamson, Z. F. (1987). Seven principles for good practice in undergraduate education. AAHE Bulletin, 3, 7.

Chiu, P. H. P., \& Cheng, S. H. (2017). Effects of active learning classrooms on student learning: A two-year empirical investigation on student perceptions and academic performance. Higher Education Research \& Development, 36(2), 269-279. https://doi.org/10.1080/07294360.2016.1196475

Chow, A. F. (2015). Online homework impact in undergraduate mathematics and business statistics courses. Educational Studies, 41(3), 244-248.

Colder Carras, M., Porter, A. M., Van Rooij, A. J., King, D., Lange, A., Carras, M., \& Labrique, A. (2018). Gamers' insights into the phenomenology of normal gaming and game "addiction": A mixed methods study. Computers in Human Behavior, 79, 238-246. https://doi.org/10.1016/j.chb.2017.10.029

Consolazio, D. (2018). The History Of Esports. Hotspawn. https://www. hotspawn. com/the-history-of-esports

Credé, M., \& Kuncel, N. R. (2008). Study habits, skills, and attitudes: The third pillar supporting collegiate academic performance. Perspectives on Psychological Science, 3(6), 425-453.

Credé, M., \& Niehorster, S. (2012). Adjustment to college as measured by the student adaptation to college questionnaire: A quantitative review of its structure and relationships with correlates and consequences. Educational Psychology Review, 24(1), 133-165. 
Credé, M., Roch, S. G., \& Kieszczynka, U. M. (2010). Class Attendance in College: A Meta-Analytic Review of the Relationship of Class Attendance With Grades and Student Characteristics. Review of Educational Research, 80(2), 272-295. https://doi.org/10.3102/0034654310362998

Creswell, J. W., Plano Clark, V. L., Gutmann, M. L., \& Hanson, W. E. (2003). Advanced mixed methods research designs. Handbook of Mixed Methods in Social and Behavioral Research, 209, 240.

Cruz, C., Hanus, M. D., \& Fox, J. (2017). The need to achieve: Players' perceptions and uses of extrinsic meta-game reward systems for video game consoles. Computers in Human Behavior, 71, 516-524. https://doi.org/10.1016/j.chb.2015.08.017

Dale, G., Joessel, A., Bavelier, D., \& Green, S. (2020). A new look at the cognitive neuroscience of video game play. Annals of the New York Academy of Sciences, 1464(1), 192-203. https://doi.org/10.1111/nyas.14295

Davis, K., Sridharan, H., Koepke, L., Singh, S., \& Boiko, R. (2018). Learning and engagement in a gamified course: Investigating the effects of student characteristics. Journal of Computer Assisted Learning, 34(5), 492-503. https://doi.org/10.1111/jcal.12254

de las Heras, B., Li, O., Rodrigues, L., Nepveu, J.-F., \& Roig, M. (2019). A Single Bout of Exercise Improves Accuracy in Video Gaming: A Pilot Study: 2036: Board\# 192 May 30 2: 00 PM-3: 30 PM. Medicine \& Science in Sports \& Exercise, 51(6), 550-551.

DeCuir-Gunby, J. T., Marshall, P. L., \& McCulloch, A. W. (2011). Developing and Using a Codebook for the Analysis of Interview Data: An Example from a 
Professional Development Research Project. Field Methods, 23(2), 136-155. https://doi.org/10.1177/1525822X10388468

Demirbilek, M. (2014). The "digital natives" debate: An investigation of the digital propensities of university students. Eurasia Journal of Mathematics, Science and Technology Education, 10(2), 115-123.

https://doi.org/10.12973/eurasia.2014.1021a

Denson, C. D., Austin, C., Hailey, C., \& Householder, D. (2015). Benefits of Informal Learning Environments: A Focused Examination of STEM-based Program Environments. Journal of STEM Education: Innovations and Research, 16(1). http://ojs.jstem.org/index.php?journal=JSTEM\&page=article\&op=view\&path\%5 $\mathrm{B} \% 5 \mathrm{D}=1893$

Denzin, N. K., \& Lincoln, Y. S. (1994). Handbook of qualitative research. Sage Publications, Inc. http://psycnet.apa.org

Desiderato, O., \& Koskinen, P. (1969). Anxiety, study habits, and academic achievement. Journal of Counseling Psychology, 16(2p1), 162.

Devane, B., \& Squire, K. (2012). Activity Theory in the Learning Technologies (2nd ed.). Routledge.

Devilly, G. J., Brown, K., Pickert, I., \& O’Donohue, R. (2017). An evolutionary perspective on cooperative behavior in gamers. Psychology of Popular Media Culture, 6(3), 208-221. https://doi.org/10.1037/ppm0000097

Di Blasi, M., Giardina, A., Lo Coco, G., Giordano, C., Billieux, J., \& Schimmenti, A. (2020). A compensatory model to understand dysfunctional personality traits in 
problematic gaming: The role of vulnerable narcissism. Personality and Individual Differences, 160, 109921. https://doi.org/10.1016/j.paid.2020.109921

DiFrancisco-Donoghue, J., \& Balentine, J. R. (2018). Collegiate eSport: Where Do We Fit In? Current Sports Medicine Reports, 17(4), 117-118. https://doi.org/10.1249/JSR.0000000000000477

Diluna, A. (2017, June 20). College scholarships for video games? It's happening. NBC News. https://www.nbcnews.com/feature/college-game-plan/college-scholarshipsvideos-games-it-s-happening-n773996

Dodge, J. (1994). The study skills handbook: More than 75 strategies for better learning. Scholastic Inc.

Dolar, V. (2018). Does Instant Feedback on Online Homework Assignments Improve Student Learning in Introductory Economics Classes? Journal of Economics and Economic Education Research, 19(2), 1-15.

Drummond, A., \& Sauer, J. D. (2020). Timesplitters: Playing video games before (but not after) school on weekdays is associated with poorer adolescent academic performance. A test of competing theoretical accounts. Computers \& Education, 144, 103704.

Duggan, M. (2015, December 15). Gaming and Gamers [Di]. Pew Research Center: Internet, Science \& Tech. https://www.pewresearch.org/internet/2015/12/15/gaming-and-gamers/

Duncan, D. G. (2007). Student performance shows slight improvement when open notes are used during information systems exams. Journal of Information Technology Education: Research, 6(1), 361-370. 
DuPaul, G. J., Pinho, T. D., Pollack, B. L., Gormley, M. J., \& Laracy, S. D. (2017). Firstyear college students with ADHD and/or LD: Differences in engagement, positive core self-evaluation, school preparation, and college expectations. Journal of Learning Disabilities, 50(3), 238-251.

Durbach, A., \& Grey, R. (2018). Grounds for concern: An Australian perspective on responses to sexual assault and harassment in university settings. Gender Based Violence in University Communities: Policy, Prevention and Educational Initiatives, 83.

Dyer, A. M., Kristjansson, A. L., Mann, M. J., Smith, M. L., \& Allegrante, J. P. (2017). Sport Participation and Academic Achievement: A Longitudinal Study. American Journal of Health Behavior, 41(2), 179-185. https://doi.org/10.5993/AJHB.41.2.9

Eanes, R. (2013). The Value of Extracurricular Activities. Creative Child Magazine. http://www.creativechild.com/articles/view/the-value-of-extracurricular-activities

Eklund, L., \& Roman, S. (2019). Digital Gaming and Young People’s Friendships: A Mixed Methods Study of Time Use and Gaming in School. YOUNG, 27(1), 3247. https://doi.org/10.1177/1103308818754990

Elliott, Godshall, F., Shrout, J. R., \& Witty, T. E. (1990). Problem-solving appraisal, selfreported study habits, and performance of academically at-risk college students. Journal of Counseling Psychology, 37(2), 203.

Elliott, K. M., \& Healy, M. A. (2001). Key factors influencing student satisfaction related to recruitment and retention. Journal of Marketing for Higher Education, 10(4), 1-11. 
Ellis, K., \& Kao, K.-T. (2019). Who Gets to Play? Disability, Open Literacy, Gaming. Cultural Science Journal, 11(1), 111-125. https://doi.org/10.5334/csci.128

Ennis-Cole, D. (2019). Creating a Positive Learning Environment. In D. Ennis-Cole (Ed.), Seeing Autism through Parents' Feedback, Sketchnotes, Technology, and Evidence-based Practices (pp. 71-82). Springer International Publishing. https://doi.org/10.1007/978-3-030-15374-8_7

Erdmann, J., \& Clark, P. H. (2016). Librarians in the huddle: Supporting athlete success on and off the field. College \& Research Libraries News, 144-157. https://doi.org/10.5860/crln.77.3.9464

Farb, A. F., \& Matjasko, J. L. (2012). Recent advances in research on school-based extracurricular activities and adolescent development. Developmental Review, $32(1), 1-48$.

Farivar, C. (2011). The Internet of Elsewhere: The Emergent Effects of a Wired World. Rutgers University Press. https://muse.jhu.edu/book/2215

Feldman, A. F., \& Matjasko, J. L. (2005). The role of school-based extracurricular activities in adolescent development: A comprehensive review and future directions. Review of Educational Research, 75(2), 159-210.

Ferguson, C. J., \& Markey, P. (2017). Video games aren't addictive. The New York Times.

Fink, L. D. (2013). Creating significant learning experiences: An integrated approach to designing college courses. John Wiley \& Sons. 
Fish, L. A. (2015). Undergraduate Students Computer-managed Homework versus InClass Performance for Different Testing Formats. Business Education Innovation Journal, $7(1)$.

Flew, T., \& Humphreys, S. (2005). Games: Technology, Industry, Culture. Oxford University Press. https://digital.library.adelaide.edu.au/dspace/handle/2440/51227

Flipped Learning Network Hub. (2014). The four pillars of FLIP. Flipped Learning Network Hub. https://flippedlearning.org/definition-of-flipped-learning/

Franz, N., Childers, J., \& Sanderlin, N. (2012). Assessing the Culture of Engagement on a University Campus. Journal of Community Engagement and Scholarship. http://jces.ua.edu/assessing-the-culture-of-engagement-on-a-university-campus/

Freeman, G., \& Wohn, D. Y. (2018). Understanding eSports Team Formation and Coordination. Computer Supported Cooperative Work (CSCW), 27(3-6), 10191050. https://doi.org/10.1007/s10606-017-9299-4

Freeman, G., \& Wohn, D. Y. (2017). Social Support in eSports: Building Emotional and Esteem Support from Instrumental Support Interactions in a Highly Competitive Environment. Proceedings of the Annual Symposium on Computer-Human Interaction in Play, 435-447. https://doi.org/10.1145/3116595.3116635

Freeman, J., \& All, A. (2017). Academic support programs utilized for nursing students at risk of academic failure: A review of the literature. Nursing Education Perspectives, 38(2), 69-74.

Gallardo-Echenique, E. E., Marqués-Molías, L., Bullen, M., \& Strijbos, J.-W. (2015). Let's talk about digital learners in the digital era. The International Review of 
Research in Open and Distributed Learning, 16(3).

http://www.irrodl.org/index.php/irrodl/article/view/2196

García, J., \& Murillo, C. (2020). Sports video games participation: What can we learn for esports? Sport, Business and Management: An International Journal, 10(2), 169185. https://doi.org/10.1108/SBM-01-2019-0006

Gardner, M. R., \& Sheaffer, W. W. (2017). Systems to Support Co-creative Collaboration in Mixed-Reality Environments. In Virtual, Augmented, and Mixed Realities in Education (pp. 157-178). Springer.

Gawrysiak, J., Burton, R., Jenny, S., \& Williams, D. (2020). Using Esports Efficiently to Enhance and Extend Brand Perceptions - A Literature Review. Physical Culture and Sport. Studies and Research, 86(1), 1-14. https://doi.org/10.2478/pcssr-20200008

Gee, J. P. (2003). What video games have to teach us about learning and literacy. Computers in Entertainment (CIE), 1(1), 20-20.

Gillet, D., Jong, T. de, Sotirou, S., \& Salzmann, C. (2013). Personalised learning spaces and federated online labs for STEM Education at School. 2013 IEEE Global Engineering Education Conference (EDUCON), 769-773. https://doi.org/10.1109/EduCon.2013.6530194

Gnambs, T., Stasielowicz, L., Wolter, I., \& Appel, M. (2020). Do computer games jeopardize educational outcomes? A prospective study on gaming times and academic achievement. Psychology of Popular Media, 9(1), 69-82. https://doi.org/10.1037/ppm0000204 
Goehle, G., \& Wagaman, J. (2016). The impact of gamification in web based homework. PRIMUS, 26(6), 557-569.

Goette, W., Delello, J. A., \& McWhorter, R. R. (2019). Gendered Experiences of Mobile Gaming and Augmented Reality: Engagement with Pokémon Go among University Students. International Journal of Virtual and Augmented Reality (IJVAR), 2. www.igi-global.com/article/gendered-experiences-of-mobile-gamingand-augmented-reality/239898

Goltz, S. M., Hietapelto, A. B., Reinsch, R. W., \& Tyrell, S. K. (2008). Teaching teamwork and problem solving concurrently. Journal of Management Education, $32(5), 541-562$.

Greenwald, S., Kulik, A., Kunert, A., Beck, S., Frohlich, B., Cobb, S., Parsons, S., Newbutt, N., Gouveia, C., \& Cook, C. (2017). Technology and applications for collaborative learning in virtual reality. International Society of the Learning Sciences. International Society of the Learning Sciences, Philedelphia, PA. Griffiths, M. D., Kuss, D. J., \& Pontes, H. M. (2016). A brief overview of Internet Gaming Disorder and its treatment. Australian Clinical Psychologist, 2(1), 20108. https://acp.scholasticahq.com/article/787-a-brief-overview-of-internet-gamingdisorder-and-its-treatment

Griful-Freixenet, J., Struyven, K., Verstichele, M., \& Andries, C. (2017). Higher education students with disabilities speaking out: Perceived barriers and opportunities of the Universal Design for Learning framework. Disability \& Society, 32(10), 1627-1649. 
Guilmette, M., Mulvihill, K., Villemaire-Krajden, R., \& Barker, E. T. (2019). Past and present participation in extracurricular activities is associated with adaptive selfregulation of goals, academic success, and emotional wellbeing among university students. Learning and Individual Differences, 73, 8-15.

Gump, S. E. (2005). The cost of cutting class: Attendance as a predictor of success. College Teaching, 53(1), 21-26.

Halbrook, Y. J., O’Donnell, A. T., \& Msetfi, R. M. (2019). When and how video games can be good: A review of the positive effects of video games on well-being. Perspectives on Psychological Science, 14(6), 1096-1104.

Hallmann, K., \& Giel, T. (2018). ESports-Competitive sports or recreational activity? Sport Management Review, 21(1), 14-20.

Hamari, J., \& Sjöblom, M. (2017). What is eSports and why do people watch it? Internet Research, 27(2), 211-232. https://doi.org/10.1108/IntR-04-2016-0085

Hamilton, D. F., Lane, J. V., Gaston, P., Patton, J. T., MacDonald, D. J., Simpson, A. H. R. W., \& Howie, C. R. (2014). Assessing treatment outcomes using a single question. The Bone \& Joint Journal, 96-B(5), 622-628. https://doi.org/10.1302/0301-620X.96B5.32434

Hammond, P., \& Pötzsch, H. (2019). War Games: Memory, Militarism and the Subject of Play. Bloomsbury Publishing USA.

Hanghøj, T., Lieberoth, A., \& Misfeldt, M. (2018). Can cooperative video games encourage social and motivational inclusion of at-risk students? British Journal of Educational Technology, 49(4), 775-799. 
Hasan, H., \& Kazlauskas, A. (2013). Activity Theory: Who is doing what, why and how. 8.

Hatmaker, T. (2017, September 7). Blizzard will open its first U.S. esports stadium in Los Angeles next month. TechCrunch.

http://social.techcrunch.com/2017/09/07/blizzard-arena-los-angeles/

Hattenstone, S. (2017). The rise of eSports: Are addiction and corruption the price of its success. The Guardian. https://www.theguardian.com/sport/2017/jun/16/topaddiction-young-people-gaming-esports

Hewett, K. J. E. (2016). The minecraft project: Predictors for academic success and 21st century skills gamers are learning through video game experiences. https://tamucc-ir.tdl.org/handle/1969.6/851

Hill, A. (2018). Reporting sexual harassment: Toward accountability and action. The Gender Policy Report, 19.

Hine, C. (2000). Virtual Ethnography. Sage Publications Ltd. https://jet.com/product/VirtualEthnography/5f48b57b7e0a466b863bc610c6b5cf4f?jcmp=pla:ggl:nj_dur_gen_bo oks_other_media_a1:books_other_media_books_professional_technical_humaniti es_social_sciences_a1:na:PLA_785913270_41172815916_pla306778867144_c:na:na:na:2PLA15\&code=PLA15\&pid=kenshoo_int\&c=785913 270\&is_retargeting=true\&clickid=cc4b0b0b-59d7-45df-9eb4400747e52f9e\&kclid=cc4b0b0b-59d7-45df-9eb4400747e52f9e\&gclid=CjwKCAjwsfreBRB9EiwAikSUHbecxUWr98ZxrHhCiz94 a9nzRRIJDQvfNtJhT-Fy3EbGzPyySiNpCRoCIBoQAvD_BwE 
Hodes, J. S., James, T., Martin, G., \& Milliner, K. (2015). Go for the Win: A Collaborative Model for Supporting Student-Athletes. Learning Assistance Review, 20(1), 47-60. https://eric.ed.gov/?id=EJ1058010

Hogan, R., Chamorro-Premuzic, T., \& Kaiser, R. B. (2013). Employability and career success: Bridging the gap between theory and reality. Industrial and Organizational Psychology, 6(1), 3-16.

Holden, J. T., Kaburakis, A., \& Rodenberg, R. (2017). The Future Is Now: Esports Policy Considerations and Potential Litigation. Journal of Legal Aspects of Sport, 27, 46. https://heinonline.org/HOL/Page?handle=hein.journals/jlas27\&id=46\&div=\&coll ection $=$

Holden, J. T., Rodenberg, R. M., \& Kaburakis, A. (2017). Esports corruption: Gambling, doping, and global governance. Maryland Journal of International Law, 32, 236. https://doi.org/10.2139/ssrn.2831718

Hollist, K. E. (2015). Time to Be Grown-Ups about Video Gaming: The Rising eSports Industry and the Need for Regulation. Arizona Law Review, 57, 823. http://heinonline.org/HOL/Page?handle=hein.journals/arz57\&id=828\&div=\&coll ection $=$

Honebein, P. C., \& Honebein, C. H. (2015). Effectiveness, efficiency, and appeal: Pick any two? The influence of learning domains and learning outcomes on designer judgments of useful instructional methods. Educational Technology Research and Development, 63(6), 937-955. 
Hurlburt, G., Kroeker, R., \& Gade, E. (1991). Study Orientation, Persistence and Retention of Native Students: Implications for Confluent Education. Journal of American Indian Education, 30(3), 16-23.

Hurst, W. (2016, April). Extracurriculars are robbing students of their education. Inside Higher Ed. https://www.insidehighered.com/views/2016/04/11/extracurricularsare-robbing-students-their-education-essay

Hwa, C. (2016). Emerging Tools and Applications of Virtual Reality in Education. IGI Global.

Indra, E., Steffanily, \& Dinesh, T. (2019). Designing Android Gaming News \& Information Application Using Java-Based Web Scraping Technique. Journal of Physics: Conference Series, 1230, 012069. https://doi.org/10.1088/1742$6596 / 1230 / 1 / 012069$

Jacobs, H. (2015, May 11). Pro gamers explain the insane training regimen they use to stay on top. Business Insider. http://www.businessinsider.com/pro-gamersexplain-the-insane-training-regimen-they-use-to-stay-on-top-2015-5

Jacobsen, W. C., \& Forste, R. (2011). The wired generation: Academic and social outcomes of electronic media use among university students. Cyberpsychology, Behavior, and Social Networking, 14(5), 275-280.

Jahnke, I., Lee, Y.-M., Pham, M., He, H., \& Austin, L. (2020). Unpacking the inherent design principles of mobile microlearning. Technology, Knowledge and Learning, 25(3), 585-619.

Jenny, S. E., Keiper, M. C., Taylor, B. J., Williams, D. P., Gawrysiak, J., Manning, R. D., \& Tutka, P. M. (2018). eSports Venues: A New Sport Business Opportunity. 
Journal of Applied Sport Management, 10(1), 34-49.

https://doi.org/10.18666/JASM-2018-V10-I1-8469

Jenny, S. E., Manning, R. D., Keiper, M. C., \& Olrich, T. W. (2017). Virtual(ly) Athletes: Where eSports Fit Within the Definition of "Sport." Quest, 69(1), 1-18. https://doi.org/10.1080/00336297.2016.1144517

Jessi, J. L. (2018). Capable Homework Helper| College Homework Help. SSRN. https://ssrn.com/abstract=3120852

Jiwal, S., Jain, P., \& Jain, A. K. (2019). Impact of Playing Action and Puzzle Videogames on Attention and Executive Function: A Comparative Study. Indian J Physiol Pharmacol, 8.

Johnson, M. R., \& Woodcock, J. (2019). 'It's like the gold rush': The lives and careers of professional video game streamers on Twitch.tv. Information, Communication \& Society, 22(3), 336-351. https://doi.org/10.1080/1369118X.2017.1386229

Jones, C. M., Scholes, L., Johnson, D., Katsikitis, M., \& Carras, M. C. (2014). Gaming well: Links between videogames and flourishing mental health. Frontiers in Psychology, 5. https://doi.org/10.3389/fpsyg.2014.00260

Jung, D., Shim, E., Park, H., Lee, K., Lee, S., Kim, E., Chang, J. S., Jeong, S., Kim, Y., Ahn, Y. M., \& Hahm, B. (2020). The Association between Excessive Internet Gaming Behavior and Immersive Tendency, Mediated by Attention Deficit/Hyperactivity Disorder Symptoms, in Korean Male University Students. Psychiatry Investigation, 17(5), 403-411. https://doi.org/10.30773/pi.2019.0173 Junger, W. (1990). In Search of Homework That's Fun to Do. Zeitschrift Fur Padagogik, $36(2), 223-239$. 
Jyvaeskylae, U. of. (2007). How Does Online Gaming Affect Social Interactions?

ScienceDaily. https://www.sciencedaily.com/releases/2007/09/070915110957.htm

Kahu, E. R., Picton, C., \& Nelson, K. (2017). Experiencing the educational interface:

Understanding student engagement. STARS Conference, Adelaide, Australia.

Kaptelinin, V., \& Nardi, B. A. (2006). Activity Theory in a Nutshell. In Acting with technology: Activity theory and interaction design. MIT press.

Kassam, A., Iding, M., \& Hogenbirk, P. (2013). Unraveling the digital divide: Time well spent or "wasted"? Education and Information Technologies, 18(2), 215-221.

Kauweloa, N., \& Winter, J. (2019). Taking College Esports Seriously. Loading: The Journal of the Canadian Game Studies Association, 12(20), 35-50. https://doi.org/10.7202/1065896ar

Kauweloa, N., \& Winter, S. (2016). Collegiate E-sports as Work or Play. Proceedings of 1st International Joint Conference of DiGRA and FDG, 13. http://www.digra.org/wp-content/uploads/digital-library/paper_4361.pdf

Khandaker, J. (2019). Girl Gamers and Toxicity [Published MA Thesis, Univeristy of Houston]. https://uh-ir.tdl.org/handle/10657/4706

Kim, S. J. (2017). Gender inequality in eSports participation: Examining League of Legends [Published MA Thesis, University of Texas]. https://doi.org/10.15781/T2ZS2KW23

King, D. L., \& Delfabbro, P. H. (2020). Video game addiction. In Adolescent Addiction (pp. 185-213). Elsevier. 
King, D. L., \& Potenza, M. N. (2020). Gaming Disorder Among Female Adolescents: A Hidden Problem? Journal of Adolescent Health, 66(6), 650-652. https://doi.org/10.1016/j.jadohealth.2020.03.011

Kirschner, F., Paas, F., \& Kirschner, P. A. (2009). Individual and group-based learning from complex cognitive tasks: Effects on retention and transfer efficiency. Computers in Human Behavior, 25(2), 306-314. https://doi.org/10.1016/j.chb.2008.12.008

Kort-Butler, L. A. (2020). Gamers on Gaming: A Research Note Comparing Behaviors and Beliefs of Gamers, Video Game Players, and Non-Players. Sociological Inquiry, $n / a(\mathrm{n} / \mathrm{a})$. https://doi.org/10.1111/soin.12363

Kow, Y. M., \& Young, T. (2013). Media technologies and learning in the starcraft esport community. Proceedings of the 2013 Conference on Computer Supported Cooperative Work - CSCW'13, 387. https://doi.org/10.1145/2441776.2441821

Kronholz, J. (2011). Academic Value of Non-Academics. Education Next, 12(1). https://educationnext.org/academic-value-of-non-academics/

Kropp, M., Meier, A., Mateescu, M., \& Zahn, C. (2014). Teaching and learning agile collaboration. 2014 IEEE 27th Conference on Software Engineering Education and Training (CSEE T), 139-148. https://doi.org/10.1109/CSEET.2014.6816791

Küçükahmet, L. (2000). Planning and evaluation in teaching. Ankara: Nobel Publication.

Kuh, G. D., Kinzie, J., Schuh, J. H., \& Whitt, E. J. (2011). Student success in college: Creating conditions that matter. John Wiley \& Sons. 
Kulp, A. M., Pascale, A. B., \& Grandstaff, M. (2019). Types of Extracurricular Campus Activities and First-Year Students’'Academic Success. Journal of College Student Retention: Research, Theory \& Practice, 1521025119876249.

Kuncel, N. R., Hezlett, S. A., \& Ones, D. S. (2004). Academic Performance, Career Potential, Creativity, and Job Performance: Can One Construct Predict Them All? Journal of Personality and Social Psychology, 86(1), 148-161. https://doi.org/10.1037/0022-3514.86.1.148

Kwak, K. H., Hwang, H. C., Kim, S. M., \& Han, D. H. (2020). Comparison of Behavioral Changes and Brain Activity between Adolescents with Internet Gaming Disorder and Student Pro-Gamers. International Journal of Environmental Research and Public Health, 17(2), 441. https://doi.org/10.3390/ijerph17020441

Kwan, Y. W., \& Wong, A. F. L. (2015). Effects of the constructivist learning environment on students' critical thinking ability: Cognitive and motivational variables as mediators. International Journal of Educational Research, 70, 68-79. https://doi.org/10.1016/j.ijer.2015.02.006

La Corte, V., Sperduti, M., Abichou, K., \& Piolino, P. (2019). Episodic Memory Assessment and Remediation in Normal and Pathological Aging Using Virtual Reality: A Mini Review. Frontiers in Psychology, 10. https://doi.org/10.3389/fpsyg.2019.00173

Lakoff, G., \& Johnson, M. (1980). Metaphors we live by. University of Chicago Press. Lasley, E. A. (2017). Twenty-first Century Literacy, Game-based Learning, Projectbased Learning. Journal of Literacy and Technology, 18(3), 18. 
http://www.literacyandtechnology.org/uploads/1/3/6/8/136889/jlt_v18_3_lasley.p df

Latif, R. A., Aziz, N. A., \& Jalil, M. T. A. (2017). Impact of Online Games Among Undergraduate Students. 028, 10.

Lawhorne, A. (2020). Student Success Coaching in Virginia Community Colleges.

Lee, K. (2005). Gamer addiction: A threat to student success! What advisors need to know. NACADA Clearinghouse of Academic Advising Resources. https://nacada.ksu.edu/Resources/Clearinghouse/View-Articles/Game-AddictedStudents.aspx

Lenhart, A. (2015). Video Games Are Key Elements in Friendships for Many Boys. In Teens, Technology and Friendships. Pew Research Center: Internet \& Technology. http://www.pewinternet.org/2015/08/06/chapter-3-video-games-arekey-elements-in-friendships-for-many-boys/

Li, J., Han, X., Wang, W., Sun, G., \& Cheng, Z. (2018). How social support influences university students' academic achievement and emotional exhaustion: The mediating role of self-esteem. Learning and Individual Differences, 61, 120-126.

Li, S., Zhang, J., Yu, C., \& Chen, L. (2017). Rethinking distance tutoring in e-learning environments: A study of the priority of roles and competencies of Open University Tutors in China. International Review of Research in Open and Distributed Learning, 18(2), 189-212.

Lohmann, G., Pratt, M. A., Benckendorff, P., Strickland, P., Reynolds, P., \& Whitelaw, P. A. (2019). Online business simulations: Authentic teamwork, learning 
outcomes, and satisfaction. Higher Education, 77(3), 455-472.

https://doi.org/10.1007/s10734-018-0282-x

Lord, C. G., \& Lepper, M. R. (1999). Attitude representation theory. In Advances in experimental social psychology (Vol. 31, pp. 265-343). Elsevier.

Lotkowski, V. A., Robbins, S. B., \& Noeth, R. J. (2004). The Role of Academic and NonAcademic Factors in Improving College Retention. ACT Policy Report.

Lunceford, B., \& Rockwell, S. C. (2017). Reconsidering the Net Generation: Putting the focus back on the technological landscape. Explorations in Media Ecology, 16(1), 91-100. https://doi.org/10.1386/eme.16.1.91_1

Mahoney, J. L. (2003). School Extracurricular Activity Participation as a Moderator in the Development of Antisocial Patterns. Child Development, 71(2), 502-516. https://doi.org/10.1111/1467-8624.00160

Maksy, M., \& Yoon, M.-H. (2019). Supporting and Distracting Factors Affecting Student Performance in Management Information Systems: An Empirical Study at a US Commuter Public University. Journal of Accounting and Finance, 19(5), Article 5. https://doi.org/10.33423/jaf.v19i5.2251

Mallik, P. R., Metzger, M. M., Outen, H., MacKay, J., Fogle, T., Wilson, J., \& Lewis, S. (2020). Assessing Differences in Visual Cognition Between Nongamers, Moderate Action Gamers, and Heavy Action Gamers: An Alternative to Extreme Group Designs. Journal of Cognitive Enhancement. https://doi.org/10.1007/s41465-020-00169-1 
Mandernach, B. J. (2015). Assessment of student engagement in higher education: A synthesis of literature and assessment tools. International Journal of Learning, Teaching and Educational Research, 12(2).

Manero, B., Torrente, J., Fernández-Vara, C., \& Fernández-Manjón, B. (2017). Investigating the Impact of Gaming Habits, Gender, and Age on the Effectiveness of an Educational Video Game: An Exploratory Study. IEEE Transactions on Learning Technologies, 10(2), 236-246.

https://doi.org/10.1109/TLT.2016.2572702

Manero, B., Torrente, J., Freire, M., \& Fernández-Manjón, B. (2016). An instrument to build a gamer clustering framework according to gaming preferences and habits. Computers in Human Behavior, 62, 353-363. https://doi.org/10.1016/j.chb.2016.03.085

Martin, A. (2016). The Kids are Alright? Connecticut College. http://www.conncoll.edu/news/news-archive/2016/the-kids-are-alright/ McCarthy, C. (2019). Get an insider's glimpse into potential impact of esports. College Athletics and the Law, 15(12), 6-7. https://doi.org/10.1002/catl.30578

McGlone, M. S. (2007). What is the explanatory value of a conceptual metaphor? Language \& Communication, 27(2), 109-126. https://doi.org/10.1016/j.langcom.2006.02.016

McGrath, K. (2019). Leveraging Esports in Higher Education. Understanding Esports: An Introduction to the Global Phenomenon, 201. 
Mendezabal, M. J. N. (2013). Study Habits and Attitudes: The Road to Academic Success. Open Science Repository Education, Online(open-access), e70081928. https://doi.org/10.7392/Education.70081928

Mérelle, S., Kleiboer, A., Schotanus, M., Cluitmans, T. L. M., Waardenburg, C. M., Kramer, D., van de Mheen, D., \& van Rooij, A. (2017). Which health-related problems are associated with problematic video-gaming or social media use in adolescents? Clinical Neuropsychiatry: Journal of Treatments Evaluation, 14(1), 11-19. https://repub.eur.nl/pub/98403/

Merriam, S. B., \& Tisdell, E. J. (2016). Designing your study and selecting a sample. Qualitative Research: A Guide to Design and Implementation, 73-104.

Miles, A. (2013). Agile learning: Living with the speed of change. Development and Learning in Organizations: An International Journal, 27(2), 20-22. https://doi.org/10.1108/14777281311302058

Millecamp, M., Gutiérrez, F., Charleer, S., Verbert, K., \& De Laet, T. (2018). A qualitative evaluation of a learning dashboard to support advisor-student dialogues. Proceedings of the 8th International Conference on Learning Analytics and Knowledge, 56-60.

Morris, E. (2019). Participation in Extracurricular Activities and Academic Achievement: A Comprehensive Review. Western University of Kentucky.

Morrison, S. (2018, March 15). List of varsity esports programs spans North America. Entertainment and Sports Programming Network (ESPN). http://www.espn.com 
Mottet, T. P., Parker-Raley, J., Cunningham, C., \& Beebe, S. A. (2005). The relationships between teacher nonverbal immediacy and student course workload and teacher availability expectations. Communication Research Reports, 22(4), 275-282.

Mozelius, P. (2018). Game-construction students experiences of educational gamesGaming outcomes and learning outcomes. International Journal of Information and Communication Technologies in Education, 7(2), 5-16. https://doi.org/10.1515/ijicte-2018-0005

Mulcahy, D., Cleveland, B., \& Aberton, H. (2015). Learning spaces and pedagogic change: Envisioned, enacted and experienced. Pedagogy, Culture \& Society, 23(4), 575-595. https://doi.org/10.1080/14681366.2015.1055128

Myers, B. (2019). Friends With Benefits: Plausible Optimism and the Practice of Teabagging in Video Games. Games and Culture, 14(7-8), 763-780. https://doi.org/10.1177/1555412017732855

Nasution, A. I. (2015). A Study on the Relationship between Video Games and Students Academic Performance in IIUM. International Journal of Computer Science and Information Technology Research, 3(4), 106-111. https://www.academia.edu/18021456/A_Study_on_the_Relationship_between_Vi deo_Games_and_Students_Academic_Performance_in_IIUM

National Association of Collegiate Esports. (2020). About Collegiate eSports. National Association of Collegiate Esports. https://nacesports.org/about/ National Collegiate Athletic Association. (2020, May). Student-Athletes. NCAA. http://www.ncaa.org/student-athletes 
Neri, D. L. E. (2007). Learning styles and study skills among nursing students. Liceo Journal of Higher Education Research, 5(1).

Newzoo Insights - Covering the Games, Esports, and Mobile Markets. (2018). Newzoo. https://newzoo.com/insights/

Nguyen, M. (2017, December 8). ESports Jobs \& Careers in the Video Gaming Industry. Business Insider. http://www.businessinsider.com/esports-gaming-jobs-careers2017-12

Nicklen, P., Rivers, G., Ooi, C., Ilic, D., Reeves, S., Walsh, K., \& Maloney, S. (2015). An approach for calculating student-centered value in education-the link between quality, efficiency, and the learning experience in the health professions. Australia and New Zealand Association of Health Professional Educators Conference 2015 (Dr Graeme Horton 29 March 2015 to 1 April 2015), 1, 333333. http://arrow.monash.edu.au/vital/access/manager/Repository/monash:157333

Nonis, S. A., \& Hudson, G. I. (2010). Performance of College Students: Impact of Study Time and Study Habits. Journal of Education for Business, 85(4), 229-238. https://doi.org/10.1080/08832320903449550

Nordby, K., Løkken, R. A., \& Pfuhl, G. (2019). Playing a video game is more than mere procrastination. BMC Psychology, 7(1), 33. https://doi.org/10.1186/s40359-019$0309-9$

Norman, L. (2017, June). Reasons Why Kids Shouldn't Have Extracurricular Activities. Livestrong. http://www.livestrong.com/article/1000551-reasons-kids-shouldntextracurricular-activities/ 
Nurul Ulyani, M. N., Nor Aini, Y., \& Zulkifli, O. (2010). Measuring satisfaction with student housing facilities.

Nuyens, F. M., Kuss, D. J., Lopez-Fernandez, O., \& Griffiths, M. D. (2019a). The Empirical Analysis of Non-problematic Video Gaming and Cognitive Skills: A Systematic Review. International Journal of Mental Health and Addiction, 17(2), 389-414. https://doi.org/10.1007/s11469-018-9946-0

Nuyens, F. M., Kuss, D. J., Lopez-Fernandez, O., \& Griffiths, M. D. (2019b). The Potential Interaction Between Time Perception and Gaming: A Narrative Review. International Journal of Mental Health and Addiction. https://doi.org/10.1007/s11469-019-00121-1

Oates, T. P., \& Brookey, R. A. (2014). Playing to Win: Sports, Video Games, and the Culture of Play. Indiana University Press. https://muse.jhu.edu/book/36070 O'Connor, C. A., Dyson, J., Cowdell, F., \& Watson, R. (2018). Do universal schoolbased mental health promotion programmes improve the mental health and emotional wellbeing of young people? A literature review. Journal of Clinical Nursing, 27(3-4), e412-e426.

Ohayon, M. M. (2008). From wakefulness to excessive sleepiness: What we know and still need to know. Sleep Medicine Reviews, 12(2), 129-141.

Oloyede, E. O., Adebowale, O. F., \& Ojo, A. A. (2012). The Effects of Competitive, Cooperative, and Individualistic Classroom Interaction Models on Learning Outcomes in Mathematics in Nigerian Senior Secondary Schools. ISRN Education, 2012, e263891. https://doi.org/10.5402/2012/263891 
Ortony, A., Vondruska, R. J., Foss, M. A., \& Jones, L. E. (1985). Salience, similes, and the asymmetry of similarity. Journal of Memory and Language, 24(5), 569-594. http://www.sciencedirect.com/science/article/pii/0749596X85900476

Osborn, S. (2020, May). Recruiting Fact Sheet. National Collegiate Athletic Association. https://www.ncaa.org/sites/default/files/Recruiting\%20Fact\%20Sheet\%20WEB.p df

Özsoy, G., Memiş, A., \& Temur, T. (2017). Metacognition, study habits and attitudes. International Electronic Journal of Elementary Education, 2(1), 154-166.

Paaßen, B., Morgenroth, T., \& Stratemeyer, M. (2017). What is a True Gamer? The Male Gamer Stereotype and the Marginalization of Women in Video Game Culture. Sex Roles, 76(7), 421-435. https://doi.org/10.1007/s11199-016-0678-y

Palocsay, S. W., \& Stevens, S. P. (2008). A study of the effectiveness of web-based homework in teaching undergraduate business statistics. Decision Sciences Journal of Innovative Education, 6(2), 213-232.

Parker, J. (2006). Does Living Near Classmates Help Introductory Students Get Better Grades? Journal of Public Economics, 9(90), 1455-1475.

Partin, W. (2017, April 12). College Esports Programs Are Growing, But Can They Make a Winning Team? Rolling Stone. https://www.rollingstone.com/glixel/news/heroes-of-the-dorm-do-college-esportsprograms-matter-w476281

Paul, C. A. (2018). The Toxic Meritocracy of Video Games: Why Gaming Culture Is the Worst. University of Minnesota Press. https://muse.jhu.edu/book/58306 
Perloff, R. M. (2016). The Dynamics of Persuasion: Communication and Attitudes in the Twenty-First Century. Routledge.

Pietersen, A. J., Coetzee, J. K., Byczkowska-Owczarek, D., Elliker, F., \& Ackermann, L. (2018). Online gamers, lived experiences, and sense of belonging: Students at the University of the Free State, Bloemfontein. Qualitative Sociology Review, 14(4), $122-137$.

Pope, B. (2017, October 24). The Gamer Subculture. The Gamer Subculture. https://www.thelines.com/colleges-universities-integrating-esports/

Popescu, E., \& Ghita, D. (2013). Using social networking services to support learning. Lecture Notes in Computer Science (Including Subseries Lecture Notes in Artificial Intelligence and Lecture Notes in Bioinformatics), 8167, 184-193. https://doi.org/10.1007/978-3-642-41175-5_19

Prensky, M. (2006). Don't bother me, Mom, I'm learning!: How computer and video games are preparing your kids for 21 st century success and how you can help! Paragon House St.

Purdie, N., \& Hattie, J. (1999). The relationship between study skills and learning outcomes: A meta-analysis. Australian Journal of Education, 43(1), 72-86.

Quadlin, N. (2017). Funding sources, family income, and fields of study in college. Social Forces, 96(1), 91-120.

Quinton, S. (2016). The High Cost of Higher Education. Stateline: The Pew Charitable Trusts. https://www.pewtrusts.org/en/research-andanalysis/blogs/stateline/2016/01/25/the-high-cost-of-higher-education 
Radhakrishnan, P., Lam, D., \& Ho, G. (2009). Giving university students incentives to do homework improves their performance. Journal of Instructional Psychology, 36(3), 219.

Rath, D. (2014, March 5). How Do Your Learning Spaces Measure Up? Campus Technology. https://campustechnology.com/articles/2014/03/05/how-do-yourlearning-spaces-measure-up.aspx

Reddy, V. K., Said, L., Sengupta, B., Chetlur, M., Costantino, J. P., Gopinath, A., Flynt, S., Balunaini, P., \& Vedula, S. (2015). Personalized Learning Pathways: Enabling intervention creation and tracking. IBM Journal of Research and Development, 59(6), 4:1-4:14. https://doi.org/10.1147/JRD.2015.2456711

Reeves, S., Peller, J., Goldman, J., \& Kitto, S. (2013). Ethnography in qualitative educational research: AMEE Guide No. 80. 35(8), e1365-e1379. https://doi.org/10.3109/0142159X.2013.804977

Reitman, J. G., Anderson-Coto, M. J., Wu, M., Lee, J. S., \& Steinkuehler, C. (2020). Esports research: A literature review. Games and Culture, 15(1), 32-50.

Richtel, M. (2013). Digitally aided education, using the students' own electronic gear. The New York Times, 22.

Riker, H. C., \& DeCoster, D. A. (2008). The Educational Role in College Student Housing. Journal of College \& University Student Housing, 35(2).

Roman, T. A., Callison, M., Myers, R. D., \& Berry, A. H. (2020). Facilitating Authentic Learning Experiences in Distance Education: Embedding Research-Based Practices into an Online Peer Feedback Tool. TechTrends, 64(4), 591-605. 
Rosenberg, G. (2017, February 23). Go To College, Play Video Games. E-Sports Make A Play For The Big Ten. National Public Radio. https://www.npr.org/sections/alltechconsidered/2017/02/23/515853132/go-tocollege-play-video-games-e-sports-make-a-play-for-the-big-ten

Roth, W.-M., \& Lee, Y.-J. (2007). “Vygotsky's neglected legacy”: Cultural-historical activity theory. Review of Educational Research, 77(2), 186-232. http://rer.sagepub.com/content/77/2/186.short

Routon, P. W., \& Walker, J. K. (2015). Student-Athletes? The Impact of Intercollegiate Sports Participation on Academic Outcomes. Eastern Economic Journal, 41(4), 592-611. https://doi.org/10.1057/eej.2014.32

Rusk, F., Stlaahl, M., \& Silseth, K. (2020). Exploring Peer Mentoring and Learning Among Experts and Novices in Online in-Game Interactions. Proceedings of the 14th International Conference on Game Based Learning, Ed. P. Fotaris, 461468.

Ryan, T., Henderson, M., \& Phillips, M. (2019). Feedback modes matter: Comparing student perceptions of digital and non-digital feedback modes in higher education. British Journal of Educational Technology, 50(3), 1507-1523.

Sample size for Qualitative Interviews. (2015, March). The Academic Triangle. https://researcholic.wordpress.com/2015/03/20/sample_size_interviews/

Samsuri, S., Ting, C. T., Ariff, M. F. H. bin M., Karthigesu, D., \& Hoong, L. Y. (2019). To Study the Effects of Video Games on Concentration, Attention and Reaction Time Among Undergraduate Students: A Randomised Controlled Trial. 
International Journal of Public Health and Health Systems, 4(3), 65. https://doi.org/7550173

Sanders, J., \& Williams, R. (2019). The Relationship Between Video Gaming, Gambling, and Problematic Levels of Video Gaming and Gambling. Journal of Gambling Studies, 35(2), 559-569. https://doi.org/10.1007/s10899-018-9798-3

Sandi-Urena, S., Cooper, M., \& Stevens, R. (2012). Effect of Cooperative Problem-Based Lab Instruction on Metacognition and Problem-Solving Skills. Journal of Chemical Education, 89(6), 700-706. https://doi.org/10.1021/ed1011844

Santucci, A. (2012). The Effect of Sports Participation on GPAs: A Conditional Quantile Regression Analysis. University of California, Berkeley.

Saz, A., Engel, A., \& Coll, C. (2016). Introducing a Personal Learning Environment in Higher Education. An Analysis of Connectivity. Digital Education Review. http://eric.ed.gov.outside.www.hlg.edu:8080/?q=small+university+learning+envir onment\&id=EJ1106179

Schaeperkoetter, C. C., Mays, J., Hyland, S. T., Wilkerson, Z., Oja, B., Krueger, K., Christian, R., \& Bass, J. R. (2017). The "New” Student-Athlete: Journal of Intercollegiate Sport, 10(1), 1-21. https://doi.org/10.1123/jis.2016-0011

Schargel, F. P., \& Smink, J. (2014). Strategies to help solve our school dropout problem. Routledge.

Schepens, V. A. C. (2019). Student Life Balance [Bachelor thesis]. http://localhost/handle/1874/392836 
Schmidt, S., \& Shreffler, M. (2015). Motivations for eSport consumption: A road map for traditional sports online spectating. 2015 Sport Marketing Association Conference.

Scholz, T. M. (2019a). A Short History of eSports and Management. In T. M. Scholz (Ed.), ESports is Business: Management in the World of Competitive Gaming (pp. 17-41). Springer International Publishing. https://doi.org/10.1007/978-3-03011199-1_2

Scholz, T. M. (2019b). Introduction: The Emergence of eSports. In T. M. Scholz (Ed.), ESports is Business: Management in the World of Competitive Gaming (pp. 116). Springer International Publishing. https://doi.org/10.1007/978-3-030-11199$1 \_1$

Schwartz, D. G. (2017). Research (In) Complete: An Exploratory History of Competitive Video Gaming. Gaming Law Review, 21(8), 542-556.

Seo, Y., \& Jung, S. (2016). Beyond solitary play in computer games: The social practices of eSports. Journal of Consumer Culture, 16(3), 635-655. https://doi.org/10.1177/1469540514553711

Seow, P., \& Pan, G. (2014). A literature review of the impact of extracurricular activities participation on students' academic performance. Journal of Education for Business, 89(7), 361-366.

Sharples, J., Blatchford, P., \& Webster, R. (2016). Making best use of teaching assistants (Education Endowment Foundation) [Educational]. Education Endowment Foundation. www.educationendowmentfoundation.org.uk 
Shim, S. S., \& Ryan, A. M. (2012). What do students want socially when they arrive at college? Implications of social achievement goals for social behaviors and adjustment during the first semester of college. Motivation and Emotion, 36(4), 504-515. http://link.springer.com/article/10.1007/s11031-011-9272-3

Shochet, R. B., Colbert-Getz, J. M., \& Wright, S. M. (2015). The Johns Hopkins Learning Environment Scale: Measuring Medical Students' Perceptions of the Processes Supporting Professional Formation. Academic Medicine, 90(6), 810818. https://doi.org/10.1097/ACM.0000000000000706

Short, E., \& Weidner, N. (2019). Gamers at work: Predicting workplace-relevant behaviours across domains. Journal of Gaming \& Virtual Worlds, 11(2), 161177. https://doi.org/10.1386/jgvw.11.2.161_1

Shulruf, B. (2010). Do extra-curricular activities in schools improve educational outcomes? A critical review and meta-analysis of the literature. International Review of Education, 56(5), 591-612. https://doi.org/10.1007/s11159-010-9180-x

Simmons, J. (2020). Class Scheduling.

Sogari, G., Velez-Argumedo, C., Gómez, M. I., \& Mora, C. (2018). College students and eating habits: A study using an ecological model for healthy behavior. Nutrients, 10(12), 1823.

Soni, N. K., Gupta, K. K., \& Shrivastava, J. (2018). Awareness and Usage of Electronic Resources among LIS Scholars of Jiwaji University, Gwalior: A Survey. DESIDOC Journal of Library \& Information Technology, 38(1).

Southern, N. (2017). The rise of eSports: A new audience model and a new medium? [California State University, Stanislaus]. 
https://www.csustan.edu/sites/default/files/groups/University\%20Honors\%20Prog ram/Journals/southern.pdf

Sparx. (2017). The Unbelievable LoL World Championship 2017 Grand Final Stadium Crowd | Esports News \& Videos. Dexerto. https://www.dexerto.com/news/lolworld-championship-grand-final-stadium-crowds/38360

Spoelstra, H., Van Rosmalen, P., Van de Vrie, E., Obreza, M., \& Sloep, P. (2013). A team formation and project-based learning support service for social learning networks. Journal of Universal Computer Science, 19(10), 1474-1495. http://www.jucs.org/jucs_19_10/a_team_formation_and/jucs_19_10_1474_1495_ spoelstra.pdf

Spring, D. (2015). Gaming History: Computer and Video Games as Historical Scholarship. Rethinking History, 19(2), 207-221. http://dx.doi.org/10.1080/13642529.2014.973714

Stanton, R. (2015, June). ESports athletes put in hours of training to reach the pinnacle. Inside an ESports Training Regiment, ESPN. http://www.espn.com/espn/story/_id/13053116/esports-athletes-put-hourstraining-reach-pinnacle

Stark, P., \& Noel, A. M. (2015). Trends in High School Dropout and Completion Rates in the United States: 1972-2012. (Compendium Report NCES 2015-015). National Center for Education Statistics.

Sterk Barrett, M. C. (2015). Fostering the spiritual development of undergraduates through service-learning. 
Stocking, G. (1983). The Ethnographer's Magic. Fieldwork in British Anthropology from Tyler to Malinowski, 70-120.

Strage, A., \& Sorkhabi, N. (2017). Academic Risks Associated with Emerging Adults Seeking the College Experience. College Student Journal, 50(3), 329-334.

Stuart, M., Lido, C., Morgan, J., Solomon, L., \& May, S. (2011). The impact of engagement with extracurricular activities on the student experience and graduate outcomes for widening participation populations. Active Learning in Higher Education, 12(3), 203-215.

http://journals.sagepub.com/doi/abs/10.1177/1469787411415081

Sun, Y. (2017). Motivation To Play Esports: Case of League of Legends [PhD Thesis]. University of South Carolina.

Sutton, H. (2019). Professional programming offers pathways to two degrees in five years. Enrollment Management Report, 23(9), 6-7.

Syvänen, A., Frydenberg, M., Poutanen, J., Turunen, M., Walton, G., Syvänen, A., Frydenberg, M., Poutanen, J., Turunen, M., \& Walton, G. (2014). Interactive and Engaging Social Learning Spaces for Collaboration. 2014, 1429-1434. https://www.learntechlib.org/p/147672/

Tabbers, H. K., Martens, R. L., \& Merriënboer, J. J. (2004). Multimedia instructions and cognitive load theory: Effects of modality and cueing. British Journal of Educational Psychology, 74(1), 71-81. http://onlinelibrary.wiley.com/doi/10.1348/000709904322848824/abstract

Taylor, T. L., \& Witkowski, E. (2010). This is how we play it: What a mega-LAN can teach us about games. Proceedings of the Fifth International Conference on the 
Foundations of Digital Games, 195-202.

https://doi.org/10.1145/1822348.1822374

Tham, S. M., Ellithorpe, M. E., \& Meshi, D. (2020). Real-world social support but not ingame social support is related to reduced depression and anxiety associated with problematic gaming. Addictive Behaviors, 106, 106377.

https://doi.org/10.1016/j.addbeh.2020.106377

Thompson, M. E. (1976). The prediction of academic achievement by a British study habits inventory. Research in Higher Education, 5(4), 365-372.

Throuvala, M. A., Janikian, M., Griffiths, M. D., Rennoldson, M., \& Kuss, D. J. (2019). The role of family and personality traits in Internet gaming disorder: A mediation model combining cognitive and attachment perspectives. Journal of Behavioral Addictions, 8(1), 48-62. https://doi.org/10.1556/2006.8.2019.05

Thuma, C. (2012, October). Pew study finds 70 percent of college students play video games - Hesston College Horizon. Hesston Horizon. https://horizon.hesston.edu/pew-study-finds-70-percent-of-college-students-playvideo-games/

Tillier, C. M. (2018, January). The Incredible Rise Of eSports. NASDAQ. https://www.nasdaq.com/articles/incredible-rise-esports-2018-01-12

Todd, M. (In preparation). A Systematic Review of Literature: Undergraduate Videogaming Students [Literature Review for PHD dissertation]. University of Missouri, Columbia.

Torres-Díaz, J.-C., Duart, J. M., Gómez-Alvarado, H.-F., Marín-Gutiérrez, I., \& SegarraFaggioni, V. (2016). Internet Use and Academic Success in University Students. 
Comunicar. Media Education Research Journal, 24(2).

https://doi.org/10.3916/C48-2016-06

Toyoda, Y., \& Kanegae, H. (2019). Gaming Simulation as a Tool of Problem-Based Learning for University Disaster Education. In Neo-Simulation and Gaming Toward Active Learning (pp. 237-245). Springer.

Triberti, S., Milani, L., Villani, D., Grumi, S., Peracchia, S., Curcio, G., \& Riva, G. (2018). What matters is when you play: Investigating the relationship between online video games addiction and time spent playing over specific day phases. Addictive Behaviors Reports, 8, 185-188.

https://doi.org/10.1016/j.abrep.2018.06.003

Twenge, J. M. (2017). IGen: Why Today's Super-Connected Kids Are Growing Up Less Rebellious, More Tolerant, Less Happy-and Completely Unprepared for Adulthood-and What That Means for the Rest of Us. Simon and Schuster.

University of Rochester. (2010). Video Games Lead to Faster Decisions that are No Less Accurate. Rochester News. http://www.rochester.edu/news/show.php?id=3679

Uuskoski, O. (2011). Playing video games: A waste of time... or not. Exploring the Connection between Playing Video Games and English Grades.

Vatterott, C. (2018). Rethinking homework: Best practices that support diverse needs. ASCD.

Vessey, I., \& Galletta, D. (1991). Cognitive fit: An empirical study of information acquisition. Information Systems Research, 2(1), 63-84. http://pubsonline.informs.org/doi/abs/10.1287/isre.2.1.63 
Von Stumm, S., Hell, B., \& Chamorro-Premuzic, T. (2011). The hungry mind: Intellectual curiosity is the third pillar of academic performance. Perspectives on Psychological Science, 6(6), 574-588.

Wachelka, D., \& Katz, R. C. (1999). Reducing test anxiety and improving academic selfesteem in high school and college students with learning disabilities. Journal of Behavior Therapy and Experimental Psychiatry, 30(3), 191-198.

Wagner, P., Schober, B., \& Spiel, C. (2008). Time investment and time management: An analysis of time students spend working at home for school. Educational Research and Evaluation, 14(2), 139-153.

Walker, J. P., Sampson, V., Southerland, S., \& Enderle, P. J. (2016). Using the laboratory to engage all students in science practices. Chemistry Education Research and Practice. http://pubs.rsc.org/-/content/articlehtml/2016/rp/c6rp00093b

Walters, D., Dantu, R., \& Lovelace, K. (2019). Esports: Influencing eLeadership skills and academic performance. http://dspace.calstate.edu/handle/10211.3/214215

Wang, F. (2009). Handbook of Research on Hybrid Learning Models: Advanced Tools, Technologies, and Applications: Advanced Tools, Technologies, and Applications. IGI Global.

Wang, J., \& Shiveley, J. (2009). The impact of extracurricular activity on student academic performance. 5, 2010.

Wax, M. L. (1972). Tenting with Malinowski. American Sociological Review, 1-13.

Wenger, E., McDermott, R. A., \& Snyder, W. (2002). Cultivating Communities of Practice: A Guide to Managing Knowledge. Harvard Business Press. 
Wheeler, L. B., Maeng, J. L., Chiu, J. L., \& Bell, R. L. (2017). Do teaching assistants matter? Investigating relationships between teaching assistants and student outcomes in undergraduate science laboratory classes. Journal of Research in Science Teaching, 54(4), 463-492.

Whelan, A., Leddy, J. J., Mindra, S., Hughes, J. D. M., El-Bialy, S., \& Ramnanan, C. J. (2016). Student perceptions of independent versus facilitated small group learning approaches to compressed medical anatomy education. Anatomical Sciences Education, 9(1), 40-51. https://doi.org/10.1002/ase.1544

Wimmer-Schwarb, A. (2018, October 10). Number of NCAA college athletes reaches alltime high. National Collegiate Athletic Association. http://www.ncaa.org/about/resources/media-center/news/number-ncaa-collegeathletes-reaches-all-time-high

Wingfield, N. (2014). E-Sports at College, With Stars and Scholarship. The New York Times. https://www.nytimes.com/2014/12/09/technology/esports-collegesbreeding-grounds-professional-gaming.html

Wong, S. (2017, September 7). Studying The Growth Of Collegiate Esports. A List Daily. http://www.alistdaily.com

Yao, M., Mahood, C., \& Linz, D. (2010). Sexual Priming, Gender Stereotyping, and Likelihood to Sexually Harass: Examining the Cognitive Effects of Playing a Sexually-Explicit Video Game. Sex Roles, 62(1), 77-88. https://doi.org/10.1007/s11199-009-9695-4

Yao, X. (2019). Game Time:" Not Too Much, Nor Too Little" [Sociology Honors Project, Macalester]. https://digitalcommons.macalester.edu/soci_honors/58 
Yenawine, P., \& Miller, A. (2014). Visual Thinking, Images, and Learning in College. About Campus, 19(4), 2-8. https://doi.org/10.1002/abc.21162

Yilmaz, E., Yel, S., \& Griffiths, M. D. (2018). The impact of heavy (excessive) video gaming students on peers and teachers in the school environment: A qualitative study. Addicta: The Turkish Journal on Addictions, 5(2), 147-161. https://doi.org/10.15805/addicta.2018.5.2.0035

Yilmaz-Soylu, M., \& Bruning, R. H. (2016). Exploring Self-regulation of More or Less Expert College-Age Video Game Players: A Sequential Explanatory Design. Frontiers in Psychology, 7. https://doi.org/10.3389/fpsyg.2016.01441

Yin, R. K. (1989). Case study research: Design and methods, revised edition. Applied Social Research Methods Series, 5.

York, T. T., Gibson, C., \& Rankin, S. (2015). Defining and Measuring Academic Success. 20(5), 20.

Young, M. W. (2017). Routledge Revivals: The Ethnography of Malinowski (1979): The Trobriand Islands 1915-18. Routledge.

Yu, D. D. (2011). How much do study habits, skills, and attitudes affect student performance in introductory college accounting courses? New Horizons in Education, 59(3), 1-15.

Zajac, K., Ginley, M. K., Chang, R., \& Petry, N. M. (2017). Treatments for Internet gaming disorder and Internet addiction: A systematic review. Psychology of Addictive Behaviors, 31(8), 979-994. https://doi.org/10.1037/adb0000315

Zhao, J., LaFemina, P., Carr, J., Sajjadi, P., Wallgrün, J. O., \& Klippel, A. (2020). Learning in the field: Comparison of desktop, immersive virtual reality, and 
actual field trips for place-based STEM education. 2020 IEEE Conference on Virtual Reality and 3D User Interfaces (VR), 893-902. 


\section{Appendix A - Initial Interest Questionnaire}

Individuals interested in the study were asked the following questions, which were used to filter the participants to ensure they played more than fourteen hours of video games, were in an undergraduate higher education program, and were in at least their second semester.

What is your age?

I am age 18 or older.

I am age 17 or younger.

(The qualifying participant must answer "I am age eighteen or older.”)

Are you enrolled in an undergraduate college program as a full-time student?

Yes

No

(The qualifying participant must answer “yes.”)

Is the semester you are entering your first ever in college?

Yes, I am a first-semester freshman.

No, this will be my second, or higher, semester in college.

(The qualifying participant cannot be a first-semester freshman.)

In an average week, how many hours of video games do you watch or play?

14 hours or more a week

13 hours or less a week

(To qualify for the study, a participant must report fourteen or more hours of watching and/or playing games or be an eSport team member.)

Do you play on an official college-sponsored eSports team?

Yes

No

(Answering "yes" qualifies a participant for further consideration in study.

If the answer is "No;" the question about hours played must be fourteen or more hours per week.) 


\section{Appendix B - Consent Form}

Read through the following Consent Form. Selecting "next" at the bottom of the consent page is the participant's permission to collect the data for research

\section{Research Consent}

Because you followed the interest link on the previous web page, you have now been directed to the consent form. Proceeding through the consent form serves as permission to collect data for this research project.

\section{Participant Consent Form}

The purpose of this research study is to evaluate the study habits and attitudes of heavyvideo-gaming students in undergraduate schools. We are interested in examining the study habits and attitudes of college video-gaming students (18 and older) who play more than 14 hours of games a week, and whether additional or specialized learning supports need to be implemented by the university leaders.

Please be advised that participation is voluntary, and there are no risks associated with involvement in the study. By selecting "next" on this consent form, you will be taken to a five-question qualifying questionnaire. Those participants with answers that qualify as a participant for the study will be directed to the qualitative questionnaire with demographic questions.

The qualitative demographic questionnaire poses questions about yourself, study habits and attitudes, and offers a chance to win a $\$ 20$ incentive. This demographic questionnaire will take no longer than 10 minutes to complete. At the end of the qualitative questionnaire with demographics, you are given the opportunity to apply to participate in the research project at two additional levels.

First, you will be invited to be considered to participate in the research project at a deeper level. A virtual ethnography will be conducted with 30 selected participants from those taking the qualitative questionnaire with demographics. If selected as one of the 30 , you will be asked to commit to a 16-week long study, use a special data collecting mobile application, and answer questions three times a week using a phone or mobile device, by text, questionnaires, photos, or video. Participants completing $100 \%$ of the tasks will receive a $\$ 35$ gift card.

The researcher will have access to all answers submitted through the ethnography app for future review. If you are not selected as one of the 30 ethnography students, you will be contacted and given the opportunity to participate in the 100-question questionnaire option, which is described in the following paragraph, the second manner to be involved in the project. If you do not wish to participate in the virtual ethnography, you will be asked if you would like to help the research project in one final way and acquire more chances to win the $\$ 20$ gaming gift card by completing more questionnaire questions. To earn up to five more chances for the gift, you need to answer 100 quick and easy rating questions specifically about your study habits and attitudes. For every 20 questions 
completed of the 100, you are entered in the drawing one additional time. Completing the questionnaire can result in up to five entries for the gift drawing, plus the one entry already earned for completing the qualitative questionnaire with demographic questions. This is a total of six chances to win the gaming card. Participants involved in the sixteenweek ethnography are also eligible to receive the guaranteed $\$ 35$ game card, as well as to be entered into the drawing for the $\$ 20$ gift card.

If for any reason you do not want to continue in the project, you may end the session and leave at any time. Results from all sessions will be included in the data analysis section of the dissertation paper to be presented to the School of Information Sciences and Learning Technologies and University of Missouri research committee group. Your name will not be included in the report nor will your name be associated with any session data collected.

If you wish to speak with someone about your participation in this study, or if you feel you were not treated as described above, please contact Michelle Todd at 573-629-3202/ mrt972@mail.missouri.edu or Dr. Isa Jahnke @ jahnkei@missouri.edu.

Selecting "next" and entering the questionnaire processes is offering your consent to the following statement: "I have read and fully understand the extent of the study and any risks involved. All of my questions, if any, have been answered to my satisfaction. By clicking "next," I acknowledge my understanding of the information provided in this form and indicates my willingness to participate in this user testing session. I can print a copy of this consent form for my records."

Thank you for participating in this research study. All results will be made publicly available upon request.

Michelle Todd 


\section{Appendix C - Introductory Qualitative Questionnaire with Demographics}

Table 35 shows the survey questions including demographics and other items with possible answers and the rationale for including the item in the survey.

\section{Table 35}

Qualitative Survey with Demographic Questions and Other Items

\begin{tabular}{|c|c|c|c|}
\hline$\#$ & Question & Possible Answers & Rationale \\
\hline 1 & $\begin{array}{l}\text { What is the name of your } \\
\text { college? }\end{array}$ & Multiple possibilities & $\begin{array}{l}\text { Identify school and sort } \\
\text { by type and size of } \\
\text { school }\end{array}$ \\
\hline 2 & $\begin{array}{l}\text { In what state/province is } \\
\text { your college? }\end{array}$ & $\begin{array}{l}50 \text { states } \\
\text { Multiple possibilities }\end{array}$ & $\begin{array}{l}\text { Sort by school regional } \\
\text { location }\end{array}$ \\
\hline 3 & $\begin{array}{l}\text { Does your college have } \\
\text { an official eSports team? }\end{array}$ & $\begin{array}{l}\text { Yes } \\
\text { No } \\
\text { I'm not sure }\end{array}$ & $\begin{array}{l}\text { Compare team players } \\
\text { to individual players }\end{array}$ \\
\hline 4 & $\begin{array}{l}\text { List your home } \\
\text { state/province of } \\
\text { residence. }\end{array}$ & Multiple possibilities & $\begin{array}{l}\text { Sort by player regional } \\
\text { location }\end{array}$ \\
\hline 5 & $\begin{array}{l}\text { What is your level of } \\
\text { study? }\end{array}$ & $\begin{array}{l}\text { Freshman } \\
\text { Sophomore } \\
\text { Junior } \\
\text { Senior }\end{array}$ & $\begin{array}{l}\text { Provides level of } \\
\text { experience }\end{array}$ \\
\hline 6 & $\begin{array}{l}\text { How many semesters of } \\
\text { college have you } \\
\text { competed? }\end{array}$ & $0,1-9$, more & $\begin{array}{l}\text { Reinforces there are no } \\
1^{\text {st }} \text { time freshmen; } \\
\text { how game playing } \\
\text { correlates to level in } \\
\text { school }\end{array}$ \\
\hline 7 & $\begin{array}{l}\text { In which academic } \\
\text { discipline is your major? }\end{array}$ & $\begin{array}{ll}\text { - } & \text { Computing, Engineering, } \\
& \text { Math; } \\
\text { - } & \text { Business \& Commerce; } \\
\text { - } & \text { Health-Wellness and } \\
& \text { Medical; } \\
\text { - } & \text { Creative, Design/Performing } \\
& \text { Arts; } \\
\text { - } & \text { Other (e.g., Biblical Studies); } \\
\text { - } & \text { Natural, Environmental, Life } \\
& \text { Sciences; } \\
\text { - } & \text { Communication, Journalism, } \\
& \text { Writing and Media; } \\
\text { - } & \text { Education and Helping } \\
& \text { Professions; } \\
\text { - } & \text { Culture and Society; } \\
\text { - } & \text { Social and Behavioral. }\end{array}$ & Sort by majors \\
\hline
\end{tabular}


Table 35 (continued)

\begin{tabular}{|c|c|c|c|}
\hline 8 & $\begin{array}{l}\text { List your specific major } \\
\text { of study. }\end{array}$ & Open ended & Intentionally blank \\
\hline 9 & $\begin{array}{l}\text { How many credit hours } \\
\text { are you enrolled in for } \\
\text { this semester? }\end{array}$ & $\begin{array}{l}\text { Less than } 12 \\
12-18 \\
19 \text { or more }\end{array}$ & $\begin{array}{l}\text { Scheduling load; } \\
\text { provides insight to goal } \\
\text { setting and completion } \\
\text { of hours at the end of } \\
\text { semester }\end{array}$ \\
\hline 10 & $\begin{array}{l}\text { Select the range of your } \\
\text { current GPA as it is as the } \\
\text { beginning of this current } \\
\text { semester. }\end{array}$ & $\begin{array}{ll}- & 4.0 \\
- & 3.5 \text { to } 3.9 \\
- & 3.0 \text { to } 3.4 \\
- & 2.5 \text { to } 2.9 \\
- & 2.0 \text { to } 2.4 \\
- & 1.5 \text { to } 1.9 \\
- & \text { Lower than } 1.5\end{array}$ & GPA level \\
\hline 11 & What is your gender? & $\begin{array}{l}\text { Male } \\
\text { Female } \\
\text { Do not wish to state }\end{array}$ & Sort by gender \\
\hline 12 & $\begin{array}{l}\text { Describe the way you } \\
\text { play video games at } \\
\text { college }\end{array}$ & $\begin{array}{ll}\text { - } & \text { I play on an official college } \\
\text { team. } \\
\text { - } \quad \text { I play at a competitive level } \\
\text { with a team of friends. } \\
\text { - } \quad \text { I play at a competitive level } \\
\text { by myself. } \\
\text { - } \quad \text { I play for leisure. } \\
\text { - } \quad \text { Other }\end{array}$ & $\begin{array}{l}\text { Understand gaming } \\
\text { habits }\end{array}$ \\
\hline 13 & $\begin{array}{l}\text { Why do you play video } \\
\text { games? }\end{array}$ & 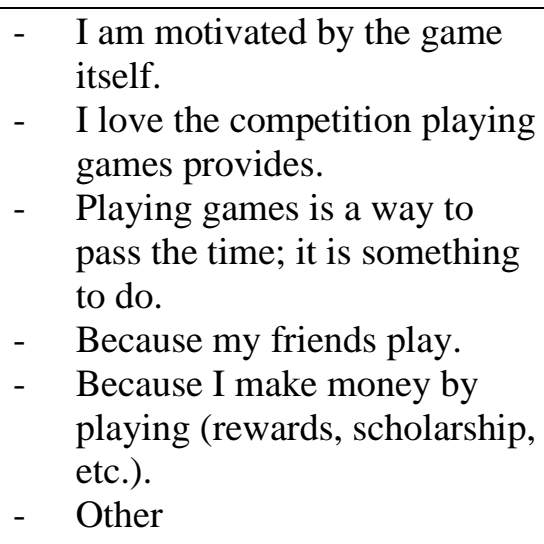 & Understand motivation \\
\hline 14 & $\begin{array}{l}\text { How has video-gaming } \\
\text { interfered or gotten "in the } \\
\text { way of" your academic } \\
\text { (school) studies? }\end{array}$ & Open ended & $\begin{array}{l}\text { Interaction between } \\
\text { gaming and study }\end{array}$ \\
\hline
\end{tabular}


Table 35 (continued)

\begin{tabular}{|c|c|c|c|}
\hline 15 & $\begin{array}{l}\text { How has academic } \\
\text { (school) study interfered } \\
\text { or gotten "in the way of" } \\
\text { your video-gaming? }\end{array}$ & Open ended & $\begin{array}{l}\text { Interaction between } \\
\text { gaming and study }\end{array}$ \\
\hline 16 & $\begin{array}{l}\text { List your motivations for } \\
\text { coming to college } \\
\text { (school)? }\end{array}$ & Open ended & Understand motivation \\
\hline 17 & Rate your academic performance. & $\begin{array}{l}0-10 \\
0=\text { Very poor }- \text { I am } \\
\text { usually behind in most } \\
\text { classes. } \\
10=\text { Very efficient }- \text { I get } \\
\text { all work completed, and } \\
\text { presented on time. }\end{array}$ & Perceived performance \\
\hline 18 & Rate your game performance & $\begin{array}{l}\text { Professional level; } \\
\text { Semi-professional level; } \\
\text { College competitive } \\
\text { team; } \\
\text { For fun. }\end{array}$ & Perceived performance \\
\hline
\end{tabular}

\begin{tabular}{llll}
\hline 19 & Estimate the number of HOURS & 1 to 24 & Gaming practices \\
PER DAY you watch or play & &
\end{tabular}
video games.

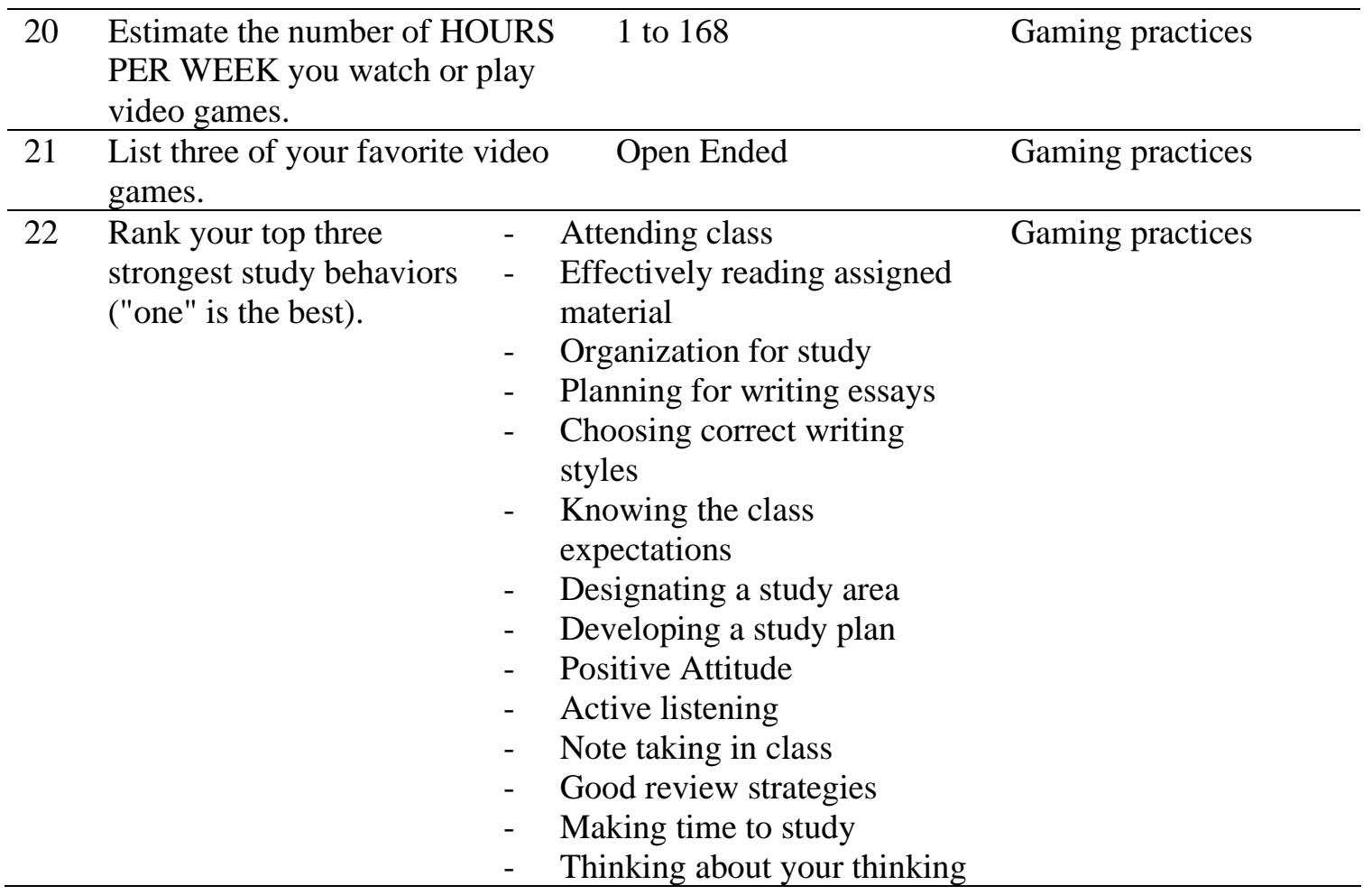


Table 35 (continued)

- $\quad$ Avoiding distractions such as

social media

- Proper rest

- Proper nutrition

- Other

23 Estimate the HOURS PER 1 to 24

DAY you spend studying

for school academics.

24 Estimate the HOURS PER

1 to 168

Gaming practices

WEEK you spend studying for academics at school.

\begin{tabular}{lllc}
\hline 25 & $\begin{array}{l}\text { Do you consider yourself a } \\
\text { procrastinator? }\end{array}$ & Yes/No & Work methods \\
\hline 26 & What motivates you to study? & Open ended & Attitudes \\
\hline 27 & $\begin{array}{l}\text { What motivates you to play } \\
\text { games? }\end{array}$ & Open ended & Attitudes \\
\hline
\end{tabular}

28 How do you prefer to - Alone Gaming habits
play games?

- With a group of close friends

- With any group of acquaintances

- On a formal team

- Other

29 How do you prefer to study?
- Alone

- With a group of two to three people

- With a small study group of four to eight people

- In a large group of 10 or more people

- Other
Gaming practices
Study skills

\section{Attitude}

Attitude

Open ended Attitude
Study skills

(describe using a metaphor)

32 My study habits are like Open ended

(describe using a metaphor) 
Table 35 (continued)

\begin{tabular}{|c|c|c|c|}
\hline 33 & $\begin{array}{l}\text { At what level do video } \\
\text { games hinder your } \\
\text { academic study? }\end{array}$ & $\begin{array}{l}\text { My studies are severely } \\
\text { hindered by games; I choose } \\
\text { games over homework almost } \\
\text { every day. } \\
\text { My studies are hindered by } \\
\text { games more often than not } \\
\text { (three to four times out of } \\
\text { five). } \\
\text { My studies are hindered by } \\
\text { games only moderately (one } \\
\text { to two times out of five). } \\
\text { My studies are rarely } \\
\text { hindered by games. I can } \\
\text { easily put games aside until } \\
\text { all my work is completed. }\end{array}$ & Delays \\
\hline 34 & $\begin{array}{l}\text { At what age did you start } \\
\text { seriously playing video } \\
\text { games? }\end{array}$ & List ages & $\begin{array}{l}\text { Background } \\
\text { experiences }\end{array}$ \\
\hline 35 & $\begin{array}{l}\text { Sometimes, video-gaming } \\
\text { students can play games for } \\
\text { extended periods of time. } \\
\text { Estimate the greatest amount } \\
\text { of time in hours, you have } \\
\text { ever played video games at } \\
\text { one setting. For example, } \\
\text { playing all night might equate } \\
\text { to "eight hours." }\end{array}$ & List numbers & Practices \\
\hline 36 & $\begin{array}{l}\text { Are you a ranked player? } \\
\text { What ranking in which } \\
\text { game? }\end{array}$ & Yes/No & Gaming practices \\
\hline & $\begin{array}{l}\text { Do you want to enter your } \\
\text { name into the drawing for a } \\
\$ 20 \text { STEAM card for taking } \\
\text { the demographic survey? }\end{array}$ & Yes/No & $\begin{array}{l}\text { If no, participants are } \\
\text { thanked. } \\
\text { If yes, they are directed } \\
\text { to participate further. }\end{array}$ \\
\hline
\end{tabular}


Table 35 (continued)

Would you like to be contacted about participating in a 16-week long research study, using your mobile phone? If selected, you will receive a \$35 STEAM gift card for participating.

\section{Yes/No}

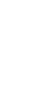

If yes, people are entered into the pool of names to select participants for the virtual ethnography. If selected, they will take the SSHA survey at the end of the 16week study.

If people are not interested, they will be asked to take the SSHA survey now.

If yes, go to survey now or enter your number and a link to the survey will be sent. attitudes in order to be entered five times into a drawing to win a STEAM Game card? 


\section{Appendix D - Questionnaire of Study Habits and Attitudes (SSHA)}

The 100-question Questionnaire of Study Habits and Attitudes (SSHA) is shown below (Brown \& Holtzman, 1967). Questions have been divided into five twentyquestion sections for the purpose of helping the participants taking the exam in Phase 1 to feel less overwhelmed by the 100 questions. For each section completed a chance for winning an incentive is offered.

If the participants are a part of the virtual ethnography, they will be answering five questions per week until the questionnaire is completed. These participants receive a larger guaranteed incentive for completing the sixteen-week research study.

Answer the following questions with the corresponding letter that represents your answer.

- Rarely (0 to $15 \%$ of the time, after first Freshman semester of college until now)

- Sometimes (16 to 35\% of the time, after first Freshman semester of college until now)

- Frequently (36 to $65 \%$ of the time, after first Freshman semester of college until now)

- Generally (66 to $85 \%$ of the time, after first Freshman semester of college until now)

- Almost always (86 to $100 \%$ of the time, after first Freshman semester of college until now)

1. When my assigned homework is extra-long or unusually hard, I either quit or study only the easier parts of the lesson.

2. In preparing reports, themes, and other written work, I make certain that I clearly understand what is wanted before I begin work.

3. I feel that teachers don't understand the needs and interests of students.

4. My dislike for certain teachers causes me to neglect my school work. 
5. If I have to be absent from class, I make up missed lessons without being reminded by the teacher.

6. I have trouble saying what I want to say on tests, reports, and other work to be turned in.

7. My teachers make their subjects interesting and meaningful to me.

8. I feel that I would study harder if I were given more freedom to choose subjects that I like.

9. Daydreaming distracts my attention from my lessons while I am studying.

10. My teachers criticize my written work for being poorly planned or hurriedly written.

11. I feel that teachers allow their likes or dislikes for students to influence their grading too much.

12. Even though I don't like a subject, I still work hard to make a good grade.

13. Even though an assignment is dull and boring, I stick to it until it is completed.

14. I give special attention to neatness on themes, reports, and other work to be turned in.

15. I believe that the easiest way to get good grades is to agree with everything the teachers say.

16. I lose interest in my studies after the first few days of school.

17. I keep all my work for each subject together and carefully arranged in some planned order.

18. I memorize spelling rules, definitions of words, rules of grammar, etc., without really understanding them. 
19. I think that teachers like to show who's boss too much.

20. I believe that teachers really want their students to like them.

(Page Break in Qualtrics)

21. When I am having trouble with my school work, I try to talk it over with the teacher.

22. I hesitate to ask a teacher for further explanation of an assignment that is not clear to me.

23. I feel that teachers are too narrow-minded and set in their ways.

24. I feel that students are not given enough freedom in selecting their own topics for themes and reports.

25. I do not bother to correct errors on the papers my teachers have graded and returned to me.

26. I get nervous and confused when taking a test and fail to answer questions as well as I otherwise could.

27. I think that teachers expect students to do too much studying outside of class.

28. Lack of interest in my school work makes it hard for me to keep my attention on my reading assignments.

29. My place of study at home is kept neat and businesslike.

30. I have trouble with spelling, grammar, and punctuation while writing themes and reports.

31. When explaining a lesson or answering questions, my teachers use words that I do not understand. 
32. Unless I really like a subject, I believe in doing only enough to get a passing grade.

33. Interruptions disturb my studies when I am studying at home.

34. In taking notes, I tend to write down things which later turn out to be unimportant.

35. My teachers fail to give enough explanation of the things they are trying to teach.

36. I feel confused and undecided as to what I want to study in school and what I want to do after I get out of school.

37. It takes a long time for me to get warmed up to the job of studying.

38. I do poorly on tests because I find it hard to think clearly and plan my work within a short period of time.

39. I feel that teachers are too strict and know-it-all in dealing with students.

40. Some of my school work is so uninteresting that I have to make myself do the assignments.

(Page Break in the Qualtrics)

41. I am unable to study well because I get restless, moody, or have the blues.

42. I skip over the figures, graphs, and tables in a reading assignment.

43. I believe that teachers secretly enjoy giving their students a "hard time."

44. I believe that having a good time and getting one's full share of fun out of life is more important than studying.

45. I put off doing written assignments until the last minute.

46. After reading several pages of an assignment, I am unable to remember what I have just read.

47. I think that teachers tend to talk too much. 
48. I believe that teachers tend to avoid discussing present-day problems and events with their classes.

49. When I sit down to study, I find myself too tired, bored, or sleepy to study well.

50. I find it hard to pick out the important points of a reading assignment — points that later appear on tests.

51. I feel that teachers try to give the same amount of attention and help to all their students.

52. I feel that my grades show about what I can really do.

53. I waste too much time talking, watching $\mathrm{TV}$, listening to the radio, going to the movies, etc., for the good of my studies.

54. When in doubt about the proper form for a written assignment, I find a model or guide to follow.

55. The illustrations, examples, and explanations given by my teachers are dull and hard to understand.

56. I feel that it is not worth the time, money, and effort that one must spend to get a college education.

57. My studying at home is done in an easy-going, unplanned manner.

58. When reading a long assignment, I stop now and then to try to remember what I have read.

59. I feel that teachers tend to look down upon their poorer students and make fun of their mistakes.

60. Some of my classes are so boring that I spend the class period drawing pictures, writing notes, or daydreaming instead of listening to the teacher. 


\section{(Page Break in the Qualtrics)}

61. Having too many other things to do causes me to get behind in my school work.

62. I seem to get very little done for the amount of time I spend studying.

63. I feel that teachers make their subjects too hard for the average student.

64. I feel that I am taking subjects which will do me little good.

65. I try to do my assignments at school so as to reduce my homework.

66. I can study a reading assignment for only a short while before the words stop making sense.

67. I think that football coaches do more for school life than do the teachers.

68. I believe that the main job of the schools is to teach students things that will help them earn a living.

69. Problems outside of school — with other students or at home — cause me to neglect my school work.

70. I copy the diagrams, drawings, tables, and other illustrations that the teacher puts on the blackboard (boards).

71. I feel that teachers think more about grades than they do about the real purpose of schools (education).

72. I try to become really interested in every subject I take.

73. I complete my homework assignments on time.

74. I lose points on tests because I change my first answer only to discover later that I was right the first time.

75. I think that students who ask questions and take part in class discussion are only trying to "get in good" with the teacher. 
76. I feel that the main reason for going to college is to be admired and envied by others.

77. I like to have a radio, record player (music), or television set turned on while I'm studying.

78. When getting ready for a test I arrange facts to be learned in some planned order-order of importance, order in which taught, order of time in history, etc.

79. I believe that teachers deliberately give tests on the days following parties and ball games.

80. I believe that having a winning football team is just as important as learning history or math.

(Page Break in the Qualtrics)

81. With me, studying is sort of hit-or-miss depending on the mood I'm in.

82. I am careless about spelling, punctuation, and grammar when answering test questions.

83. I believe that one way to get good grades is by using flattery on your teachers.

84. I think that it might be best for me to drop out of school and get a job.

85. I study an hour or more each day outside of school.

86. Although I work until the last possible minute, I am unable to finish tests within the time allowed.

87. I feel that it is almost impossible for the average student to do all of his assigned homework.

88. I feel that the things taught in school do not help one to meet adult problems.

89. I keep my assignments up to date by doing my work regularly from day to day. 
90. If time is left, I take a few minutes to check over my answers before turning in my test paper.

91. I feel that the ridiculous assignments made by teachers are the main reason for student cheating.

92. Too much reading or studying gives me a headache.

93. I prefer to study my lessons alone rather than with others.

94. When tests are returned, I find that my grade has been lowered by careless mistakes.

95. I feel that students cannot be expected to like most teachers.

96. I feel like skipping school whenever there is something I'd rather do.

97. At the beginning of a study period, I plan my work so that I will make best use of my time.

98. During tests I forget names, dates, formulas, and other details that I really do know.

99. I believe that teachers go into teaching mainly because they enjoy it.

100. I believe that higher grades are given to students who can memorize facts than to those who think things through. 


\section{Appendix E - Indeemo Virtual Ethnography Tasks and Weekly Timeline}

For using Indeemo during the sixteen-week study, participants were asked to complete following steps.

1. Install and use a mobile application, Indeemo, which was the tool used to capture the ethnography data. The Indeemo company indicated in a phone interview with the researcher that recent improvements had been made to the system, affirming the software works on both Android and iPhone platforms.

2. Create a schedule document reflecting their anticipated semester using a free website https://www.freecollegeschedulemaker.com/

3. Respond to a short list of questions or tasks three to five times a week. These tasks included answering multiple-choice and short answer questions, rating events using five-point scales, taking photos, and producing one-minute think-aloud videos.

4. Respond to random chats/tasks sent throughout the study. These tasks required a photo or a response with a short text.

5. Provide an interview with the researcher if requested.

6. Complete the 100-question SSHA survey, integrated into the weekly questions, a few questions at a time.

7. Complete $100 \%$ of the study tasks in order to be eligible for the incentive gift card within the stated time restrictions.

\section{One-time-only Task 1.}

Participants created and shared a copy of their anticipated school semester schedule. Following this link https://www.freecollegeschedulemaker.com/, students showed expected times for classes, studying, practices/rehearsals, meals, personal care, extracurricular activities, gaming, and sleeping. Participants were asked to indicate the estimated time allotted for each event to the nearest 15-minute increment. This schedule was used as a baseline framework to evaluate various task reports and activities for the semester, such as identification of class schedule and free time. 


\section{Weekly Tasks.}

There were a variety of weekly tasks that participants completed. Sometimes students were asked to do one-minute think-aloud videos to answer questions. An example question is Describe a major academic milestone this week and how you prepared for it. Other times questions presented could be answered on a binary scale or a Likert scale by easily typing in some text.

The questions could include items about gaming and study habits, as well as attitudes about studying. An example question is Rate how you feel about your academic day-Bad ----- to ------ Great 12345 If great, tell why and what worked well. If bad, tell why and what could have helped.

Finally, once a week the participants were asked to answer up to eight questions from the SSHA survey (Appendix D).

\section{Weekly Random Tasks.}

At random times during the week, participants were asked to respond to a question in an attempt to catch them in the moment of life. For example, a message was sent asking, "What are you doing now?", and the student responded as quickly as able after viewing the question with a description and a photo of the activity.

Each task was open for only 30 minutes. For example, when receiving the task, the student might have been eating and responded with a text and a photo with the food item. The random responses helped to indicate if the student behavior was close to the anticipated schedule providing possible insight into activity related to study and extracurricular activities.

Other tasks asked for screenshots of the student learning management systems 
reports, such as attendance and grade checkpoint. All efforts were made to reach out to participants who showed signs of waning from the study to determine the reasons for reduced participation. When participants dropped out of the study, the researcher asked for a 40-minute interview from the individual and made an effort to capture the remaining data that would have been completed on the Indeemo platform.

Final Indeemo questions asked participants about learning supports that students desired that could help them improve their academic performance. These specific questions were formulated based upon the data collected during the research.

\section{— Weekly questions}

How many hours of games did you play yesterday?

How many hours were you in class or study?

Describe anything that interfered with your academic study/preparedness this week.

Describe the major assignments and activities you have for this week.

Send a photo of what you are doing now. What should you be doing right now?

— Week 1 - Self Introduction

Record a short one-minute video on the Indeemo app, introducing yourself. Explain what type of academic student you are and why you play video games at college.

- Week 1 - Create an anticipated week schedule

This is the only task in the study that may take a few moments to complete and may be best accomplished on a larger screen. All other tasks in the remainder of the research study can be done in under a minute.

Please go to the following site (https://www.freecollegeschedulemaker.com/) and create a model of your expected daily (24-hour) schedule for an average week of the semester. Now that school has started, you have a good idea about your schedule. Include class hours, meal times, anticipated sleep hours, work hours, extracurricular hours, and all activities in which you have commitments. Also, include the hours you think you will dedicate to homework and video-gaming. 
https://www.freecollegeschedulemaker.com/

When finished filling out the schedule, save an image of the schedule using the "save as image" button. You may also use the export button to save the file and upload the .csmo file here or take a photo of the week schedule.

You may upload as an image, a .csmo file, a pdf, or a photo.

— Week 1 - Screenshot of Transcript

Please provide a screenshot or photo of your unofficial transcript as it stands at the beginning of this Fall 2019 semester.

— Week 1 - Weekly Wrap-up Question

Please follow this link to answer five short questions: https://missouri.qualtrics.com/jfe/form/SV_6staTrgyVRIGKgJ

—Week 2 - SSHA Questions 1- 8

Follow this link to answer the eight short multiple-choice questions from the Survey of Study Habits and Attitudes. https://missouri.qualtrics.com/jfe/form/SV_3gB3hP70BShFhSR

—Week 2 - Video/Text - Learning Supports

Record a short video or type with text to describe any learning supports available on your campus that you have used.

Learning supports are any tools that make your study more effective or provide you with some type of service.

What other learning supports or services do you wish were available on your campus?

- Week 2 - Random task - Photo - What are you doing now?

Please take a photo of the activity you are involved in when receiving this notice (please use discretion).

For example, if you are walking across campus, take a photo and caption it. If you are playing a game, take a photo and caption it. If you are studying, take a photo and caption it. In the caption, indicating that doing this particular task would be considered "on task" for your day - are you doing what you should be doing?

- Week 2 - Video - Week Reflection

Create a one-minute video describing the following: 
- What major milestones occurred this week in your academic study?

- What major milestones occurred this week in your gaming?

- Describe the approaches/patterns you noticed occurring in your study-habits that helped you be academically successful this week?

- Describe the approaches/patterns you noticed occurring in your gaming habits that helped you be a successful gamer this week?

- What could have helped you be even more successful in both your studies and gaming?

- Week 3 - SSHA Questions 9-16

Follow this link to answer the eight short multiple-choice questions from the Survey of Study Habits and Attitudes:

https://missouri.qualtrics.com/je/form/SV_5hVgqUzB4FqYLB3

— Week 3 - Extracurricular Activities

List extracurricular activities you enjoy or participate in, other than gaming.

- Week 3 - Extracurricular Activities Video

How does gaming help or hinder your academic success as compared to other extracurricular activities you or other friends may be involved in?

Explain your answer in a short one-minute video.

- Week 3 - Random Photo - What are you doing now?

Please take a photo of the activity you are involved in when receiving this notice (please use discretion).

For example, if you are walking across campus, take a photo and caption it. If you are playing a game, take a photo and caption it. If you are studying, take a photo and caption it. In the caption, indicating that doing this particular task would be considered "on task" for your day - are you doing what you should be doing?

- Week 4 Video - Study Habits

Make a one-minute video describing things you do that help you best prepare for academic assignments.

- Week 4 - Skills from College

Describe things you have learned in college that have helped you be a better gamer.

- Week 4 - SSHA Questions 17- 24 
Follow this link to answer the eight short multiple-choice questions from the Survey of Study Habits and Attitudes:

https://missouri.qualtrics.com/jfe/form/SV_414x0CqKKpDDR5P

— Week 4 - Learning New things

Please share the easiest ways for you to learn something new.

How often do you encounter these methods you need in your academic settings?

Please explain.

— Week 5 - Skills from Gaming

What skills have you learned in gaming that have made you a better academic student?

— Week 5 - Study

Take a photo of your favorite study location and describe the way you study best for an important event/task/test.

- Week 5 - SSHA Survey Questions 25-32

Follow this link to answer the 8 short multiple-choice questions from the Survey of Study Habits and Attitudes:

https://missouri.qualtrics.com/jfe/form/SV_dm8z7GaEPyHayCV

— Week 5 - Video Balance

Prepare a one-minute video discussing how you balance your gaming and studies while in college.

- Week 6 - Photo/screenshot

Take a photo or screen shot of your class attendance records.

Caption the photo with a thought about your classroom involvement; how is it going?

— Week 6 - Gaming Supports your Studies

Discuss how you feel that video-gaming and academics work together in your college experience.

Do they support one another in any way?

— Week 6 - SSHA 33-40 
Follow this link to answer the eight short multiple-choice questions from the Survey of Study Habits and Attitudes:

https://missouri.qualtrics.com/jfe/form/SV_8elUsmcqHDZQbrf

— Week 6 - Personality

In a one-minute video describe your personality.

- Week 6 - Focus

On a scale of 1 to 10 (best) select a number that describes how your college studies are going at this point in the semester. Then explain why you selected the number

— Week 7 - Locus of Control

Go to this site and take the short survey.

Take a screenshot of the results http://www.psych.uncc.edu/pagoolka/LC.html

- Week 8 - Attitude about Gaming This Week

Provide a photo, screenshot or video that describes how you felt about gaming this week. In the caption, estimate how many hours you spent gaming this week.

- Week 8 - SSHA Questions 41 - 48

Take this short survey. https://missouri.qualtrics.com/jfe/form/SV 5dOu62oQYFjO84Z

— Week 8 - Attitudes about Study

Provide a photo/screenshot or video describing how you felt about your academic study and teachers this week.

In the caption list, how many hours you spent studying outside of class during the week.

—Week 8 - Academic Stress

Share a one-minute video explaining what causes you to feel stressed while at school. How do you deal with these feelings of stress?

- Week 9 - Describe your Avatar 
Describe your avatar/character in your favorite game? What skills do you use as this character that you can transfer to academics?

— Week 9 - Learning

Describe the setting you most enjoy for academic learning.

— Week 9 - Describe Yourself

Use five words to describe the type of student you are.

- Week 9 - SSHA questions 49-56

Take this short survey:

https://missouri.qualtrics.com/jfe/form/SV_5zG8gpWPyAVXZnn

— Week 10 - Career

How do you see gaming contributing to your career path?

— Week 10 - Life Goals

How do you see gaming contributing to your life goals?

— Week 10 - SSHA questions 57 - 64

Complete the short survey:

https://missouri.qualtrics.com/jfe/form/SV_4HfYh0Ot8uuKnlP

— Week 11 - SSHA Questions 65-72

Answer the short multiple-choice questions at this link:

https://missouri.qualtrics.com/jfe/form/SV_1FD3sMnUHgiXQVL

— Week 11 - Games or Academics

Make a short video to support one of the following statements:

The things I have learned in gaming has made me a better academic student.... or

The things I have learned in my academic study has made me a better gamer.

- Week 11 - Support

What type of academic support could you use at this point in the semester? 
— Week 12 - Skills

List your best gaming skills.

List your best academic/study skills.

- Week 12 - Time/Frequency

How has your schedule changed from the one you imagined at the beginning of the semester? How are you doing with projected gaming, academic study, and sleeping segments?

— Week 12 - SSHA Questions

Complete the short multiple-choice questions:

https://missouri.qualtrics.com/jfe/form/SV 5ik8NqLb94cynPL

The final weeks were used for wrapping up and contacting participants in an effort to conduct interviews. 


\section{Appendix F - Study Habits Metaphors}

Participants were asked to define their study habits by completing the following metaphor; My study habits are like.... The responses have been grouped into the categories highlighted by the gray title shown in Table 36 .

\section{Table 36}

My Study Habits are Like ... Metaphors

\begin{tabular}{|c|c|}
\hline Metaphor & Additional Comments from Participant \\
\hline \multicolumn{2}{|l|}{ A planned attack } \\
\hline A meticulous planner & $\begin{array}{l}\text { I set aside specific time blocks where I study for } \\
\text { certain topics in classes that I need to understand more } \\
\text { about. }\end{array}$ \\
\hline $\begin{array}{l}\text { Leveling up myself as a } \\
\text { person }\end{array}$ & $\begin{array}{l}\text { I know that by putting forth effort into my studies that } \\
\text { I am investing in myself. }\end{array}$ \\
\hline Eating and drinking & I place my academics above all else. \\
\hline A turtle & Slow but stable. \\
\hline Clockwork & $\begin{array}{l}\text { I have a strict study schedule. } \\
\text { Speaks for itself }\end{array}$ \\
\hline A river & $\begin{array}{l}\text { Always flowing gently as I do what I need to do and it } \\
\text { isn't a struggle. } \\
\text { Constant and powerful }\end{array}$ \\
\hline A tempo & Typically, steady but subject to change. \\
\hline \multicolumn{2}{|l|}{ Above average } \\
\hline Restructuring a broken toy. & $\begin{array}{l}\text { Nursing classes often require you to think creatively } \\
\text { and often have multiple right answers however what } \\
\text { matters is that you choose the best one the fits. As a } \\
\text { result, I often spend my time trying to reverse } \\
\text { engineer the problem to better understand what prior } \\
\text { history could have led to some of these answers to be } \\
\text { correct and I pick the best one based on knowledge of } \\
\text { how a certain disease or illness can do to a person } \\
\text { throughout their life. }\end{array}$ \\
\hline \multicolumn{2}{|l|}{ A Responsive Attack } \\
\hline An action of potential & All at once before it is due \\
\hline An impulse & Gotta study when ya need to study. \\
\hline \multicolumn{2}{|l|}{ As needed } \\
\hline A cat chasing a mouse & Sometimes I get the mouse. \\
\hline
\end{tabular}


Table 36 (continued)

\begin{tabular}{|c|c|}
\hline Sweet stress & $\begin{array}{l}\text { Studying is stressful, but will eventually lead to a } \\
\text { sweeter reward }\end{array}$ \\
\hline A robot & As they are consistent in their performance \\
\hline $\begin{array}{l}\text { My study habits are like speed } \\
\text { runs of games. }\end{array}$ & $\begin{array}{l}\text { I spend less time on studying, but the time I do spend } \\
\text { is efficient and I try to get stuff done. }\end{array}$ \\
\hline \multicolumn{2}{|l|}{ A part of the journey } \\
\hline \multicolumn{2}{|l|}{ Adequate } \\
\hline Laundry. & I do it when it becomes necessary. \\
\hline A necessity & I study to pass. \\
\hline \multicolumn{2}{|l|}{ A job } \\
\hline Chores & $\begin{array}{l}\text { As they are view to me as something that could help } \\
\text { clear some pathways and understanding, but not } \\
\text { entirely focused on } \\
\text { I do them because I have to } \\
\text { They're the things I don't want to do, but I do because } \\
\text { I have to. }\end{array}$ \\
\hline $\begin{array}{l}\text { Sharpening a sword before } \\
\text { battle. }\end{array}$ & $\begin{array}{l}\text { Pretty simple. Just preparing for exams. That's the } \\
\text { only use I have for studying really. }\end{array}$ \\
\hline \multicolumn{2}{|l|}{$\begin{array}{l}\text { Short Bursts of Concentrated } \\
\text { Effort }\end{array}$} \\
\hline Short bursts & Little bits \\
\hline An earthquake fault & $\begin{array}{l}\text { I have to have the pressure to do homework, whether } \\
\text { self-imposed or otherwise, and then it still takes } \\
\text { significant time until I finish it all in a burst of energy. }\end{array}$ \\
\hline $\begin{array}{l}\text { My study habits are like } \\
\text { money }\end{array}$ & $\begin{array}{l}\text { As I could potentially even out the energy I have } \\
\text { among all the projects, I must study for or ill invest all } \\
\text { of it into one project and not have enough for the } \\
\text { others. }\end{array}$ \\
\hline \multicolumn{2}{|l|}{ A sprinter } \\
\hline Burst of energy & $\begin{array}{l}\text { I tend to get a lot of good studying done in short } \\
\text { amounts of time, while the other time that I designate } \\
\text { to studying is very unproductive. }\end{array}$ \\
\hline A cat & Mostly lazy with bursts of energy \\
\hline A dying light bulb. & $\begin{array}{l}\text { Sometimes I can study but most of the times I get } \\
\text { distracted really easy or just cannot sit in place so get } \\
\text { up every five minutes and do other stuff. }\end{array}$ \\
\hline \multicolumn{2}{|l|}{ Inconsistent/Mediocre/Chaotic } \\
\hline $\begin{array}{l}\text { A chicken with its head cuts } \\
\text { off. }\end{array}$ & Very all over the place \\
\hline A rabbit with adhd & I am easily distracted from studying. \\
\hline $\begin{array}{l}\text { My study habits are like a } \\
\text { stream }\end{array}$ & $\begin{array}{l}\text { They are light and happen to fit wherever they can go } \\
\text { easily. }\end{array}$ \\
\hline \multicolumn{2}{|l|}{ Luck } \\
\hline The wind & Coming and going depending on the day. \\
\hline
\end{tabular}


Table 36 (continued)

\begin{tabular}{|c|c|}
\hline An absentee friend & Only around when something is needed. \\
\hline My car & $\begin{array}{l}\text { Rarely works until the last minute, but gets me where } \\
\text { I need to go. }\end{array}$ \\
\hline \multicolumn{2}{|l|}{ Procrastinator } \\
\hline A river & One small thing can change the flow of the it. \\
\hline A plane ride & $\begin{array}{l}\text { Sometimes, I hit a little turbulence and have trouble } \\
\text { managing my time but usually I find a way to smooth } \\
\text { it out and land safely with a good grade }\end{array}$ \\
\hline Unhealthy. & $\begin{array}{l}\text { I push myself too hard, forget to eat, and don't always } \\
\text { take care of myself because of pressures from school. }\end{array}$ \\
\hline Only exercising occasionally & You stay healthy but never at your best \\
\hline $\begin{array}{l}\text { if I find the time, I find the } \\
\text { time, }\end{array}$ & $\begin{array}{l}\text { I have decided to take on more responsibility in my } \\
\text { personal life and at the moment I have always been } \\
\text { terrible at studying so I just try to learn the best way I } \\
\text { can: hands on }\end{array}$ \\
\hline \multicolumn{2}{|l|}{ Passive acceptance } \\
\hline A mediocre pizza & $\begin{array}{l}\text { They're good enough for what you want them for, but } \\
\text { there's definitely better out there. }\end{array}$ \\
\hline A flaky friend & $\begin{array}{l}\text { Can show up and have everything be fine, but is super } \\
\text { inconsistent and can cost you a lot of wasted time. }\end{array}$ \\
\hline A dice & $\begin{array}{l}\text { Sometimes, they are good, sometimes they are bad. } \\
\text { A roll of the dice }\end{array}$ \\
\hline Shaving & $\begin{array}{l}\text { You don't really wanna do it but it's worth it } \\
\text { afterwards }\end{array}$ \\
\hline Chores & $\begin{array}{l}\text { As they are view to me as something that could help } \\
\text { clear some pathways and understanding, but not } \\
\text { entirely focused on }\end{array}$ \\
\hline A rollercoaster & $\begin{array}{l}\text { Sometimes, they're climbing at a steady pace, and } \\
\text { sometimes shit happens and life gets fast and } \\
\text { uncontrollable. But in the end, it's always a good time. }\end{array}$ \\
\hline Sloth & I study very slowly \\
\hline An embryo & $\begin{array}{l}\text { They slowly develop depending on the class and work } \\
\text { well in the end. }\end{array}$ \\
\hline \multicolumn{2}{|l|}{ An organized mess } \\
\hline Tasteless food & It's decent but not the best \\
\hline \multicolumn{2}{|l|}{ Mediocre } \\
\hline \multicolumn{2}{|l|}{$\begin{array}{l}\text { A flowing river when I listen } \\
\text { to music but a slug when } \\
\text { music doesn't exist. }\end{array}$} \\
\hline Food in the fridge. & Sometimes it's there sometimes it isn't \\
\hline \multicolumn{2}{|l|}{ Time-consuming work. } \\
\hline Eating & $\begin{array}{l}\text { I do it at set times and until I need to stop or run out of } \\
\text { food/materials }\end{array}$ \\
\hline
\end{tabular}




\section{Table 36 (continued)}

\begin{tabular}{|c|c|}
\hline $\begin{array}{l}\text { My study habits are like the } \\
\text { ocean. }\end{array}$ & $\begin{array}{l}\text { Sometimes, it's collected and predictable, other times } \\
\text { it's erratic }\end{array}$ \\
\hline $\begin{array}{l}\text { Okay. I could do better I'm } \\
\text { organizing time to study }\end{array}$ & $\begin{array}{l}\text { My study habits slip away from me often, and it takes } \\
\text { a lot of effort for me to completely dive in to study } \\
\text { session. }\end{array}$ \\
\hline Getting by & $\begin{array}{l}\text { They can be better as I tend to postpone a lot, but I'm } \\
\text { still trying to adapt to university since it has been my } \\
\text { first year there }\end{array}$ \\
\hline Flying out of airports. & $\begin{array}{l}\text { It may take some time to get going, but once it's } \\
\text { started it goes fairly uninterrupted. }\end{array}$ \\
\hline A sloth. & Slow to start, but I will get there. \\
\hline Pulling teeth from a shark & $\begin{array}{l}\text { I say this because there's hundreds of things I have to } \\
\text { do, but I really, really don't want to. Whether I do it or } \\
\text { not, though, I can possibly get bit. }\end{array}$ \\
\hline \multicolumn{2}{|l|}{ A mess } \\
\hline \multicolumn{2}{|l|}{ A mouse in a glue trap } \\
\hline A complicated relationship. & $\begin{array}{l}\text { Setting up study times don't usually work for me. I } \\
\text { feel too constrained and get stressed out if I miss a } \\
\text { day. }\end{array}$ \\
\hline \multicolumn{2}{|l|}{ Non-Existent/Poor } \\
\hline \multicolumn{2}{|l|}{ Non-existent } \\
\hline \multicolumn{2}{|l|}{ Almost non-existent } \\
\hline Procrastination & I don't sometimes \\
\hline Almost nonexistent & I hate studying \\
\hline A broke mess & Unorganized and usually unhelpful \\
\hline \multicolumn{2}{|l|}{ A brick } \\
\hline Pushing a mountain & It gets me nowhere \\
\hline
\end{tabular}




\section{Appendix G - Gaming Metaphors}

Each participant was asked to define gaming by completing the following metaphor; Gaming is like ... . The responses have been grouped into the categories highlighted in gray by their attitude tone shown in Table 37. Red is negative, green is positive, and yellow is a mix of positive/negative.

\section{Table 37}

Gaming is Like ... Metaphors

\begin{tabular}{|c|c|}
\hline Metaphor & Additional Comments from Participants \\
\hline \multicolumn{2}{|l|}{ Gaming is like... } \\
\hline \multicolumn{2}{|l|}{ Negative } \\
\hline \multicolumn{2}{|l|}{ An obsession } \\
\hline \multicolumn{2}{|l|}{$\begin{array}{l}\text { A benign } \\
\text { distraction }\end{array}$} \\
\hline $\begin{array}{l}\text { A drug or } \\
\text { addiction }\end{array}$ & $\begin{array}{l}\text { It's addicting and fun, but can also waste time. } \\
\text { The more you do it the more you want to do it. }\end{array}$ \\
\hline A domino track & I almost can't stop after I start playing. \\
\hline \multicolumn{2}{|l|}{$\begin{array}{l}\text { Relaxing } \\
\text { Escapism } \\
\text { Pleasant } \\
\text { Emotions }\end{array}$} \\
\hline An escape & $\begin{array}{l}\text { Allow me to be able to relax and forget about the world } \\
\text { As corny as it sounds its true. I use gaming as a means to explore } \\
\text { the reality created by artists. Of course, not forgetting reality } \\
\text { altogether. } \\
\text { I don't have to worry about real world issues. } \\
\text { I play to have fun, take breaks, and improve. }\end{array}$ \\
\hline $\begin{array}{l}\text { My cares flow } \\
\text { away }\end{array}$ & $\begin{array}{l}\text { It helps me relax and enjoy myself, and work less on the stresses } \\
\text { of life. }\end{array}$ \\
\hline $\begin{array}{l}\text { An alternative to } \\
\text { a real live social } \\
\text { world }\end{array}$ & \\
\hline Flying on a cloud & $\begin{array}{l}\text { You lose track of tinge, loving life, and just floating through } \\
\text { euphoria. }\end{array}$ \\
\hline
\end{tabular}




\section{Table 37 (continued)}

\begin{tabular}{|c|c|}
\hline $\begin{array}{l}\text { The pure } \\
\text { happiness of } \\
\text { being a kid }\end{array}$ & \\
\hline $\begin{array}{l}\text { A dream or } \\
\text { fantasy }\end{array}$ & $\begin{array}{l}\text { In video games, you can do things you can't do in real life and } \\
\text { experience new things. }\end{array}$ \\
\hline Another world & It's like experiencing a new reality and living in a book or movie. \\
\hline A sweet release & Gaming is a way to relax after a hard day of class and work. \\
\hline A nap & $\begin{array}{l}\text { It gives me some time away from my projects sand work. } \\
\text { Allowing my mind to wonder and destress. } \\
\text { A chance to relax. }\end{array}$ \\
\hline $\begin{array}{l}\text { A mental } \\
\text { vacation }\end{array}$ & $\begin{array}{l}\text { It allows the mind to focus on something other than normal life. } \\
\text { tasks while also stimulating decision making and allowing strategy } \\
\text { development. }\end{array}$ \\
\hline $\begin{array}{l}\text { A vacation or a } \\
\text { getaway }\end{array}$ & $\begin{array}{l}\text { It's departure from the stress of reality and help to put me in a } \\
\text { good state of mind. }\end{array}$ \\
\hline \multicolumn{2}{|r|}{ ( } \\
\hline $\begin{array}{l}\text { Exploring an } \\
\text { undiscovered } \\
\text { world }\end{array}$ & It is always interesting to explore the worlds that games create. \\
\hline A road trips & $\begin{array}{l}\text { You discover new things along the way about your favorite game. } \\
\text { as changes occur with your friends and people you enjoy playing } \\
\text { with, meeting new people as well. }\end{array}$ \\
\hline An adventure & $\begin{array}{l}\text { You never know who you are going to meet when playing games, } \\
\text { and you do not know what is going to happen. }\end{array}$ \\
\hline \multicolumn{2}{|r|}{ 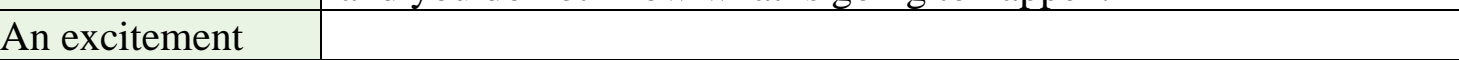 } \\
\hline A concert & You get pumped or relaxed. \\
\hline A theme park & There is always something new to do. \\
\hline \multicolumn{2}{|l|}{$\begin{array}{l}\text { Work - } \\
\text { Achievement - } \\
\text { Challenge }\end{array}$} \\
\hline $\begin{array}{l}\text { Learning to break } \\
\text { barriers: }\end{array}$ & $\begin{array}{l}\text { Some games are entirely about learning to work despite how angry } \\
\text { you may be at another player... Or it might be a physical barrier } \\
\text { you need to improve your game and progress. You may need to } \\
\text { improve a personal skill. }\end{array}$ \\
\hline \multicolumn{2}{|l|}{$\begin{array}{l}\text { Solving a } \\
\text { complicated math } \\
\text { problem or a } \\
\text { challenge }\end{array}$} \\
\hline $\begin{array}{l}\text { Learning any } \\
\text { other skill }\end{array}$ & $\begin{array}{l}\text { I play clarinet at a very high level and something that surprised me } \\
\text { most is that the learning process is almost identical between the } \\
\text { two. } \\
\text { You identify your weaknesses and slowly chip away at problems } \\
\text { until you refine your play style to the highest degree possible. }\end{array}$ \\
\hline
\end{tabular}


Table 37 (continued)

\begin{tabular}{|c|c|}
\hline A grind & $\begin{array}{l}\text { To achieve a certain level of competition, I need to put the time in } \\
\text { to improve my game play. }\end{array}$ \\
\hline Work & $\begin{array}{l}\text { It has become less fun for me know that I'm kind of relying on } \\
\text { gaming to get anywhere in terms of work/networking. }\end{array}$ \\
\hline Investing & It is something I hope can turn into something greater. \\
\hline Drawing & $\begin{array}{l}\text { You start out terrible, but it takes a lot of practice and mistakes to } \\
\text { improve one's performance. }\end{array}$ \\
\hline A battle of wits & $\begin{array}{l}\text { Any game with an opponent, you have to outthink and out execute } \\
\text { them. }\end{array}$ \\
\hline $\begin{array}{l}\text { A never-ending } \\
\text { competition }\end{array}$ & Everyone wants to get better and more people keep joining. \\
\hline Sport or athletics & $\begin{array}{l}\text { This only applies to multiplayer games, but these kinds of games } \\
\text { are very similar to any sport. } \\
\text { It is a very social activity that functions as a competitive outlet for } \\
\text { many. } \\
\text { It is very rewarding to succeed in just like sports. }\end{array}$ \\
\hline $\begin{array}{l}\text { A pickup } \\
\text { basketball game }\end{array}$ & $\begin{array}{l}\text { You can play just for fun and take time to enjoy yourself or you } \\
\text { can find more competitive people to play with in order to improve. }\end{array}$ \\
\hline \multicolumn{2}{|r|}{ 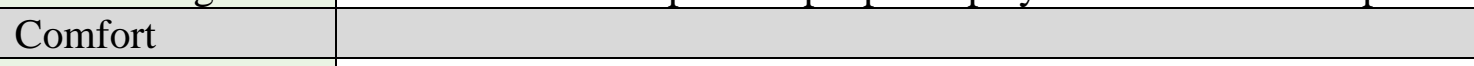 } \\
\hline A friend & Always waiting for you to hang out with them. \\
\hline Social media & $\begin{array}{l}\text { It brings a variety of people from all around the world into one } \\
\text { setting. }\end{array}$ \\
\hline A story & It's something you can get engrossed in \\
\hline Art & $\begin{array}{l}\text { There are never right or wrong decisions, just different } \\
\text { interpretations of what you should do. }\end{array}$ \\
\hline Home & $\begin{array}{l}\text { It's a way to unwind after a bad day or calm down if you're feeling } \\
\text { anxious. } \\
\text { I recharge my batteries for social interaction by playing video } \\
\text { games. }\end{array}$ \\
\hline A lifestyle & $\begin{array}{l}\text { Without it, I don't know what to do. } \\
\text { I don't know how to talk much with others, and it's the only real } \\
\text { topic that can keep me going. }\end{array}$ \\
\hline A shower & You will feel uncomfortable if you don't take a shower. \\
\hline \multicolumn{2}{|l|}{ Food } \\
\hline Bacon & You can never go wrong with it as long as you're having fun \\
\hline Chocolate & $\begin{array}{l}\text { In moderation it is great, but too much and it can be unhealthy. } \\
\text { It's awful sometimes, but great others. }\end{array}$ \\
\hline $\begin{array}{l}\text { An Xbox of } \\
\text { chocolates }\end{array}$ & I never know when I'm going to sweat. \\
\hline Ambrosia & Too much and it will make you sick, too much and you crave it. \\
\hline Bread & Good for the short term, but won't sustain you forever. \\
\hline
\end{tabular}




\section{Table 37 (continued)}

\begin{tabular}{|c|c|}
\hline Supportive & \\
\hline $\begin{array}{l}\text { A subset of } \\
\text { everything }\end{array}$ & $\begin{array}{l}\text { Gaming has become a big part of my life; it is too difficult to } \\
\text { separate from self-exploration. } \\
\text { It helped me figure out the kind of person I wanted to be in order } \\
\text { to practice it for the real world. } \\
\text { Minecraft helped me utilize my creativity and become a computer } \\
\text { scientist and artist, whereas overwatch has helped me become } \\
\text { more confident in leading teams and making decisions. }\end{array}$ \\
\hline
\end{tabular}

Green $=$ Positive

Yellow $=$ Neutral or combined positive and negative Red $=$ Negative 


\section{Appendix H - Academic Metaphors}

Each participant was asked to define gaming by completing the following metaphor; Academic study is like .... The responses have been grouped into the categories highlighted in gray by their attitude tone shown in Table 38. Red is negative, green is positive, and yellow is a mix of positive/negative.

\section{Table 38}

Academic Study is Like ... Metaphors

\begin{tabular}{|c|c|}
\hline $\begin{array}{l}\text { Metaphor } \\
\text { Academic study } \\
\text { is like .... }\end{array}$ & Additional Comments from Participants \\
\hline \multicolumn{2}{|l|}{$\begin{array}{l}\text { An unpleasant } \\
\text { necessity to } \\
\text { achieve reward }\end{array}$} \\
\hline A job & $\begin{array}{l}\text { As I need to focus on it, so I am able to continue doing things I } \\
\text { want. } \\
\text { It's stressful and basically required, have to live through it. } \\
\text { As you must try your hardest at it unless you want to fail. }\end{array}$ \\
\hline Paying Taxes & You gotta do it, but it still sucks. \\
\hline Working out & $\begin{array}{l}\text { It may be irritating to do sometimes, but once it's done, you feel } \\
\text { like you are now better off. } \\
\text { You need to put in the necessary time and effort in order to see } \\
\text { results and achieve your goals. } \\
\text { It sucks while doing it, but you develop a lot. I've realized how } \\
\text { much I've learnt over the past years when I apply those things in } \\
\text { projects and such. Obviously at the time it didn't feel fulfilling but, } \\
\text { it's like a future investment which you'll be rewarded eventually. } \\
\text { Where's gaming is very immediate. you either get punished or } \\
\text { rewarded as you are playing. }\end{array}$ \\
\hline Exercising & You do it because you have to but never really are in the mood \\
\hline Lifting & It sucks while you're doing it but it will pay off \\
\hline Braces & $\begin{array}{l}\text { You definitely don't want them and it sucks but you have to deal } \\
\text { with it for a while so it can fix your teeth. }\end{array}$ \\
\hline Doctor visits & While I don't like them, they are necessary. \\
\hline
\end{tabular}


Table 38 (continued)

\begin{tabular}{|c|c|}
\hline $\begin{array}{l}\text { Going to the } \\
\text { dentist }\end{array}$ & $\begin{array}{l}\text { You really don't want to do it, it sucks while doing it, but you're } \\
\text { kinda glad you did it. } \\
\text { I dread doing it, but I typically feel better once it's over. }\end{array}$ \\
\hline $\begin{array}{l}\text { A monotonous } \\
\text { journey }\end{array}$ & $\begin{array}{l}\text { Studying is like a long trek through the desert, but it has a goal in } \\
\text { mind. }\end{array}$ \\
\hline $\begin{array}{l}\text { A long journey to } \\
\text { a greater reward }\end{array}$ & I want to have an impact and make people smile. \\
\hline $\begin{array}{l}\text { Climbing a } \\
\text { mountain }\end{array}$ & $\begin{array}{l}\text { It is a struggle, but feels good to finish. } \\
\text { You'll hate it at first but, in the end, it will be worth it }\end{array}$ \\
\hline A long hike & $\begin{array}{l}\text { Parts of academic study can be very enjoyable. In college, I am } \\
\text { able to take a lot more classes that actually interest and engage me. } \\
\text { However, it is still school; where I have to take time out of my day } \\
\text { to prove I have learned things. It is a long process, can be } \\
\text { exhausting physically and mentally at times, but in the end, it is } \\
\text { worth it. }\end{array}$ \\
\hline Marathon & $\begin{array}{l}\text { Most of the journey is very difficult and strenuous, where the } \\
\text { beginning feels the easiest and the end feels most relieving }\end{array}$ \\
\hline $\begin{array}{l}\text { Training } \\
\text { discipline }\end{array}$ & $\begin{array}{l}\text { The information you learn is only moderately useful at best, but the } \\
\text { real-life benefit of academic study is that it shows your hard work, } \\
\text { dedication, and willpower; traits that are wildly important for } \\
\text { everyone in their future lives. }\end{array}$ \\
\hline Slight suffering & $\begin{array}{l}\text { It hurts to study for classes when you could be doing something } \\
\text { else but, in the end, it's good for you in the long run. }\end{array}$ \\
\hline A harsh parent & $\begin{array}{l}\text { There's part of you that doesn't like them and you know you need } \\
\text { to do what they say, but you still love them and your relationship is } \\
\text { very special. }\end{array}$ \\
\hline $\begin{array}{l}\text { Cleaning my } \\
\text { room }\end{array}$ & Necessary but not wanted. \\
\hline $\begin{array}{l}\text { Sharpening a } \\
\text { work tool }\end{array}$ & It maybe isn't always fun, but it gets the job done. \\
\hline Your own skills & Is boring for now but benefit you in the future. \\
\hline $\begin{array}{l}\text { Vegetables } \\
\text { (Broccoli) }\end{array}$ & You know it's good for you but you don't love it. \\
\hline Chores & $\begin{array}{l}\text { No one wants to do them but it has to be done. } \\
\text { Needs to be done but is annoying. }\end{array}$ \\
\hline A necessity & It is needed to be successful. \\
\hline $\begin{array}{l}\text { It's something } \\
\text { that needs to be } \\
\text { done to secure } \\
\text { my future }\end{array}$ & \\
\hline
\end{tabular}




\section{Table 38 (continued)}

\begin{tabular}{|c|c|}
\hline Struggle & \\
\hline A battle & A constant struggle for success in ever increasingly negative odds \\
\hline $\begin{array}{l}\text { Training } \\
\text { discipline }\end{array}$ & $\begin{array}{l}\text { The information you learn is only moderately useful at best, but the } \\
\text { real-life benefit of academic study is that it shows your hard work, } \\
\text { dedication, and willpower; traits that are wildly important for } \\
\text { everyone in their future lives. }\end{array}$ \\
\hline $\begin{array}{l}\text { A slow release } \\
\text { valve moving } \\
\text { toxic gas out of a } \\
\text { contained room. }\end{array}$ & It helps, but it's not substantial. \\
\hline Eating & It feels like a requirement. \\
\hline Black coffee & Only some people like it. \\
\hline Agony & \\
\hline Boring. Boring & \\
\hline $\begin{array}{l}\text { Hurdles that have } \\
\text { to crossed }\end{array}$ & \\
\hline Means to an end & \\
\hline $\begin{array}{l}\text { A way to pass } \\
\text { classes }\end{array}$ & \\
\hline Obligations & $\begin{array}{l}\text { I don't like it at all, but I know I have to otherwise It'll face severe } \\
\text { consequences. I don't think there's any payoff/reward for me either. }\end{array}$ \\
\hline $\begin{array}{l}\text { Academic study } \\
\text { is like workout }\end{array}$ & You will get nothing as your age grow. \\
\hline Having cancer & Everyone cares about you at first, and then you're alone and dying. \\
\hline Impossibility & \\
\hline Milk puzzle & It takes a lot of time, but sometime it is too hard to solve. \\
\hline Drugs & $\begin{array}{l}\text { You pay a whole lot of money for them and probably have to go to } \\
\text { therapy after you're done. }\end{array}$ \\
\hline $\begin{array}{l}\text { Walking through } \\
\text { mud }\end{array}$ & It's hard and where are you going? \\
\hline A tough journey & \\
\hline Trying to fight & $\begin{array}{l}\text { Sometimes you can really get the concept and overcome the class } \\
\text { and other times it beats you up mentally. }\end{array}$ \\
\hline $\begin{array}{l}\text { Hard, } \\
\text { demanding, and } \\
\text { exhausting }\end{array}$ & \\
\hline A challenge & It's another step to overcome. \\
\hline A drag & \\
\hline Hell & \\
\hline $\begin{array}{l}\text { Dragging a bag } \\
\text { of bricks up a } 10- \\
\text { mile-tall } \\
\text { mountain }\end{array}$ & I feel bored, tired, and annoyed at studying and all its components. \\
\hline
\end{tabular}


Table 38 (continued)

\begin{tabular}{|c|c|}
\hline A grind & $\begin{array}{l}\text { I need to put time and effort into my studies in order to pass my } \\
\text { classes. }\end{array}$ \\
\hline Work & It can be boring and a chore at times. \\
\hline Boot camp & $\begin{array}{l}\text { My college pushes students very hard so that we'll be the best at } \\
\text { what we do, but it is often exhausting. }\end{array}$ \\
\hline $\begin{array}{l}\text { Going through } \\
\text { the motions }\end{array}$ & $\begin{array}{l}\text { Let's face it, unless the classes involve your major then you're just } \\
\text { kind of there and not engaged. }\end{array}$ \\
\hline A plant & If you forget about it, it will die. \\
\hline \multicolumn{2}{|l|}{$\begin{array}{l}\text { A stick in the } \\
\text { mud }\end{array}$} \\
\hline \multicolumn{2}{|l|}{ Adventure } \\
\hline $\begin{array}{l}\text { Hiking a } \\
\text { mountain }\end{array}$ & $\begin{array}{l}\text { While the task may seem daunting or even impossible, it is one that } \\
\text { can be achieved through determination and self-discipline. }\end{array}$ \\
\hline Discovery & It's creating something new and creating new connections. \\
\hline Cooking & $\begin{array}{l}\text { If you take time and follow the right steps, even though it may be } \\
\text { difficult, you end up with an enjoyable reward much like studies } \\
\text { allow for more opportunities for the future. }\end{array}$ \\
\hline A hallway & $\begin{array}{l}\text { It's just a path you choose that leads to many doors. It's a necessary } \\
\text { part of the journey to your end goal which is a career. }\end{array}$ \\
\hline An advancement & I can do more when I know more. \\
\hline $\begin{array}{l}\text { A twisting path } \\
\text { with different } \\
\text { maps }\end{array}$ & $\begin{array}{l}\text { Because everyone has different skill sets, and some people have a } \\
\text { really good map, others have an outdated one, and some just have a } \\
\text { shred of paper. It's not an even playing field, but everyone walks it } \\
\text { at some point. }\end{array}$ \\
\hline \multicolumn{2}{|l|}{ The coolest ever } \\
\hline \multicolumn{2}{|l|}{ A road } \\
\hline \multicolumn{2}{|l|}{ Progression } \\
\hline A stepping stone & There is more to come. \\
\hline Paddle boarding & $\begin{array}{l}\text { The more you work on standing up without falling, the easier it } \\
\text { gets. }\end{array}$ \\
\hline $\begin{array}{l}\text { Academic study } \\
\text { is like a vast } \\
\text { expanse of } \\
\text { unknown horizon }\end{array}$ & $\begin{array}{l}\text { There is so much promise and mystery for the future and pushing } \\
\text { forward with academics allows progress towards that promising } \\
\text { future. }\end{array}$ \\
\hline \multicolumn{2}{|l|}{ Practical } \\
\hline Oiling a gear & $\begin{array}{l}\text { Academic study is all about using your brain and learning how to } \\
\text { utilize different components of it in order to process information } \\
\text { quicker and more effectively. Some studies require creativity to be } \\
\text { improved while others require logical skills some require both. }\end{array}$ \\
\hline $\begin{array}{l}\text { A focused state } \\
\text { surrounding } \\
\text { academia }\end{array}$ & \\
\hline
\end{tabular}




\section{Table 38 (continued)}

\begin{tabular}{l|l} 
Breathing & $\begin{array}{l}\text { It's something that I usually do passively. I never really have to } \\
\text { think about it. I tend to just do it when necessary. }\end{array}$ \\
\hline History & You learn from the mistakes of the past to create a brighter future. \\
\hline $\begin{array}{l}\text { Doing a connect } \\
\text { the dots }\end{array}$ & $\begin{array}{l}\text { Everything is more or less connected in a field of study and it is } \\
\text { cool to see how things connect on a deeper level by studying them. }\end{array}$ \\
\hline Pass time. & $\begin{array}{l}\text { You learn what you want and there are things you don't want but } \\
\text { still go over. You always learn throughout life whether you are } \\
\text { bored or interested. Either way you end up learning about stuff. }\end{array}$ \\
\hline
\end{tabular}

Green $=$ Positive

Yellow $=$ Neutral or combined positive and negative

Red $=$ Negative 


\section{Appendix I - Coding Book}

The qualitative data was analyzed by using a list of closed codes created from literature and open-ended coding methods were applied (Berg \& Lune, 2004; Boellstorff et al., 2012; Yin, 1989). Data was collected from the open-ended questions on the qualitative questionnaire with demographics, all open-ended data gathered through Indeemo, and the 31 interviews were used as the texts for coding. An additional component of the coding analysis was the evaluation of visual elements, such as the semester schedule of the student, as well as the transcribed photos and videos captured during the assigned Indeemo tasks.

A four-part coding book was established, which included codes for gaming habits, study skills, and attitudes. The coding book was developed through a four-cycle iterative exploratory process of data analysis looking for evidence of key concepts and themes to develop.

The first cycle, or the initial pre-data-collection thematic coding book, began with the researcher identifying some broad categories of demographics, gaming habits, study skills and attitudes from anticipated answers participants provided when taking the initial interest and qualitative questionnaire with demographics, as well as the tasks and questions designed for the virtual ethnography.

During the second iteration of the coding cycle, all participant answers from each of the qualitative data collection methods used in the initial interest survey, the qualitative questionnaire with demographics survey, and the Indeemo tasks were clustered by topical questions. For example, each participant's answer to the question "What is the easiest 
way for you to learn something new?" was clustered, so themes would be easier to identify. Appendix J lists the index of clustered topics.

The third iteration for coding analysis occurred as the researcher read through the initial clusters and applied a one to two-word code word, attempting to capture the behavior and tone of main ideas found within participants' responses. For example, if the participant was describing class attendance as an important study habit, the code written was attendance - positive. During this cycle, two experts were enlisted to conduct similar identification coding on two randomly selected clustering sections. The experts added their one to two-code word responses to the statements, and then the researcher and experts compared notes to ensure inter-rated reliability existed within the coding procedure (Berg \& Lune, 2004; Boellstorff et al., 2012; Yin, 1989).

During the fourth integration, the researcher read through transcripts and codes again, analyzing them for the semantic deeper meanings. It was within this reading that the "study habit approaches," "types of heavy-video-gaming students," "possible learning supports" were identified, and these categories are discussed in more detail in the results section of the paper (Chapter IV). After establishing the final pattern codes to be used for the analysis in the study, two experts were enlisted to conduct sample coding to ensure that inter-rated reliability existed within the coding procedure (Berg \& Lune, 2004; Boellstorff et al., 2012; Yin, 1989).

Table 39 was used to identify some demographic information about the players. Shown in the table is the category of the code, the code terms used, the expected data that was expected, and an example of the date collected. Details of the data collected are found in Chapter IV of this research study. 
Table 39

Demographics Survey Coding Book

\begin{tabular}{|c|c|c|c|}
\hline Category of Code & Code & Expected data & $\begin{array}{l}\text { Example of Data } \\
\text { Collected }\end{array}$ \\
\hline Age & Age & $\begin{array}{l}\text { All players to be of } \\
\text { age to be enrolled in } \\
\text { fulltime } \\
\text { undergraduate } \\
\text { programs }\end{array}$ & Ages 17 to 25 \\
\hline Gender & $\begin{array}{l}\text { Male, Female, } \\
\text { prefer not to } \\
\text { disclose }\end{array}$ & $\begin{array}{l}\text { Male gender } \\
\text { domination }\end{array}$ & $\begin{array}{l}\text { Male }-81 \\
\text { Female - } 9 \\
\text { Not disclosed - } 3\end{array}$ \\
\hline Location & World location & Various locations & $\begin{array}{l}32 \text { Different states } \\
\text { identified } \\
\text { Missouri - } 45\end{array}$ \\
\hline $\begin{array}{l}\text { Grade level of } \\
\text { participants }\end{array}$ & $\begin{array}{l}\text { Freshman, } \\
\text { Sophomore, Junior, } \\
\text { Senior }\end{array}$ & $\begin{array}{l}\text { A range of school } \\
\text { levels, but no first } \\
\text { semester freshman }\end{array}$ & $\begin{array}{l}F-4 \\
S-34 \\
J-34 \\
S R-21 \\
\end{array}$ \\
\hline Study disciplines & $\begin{array}{l}10 \text { major study } \\
\text { divisions of study }\end{array}$ & A listing of majors & $\begin{array}{l}\text { Computing, } \\
\text { Engineering and } \\
\text { Math }-45 \text { students }\end{array}$ \\
\hline $\begin{array}{l}\text { Credit load per } \\
\text { semester }\end{array}$ & $\begin{array}{l}\text { Ranges of credit } \\
\text { hours taken } \\
12 \\
13 \\
14, \ldots \\
\text { More than } 17\end{array}$ & $\begin{array}{l}\text { A list of credit hour } \\
\text { involvement }\end{array}$ & $\begin{array}{l}17 \text { credits in the } \\
\text { semester - } 14 \\
\text { students }\end{array}$ \\
\hline GPA & $\begin{array}{l}\text { Grade Point } \\
\text { Average Ranges } \\
\text { every } .5 \text { scale }\end{array}$ & $\begin{array}{l}\text { Self-reported from } \\
\text { transcript }\end{array}$ & $\begin{array}{l}\text { 3.0-3.4 Range - } 34 \\
\text { students }\end{array}$ \\
\hline
\end{tabular}

Other themes may

be identified

through process 
Table 40 lists some initial gaming habits code words that were influenced by the delimiters found in the work of (Manero et al., 2016, 2017):

\section{Table 40}

Gaming Habits Coding Book

\begin{tabular}{|c|c|c|c|}
\hline Category of Code & Code & Expected data & $\begin{array}{l}\text { Example of Data } \\
\text { Collected }\end{array}$ \\
\hline Time devoted to play & Hours/Minutes & $\begin{array}{l}\text { Self-reported hours } \\
\text { of play }\end{array}$ & $\begin{array}{l}\text { Mean of } 27.22 \\
\text { hours a week }\end{array}$ \\
\hline Level of game play & $\begin{array}{l}\text { Ranking status in } \\
\text { games } \\
\text { Professional, } \\
\text { Ranked level, } \\
\text { leisure }\end{array}$ & $\begin{array}{l}\text { Ranked level in the } \\
\text { game }\end{array}$ & $\begin{array}{l}\text { Leisure }-28 \\
\text { students }\end{array}$ \\
\hline Type of game play & $\begin{array}{l}\text { Recreational or } \\
\text { eSports team } \\
\text { member }\end{array}$ & $\begin{array}{l}\text { Identify with one } \\
\text { of the groups }\end{array}$ & $\begin{array}{l}\text { Recreational - } \\
76.56 \% \\
\text { eSports }-23.44 \%\end{array}$ \\
\hline $\begin{array}{l}\text { Collaborations in } \\
\text { games }\end{array}$ & $\begin{array}{l}\text { Preference of group } \\
\text { or individual play }\end{array}$ & $\begin{array}{l}\text { How the social } \\
\text { component factors } \\
\text { into gaming }\end{array}$ & $\begin{array}{l}\text { Play with friends } \\
\text { 28- students }\end{array}$ \\
\hline $\begin{array}{l}\text { Motivation/Reasons } \\
\text { to play }\end{array}$ & $\begin{array}{l}\text { (1) Metaphors of } \\
\text { play } \\
\text { (2) Descriptions of } \\
\text { why they play - } \\
\text { competitive, } \\
\text { leisure, esports } \\
\text { team, by self } \\
\text { (3) Motivations for } \\
\text { play - completion, } \\
\text { the game, pass } \\
\text { time, friends, } \\
\text { rewards }\end{array}$ & $\begin{array}{l}\text { Understand the } \\
\text { motivation and } \\
\text { reasons for playing }\end{array}$ & $\begin{array}{l}\text { Competitive }-44 \\
\text { students }\end{array}$ \\
\hline
\end{tabular}

Other themes may be identified through process 
Table 41 identifies initial code words related to study skills and habits that were influenced by the code delimiters found in the SSHA (Brown \& Holtzman, 1967), and lists of study habits named in literature (Aquino, 2011; Bulent et al., 2015; Credé \&

Kuncel, 2008; Elliott et al., 1990) .

\section{Table 41}

Study Skills Coding Book

\begin{tabular}{|c|c|c|c|}
\hline $\begin{array}{l}\text { Category of } \\
\text { Code }\end{array}$ & Code & Expected data & $\begin{array}{l}\text { Example of Data } \\
\text { Collected }\end{array}$ \\
\hline $\begin{array}{l}\text { Academic Skills } \\
\text { learned in } \\
\text { gaming }\end{array}$ & $\begin{array}{l}\text { List of study skills } \\
\text { specifically named }\end{array}$ & List of skills & $\begin{array}{l}\text { Typing, } \\
\text { persistence, and } \\
\text { problem solving }\end{array}$ \\
\hline Reasons to study & $\begin{array}{l}\text { Open-ended statements } \\
\text { from participants }\end{array}$ & $\begin{array}{l}\text { Understand } \\
\text { motivation to study }\end{array}$ & $\begin{array}{l}\text { Good grades, peer } \\
\text { pressure, please } \\
\text { family }\end{array}$ \\
\hline Metaphors & $\begin{array}{l}\text { Study attitudes } \\
\text { identified through } \\
\text { statements of } \\
\text { participants }\end{array}$ & $\begin{array}{l}\text { Attitudes of } \\
\text { Positive, Negative } \\
\text { and Neutral tone }\end{array}$ & $\begin{array}{l}\text { It sucks while } \\
\text { doing it, but you } \\
\text { develop a lot. I've } \\
\text { realized how much } \\
\text { I've learnt over the } \\
\text { past years when I } \\
\text { apply those things } \\
\text { in projects and } \\
\text { such. Obviously at } \\
\text { the time it didn't } \\
\text { feel fulfilling but, } \\
\text { it's like a future } \\
\text { investment which } \\
\text { you'll be rewarded } \\
\text { eventually. }\end{array}$ \\
\hline
\end{tabular}


Table 41 (continued)

\begin{tabular}{llll}
\hline $\begin{array}{l}\text { Learning supports } \\
\text { desired by gamers }\end{array}$ & $\begin{array}{l}\text { Open-ended statements } \\
\text { from participants }\end{array}$ & $\begin{array}{l}\text { Items that } \\
\text { would help } \\
\text { the students in } \\
\text { study }\end{array}$ & $\begin{array}{l}\text { Adjusted schedules, } \\
\text { meaningful } \\
\text { assignments }\end{array}$ \\
\hline Study practices & $\begin{array}{l}\text { Open-ended statements } \\
\text { from participants }\end{array}$ & $\begin{array}{l}\text { Practices of } \\
\text { study }\end{array}$ & $\begin{array}{l}\text { Attend class, know } \\
\text { class expectations, } \\
\text { take notes, listen }\end{array}$ \\
actively
\end{tabular}


Table 41 (continued)

\begin{tabular}{|c|c|c|c|}
\hline \multirow[t]{6}{*}{$\begin{array}{l}\text { Work Methods-a } \\
\text { measure of effective } \\
\text { study skills }\end{array}$} & \multicolumn{2}{|l|}{$\begin{array}{l}\text { Regular study: } \\
\text { (multitask/focus, sleep } \\
\text { well, spaces between } \\
\text { learning sessions, } \\
\text { timeliness, setting and } \\
\text { accomplishing goals) }\end{array}$} & $\begin{array}{l}\text { The WM score } \\
\text { indicates students } \\
\text { have a middle-of- } \\
\text { the-road work } \\
\text { methods skill set } \\
\text { that may help them } \\
\text { about } 51.3 \% \text {, but } \\
\text { that leaves a lot of } \\
\text { room for work that } \\
\text { does not get } \\
\text { completed. }\end{array}$ \\
\hline & $\begin{array}{l}\text { Efficient reading: (read } \\
\text { material before class, } \\
\text { reading activity) } \\
\text { Listening to lectures: } \\
\text { (ways to listen, review } \\
\text { and test oneself) }\end{array}$ & & $\begin{array}{l}\text { In qualitative } \\
\text { responses, "class } \\
\text { attendance" had the } \\
\text { highest score of } \\
47.3 \% \text {. }\end{array}$ \\
\hline & $\begin{array}{l}\text { Noting: (note taking } \\
\text { methods, use of } \\
\text { memory aids) } \\
\text { Efficient written } \\
\text { expression: (papers } \\
\text { written) }\end{array}$ & & \\
\hline & $\begin{array}{l}\text { Participating in the } \\
\text { lesson actively: (paying } \\
\text { attention in class, use of } \\
\text { time in class, arriving to } \\
\text { class ahead of time) }\end{array}$ & & \\
\hline & $\begin{array}{l}\text { Completing homework: } \\
\text { (preparing, revising, } \\
\text { completing, presenting) }\end{array}$ & & \\
\hline & $\begin{array}{l}\text { Preparation for exams: } \\
\text { (prepare, timeliness, } \\
\text { attending) }\end{array}$ & & \\
\hline Net Promoter scale & $\begin{array}{l}\text { Detractor, Passive, } \\
\text { Promoter }\end{array}$ & $\begin{array}{l}\text { Understand } \\
\text { motivation to } \\
\text { work }\end{array}$ & $\begin{array}{l}\text { Detractor }-19 \\
\text { Passive }-49 \\
\text { Promoter }-25\end{array}$ \\
\hline $\begin{array}{l}\text { Other themes may be } \\
\text { identified through } \\
\text { process }\end{array}$ & & & \\
\hline
\end{tabular}


Table 42 lists initial code words used for attitudes categories found in literature (Aquino, 2011; Ballado-Tan, 2014; Özsoy et al., 2017; Perloff, 2016).

\section{Table 42}

\section{Attitudes Coding Book}

\begin{tabular}{|c|c|c|c|}
\hline Category of Code & Code & Expected data & $\begin{array}{l}\text { Example of Data } \\
\text { Collected }\end{array}$ \\
\hline $\begin{array}{l}\text { Teacher Approval- } \\
\text { a measure of } \\
\text { student opinions } \\
\text { about teacher } \\
\text { classroom behavior } \\
\text { and methods }\end{array}$ & $\begin{array}{l}\text { Tone of attitudes, } \\
\text { positive or negative } \\
\text { Connected/Disengaged }\end{array}$ & $\begin{array}{l}\text { Students offer } \\
\text { statements such as } \\
\text { "I like" or "I don't } \\
\text { like this...." }\end{array}$ & $\begin{array}{l}\text { The overall TA } \\
\text { score of } 43.6 \\
\text { percent }\end{array}$ \\
\hline $\begin{array}{l}\text { Educational } \\
\text { Acceptance- a } \\
\text { measure of student } \\
\text { approval of } \\
\text { educational } \\
\text { objectives, } \\
\text { practices, and } \\
\text { requirements }\end{array}$ & $\begin{array}{l}\text { Tone of attitudes, } \\
\text { positive or negative }\end{array}$ & $\begin{array}{l}\text { Students offer } \\
\text { statements such as } \\
\text { "I like" or "I don't } \\
\text { like this...." }\end{array}$ & $\begin{array}{l}\text { The EA of } 49.7 \\
\text { percent were a bit } \\
\text { lower overall. The } \\
\text { students have less } \\
\text { confidence in the } \\
\text { instructors and } \\
\text { learning systems } \\
\text { than they do in } \\
\text { their own abilities. }\end{array}$ \\
\hline Metaphors & Attitudes identified & $\begin{array}{l}\text { Attitudes of } \\
\text { Positive, Negative } \\
\text { and Neutral tone }\end{array}$ & $\begin{array}{l}\text { "Gotta study when } \\
\text { ya need to study." }\end{array}$ \\
\hline $\begin{array}{l}\text { Other themes may } \\
\text { be identified } \\
\text { through process }\end{array}$ & & & \\
\hline
\end{tabular}

These code words were then analyzed for frequency of use, similarity in meaning, and patterns that could be identified. Two university professors holding PHDs were enlisted to conduct similar identification coding on two randomly selected clustering sections. The experts added their one-to two-code word responses to the statements, and 
then the researcher and experts compared notes to ensure inter-rated reliability existed within the coding procedure (Berg \& Lune, 2004; Boellstorff et al., 2012; Yin, 1989).

Thirdly, the researcher read through transcripts and codes again, analyzing them for the semantic deeper meanings. It was within this reading that the "study practices" and "characteristics of gamers' study habits" were identified, as shown in Table 43, and these are presented in the discussion in chapter five. Again, two university professors were enlisted to use these codes to assist in coding some samples for interrater reliability.

Table 43

Characteristics of Study Approaches and Types for Gamers

\begin{tabular}{|c|c|c|c|}
\hline $\begin{array}{l}\text { Category } \\
\text { of Code }\end{array}$ & Code & $\begin{array}{l}\text { Theme Developed from } \\
\text { Analysis }\end{array}$ & Example of Data Collected \\
\hline \multirow[t]{5}{*}{$\begin{array}{l}\text { Study } \\
\text { Approach }\end{array}$} & $\begin{array}{l}\text { Methods of } \\
\text { Study - } \\
\text { open ended }\end{array}$ & $\begin{array}{l}\text { Inconsistent/mediocre/chaotic } \\
\text { Approach }\end{array}$ & $\begin{array}{l}\text { "They're good enough for } \\
\text { what you want them for, but } \\
\text { there's definitely better out } \\
\text { there" (P33, transcript, p. } \\
\text { 39). }\end{array}$ \\
\hline & & Responsive Attack Approach & $\begin{array}{l}\text { When an assignment is } \\
\text { announced the students are } \\
\text { then "called into battle" } \\
\text { (P25, transcript, p. 262). }\end{array}$ \\
\hline & & Nonexistent/poor Approach & $\begin{array}{l}\text { "Pushing a mountain, they } \\
\text { get me nowhere" (P18, } \\
\text { transcript, p. 263). }\end{array}$ \\
\hline & & $\begin{array}{l}\text { Planned Consistent Attack } \\
\text { Approach }\end{array}$ & $\begin{array}{l}\text { These heavy-video-gaming } \\
\text { students took an offensive } \\
\text { approach to studying, setting } \\
\text { aside regular times for } \\
\text { homework and studies, "like } \\
\text { clockwork" (P54, transcript, } \\
\text { p. 263). }\end{array}$ \\
\hline & & $\begin{array}{l}\text { Short bursts of concentrated } \\
\text { effort approach }\end{array}$ & $\begin{array}{l}\text { Sometimes I can study but } \\
\text { most of the times I get } \\
\text { distracted really easy or just } \\
\text { cannot sit in place so get up } \\
\text { every } 5 \text { minutes and do } \\
\text { something" (P10, transcript, } \\
\text { p. 263). }\end{array}$ \\
\hline
\end{tabular}


Table 43 (continued)

\begin{tabular}{|c|c|c|c|}
\hline \multirow[t]{5}{*}{$\begin{array}{l}\text { Types of } \\
\text { Heavy- } \\
\text { Video- } \\
\text { Gaming } \\
\text { Students }\end{array}$} & $\begin{array}{l}\text { Methods of } \\
\text { game } \\
\text { playing - } \\
\text { open ended }\end{array}$ & Supportive colleague type & $\begin{array}{l}\text { Throughout the study, } 47 \text { of } \\
93 \text { of the gamers spoke about } \\
\text { taking on the support roles } \\
\text { within their games, and } \\
\text { keeping "watch over their } \\
\text { fellow players" (P43, } \\
\text { transcript, p. 67). }\end{array}$ \\
\hline & & $\begin{array}{l}\text { Pertinacious problem solver } \\
\text { type }\end{array}$ & $\begin{array}{l}\text { Players spoke of the number } \\
\text { of times they would keep } \\
\text { coming back to a challenge } \\
\text { in a game "try to get it, and } \\
\text { try a different way" (P84, } \\
\text { transcript, p. 160). }\end{array}$ \\
\hline & & Efficient linear thinker type & $\begin{array}{l}\text { "find the quickest path from } \\
\text { A to B" in their games (P33, } \\
\text { transcript, p. 48). }\end{array}$ \\
\hline & & Self-reliant - associate type & $\begin{array}{l}\text { Participants display a general } \\
\text { confidence, or self-reliance } \\
\text { about themselves. P45 stated } \\
\text { "I can do it" (transcript, p. } \\
41 \text { ). }\end{array}$ \\
\hline & & $\begin{array}{l}\text { Individualistic with the need } \\
\text { for community type }\end{array}$ & $\begin{array}{l}\text { "I have problems with } \\
\text { thinking that I have } \\
\text { something valuables to } \\
\text { contribute to the group } \\
\text { conversations. I know I am } \\
\text { an important part of the } \\
\text { team, and what I want to say } \\
\text { is important, but I struggle } \\
\text { with weather others will } \\
\text { want to hear what I have to } \\
\text { say" (transcript, p. 208). }\end{array}$ \\
\hline
\end{tabular}




\section{Appendix J - Index of Transcripts}

This list shows data clustering of participants responses and the pages.

Category

Section pages

Introductions

Personality

Rate experience

Schedule $16-23$

Attendance $24-29$

GPA 30-35

What type of student are you? $36-41$

Favorite place to study $42-48$

Best academic skill $49-57$

Ways to learn something new $58-64$

Learning supports/ Types of supports 65- 96

Use of tutoring or learning supports $97-104$

Academic milestones $105-111$

Patterns in academics $112-115$

What could make you more successful? $116-119$

Do classes provide what you need? $120-123$

What have you learned in academics that made you a better gamer? $124-132$

Games played $132 \mathrm{a}$

Type of gamer $133-136$

Hours per week $137-141$

Why play games? $142-146$ 
Do you play alone or with people?

Gaming milestones

$153-155$

Patterns in gaming $156-158$

Learned in gaming that makes you a better academic student. $159-167$

How to quit gaming or better balance the two $168-177$

Games hinder or help $178-186$

Life goals $187-190$

Career goals 191-194

Extracurriculars $195-203$

Do extracurricular activities interfere? $204-207$

Stressed $208-222$

Handle stress $223-227$

Not sure 228 - end of book

Age $221 \mathrm{a}$

Enrolled in undergrad $222 a$

Semester in college $223 a$

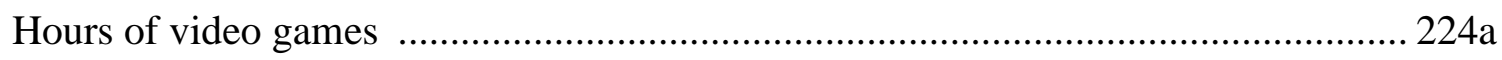

Do you play on official college esports team? .............................................. 225a

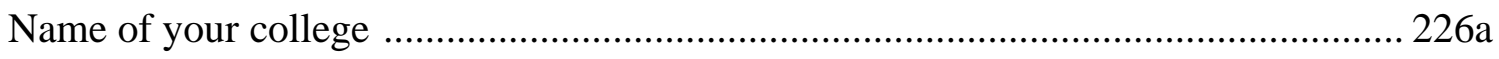

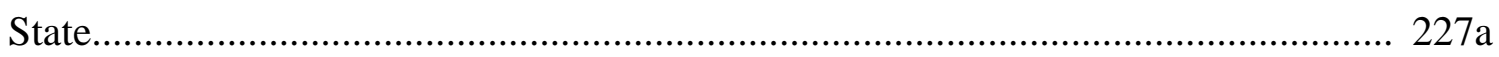

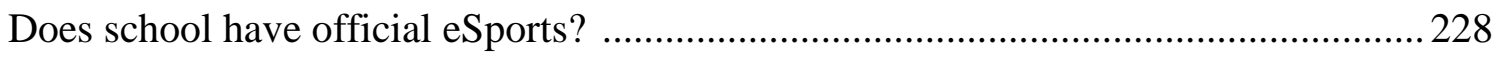

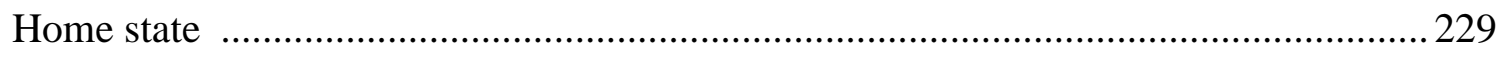

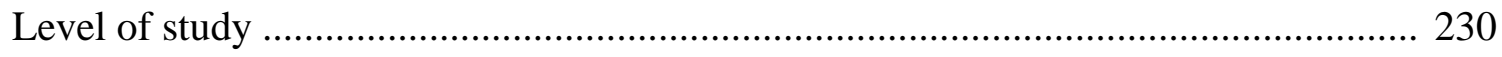




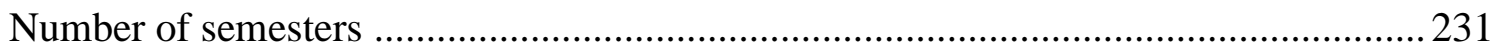

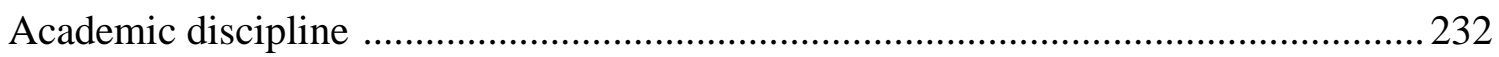

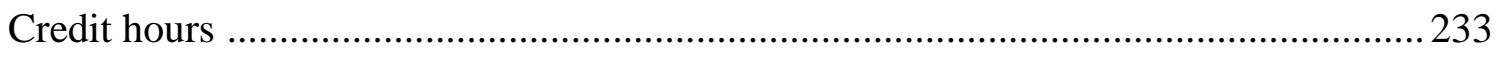

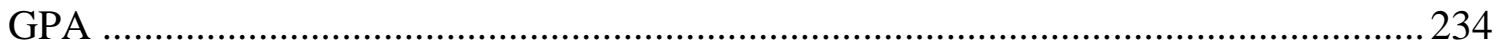

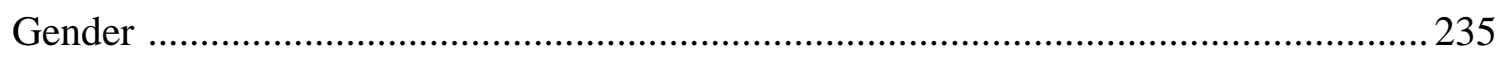

Describe the way you play video games .......................................................236 -237

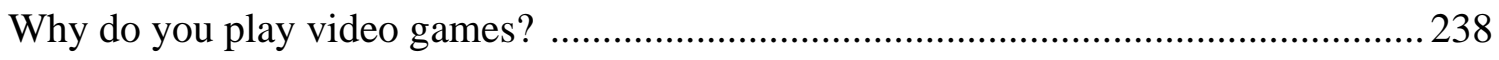

How has video-gaming interfered or gotten in the way? ..........................................239

How has academic study gotten in the way of video? ...............................................240

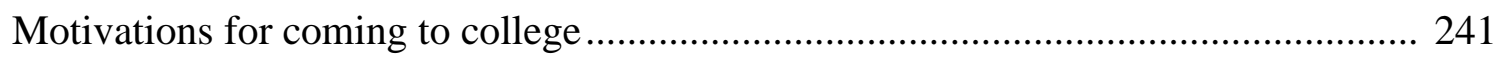

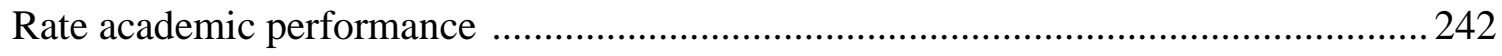

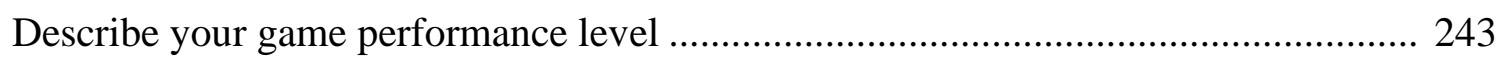

Hours per week video games ............................................................................. 244

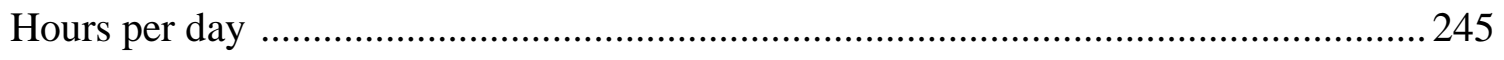

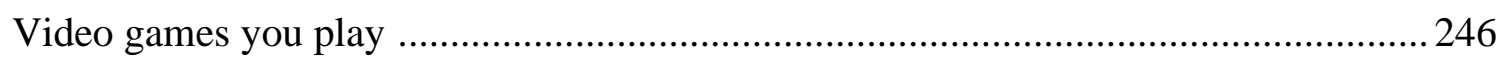

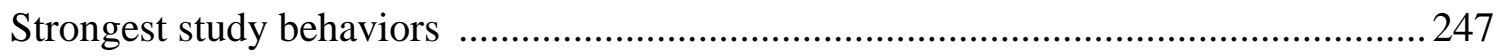

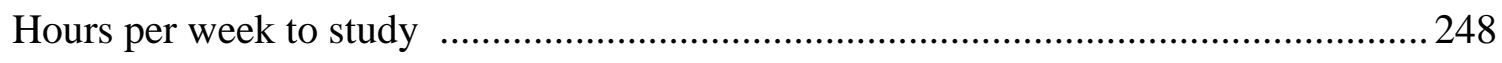

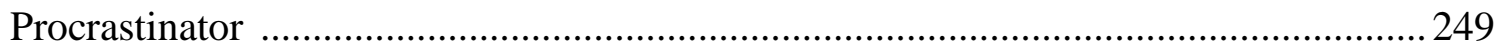

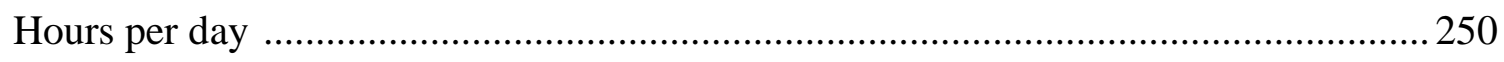

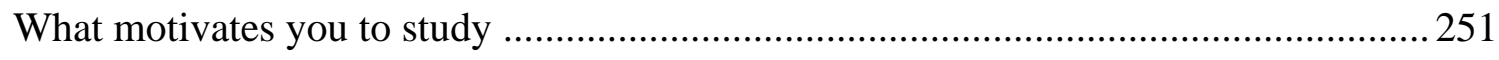

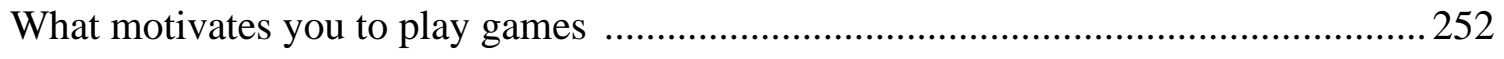

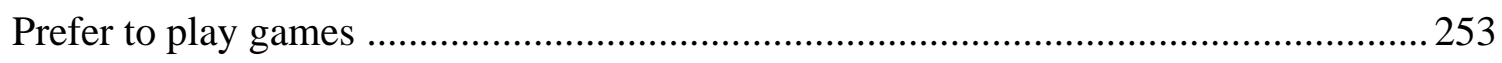

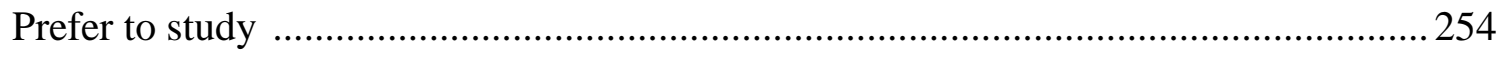




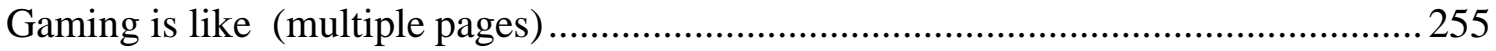

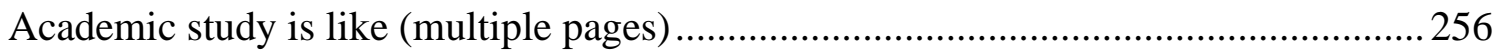

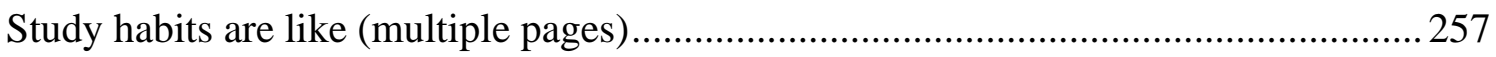

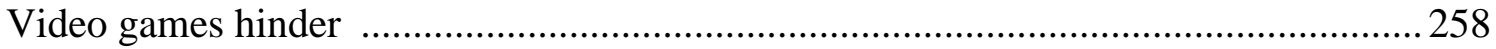

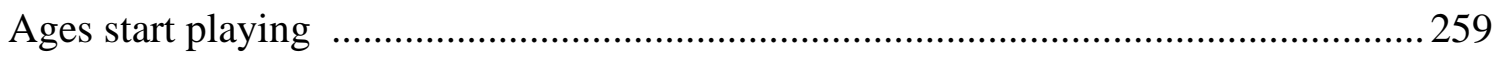

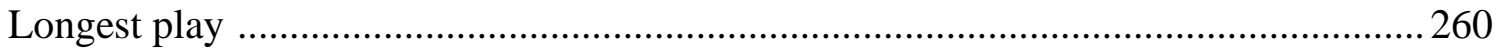

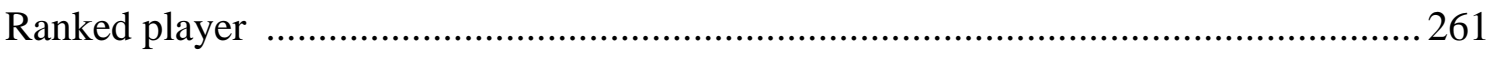

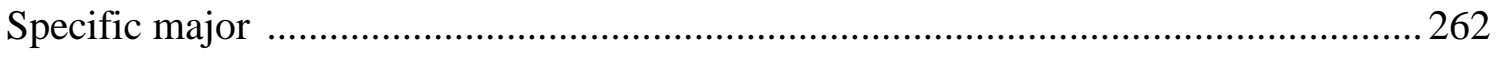

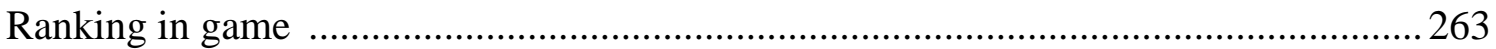




\section{Appendix K - Video-Gaming Student Matrix To Develop Learning Support}

This is a three-step exercise to provide heavy-video-gaming students and educational professionals with a tool to assist building an academic performance plan, which will address the students' study practices, gaming student type, and possible learning supports that best align.

Step 1 - Instructions: The video-gaming student should make one selection from the Student Type column and one selection from the Study Approach row. Base the selections on the categories described below the grid.

Place a mark in the grid where the two selections meet. Then look at Learning Support numbers (LS\#) for both selections. Using these learning support suggestions found on page two, formulate an academic performance plan with your advisor.

\begin{tabular}{|c|c|c|c|c|c|c|c|}
\hline & LS \#1 & $\mathrm{LS} \# 2$ & LS \#3 & LS \#4 & LS \#5 \\
\hline & & & \multicolumn{5}{|c|}{ See page two of the form for learning support (LS) suggestions. } \\
\hline & & \multirow{2}{*}{ Study Approach $\rightarrow$} & \multirow{3}{*}{$\begin{array}{l}\text { Inconsiste } \\
\text { nt/Medioc } \\
\text { re/Chaotic }\end{array}$} & \multirow{3}{*}{$\begin{array}{l}\text { Responsiv } \\
\text { e Attack }\end{array}$} & \multirow{3}{*}{$\begin{array}{l}\text { Nonexiste } \\
\text { nce/poor }\end{array}$} & \multirow{3}{*}{$\begin{array}{l}\text { Planned } \\
\text { Consistent } \\
\text { Attack }\end{array}$} & \multirow{3}{*}{$\begin{array}{l}\text { Short } \\
\text { Bursts of } \\
\text { Concentra } \\
\text { ted Effort }\end{array}$} \\
\hline & & & & & & & \\
\hline & & $\begin{array}{l}\text { Type } \\
\text { of Student } \downarrow\end{array}$ & & & & & \\
\hline LS \#6 & \multirow{5}{*}{ 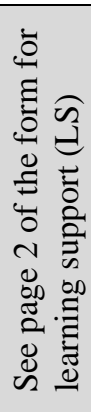 } & $\begin{array}{l}\text { Supportive } \\
\text { Colleague }\end{array}$ & & & & & \\
\hline LS \#7 & & $\begin{array}{l}\text { Pertinacious } \\
\text { Problem Solver }\end{array}$ & & & & & \\
\hline LS \#8 & & $\begin{array}{l}\text { Efficient Linear } \\
\text { Thinker }\end{array}$ & & & & & \\
\hline LS \#9 & & $\begin{array}{l}\text { Self-reliant } \\
\text { Associate }\end{array}$ & & & & & \\
\hline $\begin{array}{l}\mathrm{LS} \\
\# 10\end{array}$ & & $\begin{array}{l}\text { Individualist with } \\
\text { need for community }\end{array}$ & & & & & \\
\hline
\end{tabular}

\begin{tabular}{ll}
\hline Study Approach & Summary Description \\
\hline Inconsistent/Mediocre/Chaotic & $\begin{array}{l}\text { Students do not plan or organize their studies in any fashion, but } \\
\text { instead they just work on assignments as they want, when they } \\
\text { want. }\end{array}$ \\
\hline Responsive Attack & $\begin{array}{l}\text { Students are dependable but must be called into action. They } \\
\text { give all the effort they have for a short period of time. }\end{array}$ \\
\hline Non-Existent/Poor & Students had nonexistent or very poor study habits. \\
\hline Planned Consistent Attack & Students carefully strategize and calculate methods for studying. \\
\hline Short Bursts of Concentrated Effort & $\begin{array}{l}\text { Students study in short bursts of energy and can easily be } \\
\text { persuaded to move off of the assigned job, for one of lesser } \\
\text { priority. }\end{array}$ \\
\hline
\end{tabular}




\begin{tabular}{ll}
\hline Type of Student & Summary Description \\
\hline Supportive Colleague & $\begin{array}{l}\text { Individual who prefers playing support roles: supporting people in general, in } \\
\text { classes, and in life situations. }\end{array}$ \\
\hline $\begin{array}{l}\text { Pertinacious Problem } \\
\text { Solver }\end{array}$ & $\begin{array}{l}\text { Individual who will persist and repeat their skills to show improvement. This } \\
\text { pertinacious behavior keeps occurring until the person meets with some type } \\
\text { of success and fewer consequences. }\end{array}$ \\
\hline $\begin{array}{l}\text { Efficient Linear } \\
\text { Thinker }\end{array}$ & $\begin{array}{l}\text { Individual spends a lot of time thinking about efficiencies and logical steps, } \\
\text { which translate into finding linear paths to determine the quickest way to get } \\
\text { things done. }\end{array}$ \\
\hline Self-reliant Associate & $\begin{array}{l}\text { Individual has a general confidence or self-reliance; there is also a need to } \\
\text { associate or work with others. }\end{array}$ \\
\hline $\begin{array}{l}\text { Individualist with the } \\
\text { Need for Community }\end{array}$ & $\begin{array}{l}\text { Individuals do not regularly enjoy being the center of attention, and thus it } \\
\text { becomes difficult to put themselves into social settings and feel they have } \\
\text { things to say, and thus spend a lot of time alone. }\end{array}$ \\
\hline
\end{tabular}

\section{Suggested Learning Supports (LS)}

Step 2 - Instructions: After making the selections from The Video-Gaming Student Matrix, select the two Learning Support numbers (LS\#) and use them to formulate a Learning Support plan for the semester.

\begin{tabular}{|c|c|}
\hline LS\#1 & $\begin{array}{l}\text { Disorganized; do very little preparation; attend class and study by listening; } \\
\text { do best with demonstrations; alter course schedules so all classes have } \\
\text { collaborative lab hours; provide dedicated work spaces; change schedule } \\
\text { requiring extra lab time to help build consistency and surround with } \\
\text { resources and mentors; one month classes with four hour lecture, followed } \\
\text { by four-hour lab; collaborative lab }\end{array}$ \\
\hline LS\#2 & $\begin{array}{l}\text { Give regular reminders; utilize LMS; provide lab spaces that separate } \\
\text { personal space mimicking a work environment; use specific due dates; } \\
\text { require courses to use LMS listing assignments and dates; try to mentally } \\
\text { remember class assignments, but forgets; need reminders; distractible; } \\
\text { when in attack mode, can absorb a lot of information quickly }\end{array}$ \\
\hline LS\#3 & $\begin{array}{l}\text { Offer assignments with real life applications and reason to study; create } \\
\text { reward system for study - other than grades; establish mentoring, } \\
\text { apprenticeships, and internships; use a tangible reward system such an } \\
\text { earning scholarships; frequent feedback; does not exert effort to study; } \\
\text { either not interested or too self-confident }\end{array}$ \\
\hline LS\#4 & $\begin{array}{l}\text { Provide well organized courses and resources; provide achievable } \\
\text { assignments; use calendared due dates and detailed syllabus; provide ways } \\
\text { to expand all assignments and let the students share their achievements; } \\
\text { provide adequate time to prepare; accomplishes every assignment; do more } \\
\text { than is required; pursuit of their own personal improvement }\end{array}$ \\
\hline LS\#5 & $\begin{array}{l}\text { Break long assignments into parts - chunking; break lectures into parts; } \\
\text { provide lots of short video trainings; provide short examples that lead to a }\end{array}$ \\
\hline
\end{tabular}




\begin{tabular}{|l|l|}
\hline LS\#6 & $\begin{array}{l}\text { larger results; study in short bursts of time; focus for only about } 20 \text { minutes; } \\
\text { method finds both success and distraction }\end{array}$ \\
\hline $\begin{array}{l}\text { Place in situations where it is easy and natural to be helpful; teaching } \\
\text { situations; office lab, classroom presentations, classroom assistantships - } \\
\text { for credit }\end{array}$ & $\begin{array}{l}\text { Provide problem solving work and the time to engage with the problem; } \\
\text { provide real life problems to solve and rearrange school schedules to allow } \\
\text { for allotted lab time after class with resources and mentors }\end{array}$ \\
\hline LS\#78 & $\begin{array}{l}\text { Provide step-by-step instructions that are clear and concise; make finding } \\
\text { resources easy; they will not invest much extra time; use of lots of short } \\
\text { videos, clear instruction guides, step-by-step tutorials }\end{array}$ \\
\hline LS\#9 & $\begin{array}{l}\text { Placed in positions to associate and work on projects with others; still } \\
\text { responsible for independent work; Internships, work environments, } \\
\text { apprentices; community-of-practice }\end{array}$ \\
\hline LS\#10 & $\begin{array}{l}\text { Need a group of people to which they can belong; with regular alone time; } \\
\text { provide organized departmental activities to group the like minds and not } \\
\text { leave planning completely up to the students; let students participate in } \\
\text { leadership teams with limited meetings }\end{array}$ \\
\hline
\end{tabular}

\section{Learning Support Plan}

Step 3 - Instructions: With the help of your advisor, use the suggested learning supports shown on page two of this document, and use other known learning supports available on your campus to formulate a personal Student's Performance Plan for the semester. Write down the supports you will request and plan to implement.

\begin{tabular}{|l|l|}
\hline $\begin{array}{l}\text { School Learning Services } \\
\text { Provided }\end{array}$ & \\
\hline $\begin{array}{l}\text { Instructor Services } \\
\text { Requested }\end{array}$ & \\
\hline Self-Services Implemented & \\
\hline
\end{tabular}




\section{Vita}

Michelle R. Todd was born in Alexandria, Virginia, on September 22, 1962. She graduated from Houston High School in Houston, Missouri, in 1985. After high school, she entered Hannibal-LaGrange College, where she received her Bachelor of Science in Education degree in 1985. She received a Master of Arts in Management of Information Resources degree from Webster University, St. Louis, Missouri, in 1992. In 1999, Michelle returned to her alma mater as an instructor in the Computer Information Systems (CIS) department, of which she became chair in 2000. In 2008, she became the division chair for the Business/CIS division at Hannibal-LaGrange University. Attending Northcentral University in Prescott, Arizona, Michelle earned a certificate in Business Management in 2015. Beginning in 2016, she began working towards the PhD terminal degree in the School of Information Sciences and Learning Technologies (SISTL) at University of Missouri, Columbia.

While a part of SISLT, she was selected to serve on the research team for the LexMizzou Project, which did research on non-technical computer users writing games for augmented reality. The research was presented at the Association of Educational Communications \& Technology (AECT) at the National Conference in Kansas City, Missouri in October 2018. Additional work on this LexMizzou project has since been published in Technology, Knowledge and Learning journal, as shown in the reference below.

Jahnke, I., Meinke Kroll, M., Todd, M., \& Nolte, A. (accepted 2020, September). Exploring Artifact-Generated Learning with Digital Technologies: Advancing Active Learning with Co-design in Higher 
Education Across Disciplines. Technology Knowledge and Learning (2020). https://doi.org/10.1007/s10758-020-09473-3

During her time within the SISLT department, she served as an instructor for the Engaging Technology class for three years and then as a graduate assistant supported two additional courses: Game Design and Research Methods.

Outside of the SISTL PhD program, Michelle is a full-time assistant professor in the Computer Information Systems program at Hannibal-LaGrange University. She hosts many technical learning opportunities, as she teaches nine technology-based courses a year in an undergraduate setting as well as hosts a number of technology enrichment camps on topics such as robotics and engineering for young learners in her community.

She is a former member of the Association of Computer Machinery (ACM), as well as the Institute of Electrical and Electronics Engineers (IEEE). Michelle presented at the Annual Midwest Education Technology Conference as referenced below:

"Transform your grand instructional idea into reality: A customized teacher technology workshop", St. Charles, MO: Annual Midwest Education Technology Conference (Dennis, L., Janes, C., \& Todd, M. Feb. 2014).

Michelle has served as a research article reviewer for the following journals and conferences:

Computer Supported Collaborative Learning Conference 2018

Computer Human Interaction Conference 2106

Peer reviewer for SISTL doctorial students October 2016 
UI Review Team for University of Missouri - School of Information Sciences and Learning Technologies - usability study July 2016

She is married to Richard Charles "Chuck" Todd, and they are the parents of two adult daughters. She and her husband reside in Hannibal, Missouri. 